\title{
"So it's not always the sappy story": Women of Colour and Indigenous Women in the Indoor Sectors of the Canadian Sex Industry Speak Out
}

$$
\text { by }
$$

Menaka Raguparan

\author{
M.A., Carleton University, 2010 \\ B.Soc.Sc., University of Ottawa, 2007
}

\begin{abstract}
A thesis submitted to the Faculty of Graduate and Postdoctoral Affairs in partial fulfillment of the requirements for the degree of
\end{abstract}

Doctor in Philosophy

in

Legal Studies

Carleton University

Ottawa, Ontario

(C) 2019, Menaka Raguparan 


\begin{abstract}
The lived experiences of racialised and Indigenous indoor sex workers are often made to be invisible. Frequently, they are left unmarked and are imbedded within White indoor sex workers' experiences; alternately, stereotypes about racialised and Indigenous sex workers mean their experiences are overgeneralised and assumed to be part of street-based sectors. This study draws on forty in-depth interviews with racialised and Indigenous indoor sex workers from nine different cities across Canada in order to bring their intersectional experiences to the forefront of contemporary discussions.
\end{abstract}

Grounded in Kimberlé Crenshaw's conceptualisation of intersectionality, this dissertation takes a post-intersectionality approach of collaborative intersectionality to examine the multilayered experiences of research participants and expose multidimensional, inter-categorical complexities of and differences between participants' experiences. With the objectives of deconstructing and, at times, decolonising normative assumptions, attitudes, and political initiatives that essentialise the experiences of women in the Canadian sex industry, this study addresses a much-needed research gap by looking at racialised and Indigenous women's participation in different indoor sectors. Furthermore, it contributes to valuable analyses on human rights, employment standards, agency, and resistance within a growing body of critical sex work literature.

Tracing the experiences of research participants involved two key components: first, mapping their decisions to enter and work in the sex industry by weighing the costs and benefits against various systemic challenges; and second, exploring their everyday intersectional experiences in multiple spaces and at different times - for instance, the diplomatic negotiation and navigation of their identities, the entrepreneurial tasks performed to compete in the marketplace, their experience interacting with law enforcement, and their encounters with sex work activism. These discussions involve situating research participants' experiences within social, political, and economic contexts that are informed by historical events such as colonialism, slavery, and moral panics, as well as by contemporary events that are centred around, for example, neoliberal commercialism and whorephobia, in order to navigate the effects of stigma, criminalisation and marginalisation in their day-to-day lives. 


\section{Acknowledgements}

I sincerely thank all forty women who participated in this study, without whom this project would not have been possible. I am forever honoured and grateful for the trust you placed in me.

My supervisors, Drs. Diana Young and Lara Karaian, thank you for believing in me and guiding me throughout this journey. Diana, thank you for grounding me and for teaching me the solemn decision-making process. Lara, thank you for encouraging me to think through challenging perspectives and ideas at all stages of my research. These lessons will no doubt guide me into the future.

To my committee, Drs. Chris Bruckert and Ummni Khan, thank you for your valuable feedback and patience, particularly during the final push to transform this dissertation from draft form to defense-ready.

Drs. Kamala Kempadoo and Marie-Eve Carrier-Moisan, thank you for your thoughtful and positive feedback. They are not only invaluable for my intellectual growth, but also helps me disseminate a better version of my research.

To my four life pillars: Krish, Varman, and Archana thank you for inspiring me; and Ragu, thank you for taking this journey with me. Without your love and support I would not have done this.

இது தமிழ் பெருமிதம் மற்றும் திமிர்த்தனத்தின் ஒரு விளைவாகும்! 


\section{Table of Contents}

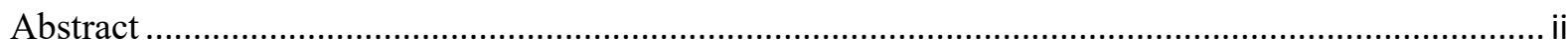

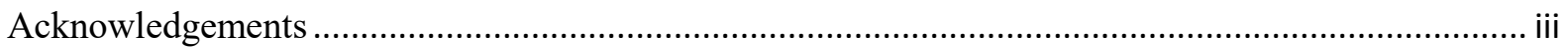

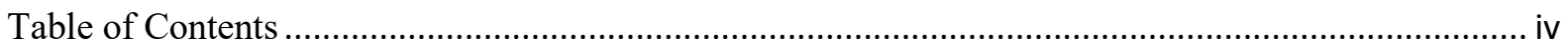

1

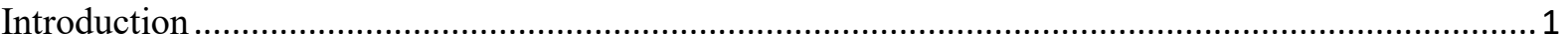

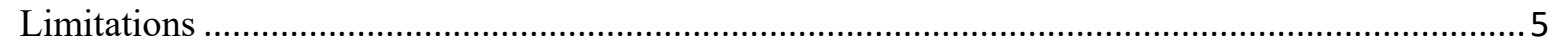

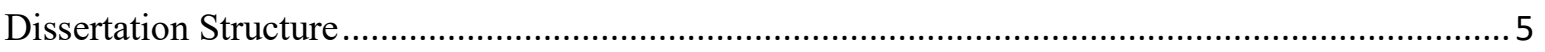

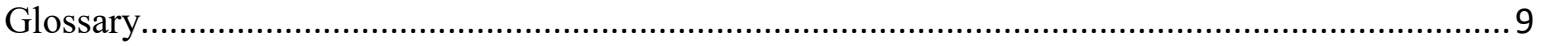

2

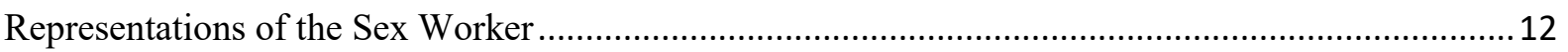

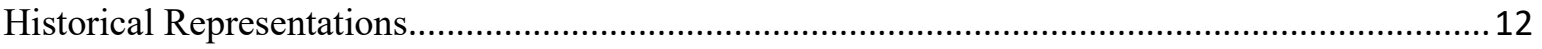

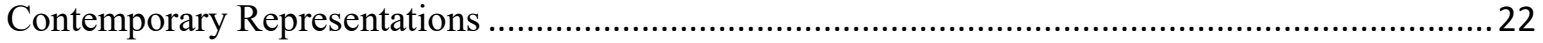

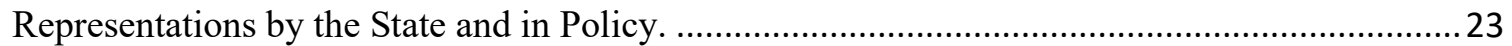

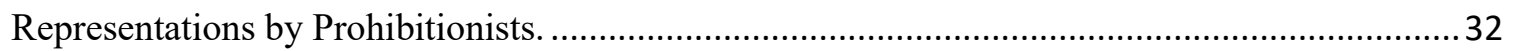

Representations by Sex Workers' Rights Advocates................................................................. 35

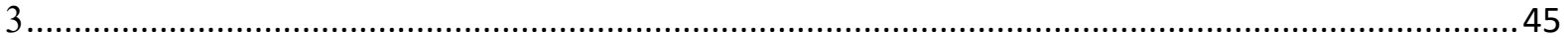

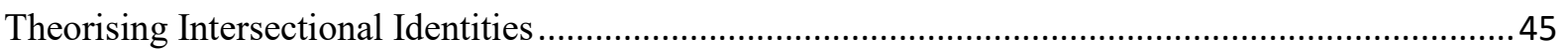

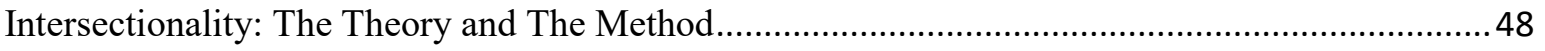

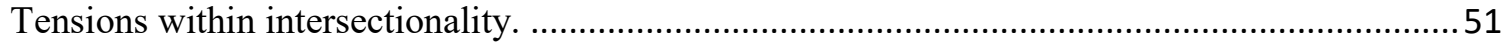

Intersectionality, Post-Intersectionality, and Racialised and Indigenous Sex Workers ....................54

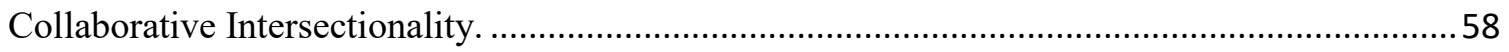

Methodological Implications of Collaborative Intersectionality .................................................. 75

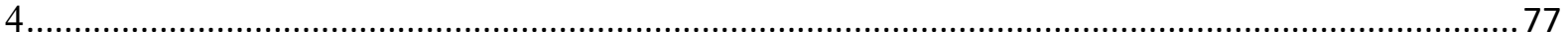

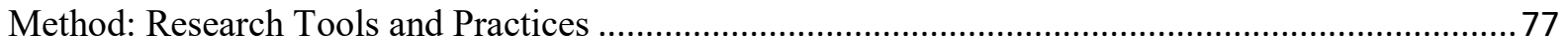

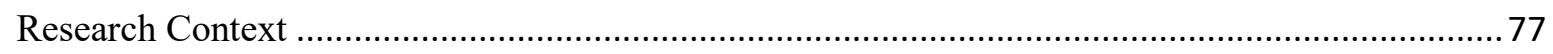

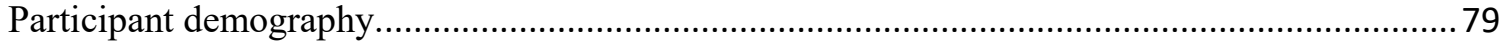

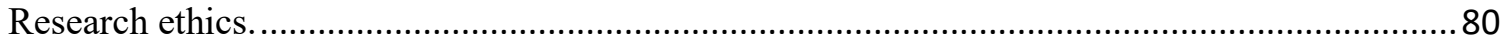

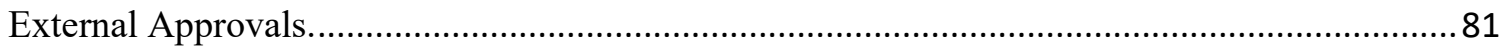

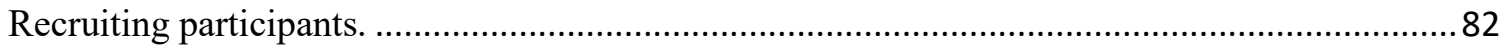

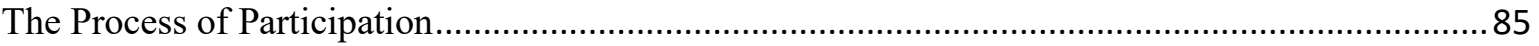




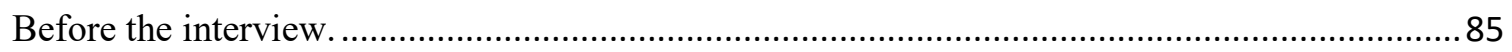

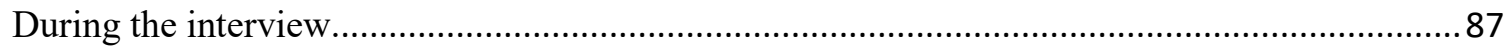

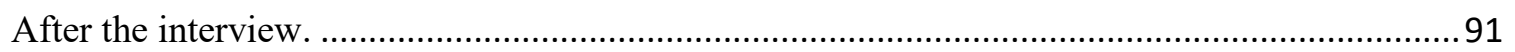

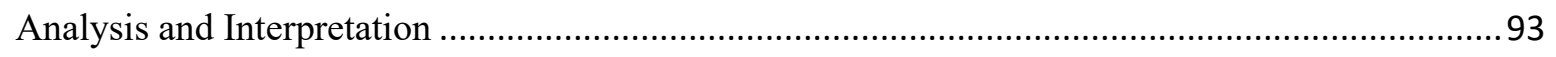

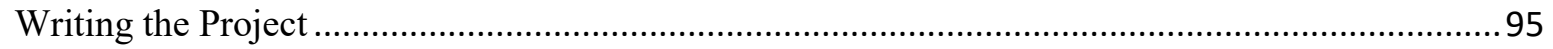

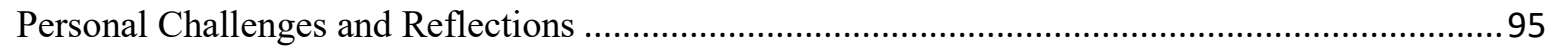

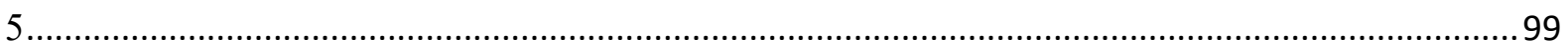

Racialised and Indigenous Women's Place in the Indoor Sectors ..................................................99

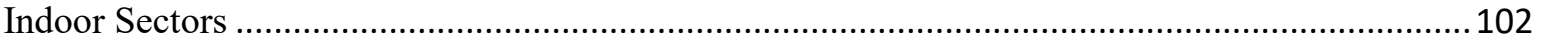

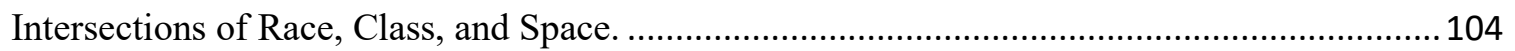

Sex Workers' Perceptions of Third Parties' Claims. .............................................................. 110

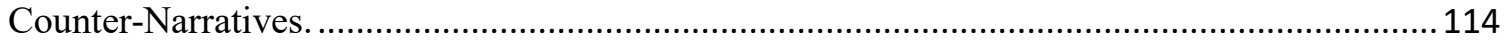

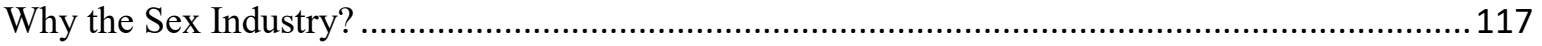

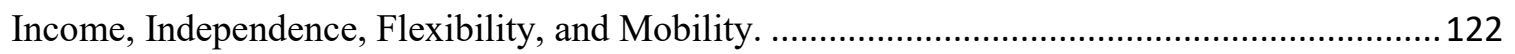

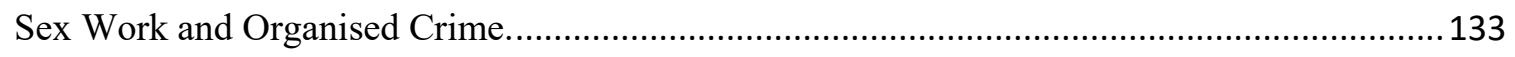

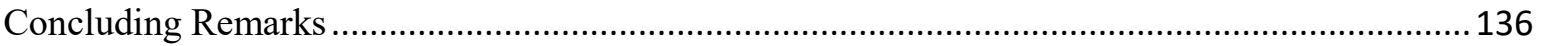

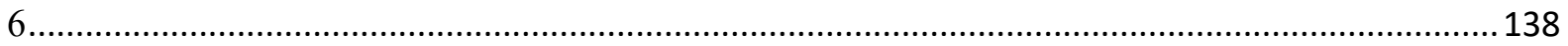

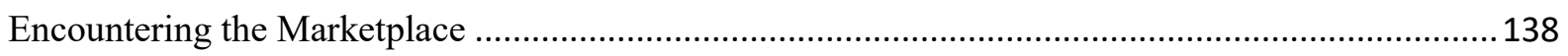

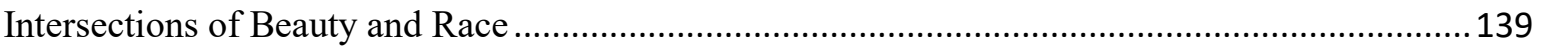

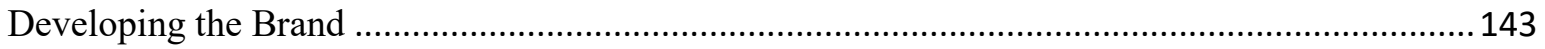

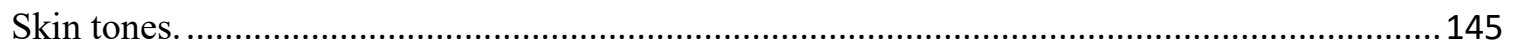

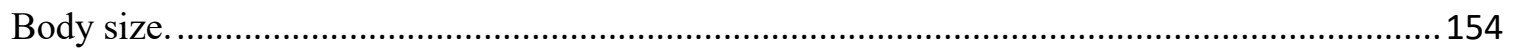

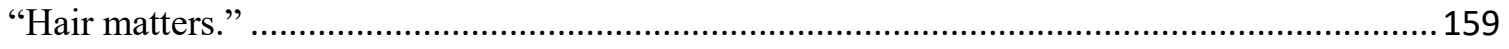

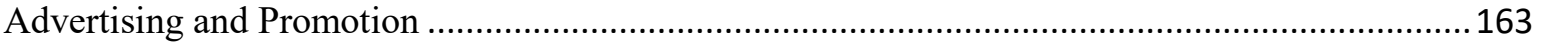

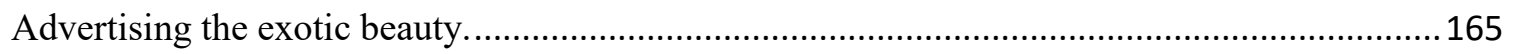

Additional purposes of advertising/marketing. ….............................................................. 170

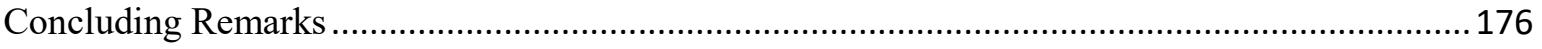

7 .

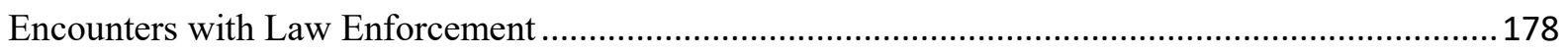

Identity management through performance ….................................................................... 180

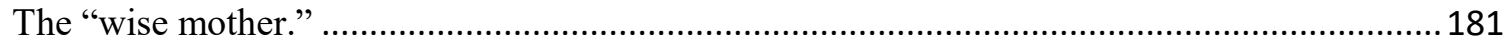

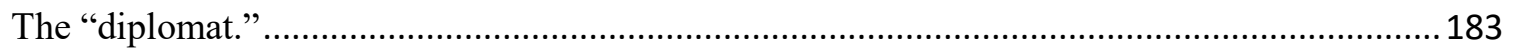




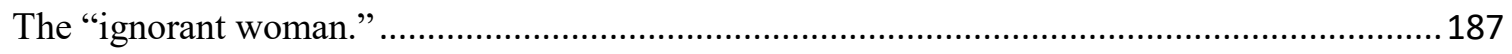

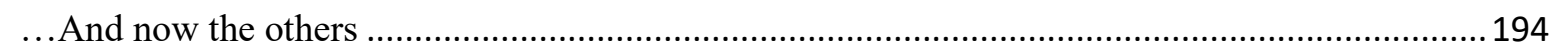

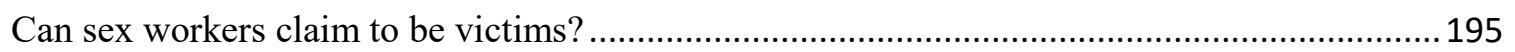

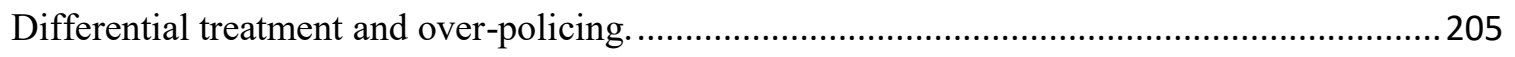

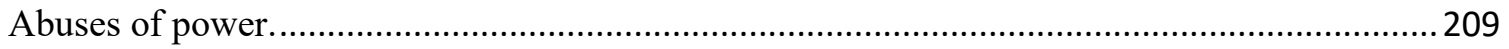

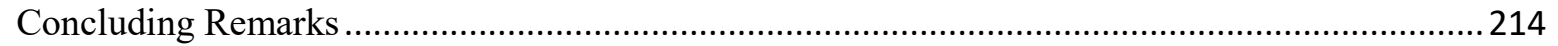

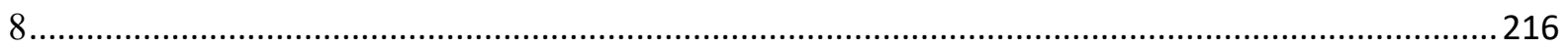

Barriers and Alternate Priorities to Engaging in Activism.......................................................... 216

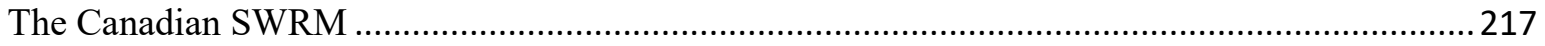

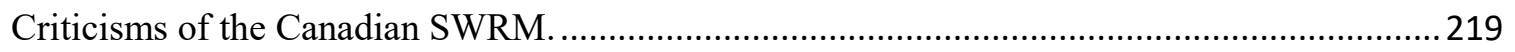

Participants' Perceptions of the Canadian SWRM...................................................................... 221

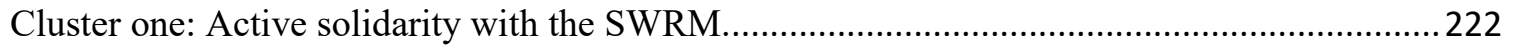

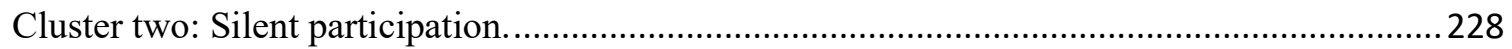

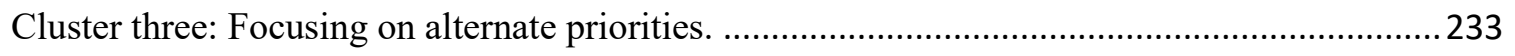

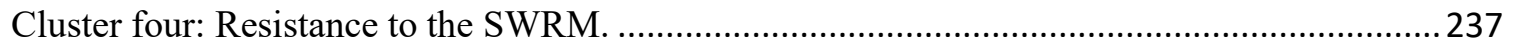

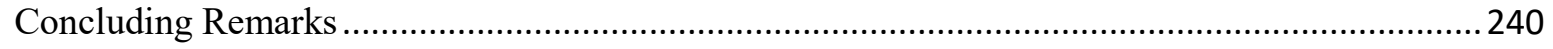

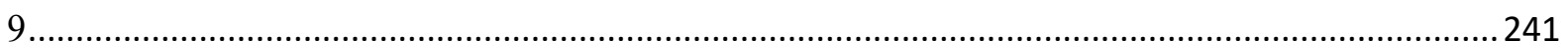

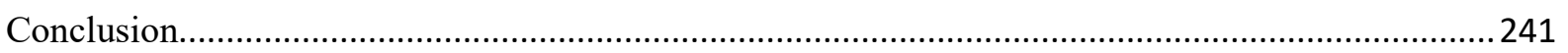

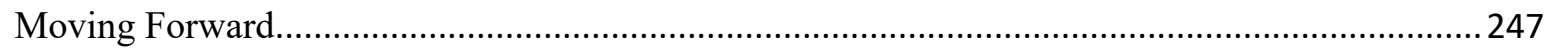

References

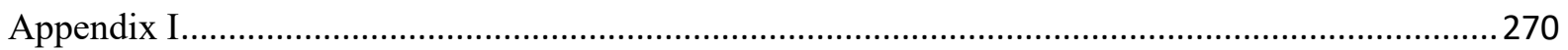

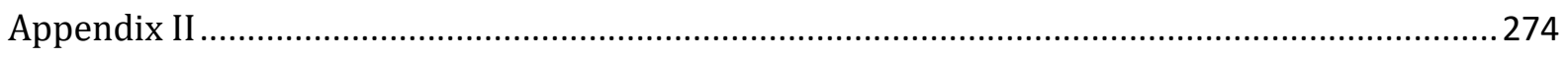

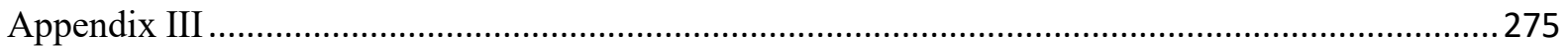

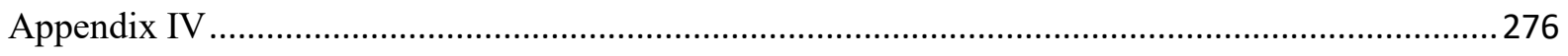

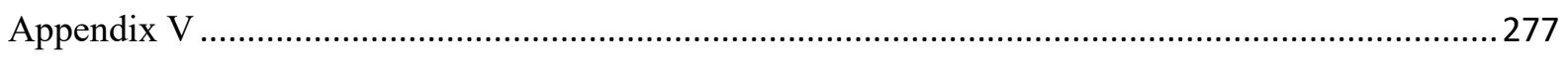

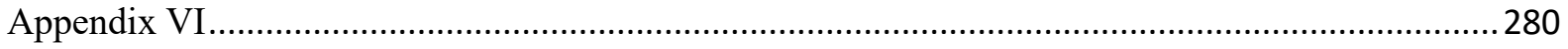

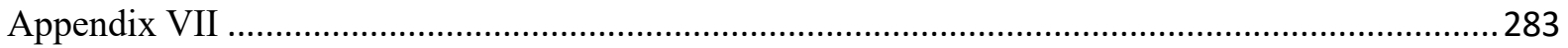




\section{Introduction}

I am not trafficked

I am tired of this trafficking argument

I came to this as a person with all kinds of

choice, and I choose to do what I do

I am of the most privileged kind of worker in this industry; my experience gonna be unique and the experience of someone with a lot of privilege

It could be really easy for me to then take on the happy hooker argument.

I am a sex worker

I am choosing to do this

I am choosing to do this

I am the empowered sex worker

I am an East Asian

I am mixed as well

I am mixed with White

I'm mixed with White, but I am not

connected to my White family

I am not trafficked, that I am definitely

[not]

I am working independently

I am all for about there being systems for getting out, if you choose, of course

There should be a retirement home for

ageing sex workers.

I am your exotic,

I am also thin

I'm fucking hot commodity

I'm gonna put a damn price tag on this

I am charging and making a lot of money

I am just charging a lot; it's because of the category that I have chosen to go into I am gonna make money out of the society that totally exotifies my sexuality

I am gonna hack this work hard bullshit mentality; hack capitalism
If I am gonna hack capitalism, then I am going to exploit all of the angles that I have.

I identify as chronically ill; It's also a big reason that I'm a sex worker

I am not going to work full time

I am also not interested in [it]

I am comfortable with that

I am not going to play your game; I went to university I got a business degree, I don't want to participate in this bullshit capitalist system, no I am gonna let you go to work, make a lot of money and I am going to exploit your fetish for me.

I am mixed

I am so independent

I am so opinionated

I am so powerful

I am so dominating; these are all true things about me

I am mixed; another benefit to that is, I get a ton of Asian guys too I am just very unique within this category of what they perceive as Asian women, and they love that shit

I am hacking capitalism and getting away with it

I am doing it to myself as a woman. 
I am frightened to death

I am so scared I get busted at the border

I am just scared that they are going to look

at my passport and [ask] why you travel so

much

I am a nuisance to them

I am a migrant worker

I am not Black,

I am safer because I am not Black

In airports, I know how to put on that

middle-class privileged face.

I am dating

I am also not out

I am very particular in who I choose to tell

I am going to tell people who are going to

support me or because I think it's going to

be of value to the movement

I don't say I am an activist; It's not my

style of movement [chuckles] it's a White

structure.
I am mixed race

I am mixed with White

I am not White [laughing]

I am Korean.

I am queer

I am second generation immigrant

I am cis gendered; I also identify as fem

I am beyond identity politics

I am not like you

I am definitely not that

I am really different and what

people say about me is wrong

and I don't know anything about

you

I am, and who I am going to

become, all of these things are very important

I am perfect, and that's the greatest privilege I am gonna have

I'm a complex creature

I am a very cynical person, but

ultimately

I am, I am a total optimist

I am choosing to do this.

[Laine] $]^{1}$

Laine's intersectional experiences in many ways challenge popular representations and characterisations of East Asian women who are involved in the sex industry. Focusing on the experiences of racialised and Indigenous indoor sex workers like Laine, this research study moves towards deconstructing and, at times, decolonising normative assumptions, attitudes, and political initiatives that essentialise the experiences of women in the Canadian sex industry. In the past decade, a growing body of activist and academic scholarship has focused on the experiences of indoor sex workers in Canada in attempts to challenge the dominant narrative that all sex workers are victims of trafficking. More recently, immigrant and migrant

\footnotetext{
${ }^{1}$ This poem was created by extracting all the "I" statements from Laine's interview transcript. I borrow the idea from Hail-Jares, Shdaimah, and Leon (2017).
} 
indoor sex workers' experiences have been brought into this conversation (Anderson et al., 2016; Butterfly, 2016; Goldenberg, Krusi, Zhang, Chettiar, \& Shannon, 2017; Ham, 2017; Ham \& Gilmour, 2016; Lam, 2016). There is, however, still a gap in the literature. For instance, while we know that $80-95 \%$ of the Canadian sex industry is made up of indoor sectors (Benoit \& Millar, 2001; Hanger, Maloney, Canada. Parliament.House of Commons.Standing Committee on, \& Canada.Parliament. House of Commons.Subcommittee on Solicitation, 2006), we do not know much about the experiences of trans people or racialised and Indigenous women in these spaces; thus, more empirical research is necessary to help us understand the various realities that impact their everyday lives. This study addresses the existing research gap by focusing on racialised and Indigenous women's participation in the indoor sectors of the Canadian sex industry. Based on qualitative interviews with forty racialised and Indigenous indoor sex workers across nine cities in Canada, this study contributes to valuable analyses of human rights, employment standards, agency, and resistance.

My primary research question is intentionally broad: How do women of colour and Indigenous women experience the indoor sectors of the sex industry? This question allows research participants to describe multiple layers of experience, from their decision to enter and work in the sex industry to how they negotiate their everyday intersectional experiences in various spaces and at different times. Within this context, mapping my participants' experiences involves exploring the process of weighing the costs and benefits of entering the sex industry, the diplomatic negotiation and navigation of their identities, the entrepreneurial tasks performed to compete in the marketplace, their experiences interacting with law enforcement, and their encounters with sex work activism. Discussions of such salient 
contemporary issues involve situating research participants' identities, actions, and behaviours within social, political, and economic contexts that are informed by historical events such as colonialism, slavery, moral panics, and contemporary events that are centred around, for example, neoliberal commercialism and whorephobia.

Given that participants' experiences within the indoor sectors of the sex industry and society at large fall within numerous intersections, my overarching analytical and methodological approach in this study is informed by feminist intersectionality - a paradigm developed initially by Black feminists in the United States to emphasise how intersecting systems of inequality shape women's lives (Beale, 1970; Collins, 1986; Crenshaw, 1989; King, 1988). The basic premise of intersectionality theory, which considers systems of inequality as mutually constitutive and reinforcing of each other, allows me to draw attention to hierarchies within the sex industry and across society to underscore the fluidity of identity categories such as race, class, gender, sexuality, and age (Cho, Crenshaw, \& McCall, 2013; Nash, 2008; Yuval-Davis, 2006). It further emphasises the fluidity of power relations by articulating that oppression and domination are co-conditioned and co-existent (LevineRasky, 2011). In my research, I start from the position that participants in this study are neither entirely victimised and powerless nor wholly dominant and powerful. Instead, their subjectivity occupies shifting positions as they straddle multiple marginalisations and "partial privilege" (Hutchinson, 2001; Mutua, 2013) in their various interactions.

From the perspective that identities are not fixed but are instead constructed, complex, and fluid, in this dissertation I rely on a post-intersectionality approach (see Cho, 2013) to highlight that identity formation and management are both subjective and structural and are represented by various languages, themes of conversations and dialogue, and power relations. 
This means they are non-essentialist and continually open to change (Brah \& Phoenix, 2004; Carbado, 2013; Choo \& Ferree, 2010; Yuval-Davis, 2006). Furthermore, I take up Cho et al. (2013) approach of collaborative intersectionality, to draw upon theoretical frameworks of performance (Goffman, 1959), spatial dimensions (hooks, 1994b; G. Rose, 1993), social, economic and cultural capital (Bourdieu, 1987), individual resistance (Scott, 1990), and stigma management (Bruckert, 2012), to conceptualise the social, economic, political, and legal contexts of my research participants' lived realities.

\section{Limitations}

This study is not a comparative study between White women's and Indigenous and other racialised women's experiences. While there may be overlap between my participants' and White women's experiences and resistance strategies, this study is limited in scope as it exclusively focusses on women of colour and Indigenous women who are working in indoor sectors of the Canadian sex industry. This study is also not generalisable to the entire population of sex workers of colour and Indigenous sex workers in Canada. For example, given that participants of this study are over the age of 18 , my participants' lived realities do not reflect or represent that of youth sex workers. Furthermore, all but one of my forty research participants are either Canadian citizens or permanent residents, therefore, lived realities and impacts of the trafficking discourses of my research participants does not reflect the experiences of visible minority migrant sex workers.

\section{Dissertation Structure}

In this dissertation, I start by tracing how racialised and Indigenous women's roles in the sex industry have been represented historically in popular narratives, as well as how they 
have been taken up in contemporary literature. The literature review in Chapter 2 maps how racialised and Indigenous women's participation in the sex industry has been perceived in various contexts. Though it is not exhaustive, nor limited to the Canadian sex industry and scholarship, it provides relevant context for how the assumed experiences of racialised and Indigenous women have been used to create protectionist policies and programs. By tracing these normative perspectives, I outline how what we claim to know about racialised and Indigenous women's participation in the sex industry came to exist.

Chapters 3 and 4 continue to lay the foundations for my study. Chapter 3 focuses on the theoretical frameworks that inform this research project. Here, I first outline Crenshaw's articulation of intersectionality theory and its key limitations. I then discuss my use of postintersectionality theory and, in particular, collaborative intersectionality to make sense of my participants' experiences. In this chapter, I argue that despite its limitations, intersectionality theory remains useful - particularly through post-intersectionality and collaborative intersectionality - for conceptualising the experiences of partially privileged and multiply oppressed populations. In Chapter 4, I outline the procedures I used to recruit research participants, collect interview data, and analyse and interpret the stories that participants shared with me. Within this chapter, I also discuss the limitations of my methodology and some of the challenges I encountered during the interviewing phase.

In Chapter 5, I briefly present the landscape of the Canadian sex industry and locate my participants' place within it. Focusing on hiring practices within third-party ${ }^{2}$ establishments within the indoor sectors of the Canadian sex industry, I explore how some

${ }^{2}$ Bruckert and Law (2013) define "third party" in sex industry as anyone who is involved in a transaction that is neither the sex worker nor the client. 
third-party managements limit the inclusion of women of colour. In this chapter, I raise the question of whether such practices might be more or less racist than other practices of racial stratification within mainstream industries. I also inquire as to how women in this study resist such hiring practises. Next, I map participants' reasons for engaging in the sex industry despite its systemic oppressions. In doing so, I bring to light multiple contributing factors, including women's greater poverty, systemic racism, and a desire to attain social mobility and a better quality of life. In this chapter, I articulate how participants use the sex industry to resist and transform their social status and structural position. The stories featured in this chapter not only highlight the ambiguity of and opposition to the racial stratification practices within the industry, but they also emphasise the fluidity of social status and draw attention to my research participants' concurrent positions as multiply marginalised and partially privileged individuals.

Chapters 6, 7, and 8 take up three distinct analytical threads, which are woven together to articulate how the experiences of racialised and Indigenous participants in this study have been shaped. In Chapter 6, I focus on participants' practices within the marketplace, which involve mobilising performances of race, class, gender, sexuality, and beauty, to compete in the marketplace and earn an income. I chart the processes in which participants (re)construct their economic subjectivities. The process of becoming an economic subject, as I show, is both unstable and paradoxical; it enables and constrains both expressions and representations of identity. That is, the various entrepreneurial tasks that participants carry out highlight the dynamics of control in the contemporary marketplace and enhance individual autonomy and strategic resistance. 
In Chapter 7, I address research participants' encounters with law enforcement. Here, I trace how my participants conceptualise and strategically perform their (il)legal subject positions as they mobilise various identities such as "victim," "mother," and "immigrant" to shape the outcomes of their interactions with law enforcement. In this chapter, I also shed light on how the law-in-books and law-in-action (see Pound, 1910) often contradict each other. Examining dominant policy narratives that classify women and girls in the sex industry as essentially "victims," I show how, in practice, some racialised and Indigenous sex workers are not only denied the position of the victim but are also re-victimised by law enforcement officials. It is important to note that the objective of this chapter is not to divide the SWRM along race lines or to silence White sex work activists. Rather the goal is to highlight how some women of colour and Indigenous women feel about sex work activism and the SWRM. This information can be useful for the reflexive practices of SWRO and SWRM in their goals towards becoming inclusive.

In Chapter 8, I focus on participants' barriers to engaging in sex work activism and the alternative priorities they hold. I classify my participants into four interrelated clusters to highlight the structural, political, and representational dilemmas they face in their decisionmaking processes and explain how and why they choose to be or not be involved in sex work activism. The four clusters are (1) those who publicly engage in sex work activism, (2) those who strategically micro-mobilise through interpersonal and social interactions, (3) those who do not participate in sex work activism due to race-, class- and space-related barriers, and (4) those who reject sex work activism entirely.

I conclude this project by reiterating the key findings of my study and briefly discussing steps for further research. Given the recent momentum on research that focuses on 
racialised women's experiences within the indoor sectors, continuing to engage in conversations with this population, I believe, will not only allow us to acquire both more indepth and more expansive knowledge but will also provide us with much-needed social, political, and legal awareness about the issues facing a cross-section of a particular multiply marginalised population.

\section{Glossary}

Woman I use this term to refer to all research participants of this study, while fully acknowledging that it is neither a static category nor one with internal homogeneity. I use it partly because each of my participants identified as such for their work and/or in their daily lives, and partly because it is an everyday speaking term that is available and familiar to us.

Sex worker I use this term in general when referring to the broad group of people who perform sexual labour. I move between sex worker and various other terms, including women in the sex industry, women participating in the sex industry, and women involved in the sex industry depending on the context and specificities of my analysis. I also use the term "prostitutes," although minimally, when referring to particular historical documents that take up specific segments of the sex working population.

\section{Racialised women/Women of colour}

I use the terms racialised and women of colour interchangeably to refer to participants who self identify as non-White and as belonging to a visible minority group and when referring to these participants collectively. In Canada the term racialised is favoured among agencies such as the Ontario Human 
Rights Commission (Policy and guidelines on racism and racial

discrimination, 2005) and the Canadian Centre for Policy Alternative (Block, 2017) when refereeing to visible minority communities. The Commission states that it prefers the term "racialized person" or "racialized group" over "racial minority", "visible minority", "person of colour" or "non-White" “as it expresses race as a social construct rather than as a description based on perceived biological traits. Furthermore, these other terms treat "White" as the norm to which racialized persons are to be compared and have a tendency to group all racialized persons in one category, as if they are all the same" (Policy and guidelines on racism and racial discrimination, 2005, p. 12). I also follow Canadian scholars such as Jiwani (2002), Chan and Chunn (2014) and Kaye (2017a) in using the term racialized women.

Inspired by scholars such as Crenshaw (1991) in the context of legal discourse, Kempadoo (2001) in the context of global sex industry, Hunter (2002) in the context of beauty standards, and Catro and Corral (1993), and Gabriel (1999) in the context of employment, I use of the term women of colour interchangingly to refer to my participants.

Wherever possible and relevant, I also use culturally and/or ethnically specific terms to further acknowledge the differing experiences of variously racialised people.

Indigenous I use this term to refer to participants who self-identify as such. In addition to considering the different histories of Indigenous populations and other racialized populations in Canada, it is noteworthy that the Indigenous 
participants involved in this study indicated they sometimes - or often - are read as White in their everyday social interactions. According to these participants, their ability to pass as White positions them in such a way to avoid processes of racialisation. Given that they are thus afforded certain privileges, these participants indicated that they prefer to use the term Indigenous over the term racialised. My use of the term Indigenous is similar to that used by other scholars working with Indigenous populations in the context of the sex industry and sate violence (Bourgeois, 2015; Hunt, 2013; Kaye, 2017a; Smith, 1999). I also use the word "Aboriginal" in this study, although minimally, when referring to particular documents that use this term. 


\section{Representations of the Sex Worker}

In this chapter, I briefly review how the sex worker has been and is represented in popular media, state and policy debates, and lobbyist literature. By mapping historical and contemporary configurations of the sex worker, I attempt to tease out how racialised and Indigenous women's involvement in the sex industry has been conceptualised over time and in different contexts. Understanding these configurations allows us to see how, more often than not, overgeneralisations, stereotypical assumptions, and moral judgements - rather than evidence and experiential knowledge - inform law and policy debates, public opinion, and lobbyist initiatives. While this literature review is not exhaustive, it includes selected pieces of governmental, nongovernmental, and academic literature that are either primarily centred on racialised and Indigenous sex workers' experiences or those that have had a profound or particular effect on racialised and Indigenous women's experiences in the sex industry. While the primary focus of this literature review is on the Canadian context, I supplement my arguments with non-Canadian sources in order to provide further context and background for national debates.

\section{Historical Representations}

In this section, I focus on the social, cultural, and legal understandings that have shaped the meaning of "prostitution" in the colonial context. In mapping these shifting definitions, I also bring to light how racialised and/or Indigenous women's roles in prostitution were understood and regulated differently in the past than they are today. Recognising the historical representation of racialised and Indigenous bodies in the sex 
industry highlights the complexities involved in analysing contemporary representations of racialised and Indigenous sex workers. Developing a meaningful understanding of the attitudes, sentiments, and events that have informed historical descriptions of racialised and Indigenous sex workers in Canada is a difficult task due to the limited amount of literature that focuses primarily on the Canadian context. Therefore, I draw upon additional research conducted in the British colonies and in Chicago, USA, in my effort to historicise contemporary representations of racialised and Indigenous sex workers.

Focusing on British India in the nineteenth and early-twentieth centuries, Philippa Levine (2000) unpacks the complex historical identities that classify racialised female bodies and their role in sexual commerce. Exploring the British Imperial rule, centred on the regulation of prostitution in Britain and in the colonial site of India, Levine argues that "prostitution must be seen as a crucial artefact of colonial authority in India, and [...] therefore of significance for our understanding of the operations of that colonial authority" ( $p$. 7). Given that prostitution was one of the main sites of interracial contact between the coloniser and the colonised, "where white men purchased the sexual service of native women," prostitution became "a central prop of masculinized colonial rule" (p. 7). Efforts to maintain a masculinised colonial authority included distinguishing and fixing the differences between women who were deemed to be 'respectable' and those who were deemed to be 'unrespectable,' as well as developing a racial hierarchy that secured proper models of feminine behaviours for women, describing "the body and character of the prostitute even while acknowledging that no proper legal definition [of the prostitute] had been constituted" (p. 7). According to Levine, classifying the prostitute while simultaneously struggling to 
define the act of prostitution "suggests a linguistic colonization with far-reaching ramifications for those so colonized" (p. 7).

Language and classification schemes that were used to describe the prostitute in this context were reliant on ideas and stereotypes of the Indian body and perceived differences between "colonial" and "native" values, practices, sexual habits, preferences, and boundaries. The definition of the prostitute, Levine suggests, was subjected to "race, class, caste, religion, and clientele" (p. 8). With India being known as the "melting pot for sexual commerce" (p. 8), the racially charged classifications of the prostitute placed European and foreign prostitutes (mainly from Eastern Europe and the Mediterranean) at the top of not only the raced hierarchy but also the respectability hierarchy, followed by Japanese, Chinese, Mauritian, and Persian/Asiatic Jewish women. Levine (2000) explains, "at the bottom of the pile, and most significant in number, were the local women, Indian and Burmese - whose rates for services and whose alleged standards were significantly lower than those of their foreign competitors" (p. 10). Furthermore, brothels were divided into first class and second class. First class brothels, even though serviced by both Indian and European women, were "reserved exclusively for European clientele" (p. 10). These first-class brothels charged higher rates to deter local men from frequenting them and to protect the superiority and White privilege that characterised their establishments. Conversely, second class brothels were frequented by local and Indigenous men.

Levine (2000) further explains that while the European and American discourses on the 'White slave trade' during this time focused on innocent White women being trapped in prostitution, Indian discourse positioned European prostitutes as exercising greater choice and agency, with government officials asserting that "these women arrived in India by their own 
volition and with precise knowledge of how they intended to earn their living" (p. 12).

Conversely, officials not only "insisted upon the passive ignorance of Indian women born into prostitution, raised in expectation of it and thus unable to escape its fetters," but they also depicted them as blindly sacrificing themselves, their rights, and their freedoms by engaging in prostitution (Levine, 2000, p. 12). By coding Indigenous values and practices of sexual behaviour as "disreputable," the informal race-based classifications of the prostitute that secured a place in the brothel hierarchies justified British colonialism as a need for certain kinds of authority in the colonial setting. Ultimately, during this period, even while the legal definition of prostitution remained elusive, its classification as a gendered, racialised, and classed activity became a "weapon wielded in the colonial context as if it were proof of the need for the civilising mission" (Levine, 2000, p. 17). Focusing on the advent and elaboration of legislation around contagious diseases, female prostitutes in these colonial sites - including also the Straits Settlements (Singapore), Hong Kong, and Queensland (Australia) - were thus subjected to registration, inspection for venereal disease, and detention if found to be in an infectious state (Levine, 2003). Levine (2003) argues that such regulatory attempts were not only focused on protecting the health of British soldiers abroad, but they also sought to address the supposed need to instill 'proper practices' about sex and sexuality to the sexually disordered colonised peoples.

In Canada, the nation-building efforts of the late-nineteenth and early-twentieth centuries - notably, through processes of Christianisation and Canadianisation - focused on instilling Eurocentric ideals of sexual purity, such as marital monogamy, and the distinct gender roles of female homemaker and male breadwinner. These priorities implicitly portrayed Indigenous traditions and communities of colour as being less civilised than those 
of White, Anglo cultures (Sangster, 2001; Valverde, 2008). The sexual conscience of Indigenous women, especially their sexual independence, was perceived to be uncontrollable and less pious than that of non-Indigenous women, thus projecting the view that they were 'unreformable' (Barman, 2004; Perry, 2005; Sangster, 2001). Considering how quickly Indigenous women "became sexualized as prostitutes in colonial British Columbia" (Barman, 2004, p. 215), it is not a surprise that the popularity of the image of the isolated and dangerous Indigenous woman resulted in the conception that Indigenous women were all a "community of prostitutes" (Barman, 2005, p. 205; also see Carter, 2000).

Indigenous women on the streets were portrayed almost exclusively as either "prostitutes" or "crones" (Barman, 2005, p. 205). As Barman (2005) notes, "[t]he Victoria press referred, often almost in passing, to 'prostitution, so common with Northern [Indian] women'; to 'women [having] rendered the whole outskirts of the town a perfect brothel'; and to how "the squaws might all be considered as prostitutes"' (p. 205). This bolstered the beliefs that all Indigenous women who visited dance halls were prostitutes and the reservations outside of towns were perfect locations for brothels (Barman, 2005; also see Ryley, 1997). Indigenous women were thus subjected to harsh restrictions under the Indian Act, adding to the Canadian Criminal Code provisions, such as the Vagrancy Act that already criminalised women's activities perceived to be in relation to prostitution (Carter, 2000; W. Moss \& Gardner-O'Toole, 1991; Sangster, 2001). During this time, while vagrancy laws were frequently used to criminalise prostitutes (Bright, 1995; Poutanen, 2002), the equation of Indigeneity and sex work justified not only formal constraints but also informal regulatory regimes (e.g., pass systems) that marginalised Indigenous women's presence in towns and 
settlements and which increasingly narrowed their opportunities to lead lives that were not always already criminalised (Carter, 2000).

Even though there are indications that some Indigenous women worked as sex workers in late-nineteenth and early-twentieth-century Canada, there is no evidence to suggest that prostitution was any more prevalent amongst Indigenous women than European women. Furthermore, evidence shows that formal and informal regulations, such as the overlapping assimilative projects of missions and residential schools, framed prostitution as a sign of personal disposition or as a marker of the inherent immorality of Indigenous women, rather than as an economic need (Carter, 2000; Sangster, 2001). As Carter (2000) suggests, the predominant image of "the squalid and immoral 'Squaw,' [who] lived in a shack at the edge of town," and whose "physical removal or destruction can be understood as necessary to the progress of civilization" contradicted the complex roles and identities of Indigenous women (p. 61). Negative stereotypes of Indigenous women were not only popular but were also used by state officials and media to further denigrate Indigenous women (Carter, 2000). For instance, when the North West Mounted Police (NWMP) received complaints of their officers' disgraceful and immoral behaviours in Western Canada, the institution's response was

not to deny that there had been "immorality" in the West, but to exonerate the men and blame the Aboriginal women, who were said to have behaved in an abandoned and wanton manner and were supposedly accustomed to being treated with contempt, to being bought and sold as commodities, within their own societies. (Carter, 2000, p. 67)

Carter (2000) notes that such sentiments were picked up by the print media and echoed repeatedly for years over, which depicted Indigenous women as having "loose morals" (p. 68). These Indigenous women "were prostitutes before they went to live with White men," 
and the men "did not encourage this behaviour but were simply 'taking advantage of an Indian's offer"' (Carter, 2000, p. 69). In this regard, processes of racialisation not only used social characteristics, cultural characteristics, and sexualities - mainly female sexualities - as major defining factors between European settlers and Indigenous peoples, but they also specifically included involvement in prostitution as a marker of racialised difference (see McCalla \& Satzewich, 2002).

Existing research on Canadian contexts shows that the regulation of prostitution characterised it as a decidedly racialised activity that was not contained to Indigeneity alone. For example, in her work Gold Diggers of the Klondike, Bay Ryley (1997) recounts that the North-West Mounted Police, in its efforts to purge the "disreputables" from Dawson City, Yukon, ordered all prostitutes to leave the city limits in 1901: "No dilly-dallying will be tolerated by the Police as all must get out - Whites, niggers and Japs, the colour line not being recognised in the order" (1997, p. 32). As Ryley (1997) claims, the regulation measures against prostitution in the early twentieth century are indicative of racialised women's involvement in prostitution, and this evacuation order points to the racial diversity among the "scarlet women" in Dawson City. Along similar lines, narratives of White slavery depicted Chinese men as being dangerous traffickers, and Chinese women who served as prostitutes in brothels servicing male Chinese and "[W]hite men in search of 'the exotic" were thus deemed worthy of rescuing by White female reformists (Valverde, 2008, p. 87). White women settlers who sought to 'properly reform the prostitute' established rescue homes for Chinese women who had been forced into prostitution, and they included domestic servants, abused wives, Japanese immigrants, and Asian children in the teachings of Protestant principles with "very specific expectations that these women would show Christian 
repentance and would transform themselves into penitent but saved pious women" (Valverde, 2008, p. 88).

Meanwhile, Sangster (2001) notes that during the interwar period (1918-1939), the sexual regulation of girls and women in Ontario invoked feeble-mindedness as crucial causes of promiscuity and prostitution. In their efforts to polarise "dissolute" versus "normal" women, criminology and social work experts assumed that "those lingering near the bottom of the social ladder" - namely, the supposedly ignorant, poor, amoral, and "the primitive and semi-civilized races from Siam to Haiti" - were not only more promiscuous and contributed to the spread of venereal disease, but they were also somehow reasonably equated with prostitutes, regardless of their (non-)involvement in the sex industry (Sangster, 2001, pp. 8990).

Cynthia Blair's (2010) work on Black female sex workers in Chicago at the turn of the century provides a glimpse into ways in which systems of generalisation, stereotyping, and moral judgement about racialised bodies and sexuality influenced how Black sex workers were represented. According to Blair, Black prostitutes' increased visibility in the city's sex economy ${ }^{3}$ between 1870 and 1930, sparked a complex array of responses from Black and White, respectable and disrespectable urbanites, to the extent that Black prostitutes had to negotiate their economic life on the shifting terrains of sexual ideologies, racial politics, respectability politics and the "moral geography" of the city (p. 3). During this time, Black women's involvement in prostitution was explained in two main ways: either as a "post-

\footnotetext{
${ }^{3}$ Between 1870 and 1930, Black sex workers who worked in brothels located in racially diverse and racially divided districts moved onto the streets, into apartments, and into the nightclubs of Chicago's Black Belt neighbourhood. The presence of Black sex workers in public spaces and their labour in the sex industry not only threatened "the moral, sexual, social, and spatial divides that shaped the turn-of-the-century racial politics in Chicago," but it also challenged the respectability politics (Blair, 2010, p. 3).
} 
emancipation continuation of the sexual exploitation that their ancestors endured during slavery" and/or as a continuation of their inherent violent criminality and theirs positions as “Amazons," “African giantesses," or "gigantic Negresses” (Blair, 2010, pp. 10,96). During the 1880 s, daily papers, city guidebooks for tourists, and popular accounts of city living depicted these Black prostitutes in a "strange bundle of excess - as extraordinarily large in height and girth, and possessing brutish strength and cunning, prone to violent rages and an increased appetite for criminal activity" (Blair, 2010, p. 96).

The menacing imagery of the Black prostitute, Blair notes, on the one hand, was similar to that of other prostitutes and criminals (e.g., thieves and gamblers); on the other hand, it was unique in that it portrayed them as being physically strong, violent, "larger than life, [and] out of proportion to the landscape [they] roamed" (p. 95). This figure of the excessive Black woman was branded with names such as "Big Mag," "Hattie Briggs," "Black Susan Winslow," "Cheyenne," the "Bad Lands," "Bengal Tigress," and "Coon Hollow" (Blair, 2010, pp. 94-104). Such representations were then used to caution late-nineteenthcentury Chicagoans and visitors about the type of Black women who were working in the local sex industry. For example, newspaper reports described the Bengal Tigress as being ferocious and as having the temperament of a predatory animal, which then generated both fascination and terror among consumers of these images, who were largely middle-class White people. By 1936, the Bengal Tigress was also associated with imagery of the "pimp," described as a "gigantic Black woman" who "bossed" a group of Black prostitutes and who "always was ready to battle with the police when her place was raided" (Blair, 2010, p. 95).

The representations of Black prostitutes were very clearly different from the representations of White prostitutes, both of which were included in newspapers and city 
guide books for tourists. However, unlike the crude images of Black prostitutes, White prostitutes were depicted as refined parlour house workers and as innocent victims. The accompanying text regarding White sex workers expressed concerns, which were popular during this period, about the moral dangers awaiting young and frail White women and girls who were exposed to the moral traps of urban centres, including the sex trade (Blair, 2010; see also Valverde, 2008). Blair notes that, while White prostitutes' portrayals as parlour workers, innocent victims, and/or cunning women were featured as contrasting with the respectable White female urbanite, representations of Black prostitutes as ill-governed and menacing were not only mean-spirited, but they also cast a criminal shadow over all Black women who resided in the district, regardless of their employment status.

In Canada, Chinese immigrants (as traders and rail road workers) and Japanese immigrants (as farmers, fishermen, and coal mine workers) settled in the nineteenth century; Sikh communities settled in Canada during the early twentieth century; and Black people (as slaves or as those fleeing slavery in the USA) arrived long before that (Adachi, 1991; Mackey, 2010; Mar, 2010; Morton, 1973). However, we do not know much about how women from these ethnic communities were represented in Canada, nor within the sex industry. Given this lack of scholarly literature, mapping the historical context of racialised women's participation in the Canadian sex industry is an important priority for critical sex work studies. Fleshing out a historical perspective will allow us to understand more about specific events, emotions, and attitudes that led to the establishment and maintenance of, for example, the rhetoric of South Asians and East Asians as fitting the binary of "predatory trafficker" and "trafficked victim," respectively. 


\section{Contemporary Representations}

At the turn of the twenty-first century, discourses surrounding sex work and sex workers shifted. Where sex work had previously been treated as a public nuisance and as a form of deviance that posed a danger to respectable women, it started to be seen instead as a site of risk for women in the industry, with human trafficking for the purpose of sexual exploitation being a key threat. Drawing on articles from major Canadian newspapers, Brunschot, Sydie, and Krull (2000) trace representations of prostitution in the mass media and in the public imagination. They identified four prominent recurring themes: sex workers as public nuisance, sex workers as victims of child abuse, sex workers as victims of violence, and non-Western sex workers as particularly vulnerable. Similarly, in tracing the popular mainstream media representations of sex workers in Victoria, BC, between 1980 and 2004, Hallgrimsdottir, Phillips, and Benoit (2006) argue that "[d]iscourses assigning criminal culpabilities and individual responsibility to sex workers disappear after the late $1980 \mathrm{~s}[\ldots]$ [r]eplacing them are discussions that move responsibility $[\ldots]$ towards others, including clients, pimps and the "global sex trade"' (p. 269).

By the early 1990s, most documented characterisations of sex workers showed them as "lacking [in] responsibility, agency and capability" (Hallgrimsdottir et al., 2006, p. 273). Furthermore, in addition to depicting an inherent risk of violence in the lives of sex workers, these narratives focused on the vulnerability and youth of the women in the sex industry, also projecting a racialised undertone by overgeneralising the global trafficking of women and children from foreign countries (Hallgrimsdottir et al., 2006). According to Hallgrimsdottir et al. (2006), the shift in popular representations of sex workers paralleled representative shifts in public opinion and "in state and policy discourse, which [largely] identified abuse as the 
distinguishing features of sex workers' lives both prior to and during their involvement in the sex industry" (p. 273; (also see Brock, 1998; Brunschot et al., 2000)).

\section{Representations by the State and in Policy.}

As a nation, Canada has long been struggling to respond to issues related to the sex industry and women's involvement in it. In their attempts, Canada has sought to define the identity of Canadian sex workers through law and policy reforms. As Leslie Jeffrey (2004) notes, there has also "been a number of attempts to change the law governing prostitution since the 1970s at the federal, provincial and municipal levels" (p. 84). In the early 1980s, the Canadian government was concerned about prostitution and the growing number of public complaints that focused on the "public nuisances" caused by street-level prostitution, particularly for the "good" and "moral" female residents in neighbourhoods where prostitution was taking place. The government responded by appointing an extraparliamentary committee, the Fraser Committee, to investigate the matter and make recommendations on how to address these concerns (Brock, 1998; Fraser, 1985; Jeffrey, 2004). Critical of the Fraser Committee's recommendations, Brock (1998) argues that while suggestions to decriminalise both prostitutes and clients and the proposal to shift street solicitation to a more general nuisance category are positive outcomes, the latter recommendation was so broad that the bulk of nuisance offences continued to be related to prostitution rather than to publicly indecent activities such as excess noise and littering. Despite the recommendations of the Fraser Committee, in 1985 the Canadian state responded by adding the communication provision (s.195) to the existing anti-prostitution laws, which, under the guise of controlling public nuisance and protecting supposedly good women from 
the dangers of being mistaken for prostitutes, outlawed all prostitution-related activities in public.

By the mid-1990s, the Canadian government had shifted its focus from protecting only "good" women to addressing the risks faced by the so-called vulnerable victims of the sex industry. In this regard, the mid-1990s not only mark the Canadian government's entrance into international policy debates on trafficking but also its steady increase in anti-trafficking responses (Jeffrey, 2005). Jeffrey (2005) interprets this as "an exercise in maintaining a particular gendered and raced neo-colonial identity" (p. 33). As such, national anti-trafficking strategies that were developed during this time ignored "the inherent complexities of trafficking" and produced "over enthusiastic responses" to human trafficking with limited evidence (Sanghera, 2005, p. 21). At the same time, more often than not, they conflated human trafficking with sex work (see Farley, 2004; Jeffreys, 2008; Leidholdt, 2004). Ultimately, Canada's anti-trafficking initiatives have had negative impacts on individuals working in the sex industry (Kaye, 2017b; O’Doherty, Millar, Clancey, \& Mackenzie, 2018). In what follows, I draw attention to some examples of state policy responses that have had an effect on how racialised and Indigenous sex workers are characterised and classified.

By the end of the 1990s, when attention finally fell on the almost-three-decade-long endemic killings and disappearances of sex workers in Vancouver and Edmonton, in addition to various other response initiatives (see Ferris, 2015), a parliamentary committee - the Subcommittee on Solicitation Laws ${ }^{4}$ - was struck to understand the ways in which antiprostitution laws outlined in the Criminal Code have failed to prevent human rights abuses

\footnotetext{
${ }^{4}$ Hereafter referred to as the Subcommittee.
} 
against sex workers. The Report of the Subcommittee on Solicitation Laws (2006) considered a wide range of empirical evidence, concluding that women represented $75-80 \%$ of all people who sell sexual services in Canada and that there is a high prevalence of Indigenous women selling sexual services in some parts of Canada. This report also estimated that Indigenous women comprise $70 \%$ of street-based prostitutes in Winnipeg and one-third of the more than seventy women who disappeared from Vancouver's Downtown Eastside. Additionally, the Subcommittee report recognises that, compared to other women, Indigenous women are more likely to face drug and alcohol dependency and extreme poverty. Like other racialised groups, the report explains that Indigenous women are also affected by racial profiling, excessive police intervention, and under-protection from the law.

Despite these substantial findings, the policy recommendations put forth by the Subcommittee to address the prostitution "problem" fail in several ways: First, they fail to address systemic issues that lead to Indigenous women's overrepresentation within the streetbased sex industry (see Ferris, 2015) - including the issue of missing and murdered Indigenous women. Second, they maintain the conflation of human/sex trafficking with sex work writ large. ${ }^{5}$ Finally, they depict the typical Indigenous sex worker as "low class," impoverished, and street-based - a representation similar to the popular "lone street-walker" trope that was prevalent in mainstream Canadian media during the early 2000s (Ferris, 2007) - which further invisibilises Indigenous sex workers who do not fit this narrow mould. Furthermore, the Canadian state was able to selectively read this report to shift their focus

\footnotetext{
${ }^{5}$ In the introduction to the edited volume entitled Trafficking and Prostitution Reconsidered, Kempadoo (2012) provides a detailed account of the development of narratives that conflate sex work with human trafficking for the purposes of sexual exploitation, which is also referred to as "sex trafficking" and/or "sex slavery."
} 
onto issues of human trafficking and sex trafficking. That is, the Canadian government responded to the crisis of Indigenous women's overrepresentation within the sex industry and their increased risk of violence by doubling down on an ideology that emphasises the protection of the vulnerable victim, the prevention of human trafficking, and the prosecution of victimisers and traffickers at the expense of misrepresenting and neglecting the lived experiences of many Indigenous women.

In another report, published in 2007, titled Turning Outrage into Action to Address Trafficking for the Purpose of Sexual Exploitation in Canada (Ratansi, 2007), the Standing Committee on the Status of Women ${ }^{6}$ states explicitly that "prostitution and pornography are forms of sexual exploitation, wherever they occur - on the street, in massage parlours, in modeling agencies, etc., or through escort agencies" (p. 3). In this report, the Standing Committee - despite contradicting evidence (see Weissbrodt \& Meili, 2012) - identifies women and children as the majority of the victims of human/sex trafficking and identifies prostitutes in particular as being victims of sexual exploitation. From this essentialist position, the Standing Committee recommends that prostitutes should not be treated as criminals for selling sexual services or for being found in bawdy houses; instead, the report argues, they must be given access to adequate services to allow them to "escape" the prostitution environment. Recommendation 25 of this report calls for a better police relationship to and increased trust-building with Aboriginal women.

The Standing Committee's report, which also highlights the Canadian government's role in addressing the vulnerabilities of migrant and immigrant women's victimisation and

\footnotetext{
${ }^{6}$ Hereafter referred to as the Standing Committee.
} 
exploitation, not only takes a protectionist position but also justifies the paternalist and criminalising approach towards these women being involved in the sex industry (Jeffrey, 2005). The protectionist attitude is particularly evident in recommendations $14,{ }^{7} 15,{ }^{8}$ and $16,{ }^{9}$ which are each aimed at improving Canadian immigration policies and practices. These recommended changes, however, would make it difficult for women to independently immigrate/migrate, resulting in their increased vulnerability for human/sex trafficking. These recommendations also suggest amendments to Citizenship and Immigration's Pre-Removal Risk Assessment (PRRA) process, so that it could be used to assist victims of trafficking who may face deportation and who would be at risk if returned to their countries of origin.

Recommendation 22 in this report calls for police training that would increase sensitivity towards the circumstances of immigrant women. It is not clear the extent to which these recommendations were implemented or even considered, especially given the criminalisation, deportation, and harassments reported by migrant sex workers who are often assumed to be victims of sex trafficking (Butterfly, 2016; Millar, O’Doherty, \& SWAN, 2015). In this sense, the Canadian states' emphasis on protecting the vulnerable women in the sex industry, including migrants and immigrants, did not end with the Standing Committee's report. The protectionist enthusiasm is also evident in more recent law and policy initiatives (as in the case of PCEPA discussed below). In other words, states protectionist's attitudes exist despite

\footnotetext{
${ }^{7}$ Recommendation 14 suggests that "Citizenship and Immigration Canada increase access to and information on migration channels in order to increase women's ability to migrate independently and safely" (Ratansi, 2007, p. 19).

${ }^{8}$ Recommendation 15 suggests that the "House of Commons Standing Committee on Citizenship and Immigration and the Standing Committee on Status of Women review Canadian immigration barriers that may contribute to the increased vulnerability of women to trafficking in persons" (Ratansi, 2007, p. 19).

${ }^{9}$ Recommendation 16 suggests that "the federal government enrich and strengthen the pre-removal risk assessment process and provide specific policy guidelines that trafficked persons qualify as people who are at risk" (Ratansi, 2007, p. 20).
} 
evidence that sex workers are harmed by any criminalisation of the exchange of sexual services for payment (Butterfly, 2016; Kaye, 2017b; Millar et al., 2015).

A third report - the National Action Plan to Combat Human Trafficking (NAPCHT), ${ }^{10}$ released by the Ministry of Public Safety (2012) - suggests that women represent the majority of victims of human trafficking in Canada and that persons who are socially or economically disadvantaged are the most frequent targets. In this report, The Ministry of Public Safety identifies "some Aboriginal women, youth, and children, migrants and new immigrants, teenaged runaways, children who are in [state] protection,” (p. 6) and rural girls and women who move (whether voluntarily or involuntarily) to large urban centres as being most at risk for trafficking. This report is premised on conceptions that human trafficking is perpetuated by organised criminal networks and individuals, and it also distinguishes between domestic trafficking (trafficking that occurs within Canada's borders) and international trafficking (where "non-Canadian victims are brought to Canada from countries in Asia, notably Thailand, Cambodia, Malaysia, and Vietnam, as well as countries in Eastern Europe" (p. 6)). Despite acknowledging that it is difficult to determine the extent of human trafficking in Canada due to its hidden nature, this report claims that "over $90 \%$ of cases [in Canada] involve domestic human trafficking; the remaining and less than $10 \%$ involved [cases where] people [are] being brought into Canada from other countries" (p. 8).

According to the Ministry of Public Safety (2012), the core principles of Canada's plan to combat human trafficking include strategies for prevention, protection, prosecution, and partnership. This plan also clearly articulates the Canadian government's position on

\footnotetext{
${ }^{10}$ This is Government of Canada's anti-trafficking initiative, under the leadership of Steven Harper, former prime minister of Canada, which dedicated $\$ 25$ million with a significant portion of it directed toward criminal justice-based initiatives (Kaye, 2017b).
} 
prostitution, such that it is depicted as a gateway to human trafficking, that prostitution victimises the vulnerable, and that "demand for sexual services can be a contributing cause of human trafficking” (p. 11). Given that women and girls are believed to be the most popular victims of trafficking for sexual exploitation, the government sees investing in initiatives to end violence against women and girls as a key component to stop trafficking. However, the anti-trafficking strategies articulated in this report also assume that the prevention of all forms of prostitution is a critical component of responding to human trafficking. The influence of NAPCHT is evident in national anti-trafficking initiatives developed by lobbyists and special interest groups as diverse as the "Canadian Women's Foundation (CWF) [...] the Evangelical Fellowship of Canada (EFC), the Canadian Council of Refugees (CCR), the Global Alliance Against Trafficking in Women (GAATW) Canada, the Chrysalis Anti-Human Trafficking Network, Differed Dignity, the Salvation Army, and others" (Kaye, 2017b, p. 3). These groups unanimously and problematically assume that prostitution is a gateway for human trafficking and that women and girls in prostitution must therefore be rescued from their inherently violent lifestyles.

The NAPCHT's consolidated national anti-trafficking efforts in Canada exist within a criminal justice framework. The discursive separation of domestic and international trafficking becomes especially clear in the RCMP's anti-trafficking initiatives. In 2013, the RCMP released its findings on the issue of trafficking in a report entitled Domestic Human Trafficking for Sexual Exploitation in Canada (RCMP, 2013). The report states,

In Canada, the majority of victims who are trafficked domestically are trafficked for the purpose of sexual exploitation. In domestic human trafficking situations there are no international cross-border movements; all stages of the trafficking process, including the recruitment of victims, occur within Canadian borders. Victims can be moved across or within cities or provinces. The legal status of victims in domestic 
trafficking cases is irrelevant. Victims can be Canadian citizens, visitors to Canada, workers on a permit, students on a visa, etc. (p. 5)

This report further exemplifies how state agencies tend to implicate the Canadian sex industry, both street-based and indoor sectors, in the activities of human trafficking:

In domestic human trafficking for sexual exploitation, traffickers force victims to provide sexual services to customers, usually in exchange for money. Sexual services include lap dancing, masturbation, fellatio, and sexual intercourse. Additional services, commonly referred to as extras, include Greek Style (i.e. anal penetration) and Girlfriend Experience (GFE)/Porn Star Experience (PSE) (i.e. sexual act without a condom), and are encouraged by traffickers as these are charged at a higher rate. (RCMP, 2013, p. 5)

As discussed above, the repeated conflation of sex work with human trafficking for the purpose of sexual exploitation begins to shape normative discourses around sex work more generally (see Kempadoo, 2012), such that RCMP's representation of the trafficked victim is most often a woman or girl who is specifically recruited to perform sexual labour.

It is evident that the RCMP classifies socially and economically disadvantaged members of society (such as Indigenous people, LGBTQ2 individuals, "runaways," youth residing in care, migrants, and new immigrants) as the most vulnerable to, and as the most at risk of, being human/sex trafficked. Although this report does not draw any distinct attention to the race(s) of the trafficker, the RCMP classifies all indoor sectors of the sex industry and online advertising mediums as part of the trafficking enterprise. In this regard, all types of third parties are equated with traffickers.

Somewhat contradictorily, in this report, the RCMP (2013) also states that "not all individuals engaged in prostitution are victims of human trafficking; however, all trafficked victims for sexual exploitation are forced into prostitution" (p. 6). Sex work is further classified as a form of physiological control and violence inflicted on women and girls. The 
victim narrative is therefore developed in this report by classifying sex work as a choice only among limited choices for the poor, for those with drug and alcohol dependencies, for those with mental health problems, and for Aboriginal women. Within this framework, the state's paternalistic response becomes clear through its classification of police officers' role in protecting the trafficked victim; they stipulate that police officers must gain the trust of "highrisk individuals involved in prostitution" (p. 39) so that victims can come forward, though they do not acknowledge any of the reasons why sex workers may hesitate to engage with officers (e.g., over-policing, under protection, racial bias, lack of support for victims of crime). Furthermore, responsibilities to stop trafficking are extended to the general public especially clients of sex workers, taxi drivers, transportation employees, and "employees and owners of exotic dance clubs, escort/placement agencies, massage parlours, hotels/motels/inns, condo buildings, and condo/apartment complexes" (p. 40) - with recommendations warning them to be aware of their surroundings, since traffickers use all of these facilities to exploit their victims. Through this appeal to hypervigilance, we can see how the state's anti-trafficking initiatives can actually have negative impacts on individuals working in the sex industry (see Kaye, 2017b).

Canada's new anti-prostitution laws, which criminalized the purchasing and advertising of sexual services, and living on the avails of prostitution (similar to antiprostitution laws in Sweden, Norway, and Iceland) further exemplifies government's reliance on ideologies of vulnerability in the sex industry. While these new anti-prostitution laws' explicit intention is to protect sex workers through the prosecution of victimisers and traffickers, they are implicitly designed to regulate the sex industry. Criminalising a wide variety of third parties and advertising mediums reflects their broader ideology, which claims 
to target the trafficking enterprise but has much broader effects. As Bruckert (2015) explains, these new laws, implemented through the misogynistic assumption that sex workers are incapable of assessing their own risks and circumstances, will undoubtedly continue to hurt the most marginalised and vulnerable sex workers.

\section{Representations by Prohibitionists.}

Prohibitionists rely heavily on narratives of victimhood/risk to represent the contemporary sex worker. Fixated on the idea that all prostitution is violence and that an important goal for feminism should be its eradication, activists and academics in this camp contend that any form of sexual commerce is inherently dangerous for women - especially for women of colour (see Forna, 1991; Gardener, 1980; Razack, 1998b). For instance, Sherene Razack (1998b) points out that, as a socially disadvantaged group, women of colour not only occupy the lowest rungs of the prostitution hierarchy, but they also exist as bodies that absorb patriarchal violence in order to shape the lives of both middle-class women and White highclass call girls. Razack (2002) further articulates sex work as gendered and racialised violence through the case of Pamela George, an Indigenous street-based sex worker who was murdered by two White men in 1995. Razack's article follows the trend of studies focusing on the vulnerable status of street-based Indigenous sex workers and their violent victimisation within the sex industry, which have the effect of framing the sex industry as a gateway to human trafficking (Farley et al., 2004; Farley, Lynne, \& Cotton, 2005). While I do not deny the compelling argument about the overrepresentation of Indigenous street-based sex workers in incidents of violence, I follow Ferris (2015) and other sex workers' rights advocates in "[making] room for women's agency, even in the survival sex industry" (p. 135). That is, while street-based survival sex workers, especially Indigenous women, experience higher 
rates of violence (see Cler-Cunningham \& Christensen, 2001), the structure of gendered and racialised violence in this particular sector of the sex industry can be, and consistently is, resisted (see Sanders, 2004). From this position, I suggest that prohibitionist representations of contemporary sex workers as inherent victims of sex trafficking directly impact individuals who work in the sex industry: first, sex workers are affected by the fundamental principles set forth by prohibitionists and the resulting initiatives that seek to eradicate the sex industry altogether; and second, sex workers are affected by the conflation of sex trafficking with consensual forms of sex work.

According to the Native Women's Association of Canada (NWAC) (NWAC, 2014), Aboriginal women and girls are overrepresented among those being sex trafficked within Canada. NWAC's 2014 report to the Canadian Women's Foundation ${ }^{11}$ explicitly states that they understand prostitution to be a form of human trafficking. In this report, NWAC also claims that ethical attempts to address the issue of women trafficked for the purpose of sexual exploitation must include women working in prostitution and women who do not have pimps but are nevertheless exploited by clients. Thus, among their list of recommendations (e.g., access to education as a preventative measure, long-term counseling, and culturally relevant programs for those exiting prostitution), NWAC includes decriminalising the sale of sexual services while prosecuting third parties and clients. Evidently, these recommendations are in line with Canada's new anti-prostitution laws, which, as Bruckert (2015) argues, will continue to have negative effects on marginalised and vulnerable individuals working the sex industry.

${ }^{11} \mathrm{CWF}$ claims to be a leader in ending the trafficking of women and girls for the purpose of sexual exploitation, and it invested \$2 million in 2012-2013 towards anti-trafficking (Kaye, 2017b). 
Following the NWAC's report, the Canadian Women's Foundation commissioned a task force to study the issue of sex trafficking of women and girls within Canada. The task force findings, published in "No more" Ending sex-trafficking in Canada: Report of the National Task Force on Sex Trafficking (2014), rely heavily on the findings reported by NWAC (2014) and claim that Indigenous women's participation in the sex industry can be traced through several contributing factors: "the impact of colonialism on societies, the legacies of residential schools and their intergenerational effects," the impacts of the Indian Act, and various experiences including "family violence, childhood abuse, poverty, homelessness, lack of basic survival necessities, race and gender-based discrimination, lack of education, migration, and substance addiction" (p. 30). Still, none of the 25 recommendations put forth by the task force directly names these issues as the causes of Indigenous women's domestic trafficking. Instead, the task force's recommendations include the following: first, to strictly enforce existing Criminal Code provisions on human trafficking and sexual exploitation, and second, to change the Criminal Code such that the focus is shifted to the traffickers' actions rather than to those of the trafficked victims. Furthermore, this report recommends amendments only to the Temporary Resident Permits (TRPs) under the Immigration and Refugee Protection Act (IRPA). In recommendation five, the task force advises that the IRPA relax policies and take into consideration migrant women's various vulnerabilities and the psychological duress that they suffer. Evidently, the protectionist initiatives of the Canadian Women's Foundation maintain the image of the vulnerable victim - whether the victim of violence or of trafficking.

The conflation of sex trafficking with sex work in anti-trafficking discourses and responses are prevalent in the initiatives advanced by prohibitionist groups and agencies such 
as Asian Women for Equality, Northern Women's Connection, and Real Women of Canada, to name just a few. These groups, along with other prohibitionist agencies, strongly supported the Canadian anti-prostitution law reform initiatives that criminalised the purchase of sexual services (see Crack, 2014; Jay, 2014; "REAL Women of Canada: Brief on Bill C-36 Protection of Communities and Exploited Persons Act," 2014).

\section{Representations by Sex Workers' Rights Advocates.}

In contrast to prohibitionists, sex workers' rights advocates take the position that the exchange of sex between consenting adults is a valid and viable income-generating activity. ${ }^{12}$ While these advocates also invoke stories of victimhood and represent some sex workers as being at risk of experiencing violence, including through trafficking and other forms of exploitation (Childs et al., 2006; Cler-Cunningham \& Christensen, 2001), the conclusions they draw are notably different. Members of this camp argue that an increased risk of violence is the result of increased isolation, social marginalisation, racism, sexism, and other systemic factors that are prevalent in the Canadian Criminal Justice system (O'Doherty, 2011a; Shannon et al., 2008; Socias et al., 2015). These advocates further argue that the way Indigenous and racialised people as a whole are over-policed and under-protected contribute to the violence some sex workers experience in the sex industry (Amnesty, 2016; Anderson et al., 2015; Goldenberg, Liu, Nguyen, Chettiar, \& Shannon, 2015; Lam, 2016). Representations by sex workers rights' advocates tend to take into consideration the realities of sex workers' lived experiences and their right to safe working conditions, such that they criticise prohibitionists for silencing sex workers' experiential knowledge (Kaye, 2017b). As Kaye

\footnotetext{
${ }^{12}$ Herein referred to as sex workers' rights advocates.
} 
(2017b) notes, from a sex workers' rights perspective, "the rights of sex workers should not be violated in the development of a response to sex trafficking; rather, the voices of experiential workers should inform the response" (p. 147). The victimhood/risk narrative and the continued marginalisation of Indigenous sex workers foreground the discursive intersections of ongoing colonialism and systemic racism. Among sex workers' rights advocates, this can be read as a strategic manoeuvre to draw attention to the negative effects of quasi-criminal anti-prostitution laws, which are further strengthened and supported by other research in the field that points to such quasi-criminal laws as the cause for Indigenous sex workers' victimisation within the sex industry (Benoit \& Millar, 2001; Lowman, 2000).

Scholars such as Janell Hobson (2005), Tricia Rose (2004), and Denean SharpleyWhiting (2007) have examined Black women's sexual experiences, focusing in particular on the exploitation of Black women's bodies and sexualities at the intersection of their personal, cultural, and mainstream understandings/definitions of sex, sexual experiences, and intimacy within patriarchal, racial capitalism in the United States. These scholars, however, also discuss the work that has been done by Black women to reclaim their bodies and define their womanhood against the backdrop of sexual objectification that has been informed by the sexual economy of slavery. They further explain how Black women have challenged hegemonic representations of Black sexuality as pathological, through their various attempts to achieve sexual autonomy through counterhegemonic representations of Black 'sexual deviance'.

In addition to complicating representations of Black sex workers as victims, Mireille Miller-Young's ethnographic study of Black women in pornographic media presented in "Putting Hypersexuality to Work: Black Women and Illicit Eroticism in Pornography" 
(2010), and in A Taste of Brown Sugar: Black Women in Pornography (2014) are examples of scholarship that works to reclaim representations of Black women's bodies and expressions of womanhood. Focusing on how Black women utilise their perceived hypersexuality to support their survival, success, and erotic autonomy, Miller-Young's ethnographic study shows that Black women in pornographic media, while facing multiple axes of systemic discrimination and harm, also strategically "employ [original emphasis] hypersexuality and illicit eroticism to achieve mobility, erotic autonomy, and practices of self-care" (MillerYoung, 2010, p. 219). Some Black women choose to perform hypersexuality, in particular the trope of brown sugar, to derive pleasure from their own eroticism and "in an effort to express themselves as desired and desiring subjects" (Miller-Young, 2014, p. 5). In this regard, many of these Black women have to always negotiate their identity against the backdrop of being perceived as betraying the "hard-fought image of respectable [Black] womanhood," and making money to "survive and take care of their families" (Miller-Young, 2014, p. 5). According to Miller-Young, the roles Black women are increasingly taking on as directors and producers of sexually explicit media are responses to the pornography industry's simultaneous investment in and marginalisation of fantasies about Black bodies and the devaluing of Black women as both hyper-accessible and super-disposable. The women in Miller-Young's research are playing the role of agents in transforming the sex industry by intervening in racism and sexism in one particular aspect of the industry. Miller-Young argues that these women's interventions, as both performers and labourers, lay claim to legitimacy for all sex workers; therefore, feminist scholars working in this subject area should amplify the voices of sex workers of colour by directly including them in research on sexual agency. 
On the same subject matter of Black women in pornography Jennifer Nash's (2014) work further explores racialized pornography by developing a new analytical method of "racial iconography" (p. 2) [original emphasis]. According to Nash, this "new method of analyzing racialized pornography [...] embrace[s] the potential of doing [original emphasis] black feminist visual cultural studies (and, implicitly, black feminist politics) differently [...]" (pp. 2-3). In this regard, Nash's book explores different types of "racial-sexual pleasure [...]pleasures in looking, pleasures in being looked at, pleasures in performing racial fictions, pleasures in upending racial fictions" and it also includes analytical discussions on "blissful performances of hyperbolic racialization and uncomfortable enjoyment in embodied racialization" (pp. 2-3). Nash's objective is to shift the normative interpretations and preoccupations of racialized pornography, which she argues are premised on negative connotations, sympathetic representations, and 'protectionist' sentiments, and produce an "aggressive counter narrative" that applies "an interpretative framework centered on complex and sometimes unnerving pleasures" (pp. 2-3).

Adding to these literature, Siobhan Brooks (2010b) case study of "two racially stratified exotic dance clubs in Manhattan and the Bronx, New York and a lesbian club in Oakland, California” (p. 4) draws attention to how Black and non-Black Latina dancers negotiate their "erotic capital, $[\ldots]$ on both the institutional and symbolic level," at the intersection of race, class and gender to compete in the "markets of desire" (pp. 4-5). Focusing on the themes of "construction of whiteness among dancers of colour, pay differences among dancers, and safety issues for dancers," Brooks examines how racial stereotyping and racial/gender stratification affects the "inequalities among Black and Latina women" (p. 5). Based on her participants' experiences at these clubs, Brooks emphasis on a 
more complex understanding of how the "racialized erotic capital, $[\ldots][$ original emphasis] [which are] affected by variables such as weight, skin colour, speech patterns, gender presentation, and hair texture" (p. 7) shapes the life chances of people, [...] can reproduce unequal power relations [...] [and] can be converted to economic capital, such as social capital, and also can serve as a credit, especially if economic capital is lacking" (p. 7).

Rosen and Venkatesh (2008) illustrate how the firsthand experiences of sex workers are crucial sites of information. They examine how sex work has become one solution to the employment needs of the urban poor. Their research includes in-depth interviews and participant observation of Chicago's sex work economy in a study of one apartment building on Chicago's Southside where fifty of the seventy-five residents are sex workers. This study found that sex work was part of the informal or "off-the-books" (p. 417) economy of resource exchange in this geographical area, which is also characterised by low-wages. The authors argue that although the decision to engage in sex work may initially seem irrational to an outsider, the "specific localised conditions [of their participants] invert this decision and render it entirely rational" (p.417). Much like my own research findings, discussed in Chapters 5, Rosen and Venkatesh (2008) found that their participants' involvement in sex work was a short-term solution that allowed them to address the "demands of persistent poverty and instability", and they see it as a "meaningful option in the quest for a job that provides autonomy and personal fulfilment" (p. 417).

In Canada, too, several scholars have discredited the dominant narrative that sex work is necessarily a form of violence (Brock, 1998; Bruckert, 2002; Durisin, Meulen, \& Bruckert, 2018; Jeffrey \& Macdonald, 2006; Lewis, Maticka-Tyndale, Shaver, \& Schramm, 2005; van der Meulen, 2012; van der Meulen, Durisin, \& Love, 2013). Empirical counterarguments are 
drawn directly from the heterogeneity of sex workers' experiences. There is also research that focuses primarily on indoor sex workers' experiences to further disrupt the narrative that all sex workers are inherently victims (see Bruckert, 2002; Bruckert \& Parent, 2006; Law, 2012; Lewis et al., 2005; O'Doherty, 2011b; Raguparan, 2014). While limited in scope, studies that focus exclusively on racialised indoor sex workers' experiences overwhelmingly disrupt the popular assumption that they are all victims of sex trafficking (Ham, 2017, 2018; Lam, 2016).

Emphasising on the agency of Indigenous, migrant and other racialised women working in the sex industry, Canadian scholars have complicated the trafficking discourse advanced by prohibitionist groups. Problematising prohibitionist position that conflates sex work with sexual violence and sex trafficking, and the representation that Indigenous women are helpless victims of human trafficking, Sarah Hunt (2010, 2013, 2015/2016) argues that the trafficking discourse continues to fix Indigenous women's marginal status- as lacking in agency and choice, and rendering them as voiceless. Hunts' arguments are premised on two main grounds. First, she argues that prohibitionists' claims are not based on evidence such that they do not provide any concrete examples of the trafficked Indigenous girls and women. In fact, according to Hunt (2010), frontline workers in British Colombia deny the claims of Indigenous girls being domestically trafficked. Second, even though prohibitionists' claims are primarily premised on the conflation of sex work and sex trafficking, their research reports not only fail to include the experiences of women who have been trafficked, but they also fail to consider the perspectives of Indigenous sex workers. In this regard, Hunt (2010) argues that even if we make room to interpret some lived realities of Indigenous girls and women as sexual exploitation and domestic trafficking, "painting all Aboriginal sex workers as victims 
does nothing to empower this situation, and has the damaging effect of stripping their agency" (p. 29).

Hunt (2013) in advancing her argument that the conflation of sexual violence and other forms of colonial violence with sex work has damaging consequences to Indigenous communities, advocates for critical, and nuanced dialogues that centre "the voices, agency, freedom, and mobility of Indigenous sex workers" (p. 84). Progressive conversations are imperative, especially given that the current discourse and initiatives towards human trafficking fails to consider the systemic factors that play a significant role in perpetuating the vulnerabilities of Indigenous girls and women working in the sex industry and normalises the violence faced by Indigenous people. According to Hunt (2015/2016) the historical dehumanization of Indigenous people within Canadian legal system prevents Indigenous girls and women to qualify for the contemporary legal classification and emotional response that are awarded to other trafficked victims. In this regard, Indigenous girls and women who come forward to report sexual exploitation and/or trafficking are discredited. Moreover, the current discourse of domestic human trafficking and the powerful legal responses to it draws away from the role of the state in the continued colonial violence towards Indigenous people.

Julie Kaye (2017a), furthering the discussion of how the trafficking discourse and state-initiated anti-trafficking responses directly affect individuals working in the sex industry, argue that the misguided attempts to rescue victims of sex trafficking have led to the silencing and disciplining sex workers through criminal justice initiatives and immigration and foreign policy concerns. The discursive separation of the domestic and international trafficking along with their respective anti-trafficking responses, according to Kaye (2017a) positions migrants - "especially precarious-status migrant workers,"- as international, risky 
subjects, and racialised Others to be excluded; and Indigenous girls and women as "domiciled" at-risk subjects deserving protection (p. 29). Furthermore, such right-based exclusion and inclusion also "establishes a boundary between us (law-abiding national citizens - "families in their homes and communities") and them [original emphasis] (criminalised and generally racialised Others)" (Kaye, 2017a, p. 40). Kaye argues that the "them" [original emphasis] also "includes Indigenous families and communities - alongside migrants - who are blamed for perpetuating domestic forms of trafficking" (p. 40). More importantly existing anti-trafficking initiatives, Kaye argues, naturalises "structural violence against gendered and racialised bodies" (p. 29). The impacts of criminalising sex work and deporting migrant and other racialised women who engage in sex work and the naturalisation of structural violence against gendered and racialised bodies is further emphasised by the sex work activist communities and critical sex work studies (Butterfly, 2016; Maynard, 2015/2016; Millar et al., 2015; O’Doherty et al., 2018).

My final area of review in this chapter is comprised of studies that have been published in medical journals. These publications are often aimed at measuring issues related to HIV/STIs, and they frequently support the occupational health and safety and human rights of im/migrant sex workers (see Anderson et al., 2016; Goldenberg et al., 2017; Shannon et al., 2015). While the studies cited here are based on indoor sex workers' experiences only in the metropolitan area of Vancouver, they draw upon interviews and surveys with migrant and immigrant indoor sex workers and provide meaningful data. For instance, Goldenberg et al. (2017) conclude that the "criminalisation, language barriers, and stigma and discrimination related to sex work and im/migration status in shaping occupational health and safety of $\mathrm{im} /$ migrants engaged in sex work" (p. 2). Meanwhile, Anderson et al. (2016) conclude that the 
criminalisation of in-call venues undermines the health and human rights of im/migrant sex workers in those spaces. Anderson et al. (2016) also found that criminalising sex work in incall venues gives third parties leverage to limit sex workers' access to HIV/STI prevention by restricting on-site access to condoms, sexual health information, and HIV/STI testing.

Shannon et al. (2015) found that the majority of migrant indoor sex workers in their research (who comprise $25 \%$ of their total research sample) had not only completed high school but had also begun sex work at an older age than their Canadian-born counterparts. Similarly, countering common assumptions about migrant sex workers, the migrant sex workers in this study were also less likely than Canadian-born sex workers to report prior mental health diagnoses, and they were less likely to report the use of illicit injected and noninjected drugs. Finally, migrant sex workers were more likely to report higher rates of condom use and lower rates of HIV/STIs. This study further disrupt the dominant script that holds all migrant sex workers are trafficked victims who lack responsibility, agency, and capability to care for themselves or to avoid the risk of coercion, exploitation, and violence from savvy pimps and clients.

In the following chapters, I turn to the original data I collected through interviews with racialised and Indigenous Canadian indoor sex workers in 2014-2015. In order to further contribute to the sex workers' rights perspective and close some gaps in existing scholarship, I argue that my research participants have made informed decisions to work in the sex industry against the backdrop of issues such as persistent poverty, limited availability of professional 
jobs and/or jobs that pay a living wage, ${ }^{13}$ the devaluation and ghettoisation of racialised women's work, and a desire for sex, money, stability, and flexible work environments. My research participants all expressed strategic negotiations of their intersectional experiences in order to market their services, compete in the sex industry, and avoid negative consequences processes which, I argue, show vast amounts of agency, rationality, and business know-how.

${ }^{13}$ Oxfam defines living wage as "an income sufficient to pay for the basic necessities of life, to live with dignity and to participate in society. In Canada, a living wage would be more than the minimum wage, and would take into account both the cost of living in a specific community and the existence other supports, such as government benefits for children" (Ravon \& Stefov, 2016, p. 4). Compared to the average Canadian, who's monthly disposable income after tax is approximate $\$ 3000.00$ ("Cost of Living in Canada," 2016), minimum wage workers make significantly less money. Even with a minimum wage of $\$ 14.00$ per hour, a full-time employee who works 40 hours a week will take home less the $\$ 1,500.00$ every two weeks. 


\section{Theorising Intersectional Identities}

As I have shown so far, the Canadian state has sponsored various policy and program development initiatives on issues related to sex work and sex workers, but they are routinely premised on essentialist human/sex trafficking discourses. Similarly, prohibitionist scholars and activists frequently subscribe to this convenient and unidimensional approach when responding to and debating issues related to sex work. This framework, which assumes that women of colour and Indigenous women in the sex industry only engage in street-based sex work and are subjected to heightened rick of victimhood, not only fails to consider the experiences of women of colour and Indigenous women's in the indoor sectors, but also the agency, capabilities, and informed decision-making practices of street-based workers (Farley et al., 2005; Razack, 1998b). As such misrepresenting their lived experiences. My research provides a necessary counter-narrative by focusing on the everyday experiences of forty racialised and Indigenous indoor sex workers. In this chapter, I develop the theoretical framework that allows me to make sense of my participants' experiences as they negotiate their identities, choices, and actions, and as they navigate systemic race-, class-, gender-, and stigma-based stratifications within the sex industry and broader society.

The main theoretical framework I develop in this chapter is grounded in the broad category of critical feminist studies and in the more specific notion of Kimberlé Crenshaw's (1989) intersectionality. These approaches allow me to analyse my research participants' various experiences within the sex industry and society. Thus, the objective of this chapter is to provide a theoretical framework for conceptualising how my research participants (re)construct, negotiate, and resist their identity categories (through engagements with their 
race, class, and gender), body politics (e.g., skin tones, hair styles, body size), and family/community obligations against the backdrop of two interrelated social factors: first, the systemic challenges resulting from criminalisation, underemployment, unemployment, poverty, and racial discrimination; and secondly, the highly stigmatised stereotypical images of the "vulnerable prostitute," the "trafficked victim," and/or the disreputable, immoral "gold digger."

The participants in this study engage in processes of (re)construction, negotiation, and resistance on a daily basis, which often means choosing between material, discursive, and corporeal identities and practices. Making these sometimes-difficult choices requires participants to consider, on an ongoing basis, not only their position in the marketplace but also their stance on issues such as inclusivity/diversity, equality, strategic essentialism, and victims' rights. My research participants express how the decision to sometimes display stereotypical practices and identities in a specific context is informed and constrained by dominant ideologies of civilisation, (post-)colonialism, whorephobia, moral anxiety, sexual exploitation, patriarchy, and human/sex trafficking.

Throughout this study, I highlight how contemporary understandings of racialised and Indigenous sex workers, which are informed by protectionist sentiments, ongoing colonialism, racial inequalities and whorephobia affects the everyday lives of my research participants. Furthermore, I emphasise that my participants' experiences do not form a harmonious whole. Rather, their experiences are shaped by elements (e.g., identity, body politics, and stigma management) that are thoughtfully and strategically brought together to negotiate hierarchies and power relations within the marketplace and in the community, which are further defined by race, class, gender, sexuality, and other embodied factors. The tactical ensemble of these 
elements directly and indirectly affects not only my participants' autonomy, emotions, and interpersonal interactions, but also their opportunities in relation to power networks of the state, economy, and community. Drawing on my research participants' experiences, then, I move to deconstruct and decolonise narratives and attitudes which are based on stereotypical assumptions and overgeneralisations that essentialise the experiences of racialised and Indigenous women within the indoor sex industry.

This chapter is organised into three parts. First, I begin with a brief genealogy of intersectionality theory (as articulated by Crenshaw) and its main critiques. Intersectionality theory has been criticised for the ways in which plotting marginalised women's relational experiences sometimes produces an essentialised and coherent version of "the Black woman" (see Smart, 1992), which can lead to gridlocks at the point of intersection rather than emphasising the fluidity of intersectional experiences (see Puar, 2007, 2012). Taking these critiques seriously, I next explore the possibilities and tensions of examining my participants' intersectional experiences through the approach of post-intersectionality (see Cho, 2013; Choo \& Ferree, 2010; Nash, 2011). I conclude by articulating how I operationalise collaborative intersectionality, a concept developed by Cho et al. (2013) as a postintersectional approach that avoids the limitations of "traditional" intersectionality, to understand my research participants' experiences. The template of collaborative intersectionality first allows me to integrate various other theoretical and conceptual tools to avoid intersectionality's essentialism, and second, informs my understandings of various issues surrounding power relations, culture, interpersonal interactions, and the operational practices within the sex industry that my research participants face. 


\section{Intersectionality: The Theory and The Method}

Rooted in Black feminism and Critical Race Theory, Kimberlé Crenshaw coined the term intersectionality as "a method and a disposition, a heuristic and an analytical tool" (Carbado, Crenshaw, Mays, \& Tomlinson, 2013, p. 303) to conceptualise Black women's experiences of oppression, domination, and discrimination. Building off of earlier analyses of the "double jeopardy" or "multiple jeopardy" of being a Black woman (Beale, 1970; Collins, 1986; King, 1988), Crenshaw's landmark essay “Demarginalizing the Intersections of Race and Sex: A Black Feminist Critique of Antidiscrimination Doctrine, Feminist Theory and Antiracist Politics," (1989) argues that legal, feminist, and antiracist paradigms have the tendency to conceptualise and operationalise discrimination along a single categorical axis. Crenshaw writes, "in race discrimination cases, discrimination tends to be viewed in terms of sex- or class- privileged Blacks; in sex discrimination cases, the focus is on race- and classprivileged women" (p. 140).

According to Crenshaw, single-axis frameworks of "conceptualisation, identification, and remediation" of discrimination that are premised on the most privileged members of the discriminated group (e.g., White women; Black men) erase the multiple dimensions of Black women's experiences, “obscures claims that cannot be understood as resulting from discrete source of discrimination," and distorts analyses of racism and sexism since "the operative conception of race and sex become grounded in experiences that represent only a small subset of a much more complex phenomenon" (p. 140). Therefore, Crenshaw argues, the intersection of racism and sexism shapes Black women's lives in ways that cannot be accurately addressed by looking solely at the racialised or gendered dimensions of their experiences. 
Using the analogy of traffic at an intersection, cars coming and going in all four directions, Crenshaw explains that Black women can experience discrimination in any number of ways. Black women's discrimination, Crenshaw notes,

[...] may flow in one direction, and it may flow in another. If an accident happens in an intersection, it can be caused by cars travelling from any number of discriminations and sometimes, from all of them. Similarly, if a Black woman is harmed because she is in the intersection, her injury could result from sex discrimination or race discrimination. (p. 149)

Ultimately, Crenshaw suggests that

[...] Black women can experience discrimination in ways that are both similar to and different from those experienced by white women and Black men. Black women sometimes experience discrimination in ways similar to white women's experiences; sometimes they share very similar experiences with Black men. Yet often they experience double-discrimination - the combined effects of practices which discriminate on the basis of race, and on the basis of sex. And sometimes, they experience discrimination as Black women - not the sum of race and sex discrimination, but as Black women. (p. 149)

In "Mapping the Margins: Intersectionality, Identity Politics, and Violence Against Women of Color," Crenshaw (1991) develops the concept of intersectionality further "by exploring the various ways in which race and gender intersect in shaping structural, political, and representational aspects of violence against women of colour" (p. 1244). In accounting "for multiple grounds of identity when considering how the social world is constructed" (p. 1245), Crenshaw (1991) discusses structural intersectionality - that is, the way in which structural inequalities (e.g., poverty, unemployment, underemployment, financial dependence, and civic dependence) mark the experiences of violence for women of colour differently from those of White women. In a related move, Crenshaw puts forth political intersectionality to examine how both feminist and antiracist politics have, paradoxically, led to the marginalisation of women of colour who are experiencing violence. Finally, representational intersectionality draws attention to how the construction of women of colour in popular 
culture becomes a source of intersectional disempowerment through its failure to focus on the particular locations and inequalities of women of colour.

Furthermore, questioning the ways in which identity politics have been conceptualised and operationalised within feminist and antiracist theory and activism, Crenshaw (1991) argues that an intersectional approach can broaden the scope of contemporary identity politics. Although Crenshaw (1991) acknowledges that "identity-based politics has been a source of strength, community, and intellectual development" not only for African Americans but also for other people of colour and LGBTQ people, she critiques identity politics within certain strands of feminist and racial liberation movements for frequently ignoring intergroup differences (p. 1242). In other words, Crenshaw (1991) claims that embracing identity politics in the context of violence against women must include an acknowledgement of intergroup differences. Excluding this aspect is fundamentally problematic, since the violence many women experience is shaped by the interaction of other dimensions of their identities, such as race, class, and sexuality. In a more recent speech, Crenshaw (2016) clarifies that intersectionality should not be interpreted as being primarily about identity; rather, it should be understood as a framework for understanding how structures make certain identities the vehicle for vulnerability. She thus asks what types of discrimination excludes marginalised people and what policies and types of institutional structures contribute to the exclusion of some people.

Over the past three decades, Crenshaw's concept of intersectionality, as both a theoretical tool and a methodological approach, has been hailed as a significant contribution to women's studies (Hancock, 2007; McCall, 2005). Many critical scholars have used intersectionality as a framework to conceptualise systemic social oppressions and multiple 
forms of discrimination to understand how social inequality and systemic injustice occur in multidimensional ways (Collins, 1998; Grillo, 1995; Knudsen, 2006; Razack, 1998a). There are, however, critiques of the term and its limitations as well.

\section{Tensions within intersectionality.}

Since its introduction in the late 1980s, intersectionality has been adopted among other disciplines and interdisciplines in the humanities, social sciences, and natural sciences (see Bowleg, 2012; Calás, Ou, \& Smircich, 2013; Carbado et al., 2013; Carrington, Donnermeyer, \& DeKeseredy, 2014; Green, Evans, \& Subramanian, 2017; Zingsheim, 2010). The term's ambiguity, open-endedness, lack of clear-cut definition, and lack of specific parameters of inquiry gives rise to the widening scope of intersectional scholarship and praxis. These factors have also helped to clarify intersectionality's future capacities and amplify its generative focus as an analytical tool to capture and explore the experiences and power dynamics among White women and other sub-groups of dominant members of society. Consequently, widening intersectionality's possibilities and amplifying its focus has been both encouraged and criticised.

On the one hand, widening the parameters of intersectionality has given rise to complex and fluid interpretations and articulations. For instance, Calás et al. (2013) notes that thinkers such as Cathy Davis (2008) have argued that making intersectionality "available for the interests of feminist scholarship of all identities, theoretical and political perspectives" is useful (p. 710). Extending this line of thought through her criticism of certain branches of intersectionality theory, Hancock (2007) argues that making claims in the name of only Black women's and women of colour's experiences of marginalisation obscures the richness of the content - "the multivocality for which intersectionality is known" (p. 249) (also see Nash, 
2008). Moreover, according to Hancock, such a narrow scope of inquiry or content specialisation undervalues intersectionality's inherent capacity for creativity and generative potential. Fixating on a specialised content obscures the "comprehensive intellectual history of intersectionality research" and "masks the ways in which intersectionality (1) can answer new questions as yet unanswerable with traditional models, and (2) can generate strategies for political change that incorporate all of us as political beings, not simply a subset of the population discussed in a single comparative case study" (Hancock, 2007, p. 249). In response, Hancock (2007) advocates for conversations at a broader level of analysis, since intersectionality can facilitate comprehensive answers for questions of distributive justice, power, and government function that are subjects of interest to the discipline of political science and the world around us.

On the other hand, intersectionality's generative focus is seen to slow down feminist efforts. Many of the criticisms in this regard are therefore framed within intersectionality's emphasis on static and fixed identities. Staunæs (2010), for instance, claims that Crenshaw's intersectionality tends to treat categories and identities as static and unchanging over time and across space, which is not always a useful analytical outlook. Fixing categories "negates the role of the individual in navigating intersections for political and everyday purposes" (Zingsheim, 2010, p. 25). Furthermore, Carastathis (2008) argues that intersectionality's read of power relations, specifically the relations between oppression and privilege; the mutual construction of race-, gender-, and class-based discriminations that are inscribed in the experiences of the hyper-oppressed; and the complex and irreducible race and gender oppression in racialised women's experiences are concerning, as it resamples the "unitary model of identity" (p. 23) it intends to overcome. Nash (2008) is critical of intersectional 
theory's emphasis on the socio-historical facts, the continued marginalisation of Black women, and paints them, "for example, as wholly oppressed and marginalised," and instead argues for highlighting “variations within Black women's experiences that afford some Black women greater privilege, autonomy, and freedom" than others (p. 12). Purdie-Vaughns and Eibach (2008) argue that failing to recognise people with multiple subordinate identities do not always "fit the prototypes of their respective subordinate groups" leads to "intersectional invisibility" (p. 380). The consequence of such invisibility is that racialised and Indigenous women who may experience a mix of advantages and disadvantages are dropped out of the conversation.

Jasbir Puar $(2005,2007)$ claims that intersectionality's tendency to constitute an essential subject not only emulates, but perhaps also reproduces, the disciplinary requirements of a dominant normative formation of female subjectivity. This approach also attempts to constrain the messiness of identities and experiences within a formulaic grid. According to Puar (2005), it is this identity grid that runs the risk of structural co-optation. Puar (2012) further notes that intersectionality's tendency to place stable identities into a grid formation disrupts whiteness but not masculinity. Therefore, according to Puar, such articulations of intersectionality ironically reify sexual difference as the foundational category that needs to be disrupted, casting women of colour as the newest subjects of feminism while simultaneously re-securing the centrality of White women.

Considering the above-mentioned tensions surrounding common uses of intersectionality, critics have advocated for the development of a more complex intersectionality theory to conceptualise multiple identities, oppressions, inequalities, and social injustices (Hancock, 2007; Nash, 2008; Puar, 2007). Subsequently, feminist and critical 
race scholars have moved away from the crossroads model to theorise identity in more complex and dynamic ways. Cho (2013) refers to the nuanced points of departure from intersectionality as post-intersectionality - an approach that is still committed to the basic tenets of intersectionality but avoids many of its limitations, particularly its tendency to fix identities within a grid. Keeping in mind the impetus for a more complex intersectionality theory, Cho et al. (2013) provide a template for what they term collaborative intersectionality. Collaborative intersectionality, formed from within the paradigm of post-intersectional analytical frameworks, is not void of limitations but manages to draw attention to the versatility of the concept of intersectionality. In the remainder of this chapter, I articulate how I operationalise the approach of post-intersectionality by adopting the template for collaborative intersectionality to make sense of my participants' experiences in the Canadian sex industry. I also explain how "traditional" intersectionality remains useful in the analysis of my research participants' experiences.

\section{Intersectionality, Post-Intersectionality, and Racialised and Indigenous Sex}

\section{Workers}

The traditional conceptualisation of intersectionality, as articulated by Crenshaw $(1989,1991)$, provides an opportunity to foreground the stories of racialised and Indigenous women in the indoor sectors of the sex industry. I use Crenshaw's intersectionality to examine the multi-layered experiences of my research participants and expose the incoherence of responding to victimhood/risk narratives through protectionist sentiments. A vital component of Crenshaw's intersectionality, Choo and Ferree (2010) define as including the multidimensional experiences of marginalised persons and groups. Thus, using an intersectional framework allows me to locate the multidimensional, inter-categorical 
complexities of and differences between my participants' experiences (Crenshaw, 1989; McCall, 2005).

My commitment to Crenshaw's intersectionality comes through in my choice to retell the stories of my research participants in their own words - a move that counteracts the neglect racialised and Indigenous indoor sex workers have faced for so long by acknowledging that they are the best experts of their own lives. Crenshaw (1989) asserts that because "Black women are theoretically erased" (p. 139), by focusing on Black women's experiences, feminist and anti-race scholars are not only taking a necessary step forward towards addressing the long-term systematic negligence, but they are also engaging in the process of deepening conversations about core sociological issues that affect this marginalised population. I extend Crenshaw's assertion to include the experiences of my participants. Even though the participants of my study are not the most marginalised members of the sex working community, their experiences reflect a diverse range of intersectional experiences. The analysis I employ draws attention to the multiple burdens, structural inequalities, and overlapping discriminations faced by racialised and Indigenous indoor sex workers in Canada. The subject positions of my participants continuously shift between their multiple marginality (e.g., experienced through their race and sex working status), their partial privilege (e.g., their status as indoor rather than street-based sex workers, their education levels, their abilities to earn an income higher than minimum wage), and their performances of race and class markers.

I understand Chang and Culp’s (2002) “After Intersectionality” and Cho’s (2013) "Post-Intersectionality" as departures from the crossroads-type analysis outlined above and as an approach that contributes to another kind of intersectional analysis that holds broader, 
wider, deeper, and more complex commitments. The approach of post-intersectionality seeks to widen the reach and aptitude of intersectional scholarship and clarify intersectionality's capacities; specifically, it amplifies intersectionality's creative and generative focus as an "analytical tool to capture and engage [with the] contextual dynamics of power" (Cho et al., 2013, p. 788; also see Choo \& Ferree, 2010). As Choo and Ferree (2010) suggest, postintersectionality captures the methodological spirit of intersectionality (thus, it is not distinct from intersectionality) as it moves beyond the list and nonadditive process of engaging with race-, class-, gender-, sexuality-, age- based subordination. Distinguishing "between three styles of understanding intersectionality in practice: group-centered, process-centered, and system-centered" ${ }^{\prime 4}$ (p. 129), Choo and Ferree (2010) draw attention to the benefits of each as analytical tools which can then be "more widely used to inform understandings of core sociological issues, such as institutions, power relationships, culture, and interpersonal interactions" (p. 130). Walby, Armstrong, and Strid (2012) similarly argue that broadening the scope and increasing the complexity of intersectionality research allows us to overcome intersectionality's unresolved predicaments and limitations. Thus, in the past decade or so, despite criticisms of co-optation and the colonisation of critical race studies, we have seen the operationalisation of post-intersectionality approaches through researchers who are theorising the intersections of multiple identities - not only of marginalised populations, but also of subgroups of society's dominant members - to understand how their identities shape their privilege, and how space, time, structures, and institutions condition one's identities (see

\footnotetext{
${ }^{14}$ Group-centered: "emphasizes placing multiply marginalized groups and their perspective at the centre of the research"; Process-centered: "intersectionality as a process highlights power as relational, seeing the interactions as variables as multiplying oppressions at various points of intersection and drawing attention to unmarked groups"; System-centered: "seeing intersectionality as shaping the entire social system pushes analysis away from associating specific inequalities with unique institutions, instead looking for processes that are fully interactive, historically co-determining, and complex" (Choo \& Ferree, 2010, p. 129)
} 
Carbado, 2013; Carbado et al., 2013; Levine-Rasky, 2011; Puar, 2005; Staunæs, 2010;

Tomlinson, 2013).

In this study, I take the position that employing intersectionality and postintersectionality as transformative approaches can aid in conceptualising my participants' experiences as reflecting both their multiply marginalised and partially privileged positions. To operationalise the approach of post-intersectionality, I rely on collaborative intersectionality to provide a platform to engage in critical discussions about my participants' experiences in the indoor sex industry and within broader society. For example, in Chapter 6, I examine research participants' strategic performances of approximations of whiteness and racial tropes to negotiate the structural inequalities of race, gender, and class in the indoor sectors of the sex industry. In Chapter 7, I map participants' stigma management through strategic interactions with law enforcement. In Chapter 8, I focus on structural, representational, and political intersectionality (see Crenshaw, 1991) to analyse my participants' barriers to engaging in sex work activism as well as the alternative priorities they hold. Through these frameworks, this dissertation seeks to deconstruct, destabilise, and perhaps even decolonise the stereotypical, preconceived, and unyielding constructions of the racialised and Indigenous sex worker. It is in this regard that I am contributing to academic knowledge that draws on the longstanding work of sex work activists and community members.

This project also emphasises the position - popularised by feminist standpoint theory - that women's experiences should be the starting point for any knowledge production about their lived realities (see Harding, 1993; Letherby, 2003). From a standpoint epistemology, this project brings forward the stories of research participants with the intent of influencing 
contemporary debates and discussions about sex work and racialised and Indigenous sex workers (see further discussion of standpoint theory in Chapter 4). The indoor workers in this study astutely identify the ways in which their experiences of racism are not always the same as the experiences of racialised and Indigenous street-based workers; likewise, the forms of sexism these racialised and Indigenous women experience are not always parallel to the experiences of White indoor workers. In this regard, I emphasise an important position in feminist critical race studies: the personal experiences of racialised and Indigenous sex workers are indeed political. In my analysis of interview data, I aim to validate my participants' experiences of discrimination, inequality, and resistance while also disrupting their preconceived subordination within the sex industry and broader society.

\section{Collaborative Intersectionality.}

To analyse my research participants' perspectives and experiences, I rely on Cho et al. (2013), who propose a template for moving forward with intersectional analysis despite its various limitations and challenges. As a post-intersectional approach, Cho et al.'s vision for a broadened and complex view of intersectionality does not lie in the use of the term "intersectionality" itself, nor is it situated in content-specific and familiar fields of study, nor is it about relying on lists of conventional references. Rather, Cho et al. argue, what makes an analysis intersectional is

[...] its adaptation of an intersectional way of thinking about the problem of sameness and difference and its relation to power. This framing - conceiving of categories not as distinct but as always permeated by other categories, fluid and changing, always in the process of creating and being created by dynamics of power - emphasises what intersectionality does rather than what intersectionality is. (p. 795) 
For Cho et al., adopting an intersectional way of thinking along these lines can build a bridge between the two prominent camps of scholars of intersectionality: those who have adapted intersectionality from Black feminism and implemented it in many other disciplines/ interdisciplines to redefine the processes of identifying subjects and social categories and conceptualising race, gender, and other social dynamics; and those who are doubtful about incorporating mainstream methods and theories into their intersectional research. In this sense, adopting an intersectional way of thinking not only has a net-widening effect, but it can also "expand our conception of intersectional methods to include the integration of projects that bring crucial theoretical, methodological, and substantive resources to intersectionality" (Cho et al., 2013, p. 795). The future of intersectionality studies will thus, Cho et al. argue, [...] be dependent on the rigor with which scholars harness the most effective tools of their trade to illuminate how intersecting axes of power and inequality operate to our collective and individual disadvantage and how these very tools, these ways of knowing, may also constitute structures of knowledge production that can themselves be the object of intersectional critique. (p. 795796)

I follow Cho et al.'s guidance to exercise rigour and harness the most effective conceptual and analytical tools that allow me to make sense of my research participants' intersectional experiences. In the remainder of this chapter, I articulate how I operationalise the post-intersectionality approach through a collaborative intersectional framework as both a theoretical tool and a methodological approach.

\section{The fluidity of multiple identities.}

Critiques of intersectionality have suggested avoiding the essentialised subject of intersectionality by focusing on the fluidity of identification categories (Carastathis, 2008; Puar, 2012). In this sense, scholars who take the post-intersectional approach consider identities to be inherently unstable, infused, intertwined, mutually constitutive, and varying in 
time and space, such that they shape the vulnerabilities and other everyday relations in the lives of marginalised people (see Bilge, 2013; Carbado, 2013; Duong, 2012). Given that one objective of this study is to theorise participants' identities in ways that will help to avoid the possibilities of gridlocks (see Puar, 2012), it is perhaps worthwhile to briefly outline the way in which "identity" is operationalised in this study.

From a social constructionist perspective, here I conceive identities as constructed, complex, fluid, and even fictitious entities. Hekman (1999) argues that even though social constructionist theories of identity are useful for feminist needs, their parameters must be carefully outlined such that they address specifically feminist concerns. Thus, for the purpose of this study, following Hekman's (1999) suggestion, the social constructionist perspectives of identity that I adopt first emphasise agency, to highlight that "socially constructed selves are not social dupes, but agents who act and resist" (p. 21). Second, by focusing on the role of hegemonic identities of gender, race, and class, I draw attention to "the fact that all aspects of identity are not equal: some are frivolous and inconsequential, while others are all-pervasive and life altering" (Hekman, 1999, p. 22). In this regard, no matter what identities my participants adopt, their "hyper-identities" of gender, race, and class will always be part of their identity. Third, I incorporate an experiential dimension to social constructionist perspective of identity. As Hekman (1999) writes,

Identities are constructed from the social/discursive mix available to me in my contingent historical circumstances. Likewise, many identity options are closed to me because of those circumstances; my range of options may be large or radically circumscribed depending on those circumstances. [...] But identity is not just about epistemology, it is also about experience. (p. 22-23)

Hekman (1999) argues that drawing attention to the "experiential element," offers the "possibility of a middle ground [...] a sense of identity that, although constructed, is a stable 
and necessary component of human selfhood and agency" (p. 19). Grounding my conceptualisation of research participants' identities in a modified version of social constructionist perspectives of identity allows me to displace the hegemonic representations of racialised and Indigenous sex workers and draw attention to the ways their identities are often produced through a network of differential, complex, and potentially contradicting strands. Their identities are thus neither fixed nor fluid, rather are relational.

The post-intersectional approach of collaborative intersectionality allows me to adopt the modified version of social constructionist theories of identity to highlight the complexities, multiplicities, and fluidity involved in processes of identity formation. That is, a post-intersectional approach allows me to focus on the multiple dimensions of identity and draw attention to the fact that identity categories are not only subjective but are also structural in that they encompass social positioning and everyday practices; both power and social categories of identity are context-specific and constantly shifting (Brah \& Phoenix, 2004; Carbado, 2013; Choo \& Ferree, 2010; Duong, 2012; Henne \& Troshynski, 2013; YuvalDavis, 2006). Davis (2008) notes that theorising multiple and shifting identities not only coincides with Foucauldian perspectives on power dynamics and the deconstruction of normalising and homogenising categories, but it is also integral to theorising the notion of “difference" (also see Hekman, 1999). According to McCall (2005), "social life is considered too irreducibly complex - overflowing with multiple and fluid determinations of both subjects and structures - to make fixed categories anything but simplifying social fictions that produce inequalities in the process of producing differences" (p. 1773). In this regard, many thinkers who take the post-intersectional approach focus their attention on theorising the intersections of identity and various axes of differentiation such as structural inequalities among different 
classes of women (McCall, 2001), contemporary politics of belonging, which encompasses notions of citizenships, identities, and the emotions attached to them (Yuval-Davis, 2007), and the "other side" of power relations by exploring the intersections of whiteness and middle-classness rather than the more traditional categories of racialisation, gender, and working-classness (Levine-Rasky, 2011).

Furthermore, Brah and Phoenix's (2004) integrated analytical focus, which is based on varying and variable subjectivities, identities, and specific meanings that are attached to differences, places emphasis upon emotional and psychic dynamics as much as on socioeconomic, political, and cultural differences. These each require us to incorporate different kinds of difference into our analytical thinking. According to Yuval-Davis (2006), combining various types of difference shapes the boundaries of knowledge projects even where there are no explicitly oppressive social relations present. This reframing of intersectionality theory "challenges hegemonic approaches to the study of stratification as well as reified forms of identity politics" (Yuval-Davis, 2006, p. 201).

In addition to focusing on processes of identity formation and theorising difference, Carastathis (2013) argues that intersectionality's conceptualisation of identities as multiple and contradicting becomes pronounced if we focus our attention on Crenshaw's mostly ignored claims of identity categories as coalitions - alliances built across difference. According to Carastathis (2013), envisioning identity categories as coalitions allows for a counter-hegemonic interpretation of intersectionality that is more consistent with Black feminists' analysis. To this end, when conceptualised as coalitions, intersectional identities render themselves open to the possibilities of forging connections in numerous ways. Cole (2008) argues that envisioning intersectional identities as coalition highlights "new avenues 
of cooperation" (p 447), and Cho et al. (2013), referring to Carastathis work, suggest that considering identities in intersectionality as coalition "demonstrates that intersectional identity is not ready-made" (p. 802).

Inspired by the above-mentioned thinkers, the collaborative intersectional analysis presented throughout this study first allows me to highlight the multiplicity and fluidity of identities - as well as resulting experiences - particularly as my participants resist the popular representations of the vulnerable/victimised/trafficked "victim" and framings of the "Other" within existing economic, social, and political contexts. Second, it highlights the intersections of multiple axes of differentiation while also drawing attention to the intergroup differences between the subsets of racialised and Indigenous women in this study.

\section{Intersectional performances.}

In this dissertation, drawing from Ervin Goffman's dramaturgical perspective, I conceptualise my research participants identities and interactions as they perform their sexual labour. That is, I interpret participants' impetus for performing approximations of whiteness through embodiments of White beauty tropes, stereotypical racial tropes, and heteronormativity - through their aesthetic beautification practices (e.g., make-up, hair styling, clothing) - as expressions of their agency, resistance, and aptitude for succeeding as entrepreneurs. Borrowing from Stychin (1995), my participants' appropriating White beauty tropes, racial tropes, and heteronormativity can be read as "isolated acts of resistance by individual agents" (p. 22). Stychin (1995) writes, "[by] operating within and utilising the terms of the dominant discourse in subversive fashion, new identities are shaped - 
subjectivities that emerge in an oppositional relationship to the universal" to destabilise and resist their historically silenced subject positions (p. 22).

From the point of view that the world is a stage and all the people are players, Goffman's dramaturgical perspective facilitates the exploration of how individuals, when interacting with others, present themselves in particular ways to influence or persuade the impression others develop of them. According to Goffman (1959) individuals "have many motives for trying to control the impression they receive of the situation" (p. 15). Thus, dramaturgical analysis focuses on the micro order of interactions to highlight the ways in which people engage in the process of impression management. In dramaturgical sense the individual is viewed as 1) a performer- "a fabrication of impressions involved in the all-toohuman task of staging a performance" (p. 252); and 2) as a character- "a figure, typically a fine one, whose script strengthen, and other sterling qualities the performance was designed to evoke" (p. 252).

Drawing attention to the relationship between performance, character and everyday life, Goffman articulates that the process of establishing a social identity in everyday life acts functions similarly to a theatrical production, and it "becomes closely allied [with] the concept of the "front" - an aspect "of the individual's performance which regularly functions in a general and fixed fashion to define the situation for those who observe the performance" (p. 22). In this sense, a social actor's performance of an already-established role involves carrying out suitable behaviours, mannerisms, and visual appearances/looks (including dressing in appropriate clothes) that fit the desired role. Just as how a theatrical actor performs in a setting that is constructed of a stage and a backstage, with props in both settings directing the action, Goffman notes that as a "collective representation," the front establishes proper 
"setting," "appearance," and "manner" for the social role assumed by the actor, uniting interactive behaviour with the personal front (p. 27). Therefore, from a dramaturgical sense, an individuals' performance may be intentional or unintentional; it may be about shaping impressions and evoking particular responses; or it may be about following scripts of traditions and social status. In other words, a prudent and disciplined performer/actor strategically adopts their performance "to the information condition under which it must be staged" by thoughtfully concealing their actual affective expression, emotions, mannerism and behaviours and displaying the appropriate response for the situation/environment in order to manage impressions and influence certain outcomes (Goffman, 1959, p. 222).

The dramaturgical perspective, as one aspect of the collaborative intersectional analysis, allows for the exploration of research participants' strategic face-to-face interactions and performances through their behaviours and mannerisms on a given occasion which serves to inform the situation or outcome of their encounter with others. To this end, intersectional performance beings out the middle ground -the relationality between fixed and fluid social identities. Intersectional performance allows to describe participants' 1) embodiments of identities and interrelationship in their various interactions/situation; 2) strategic techniques for impression management in a given social interaction/situation; and 3) problems with impression management. Furthermore, using intersectionality with dramaturgical perspectives, this project draws attention to the capacities of my participants to direct the activities of their clients, third parties, or law enforcement personnel, by strategically concealing information about them selves to persuade and manipulate their audience, regardless of their power position to convey effectively what they want to achieve. Goffman 
(1959) argues that "power of any kind in this situation must be clothed in effective means of displaying it, and will have different effects depending upon how it is dramatized" (p.241).

The concept of intersectional performances as acts of resistance highlights the ways in which my participants consciously, intentionally, and explicitly perform their race(s), gender(s), sexuality(ies), class(es), and identity(ies) as sex workers, mothers, daughters, immigrants, and victims. Different performances, enacted in different places and times, produce different outcomes. Furthermore, participants' lived experiences, shaped by, for example, colonialism, civilisation missions, moral anxieties, and whorephobia inform the roles they perform (or fronts they put on), including which props they use and costumes they wear, to shape the outcome of their interactions, identities, body politics, and political engagements. In this regard, emphasising the relationality between fixed and fluid identity categories, intersectional performance allows me to highlight two interrelated aspects of my participants realities: first the fronts they choose when passing as White, appropriating racial tropes, and subverting impressions of racial tropes are informed by race-, class-, gender-based discourses; second, intersectional performances allows me to assert that under the mask participants' fluid and multiple subjectivities are also actively and creatively being formed through the same race-, class-, gender-based discourse that are used to construct the fronts.

Using intersectional performance, in this dissertation I highlight several key elements of my research participants' experiences: first, the fluidity and instability of the categories that are applied to them and which they apply to themselves; second, the process of converting the material body aesthetically (e.g., through make-up, hair styles, and clothing) and sometimes physically (e.g., through cosmetic surgery) as an entrepreneurial task/marketing strategy that allows them to produce a marketable service and as a strategic interaction to influence 
impressions of respectability and gender norms; third, the process of subverting structural practices that are aimed at maintaining systemic racial stratification (e.g., placing limits on hiring women of colour within the indoor sectors of sex industry, as detailed in Chapter 5); fourth, the power structures and hierarchies in the sex industry and society are not fixed, rather can be challenged and subverted as demonstrated by their relative class mobility and partial privilege; and finally, the performance of race-, class-, gender-based roles that simultaneously conform to and contradict normative assumptions about sex workers, Indigenous women and women of colour. That is, drawing attention to my participants conscious decisions to, for instance, pass as White, as respectable woman, and as good mothers, and as hyper-sexual, or as poor trafficked victim at the intersections of normative assumptions of race and sex work highlights a process that what Scott (1990) refers to as the "hidden transcripts" of everyday resistance (see also Bruckert, 2002). Hidden transcripts are the unspoken discourses that inform both everyday and exceptional acts of resistance (Scott, 1990). While research participants' performances that conform to normative assumptions are unlikely to alter social consciousness or public perceptions about sex work and sex workers, their ability to choose which front to perform allows participants to undermine dominant powers and resist cultural constructions.

\section{Partially privileged identities.}

Another conceptual dimension that is developed through post-intersectionality scholarship is the recognition of "partially privileged identities" - subgroups of people within dominant populations who experience manifestations of subordination (e.g., homophobia, heterosexism, and heteronormativity as one axis of subordination) at the intersections of gender, class, age, sexuality, etcetera (see Hutchinson, 2001). This concept shifts focus to the 
permeability of power and power relations. Post-intersectionality holds a theoretical capacity and commitment to include any and all groups of people in research analysis, particularly subgroups of the dominant population who occupy multiple social positions, rather than only including women and other marginalised members of a community (Cho, 2013; Mutua, 2013). This approach is intended to challenge hegemonic approaches to the study of stratification and highlights power as dynamic and relational.

As an analytical tool, post-intersectionality focuses on the diffuseness of power structures and how it interacts to produce different social subordinations that affect groups and individuals differently (Cho, 2013). In this regard, post-intersectionality is not only wellsuited for the task of deconstructing dominant and systemic structures, it is also useful to analyse the identities and hierarchies that constructs the experiences of partially privileged populations (Hutchinson, 2001; Mutua, 2006, 2013). Adopting a post-intersectionality approach, Mutua (2013) uses the multidimensional masculinities theory to examine how the internal and external structures and hierarchies affect the lives of partially privileged men (i.e., Black men). Responding to Crenshaw's critique that single-axis analysis is inattentive to internal hierarchy such that it "frequently conflates or ignores intergroup differences" (Crenshaw, 1991, p. 342), Mutua (2013) interprets the complexity of masculine identities along at least two axes: "an internal axis centering around performance, appearance, and behaviour, and the external one as centering on the multitude of intersecting systems such as race, class, and sexuality" (p. 361). In order to challenge the narrow reading of intersectionality as being only (or largely) about Black women, Carbado (2013) employs intersectionality to engage the experiences of men, masculinity, whiteness, and sexual orientation. By focusing on White homosexual men, Carbado argues that even though rights 
based activism in law often leads to ingraining normatively gendered and raced identities, systemic stratification is not naturally fixed. To this end, Carbado argues for a "colourblind" and "genderblind" approach to intersectionality in order to emphasise White LGBTQ peoples' experiences of discrimination and oppression (p. 817).

Applying post-intersectionality to the axes of whiteness and middle-classness, LevineRasky (2011) explores the "other side" of power relations - those that exist from the perspective of privileged positions (p. 239). In doing so, Levine-Rasky (2011) draws attention to the complexity and fluidity of power relations by articulating that oppression and domination are co-conditioned and co-existent. Furthermore, Levine-Rasky (2011) highlights that the positions and positionalities of whiteness and middle-classness "reinforce each other in some circumstances and contradict each other in others", making them partially privileged subjects (p. 239).

While scholars like Mutua (2013), Carbado (2013), and Levine-Rasky (2011) are using post-intersectionality approaches to explore the partial privilege of men's lived experiences, others have explored the partially privileged positions of women. For example, Samuels (2008) uses two case studies - one with Black-White biracial adoptees in White families and the other with Afghan refugee women - to demonstrate the co-constitutiveness of privilege and oppression at the level of the subject. Here Samuels (2008) highlights the subtle, but important differences between intersectionality and post-intersectionality. That is, while traditional "intersectionality calls on us to consider women as whole beings; recognize that not all women experience their womanhood in the same ways; many women face multiple forms of oppression, and not all women are rendered powerless" post intersectionality perspective in its efforts to represent the diversity of "feminisms" pushes the concept of 
intersectionality further, suggesting a conceptualisation that allows to recognise that "women experience their womanhood individually, and various interlocking oppressions function differently in different contexts" - that is, cause for oppression in one context may be cause for privilege in another (Samuels, 2008, p. 6). Furthermore, Samuels (2008) suggests that we take a "multisystemic approach to understanding privilege and oppression within structural macrolevels [and focus on] how these same social identities become reified or transcended on more interpersonal and/or micro levels" (p. 6). This approach illustrates one of the benefits of using intersectionality to analyse and understand women as multidimensional yet uniquely whole. Samuels (2008) argues that "[s]orting through the layers and levels of oppressions and privileges and understanding them collectively without fracturing them as additive and separate components are crucial if we are to appreciate fully the shared experiences of women as whole beings in their diverse roles and identities" (p. 8).

In another example, Purkayastha (2012) shows how immigrant women from India and Uganda who are racially marginalised in the USA are also marginalised in India and Uganda, according to the respective local racist ideologies, interactions, and institutional arrangements. The women's experiences upon return to their "home" countries after having been away changed again, depending on "variations of who is part of the privileged majority vs the marginalised minority within a country" because "these hierarchies do not always fit the White-yellow/brown-Black hierarchy extent in Western Europe and North America" (Purkayastha, 2012, p. 59). Samuels (2008) and Purkayastha's (2012) post-intersectional approaches guide me through conceptualising the sometimes-privileged positions that are occupied by my research participants. 
In this study, I rely on the notion of partially privileged subjects (as discussed above) to articulate the experiences of my participants, particularly those whose visible looks, markers of class, corporeal practices, and spatial locations do not fit the prototype of their respective subordinate groups. Using the notion of partially privileged identities to understand the experiences of my participants highlights the multiplicity, fluidity, and the dynamics of power relations and other social categories. Through the lens of partially privileged identities, we can see how relations of power and social categories sometimes intersect to reinforce the fixed nature of systemic stratifications while at other times work to contradict them.

Recognising research participants' partially privileged encounters, interactions, identities, and experiences requires consideration of their relative race and class privilege namely based on their status, or ability to pass, as middle-class and, in some cases, as White. From a post-intersectionality framework, in this study I conceptualise social class and its intersections with gender, race, and/or sexuality "as simultaneously subjective, structural, and about social positioning and everyday practices" (Brah \& Phoenix, 2004, p. 75). Therefore, drawing from Bourdieu (1987), the class analysis presented in this study is about mapping the ways research participants negotiate their identities, experiences, and body politics to symbolically represent attributes of class markers. According to Bourdieu, the symbolic indicators of class one possesses or has access to are based on status in the social world and the distribution of various forms of capital that are "the set of actually usable resources and powers," which are also potentially convertible (Bourdieu, 1984, p. 114). Bourdieu distinguishes between economic capital (financial resources and assets), social capital (connections and social networks) and cultural or informational capital (Bourdieu, 1984, 1987, 1991, 1992). Cultural capital exists in three forms: embodied (e.g., taste, social 
competencies, mannerisms), objectified (e.g., clothes, property, home), and institutionalised (e.g., credentials or qualifications). In this study, I use these three forms of capital to explore how participants enact various performances to symbolise class relations, transforming their social and/or cultural capital into economic capital and vice versa.

I place Bourdieu's notion of capital in conversation with McIntosh (1997) and Mahoney's (1997) conceptualisations of White privilege. McIntosh (1997) defines White privilege as an "invisible weightless knapsack of special provisions, assurances, tools, maps, guides, code books, passports, visas, clothes, compass, emergency gear, and blank checks” (p. 292). Similarly, Mahoney (1997) points out that the "knapsack" of White privilege

includes both unearned assets (things that should be entitlements of humanity and that everyone should have in a just society, but which in fact are awarded to the dominant race) and unearned power that is systematically conferred (those things that are damaging in human terms even as they bring advantage and are associated only with dominance, such as the freedom not to be concerned about the needs, culture, or reality of others). (p. 306)

Mahoney also reflects that people of colour do not read White privilege as invisible, nor do they see the reproduction of it through many conscious and unconscious 'mysterious' acts. Inverting the metaphor of the invisible weightless knapsack is useful for interpreting research participants' partially privileged positions. That is, based on my participants' experiences, I conceptualise partially privilege positions within the sex industry as being akin to a heavy knapsack rather than the weightless knapsack described by McIntosh. My participants' knapsacks of partial privilege are often filled with guilt, obligation, multiple burdens, conflicting commitments, and some opportunities. Unlike the unearned powers of White privilege, the partial privilege held by my participants is hard-earned. 


\section{Intersections of space and time.}

Drawing inspiration from Gillian Rose (1993), I examine the various spaces that research participants in this study inhabit on an everyday basis. Rose explains that feminists have emphasised the importance of tracing the everyday routines carried out by women, "because the seemingly banal and trivial events of the everyday are bound into the power structures which limit and confine women" (p. 17). Rose notes that "[t]he limits of women's everyday activities are structured by what society expects women to be and, therefore to do. The everyday is the arena through which patriarchy is (re)created - and [through which it is] contested" (p. 17). In mapping the everyday spaces of my research participants, I aim to understand how the spaces that they inhabit shape their identities, performances, experiences, and corporeal practices as they interact in the marketplace and in political activism.

Rose (1993) writes that "for white feminists, one of the most oppressive aspects of everyday space is the division between public space and private space" (p. 17). Drawing attention to one of the earliest discussions of the split between the public and private realm, Rose points out that for many White feminists, "the 'private' was an ideological prison [...] [because its] assignment of place within socio-spatial structures indicat[ed] distinctive roles, capacities for action, and access to power within the social order" (p. 17). However, according to bell hooks (1994b), African American people have historically believed that the homeplace or the private space, "however fragile and tenuous," has a radical political dimension (p. 42). For African Americans during racial apartheid, the homeplace was one site where they could freely confront and resist the issue of dehumanisation (hooks, 1994b). hooks (1994b) writes,

Black women resisted by making homes where all Black people could strive to be subjects, not objects, where they could be affirmed in their minds and hearts despite poverty, hardship, and deprivation, where they could restore to 
themselves the dignity denied to them on the outside in the public world. (p. 42)

Other theorists extend this intervention. For instance, from an intersectionality/postintersectionality paradigm, Valentine's (2007) approach to the complexity and fluidity of intersectionality moves beyond theorising the interplay of identity categories to consider how identifications and misidentifications are "simultaneously experienced by subjects in specific spatial and temporal moments through the course of everyday lives" (p. 18). Furthermore, reflecting on the labelling of private or public spaces at the intersections of gender, race, class, sexual orientation, and physical ability, Johnson (2005) argues that neither the public realm nor private realm is necessarily better for women. In this regard, while "some women are disadvantaged through their relegation to the private, others are harmed through a denial of access to any sphere of privacy" (p. 24). Moreover, according to Johnson (2005), these realms function in sometimes-contradictory ways, and "the benefits or burdens attached to any given division seem to be historically contingent and contested" (p. 24). Ultimately, Johnson (2005) argues that "statements like 'the personal is the political' are not simply assertions that a given issue should fall to the public rather than the private side of the line" (p. 24); instead, such statements signify that the very act of drawing a line between 'spheres' is itself political. Thus, according to Johnson, "while there is perhaps little in life that is inherently 'public' or 'private," important implications that flow from such boundary-making has significant effects in peoples lives (p. 24).

Through my conceptual analysis of space in this study, I address the tensions and contradictions that are embedded in the homeplace/private space. In addition, I consider how research participants manipulate space and material circumstances to shape their identities, performances, and capacities to earn an income in the marketplace. Therefore, my 
engagement with the intersections of spatial dimensions in connection to my participants' identities, experiences, and corporeal practices further highlights the complexities and possibilities of deploying intersectionality as an analytical tool.

\section{Methodological Implications of Collaborative Intersectionality}

My use of collaborative intersectionality highlights my commitment to Crenshaw's (1991) claim that intersectionality is a provisional concept that can be linked to contemporary politics through postmodern theory. I therefore use collaborative intersectionality to help make sense of the uncertainties, vagueness, open-endedness, and methodological malleability of intersectionality and to reconceptualise research participants' multiple and shifting identities, experiences, and corporeal practices (see Brah \& Phoenix, 2004; Chang \& Culp-Jr, 2002; Yuval-Davis, 2006). Carbado et al. (2013) refer to such an articulation of intersectional thinking as an analysis-in-progress. The seemingly random combination of theoretical tools, the vagueness inherent in integration, and the constant movement in analytical thinking makes it clear that intersectionality "theory is never done, nor is it exhausted by its prior articulations or movements" (Carbado et al., 2013, p. 304).

My adoption of collaborative intersectional analysis, as outlined in this chapter, contributes to deconstructing, destabilising, and decolonising some of the stereotypical, preconceived, and imagined notions of the sex industry and of racialised and Indigenous women's involvement therein. According to Gayatri Spivak, deconstruction teaches one to question all transcendental idealism (Landry \& Maclean, 1996). Deconstruction of hierarchical discourses helps explain social norms, individuals' emotional reactions, and even their aesthetic preferences. Given that the purpose of this study is to question hegemonic narratives and authoritarian fictions often used to describe racialised and Indigenous women 
in the sex industry, Spivak's conceptualisation of deconstruction is useful for analysing the firsthand accounts of my research participants. Further, Spivak's approach to deconstruction allows me to reject general truth claims by bringing in accounts of participants' experiences that insist upon the need to examine the process of identity construction from the bottom up. Deconstructive approaches, according to Spivak, are "not fixed and finite in the form of thought as a 'product,' but active thinking - a journey that involves moving back and forth over both familiar and less familiar intellectual terrains while constantly interrogating its own premises" (Landry \& Maclean, 1996, p. 7).

Finally, collaborative intersectionality helps me to acknowledge the significance of my participants' perspectives and then to develop an understanding of how, and why, such views may have developed in the first place. In addition, the feminist practices that I adopt recognise the production of knowledge as a political act; therefore, my own personhood and experiences - growing up within racialised communities and, more recently, conducting academic research - are always part of the research and writing process, which subsequently shapes the validity and integrity of this project (Letherby, 2003; Smith, 1999). Borrowing from Smith (1999), this project has thus been about "'researching back', in the same tradition of 'writing back' or 'talking back', that characterises much of the postcolonial or anti-colonial literature" (p. 7). That is, my efforts to bring to the forefront the perspectives and experiences of a neglected group of an already marginalised population are not only about recovery and empowerment of the oppressed, nor are they solely about struggles for self-determination, but they also involve an analysis of colonialism and the coloniser's role in scripting contemporary hegemonic narratives. It is in these respects that this project addresses my objective of decolonisation. 


\section{Method: Research Tools and Practices}

Primarily informed by interviews with forty racialised and Indigenous indoor sex workers, this research seeks to deconstruct and decolonise the overgeneralised narratives and assumptions about racialised and Indigenous women's participation in the sex industry. Borrowing from Jeffrey and Macdonald (2006), this study is “designed to 'hear' sex workers' own analysis of their lives, their work and the world around them" (p. 313). Further drawing on Jeffrey and Macdonald (2006), I start this study from a sex workers' rights position: sex work is work; sex workers are the experts; and sex workers' stories of their lived experiences are explicit forms of political resistance. I thus "present sex workers and their work as a deliberate strategy of both survival and resistance" (Jeffrey \& Macdonald, 2006, p. 316). This research adopts a feminist research practice and captures the qualitative understanding (similar to that of ethnomethodology or ethnography, rather than surveys and questionnaires) to make sense of my research participants' experiences.

Given that qualitative studies are often based on small numbers of participants who are not randomly sampled, this study - by definition - is neither generalisable to the entire population of sex workers nor representative of all racialised and Indigenous sex workers. However, focusing on racialised and Indigenous experiences within the indoor sectors of the Canadian sex industry addresses a gap in feminist, critical race, and sex work literature.

\section{Research Context}

Adopting a feminist qualitative research and data analysis approach, I aim to place my research participants' lives at the centre of social inquiry - not only to validate and 
acknowledge their positions as experts, but also to highlight their unique communal standpoint as racialised and Indigenous indoor sex workers. Given the tensions within feminist research circles, there is no single approach to or general agreement on the definition of a feminist research methodology. Despite these disagreements, "at its core, feminist research is designed to seek social justice, to enhance women's voice and influence in society, and to explore alternative ways of understanding the world through women's experiences" (Gergen, 2008, p. 280). Therefore, a feminist research methodology can be distinguished from other forms of research by the "questions feminists ask, the location of the researcher within the process of research and within theorising, and the intended purpose of the work produced" (Letherby, 2003, p. 4). Furthermore, nearly any research method can be made feminist, so long as the approach arises from the unique combinations of feminist perspectives, epistemological knowledge, and ontological existence that orient feminist theories (Allen \& Walker, 1992; P. Moss, 2007). In this regard, all descriptions of expression and reality of women are made from a particular standpoint position (Harding, 1987).

In employing a feminist standpoint position, this research also takes into account the challenge posed by women of colour who reject standpoint theory for its individualising practices related to structural truths of class, race, and other demographic variables (Anzaldúa \& Moraga, 1983; Collins, 2000; hooks, 2000; Naples, 2003). Therefore, the standpoint position I adopt here follows Collins (2000) conception of Black feminist standpoint. Collins (2000) writes,

I contend that the collective values in U.S. Black neighborhoods, when combined with the working-class experiences of the majority of Black women, historically provided collective as well as individual everyday worlds. Thus, U.S. Black culture continually created via lived Black experience with racial segregation provided a social context for the emergence of a Black women's standpoint. (p. 292) 
Collins (2000) also notes that Black women's standpoint is not static; rather, is influenced by social conditions, such as "the heavy concentration of U.S. Black women in domestic work coupled with racial segregation in housing and schools" (p. 24). These social conditions not only gave them a "common organisational network that enabled them to share experiences and construct a collective body of wisdom," but it also meant that they had the "strength to shape those same social conditions" (p. 24). In this regard, Black women's standpoint does not “emphasiz[e] how Black women's standpoint and its accompanying epistemology differ from those of White women, Black men, and other collectives," but rather, it takes the experiences of Black women "as one specific location for examining points of connection among multiple epistemologies" (Collins, 2000, p. 270). In this study, I extend the notion of Black standpoint theory and read it as racialised and Indigenous sex workers standpoint to include the experiences and perspectives of my research participants and explore their unique communal understanding of their involvement in the indoor sectors of the Canadian sex industry. In this chapter, I describe my approach to interviewing participants and interpreting their stories. Before diving into the specifics of the interview process, I first outline my participants' demography, the process of obtaining ethics approval for this research, and the process of recruiting interview participants.

\section{Participant demography.}

At the time of interview, all but one of my forty research participants were Canadian citizens or permanent residents. The one exception to this was in Canada on a student visa, enrolled at a university in one of the western provinces. Twenty-seven of my participants were born in Canada, while thirteen were born elsewhere. The women came from a variety of racialised and Indigenous experiences: two identified as belonging to an Arabic ethnicity; four 
identified as belonging to an East Asian heritage; thirteen identified as Black; three identified as Indigenous; six identified as belonging to a South Asian community; and twelve identified as mixed-race. Some of the mixed-race women have one parent who is White, while others do not. The majority of participants self-identified as women both at work and in their everyday lives. Two participants self-identified as gender non-binary but worked as women in the sex industry. All research participants were over the age of 18 years old, with the majority $(n=18)$ of women being between the ages of 25 years and 35 years old. Eleven women were over 35 years old and three women were over 50 years old.

Research participants in this study have been involved in a wide range of sectors within the Canadian sex industry (see Chapter 5), such as independent in-call/out-call sectors, escort agencies, massage parlours, strip clubs, and online sectors such as pornography and webcam work. Some women have been simultaneously involved in street-based sex work and the indoor sectors (see Chapter 5). Thirty-eight women were actively involved in sex work at the time of interview, with the majority $(\mathrm{n}=23)$ working on a full-time basis. Participants engaged in part-time sex work $(\mathrm{n}=17)$ were primarily enrolled in higher education $(\mathrm{n}=6)$, with a small portion ( $\mathrm{n}=3$ ) pursuing a job outside of the sex industry. Ten participants also identified as mothers who had the responsibility of caring for their children. Participants were recruited from nine different cities - Vancouver, Calgary, Saskatoon, Niagara Falls, Toronto, Kingston, Ottawa, Montreal, and Halifax.

\section{Research ethics.}

This study was reviewed by and received clearance from Carleton University's Research Ethics Board (see Appendix I). The research associated with this study was 
conducted in accordance with the principles of the Tri-Council Policy Statement: Ethical Conduct for Research Involving Humans and the Carleton University Policies and Procedures for the Ethical Conduct of Research.

In addition to obtaining formal ethics approval from my university and adhering to professional codes, I followed Bell's (2013) eight key signposts of feminist ethics. That is, throughout this study I consciously reminded myself of the following: (1) Do no harm to workers and the sex worker movement (also see hooks, 1994a); (2) Confidentiality, privacy, and anonymity are the cornerstones of this project; (3) Obtaining informed consent is not a static event, but rather a dynamic and continuous process (see also Smith, 1999); (4) Exercise caution when retelling research participants' stories; (5) Be mindful of the power differentials between myself (as the researcher) and the research participants; (6) Be thoughtful about how I choose to represent my research findings; and (7) Ensure that I respect participants' dignity, autonomy, and their rights to voluntary participation in this study. In addition to engaging with the above seven issues, I abide by Carleton University's research ethics and professional codes/guidelines (see also Mauthner, 1998).

\section{External Approvals.}

In addition to formal ethic approvals, four sex workers' rights organisations (SWRO) ${ }^{15}$ conducted their own reviews and concluded that this study would potentially benefit the racialised and Indigenous sex worker community. Within academia, sex workers are often referred to as sensitive, under-researched, hard-to-reach, or hidden populations, and thus

${ }^{15}$ The four SWRO are as follows: Sex Professionals of Canada (SPOC), Maggie's Toronto, POWER in Ottawa and PACE society in Vancouver. 
studying their working conditions and other related issues is known to be challenging (Benoit, Jansson, Millar, \& Phillips, 2005). Benoit et al. (2005) write,

Such populations share three main characteristics: (a) no sampling frames exist, and thus the size of the membership and group boundary is unknown; (b) acknowledgement of belonging to the group is threatening, because membership involves being the object of hate or scorn and sometimes fear of prosecution; and (c) members are distrustful of non-members, do whatever they can to avoid revealing their identities, and are likely to refuse to cooperate with outsiders or to give unreliable answers to questions about themselves and their networks. (p. 264)

In anticipation of these challenges, especially the third characteristic, the first stage of my research involved developing trust within the sex workers' rights movement (SWRM) and explaining my investment in focusing on the experiences of racialised and Indigenous women in the industry. Gaining and keeping the trust of formal organisations/representatives is as important as gaining the trust of the community participants (Bhopal, 2010; Shaver, 2005).

Given my position as an outsider in relation to sex work, SWROs vouching for me was crucial for my research process. Two aspects of the SWRM's endorsement are noteworthy here: First, while only four SWROs reviewed the research proposal, other organisations such as SWAN, Big Susie's, and several online communities were involved in vouching for this project and getting the word out to the community. Second, while many participants reported that they do not generally seek services and resources from the SWROs in their city (see Chapter 8), they all relied heavily on the endorsement of SWROs when deciding to participate in this study. I am grateful to all those who made this project possible.

\section{Recruiting participants.}

I recruited my forty research participants over a period of eight months in 2014 and 2015. Relying on the snowball sampling technique, I established three separate starting points 
for the snowballs: SWROs and their social media pages, my social and academic networks, and 'cold calls' to sex workers located online.

The SWROs, upon endorsing this research, circulated information about the study and the call for participants among their constituents. They also permitted me to post information about this work on their Facebook pages. I posted a weekly advertisement (see Appendix III) from September 2014 to February 2015, which generated significant interest and response within racialised and Indigenous sex worker communities. Sex workers who participated in interviews subsequently tweeted out the advertisement or shared it with their contacts. The net-widening effect from social media advertising made it possible for me to recruit participants from coast to coast. This snowballing also resulted in women from the United States contacting me to express their desire to participate in the study. Unfortunately, I had to decline politely because of the geographic restrictions on this research. It is important to note that in this capacity, the SWROs' role in this study was strictly limited to advertising, such that they did not influence the participant selection or recruitment. Interested women contacted me directly through email, text, or phone call, and those who met the study parameters were interviewed.

My call for participants (see Appendix II) was also circulated by email through many different networks comprised of sex workers, activist, and academics - these included networks of colleagues who also research in the field, contacts from my time volunteering with an exotic dancers' rights organisation, and connections I fostered through my research for my MA project. In this sense, I depended on my interpersonal relationships, and the sampling began with friends and colleagues (see Browne, 2005). As Browne (2005) asserts, there are methodological and ethical advantages to recruiting from previously established 
relations and networks. For instance, it allows potential participants to "'check out' the research and me both as a researcher and a person" (see Browne, 2005, p. 50). Such a vetting process could enable trust in me and increase their willingness to disclose information during our interviews (see Browne, 2005). However, it is important to note that while I recruited women who already knew each other and/or knew people within my social network, I did not personally know any of the women I interviewed.

Following Kavin Walby’s (2010) approach, I also attempted to start a snowball by directly contacting sex workers through emails and text messages. I systematically searched Backpage.com, Eros.com, Redzone.com, and individual websites, and I contacted women who identified as belonging to an ethnic group in their advertisements (see K. Walby, 2010). My first message to all participants was scripted identically (see Appendix IV), with basic information about the research project and participants' role in it. If I received a response, the second email I sent had further details about the research, including my Letter of Information (see Appendix V). All participants who responded to the second email then engaged in a series of email exchanges to ask questions about the study, confirm their eligibility, and set up a time for the interview. Some women decided not to take part in the study after participating in a series of email exchanges. Reaching out to women directly did not yield as many responses as reaching out through SWROs and through my social networks. Despite showing interest in the study, most of the workers I contacted directly were not comfortable and/or did not trust me enough to participate in the study. Some women perceived my text messages as a prank or hoax and replied with an annoyed or angry text (see O'Connell-Davidson, 1995; K. Walby, 2010). The majority of my emails and texts were left unanswered. A few women replied to inform me that they did not belong to an ethnic community even though they 
advertise as such. My marginal success with contacting women directly further emphasises the advantages of recruiting through established social networks and SWROs.

There are both advantages and drawbacks to recruiting participants using the snowball method. On the one hand, it allows access to participants who may not fit the prototype of racialisation as they enjoy the privileges of approximations to whiteness - e.g., mixed-race women with pale skin tones - and also helps to break down some of the power relations between the researcher and the participants (as the 'researched'). Because women in my study were always approached by someone they knew, it was easier to establish a relationship of trust (see Standing, 1998). On the flip side, the snowball technique is time consuming and limits the diversity of participants as it is biased towards cooperative participants (Shaver, 2005).

\section{The Process of Participation}

Participants recruited for this study voluntarily engaged in one in-depth, one-on-one interview with me. Voluntary participation necessarily included the ability to decline to answer any question(s) that they did not feel comfortable with for any reason. Although no one withdrew from the study, voluntary participation also meant that participants were free to withdraw from the interview and/or from the study at any time.

\section{Before the interview.}

All participants signed an informed consent form (see Appendix V), which they had access to in advance of the interview (Bell, 2013; Hesse-Biber, 2013b). The consent form was accompanied by a Letter of Information (see Appendix V), which contained sufficient information about the scope and goals of the project. Participants also had the opportunity to 
ask questions over email or by phone before they agreed to participate in the interview and/or before they signed the consent form (Hesse-Biber, 2013b). Consent was also obtained to audio record the interviews and to use direct quotations in the dissertation, other publications, and related presentations.

While getting informed consent was straightforward, getting women's written consent was more difficult. The difficulty was directly related to the legal constraints this group faces. Therefore, some women signed with their initials; others used pseudonyms. Often, I relied on oral consent rather than written consent. Throughout the research process, I also followed the feminist research practice of developing a rapport with my participants before, during, and after the interviews to ensure participants' continuing consent (see Bell, 2013; Bhopal, 2010). Efforts to ensure continuous consent reinforces the idea that consent indicates trust - trust that is constantly being negotiated (Smith, 1999). Conceptualising consent in this way also articulates the decolonising practices of understanding consent as a dynamic relationship rather than as a static decision (Smith, 1999).

While I was engaged in the ethical formalities of this research before the interview process, my participants were engaged in a simultaneous process of ensuring their safety and trying to minimise the awkwardness of discussing intimate and stigmatised topics with a stranger. Therefore, most participants interacted with me through social media, emails, and texts before the interview, some women sought out endorsements from sex work activists in the community, and one woman even requested proof of my university affiliation and identification before the interview. Participants received a cash honorarium of seventy-five dollars each for their time. 


\section{During the interview.}

All interviews were conducted in English. Most interviews were carried out in person, which allowed for easier rapport, though a few were conducted over the telephone and Skype audio/video call. Women who were not available to meet in person chose the telephone or Skype for convenience - some women were not in Canada when I interviewed them, and others could not meet with me during the day. As part of my fieldwork, I could only afford to travel to a few cities across Canada, but Skype made it possible for me to interview women in the towns where I was not physically present. Another advantage to using new technological mediums (such as Skype) for conducting interviews is that they give participants the choice to terminate the connection whenever they choose to, without experiencing any awkwardness or sense of obligation (Bell, 2013). On the other hand, when using the unsecured connection of Skype, I was not able to guarantee the complete anonymity of the conversation. I ensured that all participants were aware that Skype was not a secure mode of communication and this allowed participants to make an informed decision about whether or not to participate in the interview through Skype. Due to security concerns, some women opted to take part in the interview over the telephone instead.

I strived to conduct interviews in a neutral environment in which the participants felt comfortable, often in public libraries, ${ }^{16}$ university libraries,${ }^{17}$ or in a meeting room at my own university. While I acknowledge that research participants may have felt safer in a location that they were more familiar with, whether their home or workplace (see Chapkis, 1997), I did

\footnotetext{
${ }^{16}$ I used enclosed group study rooms in public libraries. Public libraries were not only easy to access, but the enclosed rooms also provided the necessary privacy that coffee shops or other public spaces lack.

${ }^{17}$ I used enclosed group study rooms in libraries of the universities participants attended as it was a convenient meeting location for them.
} 
not get ethics approval from Carleton University’s Research Ethics Board to visit workers' homes or workplaces. Carleton's research ethics committee was convinced that conducting interviews in sex workers' homes and workplaces might compromise the safety of either myself or my participants. This experience is in line with the writing of Bell (2013), who claims that when 'research participants are designated as 'somehow vulnerable,' ethics committees may have concerns about researchers accessing these people" (p. 87), which can result in significant divides between feminist ways of researching and other traditional ethical or methodological concerns. Such difference in ethical principles between researchers and university ethics committees makes it difficult to access research participants who they perceive to be vulnerable.

When I met with each participant, I conducted an open-ended, in-depth interview. Hesse-Biber (2013b) points out that "interviewing is a particularly valuable research method feminist researchers can use to gain insight into the world of their participants" (p. 185; (also see Jeffrey \& Macdonald, 2006; Vault \& Gross, 2007)). The length of the interviews varied between forty minutes and two and a half hours. In keeping with my commitment to attending to the 'subjective' understandings of an often-neglected population, the interview questions focused on particular topics and issues that shape the experiences of participants (see HesseBiber, 2013b).

The interview guide (see Appendix VII) was a written list of semi-structured questions that were approved by Carleton's Ethics Board and the SWROs. With these semi-structured interview questions, I exercised a considerable amount of flexibility of the sequence in which I asked each question; such flexibility made it possible for me to ask new follow-up questions throughout the interview, facilitating a natural flow on my part and on the interviewee's part 
(see Hesse-Biber, 2013b). Therefore, the open-ended interviews that I conducted included conversations and reciprocal dialogue, in which I also responded to comments and questions that were directed at me. For example, as mentioned above, many participants vetted me by looking at my Facebook page, my published pieces, and my MA project before they agreed to meet with me. Thus, during the interview, participants asked me about my life, my research, including its 'political' or feminist nature, my experience with racism in my everyday life, and my strategies to overcome systemic oppression. I felt it was important and fair to share aspects of my personal life given that I was asking participants to share their intimate stories. To the best of my knowledge, I answered questions honestly and felt comfortable doing so (Mauthner, 1998). Hesse-Biber (2013b) refers to this process, in which a researcher shares his or her biography with research participants, as a "participatory model."

The epistemological concerns and benefits of the research relationship in woman-towoman interviewing have been debated within feminist research circles (Finch, 1984; Harding, 1991; Oakley, 1981; Stanley \& Wise, 1993). These debates have concluded that research relationships "should be non-hierarchical, non-exploitative, reciprocal, and work on a participatory model" (Bhopal, 2010, p. 188). Additionally, they have recognised the validity of Black female academics using their 'outsider-within' status and lived experiences to engage with the academy from a Black feminist standpoint (Collins, 1986; Cook \& Fonow, 1990; Nielsen, 1990; Reinharz, 1992). As Hesse-Biber (2013b) notes, "the idea of sharing identities and stories with one another is thought to increase reciprocity and rapport in the interview process, thus breaking down the notions of power and authority invested in the role of researchers" (p. 199). 
Both Razack (1998a) and Trinh (1990) suggest that women of colour are often faced with a dilemma when asked to tell their stories - on the one hand, they do not wish to miss the opportunity to speak and record their realities, but on the other, they are concerned about how the listener will theorise and write up their stories (also see hooks, 1994a). Thus, women of colour often struggle with not only the type of story they wish to tell and the voice in which they want to tell it, but they also feel that "there are penalties for choosing the wrong voice at the wrong time, for telling an inappropriate tale" (Razack, 1998a, p. 53). Trinh (1990) notes that women of colour do not want to "indulge in marketable romanticism or a naive whining about [their] condition" (p. 373; ) (see also Razack, 1998a). The rapport I established with my research participants not only shaped the trust they had in me, but also perhaps reduced participants' dilemma for deciding which story to tell and which voice to use when telling it, allowing me to highlight their unique yet communal standpoint (see Collins, 2000).

While there are benefits to a participatory model where the researcher/interviewee relationship is non-hierarchical, non-exploitative, and reciprocal, the ethical concerns of such a practice cannot be ignored. Given the interactive nature of qualitative research where researchers interact closely with their participants, many researchers caution against getting too close to participants. Participants may perceive a warm and caring interviewer as a friend, which in turn could lead to the false illusion that there are no power or authority differentials between the researcher and interviewee (Brinkmann \& Kavle, 2012; Hesse-Biber, 2013b). This perceived closeness may make participants more vulnerable to revealing more details of their lives, disclosing experiences, and discussing emotions which they later regret (Brinkmann \& Kavle, 2012; Hesse-Biber, 2013b). Given that the researcher still holds the 
power in analysing and interpreting participants' stories, the idea of researcher-as-caringfriend has been criticised from a feminist standpoint (Burman, 1997; Hesse-Biber, 2013b).

As a feminist qualitative researcher, I expressed my honest empathy throughout the interview process. I did not fake or manipulate my emotions in order to establish rapport. At the same time, I did my best to maintained professional distance throughout the interview process. In following the Tri-Council Policy Statement: Ethical Conduct for Research Involving Humans and the Carleton University Policies and Procedures for the Ethical Conduct of Research, I often reminded participants of their rights to voluntary participation as outlined in the Letter of Information and the Consent form and that they were not required to disclose anything they did not want to. Additionally, to ensure that participants did not disclose information they would later regret, participants were allowed to retract parts of their transcript after the fact if they no longer wanted certain pieces of information to be included (see Interview Transcript Review, discussed below). Retracted parts of interviews were deleted from my transcripts.

\section{After the interview.}

I transcribed each taped interview verbatim, changing or deleting names and all other identifying information. Participants were given pseudonyms to protect their confidentiality. Participants were also given different pseudonyms in different documents produced from this research - for example, the pseudonyms used in journal articles are different from the pseudonyms used in this dissertation. In certain sections of the dissertation I have changed the pseudonyms of participants to ensure that if all the quotations from one participant is taken together they are not identifiable. This procedure enables confidentiality to be maintained as far as possible. 
Listening to the taped interviews during transcription, I realised that conversational speech is naturally filled with pauses, hesitations, and interruptions, including talking over; often with many grammatical errors, no formal sentence structure, and no punctuations. As such conversational speech, in its original state, was difficult to reproduce as coherent written text (Standing, 1998). I also realised that the interviews were full of laughter, frustrating pauses, idioms used to express anger, and slang to represent particular histories. The transcript that interviewees reviewed included the pauses, laughter, hesitations, and the grammatical erros. Transcripts also included points in the interview where the participant and I would talk over each other and where participants did not verbally articulate their stories. I believe that my body language conveyed the message of "mutual understanding," and therefore participants sometimes felt that they did not need to verbally articulate their points in more depth (see Denton \& Deane, 2010). I identify these instances in square brackets. Transcripts also included the colloquial phrases such as "yeah" and "like." Some participants had distinct speech patterns; I transcribed them verbatim but flagged them for the individuals. Participants who returned the edited transcript altered their grammar, distinctive speech patterns, slang, and some even deleted sections of their interview. Participants also altered or amended sentences where there was some hesitation or awkward phrasing. Some participants were embarrassed and offended that I had included colloquial phrases such as "yeah" and "like" in their transcript - they said I had made them look like "idiots" (see Forbat \& Henderson, 2005).

All participants reviewed the verbatim interview transcripts and made changes or corrections as they felt were necessary (Hesse-Biber, 2013b). Some participants, after reviewing their transcripts, made their own decision on what to include and what to discard 
from the pages of the transcript due to concerns about anonymity and safety. Hagens, Dobrow, and Chafe (2009) refer to this practice as "interviewee transcript review" (ITR). One of the advantages of ITR is that it reinforces the rights of research participants (Hagens et al., 2009) and is “often driven by feminist ideals of participant 'ownership' of the transcription and empowerment through seeing the version that will be used in analysis and publication" (Forbat \& Henderson, 2005, p. 1118).

\section{Analysis and Interpretation}

The processes of analysis and interpretation are not necessarily two distinct phases in qualitative research. In fact, the fluidity of qualitative research analysis can be simultaneously conducted during data collection, data analysis, and interpretation of research findings (Corbin, 2017; Hesse-Biber, 2013a). For this study, I conducted a preliminary analysis of fifteen interviews while I was still in the field collecting data. I conducted this analysis in three separate stages, focusing on five interviews at a time. The first stage of preliminary analysis allowed me to continuously modify my interview questions during the early stages of data collection. These modifications also allowed me to refine and clarify the questions in order to gather a comprehensive data set. I conducted a second round of preliminary analysis and interpretation while I was transcribing the interviews, followed by in-depth analysis and interpretation after all the interviews had been transcribed.

Transcripts from all forty interviews were imported into NVivo 10 for analysis. I utilised three stages of inductive coding to organise and separate the different themes that arose throughout the interviews. Descriptive Coding, also called Topic Coding, involves summarising small sections of data with a word or a short phrase. It consists of reading each interview transcript carefully and meticulously coding each line to obtain a broad sense of the 
primary themes of the interviews (see Hesse-Biber, 2013a). This process allowed me to understand the basic components of my research participants' identities, experiences, and corporeal practices. Following feminist research methods, the "first-level" of meaning-making therefore consisted of and came from the specific words my participants used to tell their stories.

The second level of meaning-making is where I read the interviews in order to interpret participants' stories by filtering them through my own biography and expertise as a researcher (Hesse-Biber, 2013b). Thus, the second phase of coding involved revisiting each of these broad descriptive codes and narrowing them down with subcodes (“child nodes") by asking "What is going on here? How are these codes/categories related? What is not related? And what does all this mean?" (see Hesse-Biber, 2013a, p. 335). For example, in the code "Job Satisfaction," some of the subcodes included "Flexibility," "Interactions with clients," and "Working independently vs for third parties." Certain codes were narrowed a level further ("grandchild nodes"). For example, the subcode "Working independently vs for third parties" was further narrowed with the code "Responsibilities of independent worker."

The third and final phase of coding involved reorganising the codes into main themes for discussion in respective chapters. It is in this phase that I moved "from being a participant in the research relationship to being in a position of power to translate and interpret" (Standing, 1998, p. 189) . In other words, Standing (1998) notes that "researchers hold the power of which data, which parts of the interviews, to use, how to interpret the women's words, what to use the research for, and how to represent the women's voices - what language to use to write" (p. 189) (see also Chapkis, 1997; hooks, 1994a). 


\section{Writing the Project}

To mitigate the effect of my own bias and my position of power in selecting which interviews or parts of interviews to use in my writing, I have tried to include all participants' perspectives and experiences in as many circumstances as possible. Given the large amount of data I was working with, this was not always feasible. In these instances, I followed the approach of Chapkis (1997) by seeking out perspectives that are different from my own and attempting to always include rather than edit out material that made me feel personally uncomfortable. Consciously adding material that challenges my preferred presentation of my participants minimises the danger of simply using sex workers' stories as authenticating evidence for my own viewpoints (Chapkis, 1997).

Along similar lines, I was able to realise the mistakes I made during the interview stage as I was analysing and writing up my research. Upon reflection, I realise that talking over participants or completing their thoughts and sentences appears as if I am being suggestive, indicating to them what I want them to say. This was frustrating when I was not able to provide evidence to some of my salient arguments, but in order to maintain the integrity of the research I had to exclude some valuable quotes for this reason.

\section{Personal Challenges and Reflections}

Considering that in qualitative studies, the complexity of researching private lives, "where we observe and talk to people, analyze what they do and say and publish our interpretations to the larger public, $[\ldots]$ is filled with inescapable ethical aspects" (Brinkmann \& Kavle, 2012, p. 263), and taking into account that "all knowledge is affected by the social conditions under which it is produced and that it is grounded in both the social location and the social biography of the observer and the observed" (Hesse-Biber, 2013b, p. 200), the 
practice of feminist research "requires the researchers to self-reflect on what values, attitudes, and agenda they bring to the research process" (Hesse-Biber, 2012, p. 10). With this in mind, I conclude this chapter by reflecting upon my moral and ethical responsibilities.

Throughout this project, from my original design to the writing and dissemination of my findings, I have continuously reflected upon how my personal history and positionalities have influenced the questions I ask and how my positions of power as the researcher (e.g., my values, attitudes, and agenda) have affected my data collection and interpretation of participants' stories. To the best of my ability, I have conducted myself honestly through every step of this research process, and I have represented research participants' experiences accurately and fairly. In the interest of transparency, I have used this chapter to not only outline the procedures of data collection and interpretation but also to draw attention to the limitations of my approaches.

Given my combination of 'insider' and 'outsider' positions, I have strived to exercise professional distance with my participants and their stories throughout this research. Zavella (1993) points out that the issue of conducting fieldwork with research participants who are of the same gender, race, or ethnicity as the researcher is well-debated among ethnographers: On the one side, researchers assert that ethnic insiders often have an easier time gaining access to communities similar to their own and that they are better able to frame questions in ways that respect community sensibilities. On the flip side, being a member of the subordinated group under study creates personal and ethical dilemmas for social scientists regarding their race, ethnicity, gender, political sympathies, and/or even personal failings. In my experience, the shared realities of racism and other race issues faced by me and my participants had a more significant effect on the research process than my outsider position as a non-sex worker. For 
example, participants and I discussed our struggles of navigating through everyday racial discriminations that resulted from our accents and ethnicity, and larger structural barriers. In our conversation we also compared our strategies for handling family dynamics.

It can be emotionally exhausting to continually balance my roles as a researcher and a representative of women of colour (see Mauthner, 1998). This was emphasised as I listened to research participants' stories about their everyday struggles to negotiate their positionality in the sex industry and in broader society. My exhaustion was heightened while I was conducting interviews in Vancouver, where I struggled the most to balance my dual roles and to maintain professional and critical distance. Several factors contributed to my exhaustion: By the time I got to Vancouver, I had been in the field for seven months already. During those seven months, I had lost all of my familiar routines and self-care practices. I was also becoming more vigilant of the stigma that I was experiencing because of my proximity to sex workers. In Vancouver, I had to conduct more than one interview per day to schedule all of the interested parties during my short stay. My ability to maintain critical distance was further impaired when research participants pointed out my position of privilege as a visible minority immigrant, including my ability to pursue a $\mathrm{PhD}$ with funding. Some perceived my positionality as an unfair advantage, which I do not disagree with, given that some of the women I interviewed came to Canada with completed professional degrees of their own. Such moments were uncomfortable and emphasised the complexities of insider-outsider research.

I had to grapple with my various positions and advantages again in the analysis, interpretation, and writing stages of my research. My guilt sometimes got in the way of my ability to maintain professional distance, such that I reported and interpreted everything from my participants' perspectives. I found myself reflecting a lot on the ways that access to social 
mobility hindered by systemic and structural racism has very different effects on different people of colour. For example, some of the women in my study did not get a 'mainstream' job that fit their qualifications because they spoke with an accent and because they did not inhabit dominant White aesthetics.

It took me a long time to begin asking difficult questions when analysing and thinking through the stories participants had shared with me. Some of these questions involved asking if certain experiences are reflective of racism. I also had to be cognisant of the difference between racism and race consciousness. In such instances, I had to take critical distance and evoke my 'outsider' position to avoid being perceived as naïvely complaining about our marginalised conditions. Maintaining my positionality as a researcher was important in order to meet my obligation towards my participants as well - all forty women unanimously asked me to use my "smarts" and tell their happy and sappy stories in addition to the difficult ones. Despite being a challenging process, juggling my emotions while maintaining professional distance has ultimately played a productive role in highlighting the perspectives of racialised and Indigenous indoor sex workers. 


\section{Racialised and Indigenous Women's Place in the Indoor Sectors}

In this chapter, I consider how race, class, and gender intersect within the indoor sectors of the contemporary Canadian sex industry. The objectives of this chapter are threefold: to provide an overview of the diverse range of Canadian indoor sex work; to interrogate participants' responses to race-based hiring practices employed in particular segments of the indoor industry; and to trace the logics and/or rationalisations of sex workers' participation in stigmatised and criminalised labour. First, I provide a brief outline of the basic parameters of the Canadian indoor sector to highlight its diverse labour structures and practices. Focusing on the multiplicity of this sector challenges the pan-sex industry approach that is prominent in Canadian public opinions and policy rhetoric and which is reflected in public and legal policies. This overview of the indoor sex industry is also intended to qualify the way in which it is understood and operationalised throughout this project.

The second goal of this chapter is to outline how research participants conceptualise third party management's hiring practices to restrict the inclusion of women who do not meet Eurocentric beauty ideals. While not all third parties employ such practices, those who do tend to, intentionally or unintentionally, reproduce racial stratification, which is likewise prevalent in many mainstream labour institutions. Therefore, gaining insight into research participants' perceptions of the affects and consequences of such stratification provides an opportunity to understand their rationales for engaging in this line of work. Hearing research participants' perspectives foreshadows two aspects: first, their agency and ability to filter through information that allows them to negotiate their position within various indoor sites, 
and second, their cultural capital (Bourdieu, 1987) as they display comfort in navigating what is perceived to be a bourgeois sector.

The final objective is to locate the rationales of research participants as they enter and work in a criminalised and stigmatised industry. I locate my participants' reasons for working in the indoor sector of the sex industry against the backdrop of issues such as women's greater poverty, the historic ghettoisation of racialised women's work, racism and sexism within mainstream labour forces, and the scarcity of high-paying professional jobs. My main findings here are that despite the capitalist, patriarchal, and racist tendencies of the sex industry, participants in this study believe that the sex industry provides them an opportunity to improve their socioeconomic status through the accumulation of economic and social capital in the various social spaces where they interact (see Bourdieu, 1987; Miller-Young, 2014).

Participants feel that the level of satisfaction and higher standard of living that they achieve from the income, workplace independence, flexibility, and mobility that sex work offers could not be achieved if they worked in, for instance, most minimum wage jobs within retail, hospitality, or domestic labour. Participants who also work in non-minimum wage jobs feel that their employment does not offer the kind of flexibility that allows them to care for young children or to pursue an education while working full-time. Furthermore, for some participants, working in the sex industry is a way to avoid what they perceive to be the degrading work of domestic and institutional domestic labour, ${ }^{18}$ such as cleaning "White people's houses, bathrooms, and hotel rooms; serving White people breakfast, lunch, and

${ }^{18}$ Brand (1999) uses the term institutionalised domestic work to refer to sexual division of labour performed in nursing homes, hospitals, homes for the aged, and other spaces where personnel carry out the tasks of caring and double as cooks, dishwashers, and cleaners. 
dinner in private homes, in office cafeterias, hospitals; lifting, feeding, minding, sweeping, boxing, scouring, washing, cooking” (Brand, 1999, p. 90).

Participants' stories that I retell in this chapter highlight the fluidity of their rationales for working in the sex industry. Some participants view their involvement in the sex industry as a means to experience upward mobility by improving their socioeconomic status (whether that means, for example, repaying student loans, saving for home ownership, or travelling). For others, it is merely a way to make ends meet, such that if they do not work for one day, they are not able to financially support themselves or their dependants. Women in such circumstances face intense anxieties and fears on a regular basis as they grapple with many tensions, including the risk of criminalisation if they continue to work in the sex industry and the increased risk of poverty if they exit the sex industry.

Many scholars in Canada and globally have explored women's motivation to work in the sex industry (Bouclin, 2004; Bruckert \& Parent, 2006; Day, 2007; Jeffrey \& Macdonald, 2006; Kempadoo \& Doezema, 1998; Lim, 1998; Lucas, 2005; Maher, Pickering, \& Gerard, 2013). Studies from the Global North predominantly focus on White sex workers' experiences. Here, I bring the perspectives of racialised and Indigenous Canadian women into the conversation. Even though I am not engaging in a comparative analysis of White and racialised sex workers, I acknowledge that all sex workers, regardless of their race, are inspired by aspects of what the sex industry has to offer. In addition to the relative lucrativeness, White and racialised sex workers alike are attracted to the independence, flexibility, and mobility of the sex industry. In this sense, the findings presented in this chapter are in line with existing literature. My contribution on this particular subject is found in the lines of connection that I draw between the raced, classed, and gendered challenges that 
my participants experience within the mainstream labour force and the raced, classed, and gendered opportunities that they are able to access within the sex industry.

\section{Indoor Sectors}

The indoor sectors of the contemporary sex industry are diverse. They include escorting, erotic massage, erotic dance, pornography, independent in-call and out-call services, professional domination and submission, fetish work, webcam performance, and phone sex. It is important to note that the structures, practices, and boundaries - both physical and imagined - within the various indoor sites of the sex industry are not static, linear, or ordered, but rather, they are flexible and fluid such that sex workers and clients often do not limit their participation exclusively to one site or another. It is also well-documented that the sex industry, including indoor sectors, are gendered sites and spaces, with women largely occupying the role of workers and men the role of clients (Brewis \& Linstead, 1998, 2000; Brock, 2000; Law, 2012; Lucas, 1995, 2005; Phoenix, 1999).

The exact number of people engaging in the Canadian sex industry is unknown. Estimates suggest that $80 \%$ to $95 \%$ of sex workers participate in indoor sectors of the sex industry. ${ }^{19}$ Despite criminalisation, many of the indoor sites of the Canadian sex industry actively participate in the local economy in terms of financial investments and profits, human labour, and culture (for indoor sectors' economic participation in the global context see Day (1996, 2007); Gall (2006); Kempadoo (2003); Pitcher (2015); Kay Hoang (2011)). ${ }^{20}$ For example, Bruckert and Parent (2006) suggest that the labour practices within third party-

\footnotetext{
${ }^{19}$ See Hanger et al. (2006), which states that street prostitution accounts for $5 \%-20 \%$. This report draws this data from numerous witnesses and research studies. See also Benoit and Millar (2001).

${ }^{20}$ Although there is a deep divide in whether sex work can be considered a legitimate form of labour, there is some consensus that the sex industry is part of the local and global economy. In this regard, the debate is still ongoing as to whether the industry fully, or in part, engages in the formal and informal economy.
} 
managed indoor sectors of the sex industry are consistent with other forms of non-standard labour arrangements. That is, the precarious labour market situation of these sex workers subjects them to "receiving less remuneration than the value that their labour adds to the product/services" and excludes them "from social security protection (such as Employment Insurance, Canadian Pension Plan), non-statutory benefits (health and dental plans, disability benefits, paid sick leave), and statutory rights (minimum wage, holiday and overtime pay, job protection, notice of termination)" (Bruckert \& Parent, 2006, p. 102). In addition to Bruckert and Parent (2006), other scholars have documented the labour structure and practices of the Canadian indoor sector (Benoit \& Millar, 2001; Bungay, Halpin, Atchison, \& Johnston, 2011; Jeffrey \& Macdonald, 2006). In this section, I provide an overview of the parameters of the indoor sectors in relation to my observations and the experiences of my participants.

The participants in this study can be classified into two broad categories: those who work for third party-managed sites on contractual bases, and those who work for themselves. Third party-managed sites include, but are not limited to, massage/body rub parlours, escort agencies, and strip clubs. In these sites, clients provide payment for services, which is then either given directly to sex workers or to the third parties. Third parties exercise varying levels of control, which may include setting rates for the services women provide, marketing and advertising the women and the services they provide, managing women's appointments, organising transportation for out-call services, and ensuring that women are working in safe environments (see Bruckert \& Law, 2013; Lewis et al., 2005). Sex workers employed through third party sites share their income with the third party. The amount shared between sex workers and third parties can vary based on the site and the specific agreement, though most often it ranges from $40 \%$ to $50 \%$ going to workers (see Bruckert \& Parent, 2006). 
Third parties also schedule the work days and hours of service providers. Workers' shifts vary in length, usually between eight and twelve hours per shift, and are more or less fixed. As discussed below, women in this study who work for third parties report that they do not have complete independence over their working conditions. In other words, these workers often do not have a choice in the number of hours they work or the amount they charge for services. However, many women feel that the income they earn, even after sharing with third parties, is more than what they could expect to earn from most mainstream jobs.

Counter to women who work for third party sites, those who work independently control their work schedules and hourly rates. Women in this study who work independently show interest in managing a business and often operate from a private apartment, home, and/or hotel rooms, as masseuses, escorts, or in-call and out-call service providers. Clients pay independent sex workers directly for the services they provide, based on an hourly rate or a negotiated set fee. These women's marketing and advertising practices vary from posting selfies on websites such as Backpage. $\operatorname{com}^{21}$ to professional photos on personal websites. Furthermore, given that independent sex workers have to carry out all administrative work associated with their business (e.g., answering calls, screening clients, and scheduling appointments), factors such as business planning, communications, and negotiation skills play a role in women's ability to work independently (see Mahdavi, 2013a).

\section{Intersections of Race, Class, and Space.}

Unlike street-based sex work, the indoor sectors of the sex industry are largely invisible to the public eye. The invisibility of the indoor sector hinges on certain advantages,

\footnotetext{
${ }^{21}$ It is noteworthy that in April 2018, the USA law enforcement agency seized the website Backpage.com.
} 
which add to the complexity of the sector. For instance, most massage/body rub parlours, strip clubs, and other "gentlemen's clubs" operate under the classification of "adult entertainment," regulated through municipal ordinances and by-laws pertaining to the hospitality industry and liquor licence boards (Bruckert \& Parent, 2006; Bungay et al., 2011; Lewis et al., 2005). These establishments pay an annual fee to renew their operating licences. According to van der Meulen and Valverde (2013), the licensing fee for sex-related establishments are expensive and considerably higher than for nightclubs, bars and/or restaurants (also see Lowman, 2000). For example, in the city of Toronto, owner/operator licensing fees for sexrelated establishments are upwards of $\$ 10,000$, while owner/operator licensing fees for nightclubs, bars and/or restaurants are only $\$ 400$ (van der Meulen \& Valverde, 2013). Furthermore, municipal powers to enforce the full extent of regulations for sex industry businesses varies by province and according to local pressures and desires, such that it is not uncommon for certain kinds of adult entertainment sites to be restricted in numbers and by location or to be subjected to extremely high licensing fees (Lewis \& Maticka-Tyndale, 2000; van der Meulen \& Valverde, 2013).

Even though such indoor sites are deemed to be formal/regulated organisations, as mentioned earlier, they engage in non-standard labour practices without fear of state repercussions (Bruckert, 2002). The types of non-standard labour practices that indoor sites engage in vary slightly from site to site and from location to location. While these indoor sites are prohibited by municipal by-laws from offering services involving completely nude encounters, activities in body rub parlours, such as manipulating, touching, or stimulating, are permitted (see Bungay et al., 2011; Lewis \& Maticka-Tyndale, 2000). Bruckert and Law (2013) point out that these by-laws not only vary by city, but they also "use euphemistic 
language and wilful blindness to regulate some of the indoor sex work through licensing and zoning” (p. 28). Third party establishments are often able to avoid state interference on sex work-related activities by carefully navigating these boundaries. Furthermore, third party management's strategies to avoid criminal liability affects the safety, security, and health of the sex workers at their establishments (see Anderson et al., 2016; Lewis \& Maticka-Tyndale, 2000).

In addition to paradoxical operations and regulations, the indoor sector's participation in the global economy is inconsistent. On the one hand, indoor sites are considered to be a part of the informal economy rather than being illegal (see Day, 1996, 2007; Gall, 2006; Pitcher, 2015; Sanders \& Ponsaers, 2008; Shah, 2003). The informal economy, Day (2007) writes, is "a term used loosely to refer to work that is not formally regulated, often invisible and unofficial, albeit intimately connected to state policies" (p. 76). Gall (2006) claims that "the sex industry is part of the informal economy because it is undeclared to tax authorities, involves unlawful activities and constitutes 'cash in hand"” (p. 37). Meanwhile, Pitcher (2015) argues that it is the stigma and criminalisation of sex work that drives the industry into the informal and underground economy.

On the other hand, given the licensing requirements of strip clubs and massage/body rub parlours, and through their associations with mainstream industries for services such as advertising, marketing, and security, these organisations are indeed participating in the formal economy. Furthermore, as licenced businesses, owners and managers do have to pay taxes and are also taxed at a higher rate (see Coulmont \& Hubbard, 2009). Similarly, some sex workers in Canada declare their income from sex work, as self-employed escorts/entertainment service providers or disguised under a legitimised form of labour (see 
Raguparan, 2014; SPOC, 2018). Sex workers declaring their income for tax purposes allows them to qualify for things like bank loans and mortgages (SPOC, 2018).

Race and class stratification are other prominent aspect of the indoor sex industry, both locally and globally. Both prohibitionists and sex workers' rights advocates have classified the indoor sex industry as an "upscale" or "bourgeois" sector, such that relatively economically privileged women who may classify, or pass, as middle-class more frequently operate through indoor sectors such as agencies, clubs, and private referrals (Bernstein, 2007a; Day, 2007; Kay Hoang, 2011; Mahdavi, 2010, 2013b; Razack, 1998b). Both prohibitionists and sex workers' rights advocates have also criticised the "upscale" sectors of the indoor sex industry for intensifying social inequalities such as race and class differences (Brents \& Hausbeck, 2010; Razack, 1998b). Studies also show that this relative economic privilege affords these sex workers a degree of invisibility, which allows them to be protected from state interferences by avoiding harsher and more arbitrary law enforcement practices (Bouclin, 2004; Bruckert \& Parent, 2006; Sanders \& Soothill, 2011).

Furthermore, Brooks (2010b) while examining racial stratification among Black and Latina exotic dancers in two cities in the US, found that even the public usually viewed "racism against Black women in this industry as normal because, like other appearance-based industries (such as modeling, acting), the sex industry is based on ideas of customer taste and preference" (p. 99). Similarly, Wesley (2003) points out that club owners/managers in a Southwestern metropolitan area in the US hesitate to hire women of colour as they are seen as not being able to "bring in the money" (p. 658) (also see Lever, Kanouse, \& Berry, 2005). According to participants in Wesley's (2003) study, given that whiteness is equated with 
feminine beauty, women of colour have had to work harder than White women to be profitable in the market.

In the Canadian context, Ross (2009) points out that Vancouver's nightclub culture, even during the postwar era, was stratified by socioeconomic class, geography, and race. During this time, many Black dancers not only earned less than White dancers, but they also tended to work in lower-end clubs in the city's East End, which was perceived to be shady, dark, and strange by White dancers (Ross, 2009). In the contemporary context, Bruckert and Law (2013) point out that, while not all, many third party establishments' hiring practices are influenced by agency owners' and/or managers' "conventional and Eurocentric definitions of what is attractive," which they argue "can work to the disadvantage of women who fall outside the narrow definition of conventional appearance criteria," including racialised women (p. 53). In other words, these authors argue that third parties who follow a racially stratified hiring practices believe that in the context of Western beauty tropes, which favour blond, slim, and tall workers, the ability of racialised workers to satisfy the desires of their patrons is minimal at best.

Research participants in my study overwhelmingly expressed feeling that the Canadian sex industry, especially the upscale sectors, is preoccupied with catering to the needs, desires, and fantasies of middle-class and upper-class patrons. Participants also believe that middle-class and upper-class patrons who frequent upscale sectors are mostly White heterosexual males seeking the services of White heterosexual sex workers. One participant, Aurora, explains: So I mean blond-haired, light-skinned. [...] That's what they want. [...] If I could get rid of the brown eyes, [...] I would have gone blue at some point. [...] That's what sells, right. Here, Arora alludes to how race and class stratification intersect with Eurocentric 
beauty ideals within the indoor sectors, and to her inability to measure up to those standards.

The affects and consequences of such stratification practices is that there are limits placed on the number of women of colour who can work in any one fixed indoor location.

I worked at an agency of mostly White women [...] I was like one of two Black women, may be one of five women of colour out of maybe about 20-25 women. [Jazzra]

We don't have a lot of Black women. We don't have a lot of South Asian women. We don't. Now, I have worked with five Black women when I worked at [escort agency name], but I worked at [escort agency name] for eight years. So to only see five Black women come through in eight years, that's very few. In that time period, I saw two South Asian women. [Pearlina]

Yeah, I was just hired. [...] [name of agency] hired me a month ago. They told me that they had $x$ amount of coloured girls, $x$ amount of White girls. They were looking for somebody to fit this particular grouping and I was it. [Saskia]

Indigenous participants in this study point out that indoor sectors of the Canadian sex industry operated by third parties hesitate to include Indigenous women who openly identify as such. However, if owners or managers feel that these women could convincingly pass as White, or as mixed-race, then they will be more likely to include them. Borrowing from Tate (2007), I suggest that invisiblising or distorting Indigenous women's racial identity in this way further establishes whiteness as the yardstick for beauty and mixed-race women as sexually desirable.

It is also important to note that not all third party establishments follow a racially stratified hiring practices (see Bruckert \& Law, 2013). Additionally, in this study, for instance, research participants indicated that massage parlours owned/managed by Asian third parties often prefer to hire mostly Asian women. A few White-passing Indigenous women in this study reported working for Asian-owned/operated massage parlours. According to these 
women, they were the only non-Asian workers on the roster of service providers for their particular establishment.

\section{Sex Workers' Perceptions of Third Parties' Claims.}

Participants in this study express conflicting views about the racially stratified hiring practices. Some women are supportive of the third parties' claim that the demand in the Canadian indoor sector is for Eurocentric conventions of beauty. Other women communicate their anger and frustration towards third parties that enforce such hiring practices and still others dispute the third parties' claim and argue that there is in fact a demand for women of colour.

Participants who support the third parties' claim are convinced that these owners/managers operate on the principle that customer satisfaction and maximised profits are the cornerstones of success. In this sense, in order to satisfy their customers' needs, desires, and fantasies better than their competitors, third parties supply the types of women and services that their patrons desire. According to my participants, most clients who frequent indoor sites are White, heterosexual, middle- to upper-class men who desire women who are more or less like them. Lidia explains a way to conceptualise the third party's impetus to enforce the differential hiring practices:

I think that it is very important to sort of keep in mind 'Oh, [...] they like green eggs and ham, I love green eggs and ham.' And it's just like, when you think of indoor escort agencies you think of blond hair, big boobs, a White woman. I don't know why that is, but that's just how it is [...] Like, you're thinking Playboy, Hugh Hefner, like fucking everyone's blond. And that's a lot of, in my opinion, what agencies sort of try to, I guess duplicate. It is that sort of, like, you are a real gentleman, and you are surrounded by all these pretty women, and they are all the same. 
Participants also point out that third parties who are preoccupied with profitability and customer satisfaction cater to the clients they want to attract - middle- or upper-class heterosexual White men with disposable income. As Sarena points out, in a sense, the stratified hiring practice is not about discrimination, but rather, about profitability. However, from Sarena's point of view, it is also clear that working from this particular agency affected her ability to earn money. Despite not being able to make money, Sarena was not annoyed; instead, she thought of her inability to make money as a problem of supply and demand:

I worked at [agency name], which is a much smaller, less popular agency, and when I started, the agency owner did tell me outright, she's like, 'Black women do not get booked as often and so like don't expect to be making a lot of money.' Which I didn't even understand, because when I was at the other agency, I was making tonnes of cash. When I worked independently, I was also making tonnes of cash. It was unbelievable. So I didn't quite know what she was talking about, but I actually didn't make any [money] there. I have never had calls, I never got booked and I don't think that was necessarily discrimination on the part of the phone girls or the booking [people], I think it was just, that's the demographic, that's just the demand for that particular agency.

It is clear from Sarena's experience that various factors drive the demand for the type of sex workers who are included in a given establishment, including the size of the establishment, the popularity of the site within the industry, and the type of patrons who frequent the establishment. Many participants shared Sarena's experience with and attitude towards third parties in this regard. Lidia reflected on her experience when she was told by a third party that she did not fit the market demand:

For me they [third party] [...] say well 'Oh, this is just how it is, like Asian and White people are wanted more. So, you know, we don't really have a need for like Black people.' [...] that's true and for whatever reason Vancouver is weird and people just want to hang out with White, Asian people. [...] when I was working for the first agency that was, like, literally the spiel that I got. [...] They were like, 'yeah we can take your pictures, but it's unlikely. You're just going to have to get out there and make a name for yourself.' 
Many participants in this study appreciated third party's candour in this regard. That is, they appreciated third party informing them of the possible lack of work and the low income, and that it is entirely up to racialised women to market themselves and find a way to compete in the marketplace.

In contrast, some participants, even though they believed third party's claim that the indoor sector is driven by Eurocentric conventions of beauty and customer expectations, still expressed opposition to the differential hiring practice:

Some places [...] they ask you what you look like, and the minute you say Black, they automatically tell you there are no job openings for you. Where everything else tells me equal opportunity employment, there is no such thing of that in sex work. [Shemika]

I get very irritated especially because I feel like everything is so Whitedominated in our society. Especially if you're looking at different agencies, they're not really interested, they are more interested in having blond, blueeyed, White workers, and also I noticed that when people are getting called for work it's more so White women. I've heard from many people that I know, basically not being called because they're South Asian, because they're Black, or getting, like, a lesser rate for the work that they're doing, and that's complete bullshit to me. I find that I have to work a lot harder, [...] than [...] White women and really what's the difference? It's just skin colour. [Malika]

Shemika's and Malika's frustrations are clear. Many participants in this study point to the many challenges they face when competing in the indoor sector: compared to their White coworkers, they have limited opportunities to work in third party sites, their hourly rates are lower, and they often work unfavourable hours. While women of colour are assigned lower hourly rates and unfavourable shifts, which also results in a lower income, the percentage of income that they share with third party managers is the same as that of White women. My participants explain:

I would say, as a Black woman doing this, there's so much more challenges. Well [...] the White girls would make a lot more money with a lot less effort 
[...] So, when I was working in the agency, [...] I was looking through their old [...] content, they actually had some of the old profiles still up on the website, and the [...] Black girl they had, she was 20 dollars less than everyone else and like 20 dollars doesn't seem like a huge amount, but when they are taking hundreds of dollars off of you, that's lot. [Teagan]

So for me to make good money at the agency, I was working more days than everyone else. So I will be the one who works Sundays, I will work four in the mornings. I will be working longer to be available where I was the only option if someone wanted to see somebody from the agency [...]. So say your shift is from 11 in the morning to 11 at night. Some agencies I work at, they want you to be there all day, [even] if you are not getting calls [...]. They will tell you that you are not marketable. [...] if you are not wanted then why be there? [...] If you are not marketable, why did you hire me? But they never give you a solid answer. [Shemika]

According to research participants, the lower hourly rates set for women of colour and scheduling shifts during off-peak hours means that these women also have to work longer hours than their White counterparts. Participants in this study feel that these unequal labour practices - working extended hours for lower pay - closely resembles the normalised practices women of colour face within most mainstream, feminised, and emotional labour forces (see Batnitzky \& McDowell, 2011; S. Dyer, McDowell, \& Batnitzky, 2008; Ehrenreich \& Hochschild, 2002). In this regard, research participants feel that structural challenges and everyday practices within the sex industry affects their social mobility.

The marginalisation of women of colour in the indoor sector also creates a highly competitive working environment for these women. To earn a living wage and make their time worthwhile, sex workers of colour, in addition to competing against White sex workers, they also have to compete against other women of colour (also see Miller-Young, 2014):

There was another Black escort at the agency that I worked at, who was offering more services than me. [...] she was the popular one because of the services and because she was their standard Black girl and I didn't [...] meet her standards. They always compared me to her, so I started to feel like I [need to] do more or do whatever she is doing services-wise [...]. She was 
doing a service called porn star experience, where she is doing more risky activities and getting more body fluids near her. I wasn't interested in doing that. Because she was offering that and making more money and she was complete opposite look of me. She was more dark-skinned, she was fuller than me, and she had implants. So she didn't fit anywhere near what I looked like for Black person either. But because the agency had her first and she set some standards for them they were expecting every Black person to be that way. [Shemika]

The lack of co-worker support and workplace collegiality among racialised co-workers exists in multiple industries (see Sloan, Evenson Newhouse, \& Thompson, 2013). However, according to Sloan et al. (2013), the lack of workplace social ties and perceived co-worker support among African Americans results in further disadvantages for and marginalisation of the African American working community. These types of breakdowns in the social cohesion of marginalised populations simultaneously affects the establishment of cultural capital.

While the racially stratified hiring practice has affected the quality of work and life experiences of my participants, it is noteworthy that not all women in this study have been directly affected by the same. In particular, Indigenous participants who pass as White have not been subjected to the various disadvantages of this practice. The ability of these women to pass as White renders them partially privileged, as they are able to experience many of the advantages of White women. Focusing on the interzones between multiple oppressions and partial privilege, the experiences of my participants signify the paradoxical nature of the hiring practice within the indoor sectors, throwing into question its coherence and power within the sex industry.

\section{Counter-Narratives.}

Participants in this study who operate independently contradict third party assertions that the indoor sector of the Canadian sex industry demands Eurocentric beauty conventions 
and that the differential hiring practice is a smart business strategy. In fact, these women argue that, even though it may be small, there is a demand within the indoor sector not only for women of colour but also for other groups that are typically considered low-demand - in particular, older women and full-figured women. Women in this study point out that most customers of colour prefer to seek the services of women of colour. In addition, participants explain that White clients exceptionalise and exoticise darker skin tones and beauty conventions that sit in contrast to Eurocentric standards. In this regard, research participants' strategies for managing their "bodily capital" (Bernstein, 2007b) allows them to compete in the marketplace. That is, participants who invest in their physical appearance (not just through make-up, clothes, and hair styles, but also by aspiring to the ideal body type) and perform approximations of whiteness can succeed in the sex industry.

The primary focus of Chapter 6 is on how research participants use their skin tones, hair styles, body sizes, make-up, and clothing as strategies for managing their bodily capital to help them to compete and earn money in the market. In this section, I provide a glimpse into this process in order to highlight my participants' resistance to third party claims that the indoor sector demands Eurocentric beauty conventions. Jaya, a full-time sex worker between the ages of 35 and 50, explains how women of colour have come to be desired in the sex industry. In the following quotation, Jaya points to the limited number of racialised women in the indoor sector of the Canadian sex industry, which she claims actually increases the demand for women of colour in the industry:

Maybe ten years ago or fifteen years ago, a White blond woman was the most desired, [...] now an ethnic woman is more desired in the sex industry. [...] We are sought out more for our skin colour, for our [...] exoticness. [...] we are more desired because we are few and far [...] it is something [...] men don't 
see a lot, or they are not dating, or they don't get it out in the public. We have no problems; we are desired [...], we are really desired.

I also want to draw attention to the temporality of desirability within the Canadian sex industry that Jaya highlights. It is noteworthy that notions of beauty, desirability, and profitability are highly fluid classifications within the sex industry, such that they vary according to location, time, and social context. In the next chapter, I explore the fluidity of these concepts in more depth.

Participants Pearlina and Leah both narrate their experiences encountering clients who felt they were not Black enough. In addition to highlighting their clients' perceptions of Black women being "exotic," these women have strong attitudes towards their clients' reactions to their skin colour:

Some guys come in, and they do want that true, almost African blue-Black woman, and they'll look at me and go 'you're pretty, but you're not dark enough.' I can't win. You're not light enough, not dark enough. [Pearlina] Actually, the first agency I worked for I got turned away by two [White] clients because I wasn't Black enough [...]. They told me I was too light and they told me that I was unattractive [...]. I think clients are just fascinated by Black women and just women of colour because we are so gorgeous. [Leah]

Participants in this study claim that in addition to preference for darker skin tones, different clients prefer different types of women, meaning that, contrary to third parties' narratives, there is a demand for older women, for women with fuller body sizes, and for every other variation of appearance. Malinda elaborates:

[...] a lot of them [clients], they just prefer Black girls [...]. I always thought oh, I don't have boobs, this and that, but, everybody has different tastes. Also, I learned that all my clients choose me because they prefer Black girls. Or they prefer girls that have small boobs and who are Black and [laughing] you know slim, and that's just, what they prefer. You don't have to have a [certain] look, because whoever, whatever look you have someone out there is looking for 
that. [...] I realise that there's someone out there looking for exactly what you are.

\section{Why the Sex Industry?}

Not all participants in this study entered the sex industry fully informed about the job. ${ }^{22}$ However, my participants unanimously reported that their decision to continue working in the sex industry has been an informed one. In this section, I provide an overview of various factors that participants considered in their decisions to continue in this line of work. These factors, I argue, pivot on participants' aspirations to achieve social mobility in the context of conflicting life events and/or circumstances. For example, Kalinda notes that although sex work "isn't my ideal option, it still the best option I have right now. [...] I'm so much happier doing this than I would be flipping burgers somewhere crying into my degree."

Before I discuss the factors that have kept participants working in an industry that is highly criminalised and stigmatised and which also reproduces race and class inequalities, I discuss some of the factors that deter them from the mainstream labour force. The first factor participants pointed to is their inability to earn a living wage and/or to break free of poverty by working in the mainstream labour force. Ravon and Stefov (2016) note that in Canada, nearly $60 \%$ of minimum wage workers are women. Currently, the minimum wage in Canada neither guarantees an income above the poverty line, nor is it "sufficient to meet the basic necessities of a single person, let alone an entire family" (Ravon \& Stefov, 2016, p. 6). As a result, the $60 \%$ of women in minimum wage labour are not in the position to earn an income

\footnotetext{
${ }^{22}$ Three out of forty research participants entered the industry through association with organised crime. Initially these women were not aware that they were being recruited to work in the sex industry. I discuss these women's experience at the end of this chapter.
} 
that reflects the cost of living or break out of poverty, regardless of how hard they work (Ravon \& Stefov, 2016). Participant Kimi is an Indigenous single mother who firmly believes that working in mainstream minimum wage jobs will confine her to the status of the working poor:

I worked a lot of fast food places. Places like MacDonald's and Tim Horton's, as a cashier in grocery stores and stuff. Not really anything that I can make a career, or money off of [...] I was sort of stuck, I knew people at my work that have been working there for 3 years or 4 years and still making 11 bucks an hour [...] I was tired of working two jobs for minimum wage and I saw the opportunity [...] my best friend, her roommate used to do this and make a lot of money doing it, so I thought why not give it a try and it just worked for me, I enjoy it.

The second factor is related to Man's (2004) concept of deskilling as it relates to

Chinese immigrants in Canada by undervaluing their previous education and professions.

Man (2004) writes,

Gendered and racialized institutional processes in the form of state policies and practices, professional accreditation systems, employers' requirement for 'Canadian experience' and labor market conditions marginalize Chinese immigrant women. As a result, they are being channeled into menial, part-time, insecure positions or becoming unemployed. (p. 135)

Meili's experience is an example of deskilling:

I was a dentist in China [...]. [When] I came to this country [...] They say they cannot recognise our education [...] I need money to get the license here [...] I [stared] a business by myself, a restaurant, run it for eighteen months. And I realised how difficult it is to be a boss in this country. As a small restaurant owner, I have to do everything. [...] Every day fifteen sixteen hours of working, yeah.

Participants who identified as first and second-generation Canadians did not want to work in

the same jobs as their immigrant parents, after earning degrees in Canada. Laine explains:

My own mother who came here as an immigrant, she now makes 11 dollars an hour, she works so fucking hard, she works all day from morning till night and I only let her keep her part time job, because she tells me she likes it because it gets her out of the house. I forced her to retire last year selling our convenience store, and now she works part time in the mall in the convenience 
store, she says it's fun and I'm like ok fine. It does seem pretty fun, she packs lunches and it keeps her busy and that's fine. Oh my god, after working so hard, FUCK any of that, what now I should go do that, to go pay taxes and go work hard to be a model citizen, so that I can still have zero opportunity? I mean she has been here, what this is now, almost 30 years, and we are still struggling. No, no, no, no [laughing] I'm not going to play your game. I went to university, I got a degree, I got a business degree.

It is well-documented that racialised women have historically been overrepresented in domestic and institutionalised domestic work (Brand, 1999; Man, 2004; Novek, 2013; P. Valentine, 1996). Studies also show that within the current global economy, such work is not only consistently undervalued but is also feminised, ghettoised, and pushed to the bottom of the marketplace (see Chant, 2007, 2010; Shah, 2003). Most women in this study have achieved at least post-secondary education or trades training, and it is safe to assume that they would not want to follow in the footsteps of their foremothers and sisters by doing domestic work in White people's homes or caring for the health of White people in nursing homes, hospitals, and geriatric homes (see Brand, 1999; Novek, 2013).

The third factor is related to the first and second. According to my participants, highpaying professional mainstream jobs are limited and are not readily available. These women stated that the starting salaries for low-ranking positions in professional labour forces would not allow them to make any significant economic progress (see McCall, 2007). Participants pointed out that, considering the gender pay gap, the salaries they would receive would barely cover their living expenses, which often include student loans, and would actually increase their dependence on credit cards to support a lifestyle that they are accustomed to. The women in this study feel that such mainstream jobs would confine them to poverty. In the following quotation, Melinda expresses her dissatisfaction with low-paying professional jobs:

You know, I grew up in a middle-class home and like a normal [life style]. [...] I didn't struggle that hard. [...] I have been to school, I have been to college. 
[...] while I was at school I was [always] thinking about [mainstream] work, it's all I think about. [...] The job that I was working at, I was working at [...] an airline company, and I was happy. I was like, I finally got a good job. [...] So yeah, initially I walked with my head held high [...] blablabla. I wanted to stop doing this work [sex work] [...] and then when I was there, I didn't feel like I fit in. [...] I really felt like [...] I didn't belong there. [...] I was sitting there at work for $\$ 10$ an hour knowing that I can make [more than that in sex work].

The fourth and final deterring factor that participants identified is their inability to navigate through everyday sexist and racist interactions that occur in the mainstream labour force. While my participants are certainly not naïve and know that the indoor sector of sex work also contains sexism and racism, they feel that they have more control over such encounters within the sex industry and that they are better able to mitigate the effects of these encounters.

In the quotation below, Lailani shares her experience with sexism at a mainstream job. She believes that her male employer had the impression that women in the Global South are always subjected to misogynistic encounters and that it was therefore acceptable for him to treat women from the Global South with disrespect:

Very little, no respect [when] they talk to you. They make you feel very low and just don't feel being respected. [...] Because my supervisor was an older man. So older people treat young people usually not as polite as their own age and, and I'm woman and he knows I [did] not grow up here, so he knows what it's like in those developing country, so he feel like he can treat me the same way, [...] I work there 2 years [...]. Well I didn't mind the work. The work is ok. [...] I would like to have more respect, which I think no way [laughing] getting it from this man [laughing], [...] I feel like I was under-appreciated and I feel like I deserve more appreciation.

Lailani did tell me that her clients in the sex industry appreciate her exoticness and sometimes she performs the 'submissive ethnic woman' with this in mind. However, these encounters with clients are negotiated on her terms. In the quotation below, Kamen explains her 
encounters with mainstream racism and how the sex industry allows her to claim some control as she strategically performs racial tropes. She discusses the terms and conditions of such performances:

Do I want to be a child to, or enslaved to corporate Canada, for a guaranteed income, which means guaranteed housing and food, but have to live with racist tropes? In my division [...] a White person went as a Black person for Halloween. Yes. They didn't have the Blackface on, but they had an Afro wig on and they spoke Black for an entire day and only a handful of people say that, that was problematic. [...] my kid is sick, or I have to leave at a certain time to go pick her from daycare and having that looked at as weak, because I have a child and the list really goes on. [...] Having people ask me where you really from, because of [my] skin colour. [...] But if I was White, nobody ever asks where you really from, in board meetings. So if I can live with that, I know that ok, well, I am being pimped out and this is the money that I'm making from corporate Canada, or I have to work my own, and call myself ebony goddess and exotic princess or exotic whatever and know that this is the level of racism I can deal with, and this is what I like to do for it, so I can almost accept it on my own terms [...]. Canada is racist. But it's never when you expect it, and that's what is hurtful and very difficult to digest. Because in a middle of a presentation, doing something, presenting for folks and having, you know, having someone throw out like a 'yeah my sister' or something stupid that people think that they do in solidarity, it hurts, it hurts so much and then I'm left flabbergasted and then I have to go home and heal and cry and do all of those stuff.

Both Lailani's and Kamen's stories illustrate how stereotypical tropes of racialised women have a profound hold on the mainstream labour force, affecting their job performance and life experiences. As Kamen points out, the subtlety of the discrimination often has the deepest affect because, unlike with overt discrimination, subtle everyday racism and sexism is hard to resist and leaves marginalised people feeling degraded and dehumanised (I discuss participants' performance of racial and feminine tropes in more detail in Chapter 6). The above quotations also allude to the extent to which women in this study express control over such issues within the indoor sector. 
Dewey and Kelly (2011) suggest that when society and labour markets consistently undervalue women's work, and when the market favours male-dominated industries over feminised occupations, sex work offers many women social and economic opportunities that they could not otherwise access. In the Caribbean context, Kempadoo (2001) traces how for Black and Brown women, sex work is often more lucrative than free trade zone work, domestic service, export processing, farm work, or other manual labour. Chapkis (1997), drawing on a sample of sex workers in the UK, argues that women who want to change their living conditions or their financial circumstances "do make a rational choice to do this work" and explains that "'free choice' in the contemporary labour market is something that very few people really have" (p. 62). Jeffrey and Macdonald (2006) found that sixty sex workers from three Maritime Provinces in Canada made deliberate decisions to work in the sex industry after considering all of the financial options available to them, including minimum wage work, welfare, street-based sex work, and indoor sex work. Participants in this study, after considering the factors mentioned above, made an informed decision to continue their work in the sex industry. In what follows, I highlight some of the factors that shaped my participants' decisions.

\section{Income, Independence, Flexibility, and Mobility.}

In this section, I discuss four key factors that have profoundly informed my participants' decisions to remain in the sex industry: income, independence, flexibility, and mobility. These four factors are interrelated and cannot be considered separately from one another. That said, the four factors contain a lot of diversity and inform each sex worker's decisions differently. For example, the ways in which women who work for third party sites experience the cluster is different from that of independent workers. However, my focus in 
this section is on factors that participants in this study perceived to be the advantages of the indoor sex industry.

It is well-documented that money is one of the key influential factors in sex workers' decisions to work in the industry instead of in mainstream jobs (Day, 2007; Jeffrey \& Macdonald, 2006; Maher et al., 2013; Prasad, 1999; Weldon, 2010). My participants overwhelmingly reported that the Canadian sex industry, despite its structural and operational limitations (e.g., the racially stratified hiring practice and related challenges such as lower hourly rates than White sex workers, selective hiring practices, and unfavorable scheduling), provides them the opportunity to increase their economic capital. That is to say, for some women, access to economic capital means that they are able to live a 'comfortable' lifestyle, which has attributes of middle-classness, including pursuing higher/professional education, reducing/paying off debt, saving for vehicle/home ownership, and traveling abroad for work and leisure. For others, it is a means to earn an income that meets the basic necessities of life, such as the ability to afford rent, utilities, and food.

The services of racialised and Indigenous women in this study cost between $\$ 80$ and $\$ 400$ per hour. The variation in price depends on many different factors, including skin tone, aesthetics, services offered, type of site, type of client, and geographical location. Most notably, these hourly rates, even after sharing with third parties, are significantly higher than those of any provincial minimum wage in Canada. ${ }^{23}$ Mariyam emphasises the difference between her income from a minimum wage mainstream job and her income in sex work:

I used to work at a deli, and I was going to school full-time [...] [when I started working in sex work] I was going from $\$ 9$ an hour to [...]\$120 an hour

${ }^{23}$ The minimum wage in Canada varies by province and ranges from $\$ 10.50$ to $\$ 14.00$ per hour. See http://www.gov.mb.ca/jec/invest/busfacts/workforce/min_wages.html. 
and that's so much money, right [...]. Like, I can have a really bad month at what I do, and I will still make more.

The overall experiences of my research participants on this particular issue are consistent with Black erotic dancers in Vancouver in the 1960s (see Ross, 2009). For instance, Ross (2009) points out that during the postwar era in Vancouver, even though White dancers made more than Black dancers, Black dancers still earned the equivalent of one week's salary for mainstream jobs such as nursing in just three days. With the opportunity to make a higher wage, many of my participants have transformed their economic status in various ways. Kalinda reflected on the economic capital that she is able to accumulate by working in the sex industry:

When I started doing this seriously, it took me six months to pay off my student loans, and another five months and I paid for my entire nose job. I'm debt free. I was debt free six months doing this. And I know that's not everyone's experience [...], like, this job isn't for everybody, but it can do amazing things for certain people if it is the right place for them [...]. Before I got into this work, when I was working on my degree, I was working another job, I never thought I will be making this much money, I never thought it was possible. That's one of the reasons I ran out and got my nose job. My whole life I hated my nose, but I just told myself I had to live with it. And then there I was, six thousand dollars sitting under my bed and I was like, oh I don't have to, I can do what I want, and so that year I did all that, I paid off my loans, paid off the surgery. This year I am doing a bit of travelling and then I'm gonna start saving for a home. Like, I never thought I will be able to buy a home, and that's what sex work is done for me.

Meili was a practising dentist before she immigrated to Canada. As a new immigrant, she could not afford to get the recertification that would allow her to practice dentistry here, so she started working various minimum wage jobs to make ends meet. Meili's experience exemplifies Man's (2004) concept of deskilling. However, according to Meili, working minimum wage jobs did not allow her to save any money. Below, she describes how, despite 
the stigma, performing sex work in the indoor sector allowed her to save for her child's education:

In the beginning, [...] people look down at me. I really didn't care about people. I know I need to make money for my son. I don't care about anything. Now my son is grown up, [...] I need to make money for his school. [...] This is not because we chose rich school. It's because we picked where to go for the next forty, fifty years. It's so little thing, and its four years for $\$ 200,000$.

Over the past decade or so, Meili has worked in various sites in the indoor sector. When I met Meili, she proudly told me that she was able to put down a $\$ 10,000$ deposit to secure her child's admission for a professional degree - an opportunity and a privilege that she would not have been able to afford when she first immigrated to Canada. Meili believes that investing in a $\$ 200,000$ education for her child is equivalent to investing in their social capital, which she lost when she immigrated to Canada.

While women like Kalinda and Meili use their income from sex work to 'get ahead,' others use their income from sex work to just make ends meet. Being able to afford the necessities of life, such as buying food and paying rent and utilities, means that workers do not have to depend on social assistance. For these participants, while owning a car, saving for a house, and paying for a professional education are luxuries that are out of reach, their ability to avoid ghettoised jobs and dependence on social assistance, including the normative stereotype of the racialised "welfare queen," is not only about economic capital but is also about dignity and self-respect.

Tiana explains her reasons for working in the sex industry. Tiana is a light skin Black single mother with three children. When I met with Tiana, she told me that she has always raised her children by herself, without any support from the children's father or from her extended family. Tiana tells me that as a single mother, the income from her mainstream job 
(as a personal support worker in a seniors' residence) was neither sufficient to pay for fulltime daycare for her two children nor to cover the necessities of life. Additionally, a lack of flexibility in choosing her shifts made it difficult to care for her children while working fulltime. According to Tiana, sex work offers her the option of working from home while her children are at school and allows her to earn an income that reflects the cost of living. As a result, she says, she can care for her children's economic and emotional well-beings:

I love it. I absolutely love it, and I wouldn't change it for the world. I just did all my Christmas shopping for one child, got him everything he wanted [...] This year I didn't have to go to the food bank to get a turkey for Thanksgiving, didn't have to stand in line for boots from the snowsuit fund for my kids. I didn't have to wait for Salvation Army Christmas gifts. I actually have my ham in the freezer, you know, and that makes me feel good.

Kimi, an Indigenous single mother, echoes Tianna's sentiments:

Yeah. I think it's important. Like yeah, I'm a mother, and I think it's important because as a mother and a sex worker, I'm really proud to provide food for my family and I think it's important I'm a working mother.

As we can see, for Tianna and Kimi, their sense of self-respect and dignity pivots on their ability to work for a living. A job that allows them to provide for their family, without relying on the various programs that assist the working poor (e.g., food banks, snow suit funds, and school meal programs), further enhances their feelings of self-respect and dignity. In this regard, these women are also resisting and managing stereotypical tropes about racialised and Indigenous people's unemployment. Furthermore, these women contradict the assumption that indoor sex workers are all part of the bourgeois class (see Razack, 1998b) with shallow, irresponsible, and lavish spending habits.

In addition to gaining access to financial resources, participants in this study also value the workplace independence that the indoor sector offers. In their sample of sixty sex 
workers in the three Maritime Provinces, Jeffrey and Macdonald (2006) similarly found their participants valued the independence that sex work provided. Day (2007) suggests that "[t]he longer women worked [in the sex industry], the more they appear to value their independence" (p. 91), such that their emphasis turned to the skills through which they stay in charge, dictate the terms and conditions of work, and even create new markets (also see Lucas, 2005; Maher et al., 2013; Sanders, 2005a). In my research study, women who work independently said that they had more workplace independence than those who work for third party sites. These women expressed that they value their ability to dictate the terms and conditions of their work, adjust their schedules, develop a market for themselves, and be in control of their work environment overall. In the following quotation, Talia, an independent escort, alludes to the independence she experienced through sex work:

I make a really lot of money, and I do per hour, but what that does for me, personally, is it allows me my freedom. So, I don't work a lot of hours a week. [...] Sometimes I'll work three hours a week. I can totally fund my lifestyle on working, let's see, about 10 hours a month. [...] So what that affords me is the ability to completely pick and choose my clientele. If I don't like somebody's email, I trash it; I don't even give them a return email.

In the quotations below, Jazzra, Mariyam, and Kamen emphasise the various skills they have developed that allow them to be in control of their work environments. As these women point out, these skills are not unique to the indoor sector; rather, they are transferable to any mainstream labour:

I needed work [laughs] [...] I went on to the independent [in-call and out-call service providing], so I just kind of ran my own show [chuckles]. Which turned out to be awesome and liberating. To be able to be my own boss and I definitely gained a lot of entrepreneurial skills [...] in terms of advertising and budgeting, [...] managing equipment, and working. [Jazzra]

But it's not true that women who are in the industry cannot make money any other way; they're all business women, they're all handling a business all on their own, especially independent girls, not just, like, minorities. Everyone in 
general, the way their websites are laid out, the way they handle everything [...] I think that kind of business is a lot of hard work. [Mariyam]

One of the reasons why I chose to be independent so that I have agency, I have my will and my wants, and I don't see anyone I don't want to see. I work when I want to work, and I work around my schedule of being a parent and being an activist, and I work, and I get paid as much as I work, and it creates a level of independence that is not present in the corporate world. [Kamen]

As multiply marginalised individuals, these women increase their senses of self-respect and dignity through their ability to exercise their agency and manage a business. Furthermore, while sex work is not recognised as a legitimate form of labour, the skills that these women develop in this line of work are transferable to any other form of labour. The ability of sex workers to develop "entrepreneurial skills" increases their chances of operating mainstream businesses, if they choose to do so.

Another aspect of workplace independence that is noteworthy is its relation to safety. While women who work from third party sites have access to protection through receptionists, check-in calls, drivers, and bouncers (see Lewis et al., 2005), independent workers have the freedom to dictate the terms and conditions of their work environment, which is the way they manage their safety (see Lewis et al., 2005). Tallah, in the quotation below, establishes how her sense of empowerment translates to her sense of safety on the job:

I've used the word empowering because, you know, being an escort I set my own rules, you know, and when I want to work, who I want to see, what I want to charge, the conditions, so it's very empowering. [...] I do feel safe because it's an environment that I feel in control. And there's a lot of screening done, you know, you can tell a lot by talking to someone on the phone, this is something that is a prerequisite. I need to speak to the person [...]. I'm only going to go if I know the person, it's a good client or I just had a good vibe and he's not far, he's in a high-end hotel.

The various manifestations of independence and control within my participants' work environments emphasise the incoherence of prohibition lobbyists' and policy makers' rhetoric 
that all racialised and Indigenous women in the sex industry are essentially "trafficked" sexual slaves and/or "victims" of male sexual violence. Rather than being the agentless "victims" of trafficking rhetoric, my participants show the autonomy and independence afforded to them as sex workers. This agency is also shown in their engagement with the flexibility of indoor sex work.

Flexibility is another key factor that entices women in this study to continue working in the indoor sector. The ways that participants conceptualise the independence and flexibility that sex work has to offer are highly interrelated. Meera's and Leah's discussions of flexibility highlight its interrelation to independence:

I think what attracted me to [sex work] was basically that it was really flexible and I needed something. Because I was really busy with school. [...] I like being self-employed and I like having a business, and I like making decisions, that's why I never worked for an agency. If I woke up one morning and I wasn't feeling that great, or I had something important to do, you know I could do that, so it's really, it's just really about the flexibility and needing to be able to do that and like go to school and be able to do other projects that I was interested and be able to manage my time. [Meera]

Exactly, you know what, working, I don't want to say real job, but working, like, the retail, or even in an office, they give you your hours, you can't call in sick, you don't make your own schedule. Where with me, I'll make my own schedule, I'm ok with saying no to work [in sex work]. [In mainstream work] you say no to your manager more than once they start writing you up. [Leah]

These participants also highlight subtle differences between flexibility and independence. The difference in these two concepts profoundly manifests among participants who are working while pursuing an education or training and those who identify as single mothers. All four factors - income, independence, flexibility, and mobility - work together in a cluster to shape women's decision-making processes. 
Almost $50 \%$ of my participants identify as students, pursuing some form of postsecondary education or training at the time I interviewed them for this study. These women expressed an appreciation for the ability to work fewer hours and choose their hours of work while still being able to earn a lucrative income. A portion of women in this group also pointed out that, while it is initially time-consuming to set up an independent business, once the business is established, maintaining a regular clientele and operating the business does not require a significant time commitment. Furthermore, many of the worker-students in this study reported that they have tried to work in mainstream jobs while at school, but most mainstream minimum wage positions do not offer the necessary flexibility or remuneration that is sufficient to pay for the basic necessities of life.

Similarly, participants in this study who are single parents appreciate the flexibility that sex work offers. According to these women, flexibility in their work schedule allows them to perform their childcare responsibilities and simultaneously provide for their needs. Romona reflects on her ability to effectively juggle her multiple roles while working in the sex industry, in contrast to what she found in mainstream minimum wage work:

Well, I like it because I don't work a lot of hours, I'm basically a stay at home mum, I have two children, 14 and 12 years old, and I am with them every day. It's what I wanted. When I was working a full-time job, I would come home really tired and stressed out and yelling at them, and it will be really hard to do the homework with them. It was just a nightmare. Whereas this, I work maybe 10 hours a week if that, so I have a lot of time on my hand, and I am able to pay my bills. I feel I am not rich, but I'm comfortable.

In short, flexible working hours and high income allow Ramona to effectively manage being a working single mother.

Given that sex work offers a combination of flexible work hours and high pay, some participants have used sex work to supplement their incomes while advancing or establishing 
their professional careers outside of sex work. At the time of my interviews, a few participants were pursuing professional careers as apprentices or interns while working in the indoor sector. According to these participants, trainee/intern/apprentice pay was not sufficient to support their standards of living, and as such, they chose to use sex work to supplement their income until they were made permanent full-time employees in their chosen occupations. Divya explains how working in the indoor sector allows her to meet her various life demands:

I graduated from teacher's college, and I've been job searching [...]. For a very long time I've been working [...] three jobs at one time. [...] so after graduating from teacher's college I was like, I want to be able to have a job in my field, and I'm job searching for that, and I'm volunteering at the school, but I can't actually afford to - if I work full-time, like, around minimum wage [job], I won't be able to volunteer in the school and get my foot in the door. So [sex work] is something like [an] in-between [job].

The diverse and complex organisational structure of the sex industry leads to participants' complex work histories. Sanders (2005b), in her sample of UK sex workers, and Maher et al. (2013), in their group of Australian sex workers, found that sex workers move between different sectors within the sex industry as well as moving in and out of the industry to achieve the best outcome for their life circumstances. These processes result in lengthy and complicated tenures in the industry. Sanders (2005b) claims that such mobility is the defining factor of the new economy of sex work. Research participants in this study have moved between sectors, sites, and in and out of the industry often. Usha, pointing to her complex tenure in the sex industry, notes "I did most of it. I did independent, I worked for a con family, I did escorting, and I also worked on the street."

The mobility between sectors, sites, and in and out of sex work forms a key part of my participants' decisions to work in the sex industry. Women in this study have provided many reasons why mobility is one of the key factors of this cluster. For instance, women who do not 
like the labour structure and practices of third party sites often move to a different third party site or work independently. Many women in this study move between different sites as they perform different types of sex work. For example, participants reported that they alternate between working in strip clubs and as escorts or in body rub parlours. Furthermore, given that jobs in the sex industry are readily available, some women move in and out of the industry to suit changing life events. For instance, participants who are in school, in-between jobs, or looking for a more suitable job in their field of study/training are often involved in this line of work on temporary or interim bases. In addition to moving between sectors, sites, and in and out of sex work, participants also tend to move geographically, both locally and internationally, for sex work on a permanent or semi-permanent basis. This geographic mobility, the willingness to move to different cities and/or countries, maximises their earnings (see Hannem, 2018). For example, going to places where there is demand and desirability for women of colour allows workers to increase their earning capacity. In the following accounts, Ling and Mariyam reflect on their ability to increase demand for their services by travelling to different locations:

I find especially in Vancouver [being Asian] can be a big disadvantage as well. If I were to work maybe in Calgary or like Saskatchewan or something, a predominantly White community, I think that would be a definite asset. I've even gone out to [...] Kamloops, with a friend, and it's predominantly White. [...] And we did one night or two nights or something. I did very well, just because there were no Asian girls. [Ling]

I go to Alberta to work a lot. [...] I think I am very exotic in Alberta. It's mostly Caucasian women, and there are not a lot of Asian women [...]. So in Vancouver, I can work a full day; I can put in twelve hours and the likelihood of me making any money that day is probably fifty percent. But in Calgary, or most cities in Alberta, [...] I am at least looking at $\$ 500$ to $\$ 1,000$ a day. That's a huge difference, and it kind of goes to show that my niche is more liked there than here, so I will often go there. [Mariyam] 
While participants in this study discuss the various advantages they see in continuing their tenure in the indoor sectors, they are not naïve about the criminalised, stigmatised, and precarious nature of their employment. All participants acknowledged the fact that there is no sick pay, pension-earning, or paid vacations in sex work. Despite the relatively lucrative work, independence, flexibility, and readily available jobs in the industry, participants are cognisant of the fact that if they do not work for an extended period of time they do not have an income at all (see Dewey, 2011). Similarly, some women are mindful of their decreased ability to work in the sex industry as they get older and are found to be less attractive. Thus, most women in this study have made alternate plans for the future. Asha explains her plan for when she retires from sex work:

I know that I'm not going to be able to do this forever, I know I'm not going to get pension doing this, I have no medical health, dental benefits, [...] what am I going to do and so I went back to school, I finished, a medical office administration [program]. [Asha]

\section{Sex Work and Organised Crime.}

Three women in this study, two South Asian and one Black, started working in the sex industry through their association with Canadian organised crime groups. These racialised women's encounters and relationships with these organisations add to the layers of complexity of this study. In this section, I provide a brief overview of these women's experiences. Drawing from the aggregate stories of these participants, I conclude that all three women entered the sex industry while they were young, financially desperate, and/or through friends or acquaintances who had some connection to the organised crime groups. Two of the three women had a young child in their care when they were recruited. Nicole and Geetha reflect upon their initial interactions with organised crime groups: 
I worked at 7/11. [...] My student loan was coming up, [...] I had six months until I had to start paying unless I was able to return to school, but I wasn't because [...] I couldn't afford tuition. [...] So, one of my co-workers was actively kind of recruiting me into the industry, but I didn't know that. I thought he was befriending me, listening to my financial problems - a single mom and so, I thought he was my friend. And then he introduced me to one of the Canadian crime families. So, I just went to a party, met a bunch of people. [...] So, what happened was the guy - the White guy I knew -introduced me to this family, and then, through the family, the girls then recruited me in the industry with them. [Nicole]

But these are the cool guys, these aren't your typical Brown guys, [...]. These guys were, like, they drove fancy cars, they had a lot of money, they wore really nice clothes, they were gorgeous, a lot of girls were just, like, into them. So I kind of, I felt special that out of any of the girls that they could have I was one of those girls and they made me feel very, very special that way. [Geetha]

In addition to not being fully aware of what they were getting into and with whom they were associating, none of the three women were aware that they were being groomed to work as sex workers. In other words, all three women gradually transitioned to sex work after having been involved in various criminal activities such as breaking and entering, trafficking of substances, and after having been the "spotter" for other sex workers in the group. After engaging in these kinds of criminal activities, the women feared exposure and worried about their family's reputation if their affiliation with organised crime became known. Geetha explains how the burden of wanting to protect her family from humiliation led her deeper into the organisation:

We did so much criminal activity, I remember so many times where we came so close to being busted, whether it was doing this, that, or the other and always my number one thing was, 'Oh, my God, my parents are going to find out. Don't let my parents find out.' It wasn't about being dragged off to jail, it was 'Oh my God if my parents find out, that's it.' [...] That was my biggest fear. [...] But they always hung that over my head. 'I know how scared you would be if I told your dad what you did. So you're going to shut up about this because [...].' 
All three women recognise and acknowledge that they were in exploitative relationships, not only in terms of their criminal behaviours, but also in their roles as sex workers. That is, these women pointed out that the organised crime members decided when the women worked, how much they charged, and who their clients were. More importantly, the crime groups kept the majority of money earned by the women. It is noteworthy that, according to these women, they were never subjected to physical or sexual violence.

Even though these women did not have cash in hand, they were still able to experience a higher standard of living than they would have if they were working in minimum wage jobs or receiving social assistance. As members of organised crime, these women were able to access the same economic and social capital as the group that they were associated with. Nicole explains how she lived the "high life":

It was a big night club culture, and we were the people who had the most money. The bars loved that. [...] Whether line-ups or not, we just walk in. [...] It was a way that the guys parade the girls and show off to other rivals. So, I mean, some of the lifestyle was spent doing that kind of crap.

I want to reiterate that only a very small proportion (three out of forty) of women in this study interacted with criminal organisations. All three of these women did exit the organised crime groups and continued to work in the sex industry as independent sex workers. In the quotation below, Geetha explains how she was able to transfer the skills she developed while working for the organised crime groups to her independent work:

My experience as an exploited youth stepping out of that and then going back into it kind of with eyes wide open and feeling like I had choice, power and all of that, it was a very interesting experience for me because when I was able to do it for myself - so I never worked for anybody after that. So that was the only time. And then I was always independent, I was like the perpetual hustler. I could pick up a date wherever I went. I knew what to do, I knew who to look for. 


\section{Concluding Remarks}

To an outsider, the decision to be a sex worker may seem to be irrational. In this chapter, however, I have shown that despite the deep-seated stigma and the quasi-criminal nature of the sex industry, participants in this study have made deliberate and informed decisions to enter and continue working in the indoor sectors of the sex industry. A cluster of interrelated factors - especially positive factors of income, independence, flexibility, and mobility not offered by most mainstream minimum wage or professional jobs - influences the decisions of these women. That is, women in this study feel that, even with the structural practices that tend to stratify racialised and Indigenous women's involvement within the industry, they experience a greater degree of opportunity and control by working in the sex industry than they would in mainstream jobs. To this end, the ways my participants adopt the neoliberal subject position can be seen as highlighting their individual agency and also as forms of resistance to structural limits that tend to confine them to poverty.

Furthermore, while dominant discourses totalise the sex industry as an immoral, disrespectful, and undignified form of labour, women in this study take much pride in their identity as "working women," especially over and against the classification of "welfare recipients." For women in this study, it is important that they are able to provide for their family's necessities rather than depending on various social assistance services for the working poor. The combination of these elements shapes my participants' perceptions of dignity and self-respect, which throws into question popular understandings of sex work as a disparaging and undignified form of employment.

My analysis in the remainder of this dissertation is framed through the following two stances: First, the sex industry is a complex entity with multiple practices that, on the one 
hand, can be stratifying and on the other, can be liberating for women of colour. Second, racialised and Indigenous women in this study do not only conceptualise exploitation and dignity differently from dominant understandings, but their conceptualisations also vary depending on their specific intersecting life events and circumstances. 


\section{Encountering the Marketplace}

In this chapter, I explore two types of entrepreneurial tasks that allow my research participants to compete in the contemporary Canadian sex industry: branding and promotion of their services. Given that normative beauty tropes in the Canadian sex industry, just as in any other industry, are entrenched in Eurocentric ideals, I am interested in exploring how participants in this study negotiate their racialised and/or Indigenous identities. I look at how participants, in most cases, compete in the marketplace first by developing an "erotic/exotic brand" ${ }^{\prime 24}$ and then by promoting this brand as differentiating them from other sex workers. I argue that the successful execution of these entrepreneurial tasks gives participants the opportunity to thrive not only within the Canadian sex industry, but also within the broader economic order that is characterised by high rates of unemployment in professional sectors, the continued devaluation and ghettoisation of women's work, and the increasing inability to earn a wage that reflects the cost of living.

Drawing upon Goffman (1959), Tate (2007, 2009), and Weheliye (2014), I highlight the fluidity of identities through participants' performances of race and beauty tropes. In this context, performances of race and beauty are similar to performances of gender, in that they are at once conscious and unconscious, intended and unintended, explicit and implicit, and they employ a range of elements, including clothing styles, hair styles, make-up, body language, and topics and styles of conversation in order to denote racial differences or

\footnotetext{
${ }^{24}$ I acknowledge that the term "exotic" is a loaded one and is highly problematic in reference to the various experiences of racialised and Indigenous peoples. However, as this chapter shows, women in this study strategically employ this term as a marketing tool to differentiate them from White sex workers.
} 
mimicry of whiteness (Nagel, 2010). Reading these kinds of performances as entrepreneurial tasks allows me to bring forward the agency and resistance that is involved in these practices. Furthermore, it allows me to explore the rhetoric of supply and demand that third parties often espouse and highlight participants' creative entrepreneurial tendencies and economic savviness.

This chapter is structured in three parts. First, I provide a brief overview of the intersections of race and beauty, and their influence on sexual and gender norms. Next, I analyse how participants interpret and negotiate beauty norms as they move between approximations of whiteness and strategic deployments of 'exoticism' in the process of developing their professional brand. I find that the brand developed by each research participant is not only fueled by a desire to shape identities and material benefits, but it is also deeply embedded in structural, cultural, and economic events. Finally, I discuss how participants strategically oversee the advertising and marketing of their brand against the backdrop of historical representations, colonial scripts, and normative beauty tropes. This discussion brings to light the multiplicity and fluidity of advertising/marketing approaches not

only as they advertise a service to meet customer needs, desires, and fantasies, but also as they establish autonomy, control, and manage stigma.

\section{Intersections of Beauty and Race}

Even though defining human beauty is a difficult task, Hamermesh (2011) claims that people from various walks of life tend to view beauty similarly, such that those who are regarded as good-looking generally appeal to most people. In the economic context, normative framings of beauty fiercely infiltrate most, if not all, labour markets - good looks are rewarded with premium pay and bad looks are subjected to pay penalties (Hamermesh, 
2011). As such, "ugly people earn less than average-looking people, and average-looking people earn less than the beautiful. Ugly people find entry into certain occupations more difficult; and if they choose those professions, they are penalised" (Hamermesh, 2011, p. 173).

The infiltration of beauty ideals in the labour market are noteworthy in light of Wade's (2014) claim that "One manifestation of White supremacy is the use of whiteness as the standard of beauty" (para. 1). In this regard, Wade (2014) argues, "when whiteness is considered superior, White people are considered more attractive by definition and, $[\ldots]$ the appearance of people of other races [which] deviates from that standard, [...] are considered ugly" (para. 2). However, "non-White people are still allowed to be considered beautiful, of course, as long as they look like White people" (Wade, 2014, para. 2).

Whiteness as the standard of beauty, Deliovsky (2010) argues, is a universally homogenised ideal of beauty in contemporary Western culture and is "represented by, for example the [White] Barbie doll, and the countless variations of idealised 'White' feminine beauty" (p. 101). In fact, Deliovsky (2010) notes that in the context of a society founded by European imperialism and colonialism (such as Canada), normative femininity is far from being race-neutral and is never signified outside of processes of racial domination. As such, the interwoven and conflated historical schema of whiteness and femaleness constitutes hegemonic feminine beauty (Deliovsky, 2010).

Given the influence of Eurocentric hegemonic tropes of femininity and beauty, the global sex industry also values White sexual labour (Brooks, 2010b; Kempadoo \& Doezema, 1998; Miller-Young, 2014). For example, Mahdavi (2013b) researches pay premiums for 
"Whiter" and light-skinned women and the related hierarchy of desire among a cohort of sex workers in Dubai. Mahdavi highlights the extent to which Eurocentric beauty norms have infiltrated the sex industry: Iranian, Moroccan, and Eastern European sex workers in Dubai are deemed to be more desirable due to their lighter skin colour than women from East Asia, the Philippines, India, Pakistan, and Africa. Mahdavi (2013b) explains that light-skin women largely work in expensive bars and inside "luxury apartments in wealthier parts of town"; "Brown" women often work in lower-end bars and clubs, or in brothels and massage parlours throughout the city; and "Black" women are overrepresented on the street and in the poorest and most dangerous neighbourhoods of the city (p. 26-27). Mahdavi (2013b) refers to the system of stratification in the Dubai sex industry as a raced hierarchy of demand.

Mahdavi's (2013b) concept of a raced hierarchy of demand is applicable to the Canadian context and this study. Participants in this study believe that Eurocentric beauty tropes command the market practices of the indoor sectors of the Canadian sex industry to the extent that they dictate who is desired or in demand, and therefore who stands to gain or lose in the marketplace. In the following quotation, participant Asha highlights the raced hierarchy of demand that allows White and light-skin women to make more money in the industry:

They usually say that a White girl makes more money than a Black girl. [...] But then they say that the Asian girl will make more money than the White and the Black girls. [...] Yes, an Asian girl will make a lot of money, so is the White girl. And I won't lie, it is harder for a dark-complexioned Black girl to make money, like compared to the White girl or the light-skinned girl. It's harder for darker girls; I don't know why sometimes. [...] A lot of people think that I'm Filipino, so a lot of people just think that I'm Asian. Sometimes it's a little bit easier for me [...] I know, I do pretty well [...] and all the White girls I know, they always do well. But [...] [my] Black friends [...] find it harder [...] to make money in this industry. 
It is noteworthy that the homogenisation of Eurocentric beauty tropes is not unique to the sex industry. In fact, the establishment and maintenance of beauty norms is deeply rooted in historical politics and racial dynamics. Craig (2002) points out that American national beauty contests, media advertising, women's magazines, Hollywood movies, and television programs not only establish Eurocentric ideals as the national standard of beauty, but they also perpetuate Black women's representation as "non-beauties," situating Black women and White women very differently in relation to desirability. As Robinson-Moore (2008) notes, Black women in the USA have struggled with the resulting exclusion of certain skin colours and hair types. Banks (2000) explains that "nappy hair" is neither viewed as beautiful nor as suitable for professional and economic success. Rather, "Kinky hair [...] was considered shameful” (Craig, 2002, p. 27). As such, despite mainstream beauty standards that tend to exclude or demean them, members of the Black community, including "hairdressers, entrepreneurs, models, entertainers, and others designated as beauty experts," worked "throughout the twentieth century to define a broader and more diverse ideal of beauty for themselves" (Walker, 2007, p. 3).

While anti-racism critiques, counter-discourses, and bodily practices since the $1800 \mathrm{~s}$ have focused on dismantling the dominant beauty paradigm and the way it privileges White/light-skin women, colour-consciousness and the pursuit of whiteness continues to be prominent in communities of colour (see Hunter, 2002; Tate, 2009). It is in this sense that beauty ideals become significant for race politics. Sutton (2010) writes, "racialised notions of beauty have enshrined White European aesthetic models and alternatively held the bodies of women of colour as exotic, monstrous, or ugly" (p. 9). Craig (2006) notes that since the 1980s, studies examining women's experiences with dominant beauty standards have not only 
highlighted the inherent racism within them, and their tendency to polarise Black and White forms of beauty, but they have also focused on how dominant beauty norms position White, Black, and Asian women against each other to maintain racial and gender inequality. Even though racialised women are categorically excluded from dominant beauty ideals, those who "approached the appearance of whiteness" were appreciated and/or included if they fell into "a changing spectrum of women in the marginalised and marked position of the exotic beauty" (Craig (2006)p. 163). According to Tate (2009), feminists who advocate against existing beauty ideals have avoided "a sustained discussion on specifically Black beauty" ( $\mathrm{p}$. 11). This omission centres whiteness "as the norm and the place from which all discussion must stem as it is the one standard, which speaks loudly in its silence, against which all are judged" (Tate, 2009, p. 11). Tate (2009) also writes, "It is not just Black beauty but also the White beauty that is produced through racialised and racialising discourses on aesthetics and racing stylization practices" (p. 11). Thus, drawing inspiration from Tate, in the remainder of this chapter I discuss elements of Black beauty, other kinds of racialised beauty, and intentional performances of beauty that disrupt taken-for-granted Eurocentric beauty tropes.

\section{Developing the Brand}

Participants in this study hold intentional relationships to beauty standards and selfrepresentation. Dominant society gauges one's race through skin tone, nose, eye, and lip shape, hair colour and style, and even body shape (R. Dyer, 1997), and intersections of race and beauty often impact one's ability to develop a competitive and profitable brand (Deliovsky, 2010; Wade, 2014). Thus, participants in this study often either mimic hegemonic beauty ideals through approximations of White femininity or disrupt dominant beauty standards by emphasising elements of racialised beauty and exoticism. Participants' 
performances of hegemonic beauty and of racialised beauty both begin from an acceptance of themselves as beautiful, even when their skin tone, body size, and/or hair colour and texture deviates from the norm (see Pause, 2015).

At the same time, these performances are also indicative of participants' uneasy interconnectedness with the ideals of the White beauty and the exotic other. In this section, I draw out tensions between self-acceptance and performing White or racialised beauty tropes in order to show that participants' decisions are based on their need to earn an income alongside market research of customer needs, desires, and demand for particular types of beauty. Therefore, the processes of performing whiteness and/or "exoticness" can be understood simultaneously as an embodiment and disruption of Eurocentric beauty standards. In this sense, participants in this study also highlight their concurrent roles as governable/docile subjects and as resisting agents (Foucault, 2008). The process of embodying and disrupting Eurocentric beauty ideals and racialised tropes through alternating performances of whiteness and exoticness further highlights participants' multiple marginalisations and partial privileges.

For example, performing iterations of whiteness - where participants employ selfregulating regimes and disciplinary tactics of beauty (such as dieting, exercise, and/or plastic surgery) to construct the ideal feminine body - can be understood as reifying Eurocentric beauty standards (see Bartky, 2003; Bordo, 2003). At the same time, appropriating cultural images becomes an act of resistance to dominant rhetoric, creating possibilities of opposition, independence, and alternative symbolisations of the self (see Craig, 2002; Stychin, 1995). In other words, performing "slick," "classy" woman defies preconceived notions of what and how racialised and Indigenous women are or should be, according to normative narratives 
(see Zook, 1990). Similarly, performing repertoires of exoticness by employing racialised tropes can be understood as reifying the normative construction of the Other in relation to cultural representations of White beauty. In this sense, appropriating cultural representations of racialised beauty signifies confidence, courage, and a higher degree of self-esteem - all of which are contrary to docility and obedience and resist hegemonic beauty ideals.

\section{Skin tones.}

The skin tones of my research participants vary dramatically - on the one end of the phenotypic spectrum are women with varying shades of Brown and Black skin tones. On the other end of the spectrum are participants with light skin tones that fall within the hues of yellow, beige and pale (pale skin resembling Eurocentric skin tones). Hamermesh (2011) notes that while skin tone does not directly equate with beauty, in the economic context, employers and customers may treat it as such. Hamermesh (2011) supports this assertion through the example of a small sample of African American males in which the light-skinned participants earned about $12 \%$ more income than medium- or dark-skinned participants (also see Craig, 2002).

In addition to representing markers of beauty and employment opportunities, Craig (2002) notes that light-skinned African Americans were awarded other advantages, such that "class stratification within African American communities was intimately intertwined with color stratification" (p. 43). In this regard, Hunter (2002) argues that skin tones work both as capital and as a stratifying agent to establish and maintain the racial hierarchy for women. Hunter (2005) calls the order of ranking by skin colour a "beauty queue," wherein "the lightest get the most perks and rewards, [...] and the darkest women get the least” (p. 69). Hunter's notion of the beauty queue is parallel to Mahdavi's (2013b) notion of a raced 
hierarchy of demand, mentioned above. The effects of the beauty queue and the raced hierarchy of demand within the sex industry and in the lives of racialised sex workers are well documented (Brooks, 2010a; Mahdavi, 2013b; Miller-Young, 2014; Ross, 2009; Wesley, 2003). Below, I add my participants' experiences of how their skin tones, as both capital and stratifying agent, shape their entrepreneurial actions to develop a brand. Given that light skin tones are ranked higher on the beauty queue and in the raced hierarchy of demand and stand to gain more capital, Kumarika, a participant in this study, notes that even "small subtleties in the colour of your skin, the tone of your skin, can impact your clients that you see."

\section{(Dis)advantages of performing whiteness.}

Mixed-race, Asian/East Asian, and Indigenous participants in this study explained that they frequently choose to draw on their light skin tones and other corporeal features to perform approximations of White beauty tropes in developing their brand. In the following quotation, Saskia, a mixed-race, light-skinned participant, describes her clothing, topics and styles of conversation, verbal expressions, and body language as she works to increase her social and economic capital:

I always tell all my clients you don't have to remind me about how to dress appropriately when I see you. Because I am not walking in looking like a 'hooker' [emphasis added by participant], you know. I'm very conservative. I know when to shut my mouth, how to read people [...] Like I don't talk, excuse me, with a ghetto accent. I don't use swear words or curse words or slang. Or like a familiar gesture, like lame Black woman sucks their teeth, you know what I mean. You wouldn't catch me dead doing it, at all, no [...] the opportunities are more likely to be offered to me than somebody else, and if I were raised on my dad side because my dad's side is [name of a neighbourhood]. I would never have gotten those. I don't think I would be making as much or having the same type of standards that I do. 
Kalinda, another mixed-race participant, reflects on the perks she receives from dying her hair to perform approximations of White beauty tropes:

I guess because I'm so light, and I dye my hair red [...] more like a redhead, [...] And it's hard not to take advantage of it sometimes [...] I feel like I get away with charging higher rates, where some other girls that I see, who don't pass, there's not as much demand.

Drawing on King-O'Riain (2006), these participants' performances of whiteness can be understood as "an accomplishment that takes bodily, cultural, and political effort by social actors to assert, maintain, and challenge racial meanings" (p. 4). King-O'Riain (2006) calls this "race work" (p. 3). In the quotation, below Saskia emphasises her sense of pride in race work as she resists the preconceived notions and unyielding cultural assumptions of who she should be as a racialised woman:

I identify myself as White. Yeah, I was raised the White side of my family versus the coloured side, and I am definitely Whitewashed. [chuckles] I totally am, [...] I pride myself on that. If being educated and speak well means I am White, ok I will take it, you know sadly enough I'll take it. I love that I am mixed, I love that my kids are mixed. They all came out White-looking too [chuckles]. [...] I'm not unhappy to say that I'm mixed [...] but, there's a lot more positive reinforcement towards being White in any way shape or form. [...] Oh, it just means doors are open so much more easily.

Developing a brand that relies on performing approximations of whiteness can also mean identifying as European, Mediterranean, and/or as Latina. Saskia and Tallah explain:

When I first started working, the [agency] specifically told me that I was not to identify myself as Black that, in fact, [...] because of my light colour, there's possible for people to see me as Spanish. That Black women were not [who the clients] wanted to see. [Saskia]

I think that, first of all, African Americans are not going to be valued as the most prettiest women, that's what is out there, especially in the sex industry. I think guys want to see, what they see in magazines and on television. [...] So 
right away I realised that I couldn't sell myself because I'm African. I couldn't sell myself as being African; it wasn't marketable enough. So right away I started working as a Brazilian, you know. As I got more experience, I started realising that to mimic more like the models, so I started changing, you know, arranging my hair differently, make-up, trying to get closer to the Caucasian beauty, than the African American. [Tallah]

The transformations of participants' physical appearance through make-up and hair styling highlights the fluidity of racial performance. Some mixed-race participants pointed out that even if they do not identify as belonging to a European ethnicity, their somewhat-ambiguous skin tones result in clients confusing them with members of ethnic groups that are in the White-ish category. Jaya says, “I mean people don't even get that I am of an Indian background [...] 'are you Italian or Portuguese? [...] Spanish?"”

Many participants in this study believe that performing whiteness by appropriating cultural images and materials from the dominant culture allows them to strategically (re)construct their identity as "White" rather than as racialised. The racialised performances of participants result in both benefits and drawbacks. The ability of research participants to perform approximations of whiteness positions them higher on the beauty queue and within the raced hierarchy of demand in the industry. This, in turn, allows them to compete on relatively equal ground with their White counterparts and provides them with access to economic rewards. Arguably, the key benefit of passing as White is that it mitigates the impact of sex worker stigma and the stereotypical assumptions clients may hold about race and sex work. For many participants, such strategies to manage stigma are as valuable as economic advantages. Goffman (1963) discusses passing as an effective strategy for offsetting stigma associated with visible identity categories. Goffman (1963) defines passing as "the management of undisclosed discrediting information about [the] self" (p. 42). Given 
these realities, many light-skinned participants maximise their opportunities within the industry by concealing information about their "authentic" racial identities and creating readable identities that are more desirable to clients and third parties. In this regard, the ability of light-skinned participants to render invisible their race through carefully controlling the distribution of personal information and knowledge increases their opportunity for social and economic growth.

The main drawback of performing approximations of whiteness is that they can affect the psychic state of the performer (see Goffman, 1963). That is, many participants experience a high level of anxiety in performing an identity that can collapse at any moment. According to my participants, performances of whiteness sometimes generate curiosity among clients as to their "real" racial identities, but, thus far, these curiosities have never disrupted their business interactions. Participant Merinda, who identifies as mixed-race Canadian within the industry, is often asked by clients "oh, what's your background?" Similarly, Kalinda notes that the shape of her nose often raises clients' curiosity about her racial identity:

I used to have this big honking nose that was my father's completely, but I got a nose job [...]. I felt like it was my one possible native marker, it was the one thing that people would squint at me and be like, ah maybe, I kinda see it there.

Additionally, for many participants, performing whiteness has resulted in alienation from communities of colour. For instance, Kalinda reflects on feeling alienated after her nose job:

Ifeel a little frustrated, also guilty. [...] I feel some jealousy sometimes when I go to cultural events with my sister and people just want to talk to her and not me or if I go to places [within Indigenous communities] 'oh are you here with your friend or are you here for a school project' and I'm like no, I am here because this is my space. 
Reflecting on her alienation, Saskia notes that "some of my Black friends be like 'oh well you speak like a snob'.." In other words, according to Saskia, her education, her extensive vocabulary, and her ability to avoid speaking with an accent "totally makes me an outcast."

\section{(Dis)advantages of performing exoticness.}

Research participants on the other end of the skin tone spectrum - those with darker shades of Brown and Black skin - discussed the advantages and disadvantages of performing "exoticness." Given that beauty norms are associated with whiteness or approximations of whiteness, how do women with dark skin tones compete and thrive in the sexual marketplace? Many women in this study expressed that their dark skin tone places them at the lower ranks of the beauty queue and the raced hierarchy of demand within the sex industry, affecting their ability to earn income. ${ }^{25}$ In this sense, skin tones work to stratify these participants in ways that are in line with the stratifications of Western culture more generally. This systemic stratification, combined with preconceived notions of how racialised people should be, results in clients undervaluing racialised sex workers who have visibly dark skin. Participants in this study shared their frustrations around clients who haggle for lower rates:

If you are a White woman and charging a lot like there's no audacity to asking you, that's like the big taboo and clients fucking know it too. But you know who gets asked at every single god damn time is Asian sex workers. Every single time, all the time they have the audacity to call and try to negotiate, call and try to change your rate and they think because you are Asian [...] you are gonna take it. [Laine]

I think potential clients sometimes look down on me, once they find out that I'm native, thinking that I will do stuff for cheaper just because of my ethnicity [...] Not directly, but indirectly, I can see where it's going when they start talking

\footnotetext{
${ }^{25}$ It is noteworthy that even though participants have not been able to earn higher incomes, they are indeed able
} earn enough money to cover the cost of living a comfortable life. 
to me, like 'why won't you do this' like why won't you do this for cheaper kinda thing. [Coreen]

I have to lower my rates. [...] White women who can charge 2,000 dollars a night and they will get that, no questions asked. If I were to ask for that they would be 'oh well, if I am going to pay this then what services you gonna provide.' There's all this negotiating like I'm not as valuable as a White woman. [...] I find the men who have come to me see me as this object, this exotic object, and it's frustrating. [Leah]

Of course, the inability of dark-skinned sex workers to perform approximations of whiteness poses a significant disadvantage. However, dark-skin participants resist their place in the beauty queue and raced hierarchy of demand by performing exoticness and blackness in particular ways that further develops their brand. According to these women, their performance of exotic beauty positions them as an "exceptional" figure occupying a niche market, meeting the desirability and demand of customers (see Kempadoo, 2001; RiversMoore, 2013). Historically, Black stripteasers in post-war Vancouver, who were outnumbered by White dancers, were constructed as "ethnic novelties" in the eyes of the vast majority of White Canadians (Ross, 2009, p. 119). Similarly, Kempadoo (1998) writes about how Brown and Black women in the sex industry are regarded as the "desirable, tantalizing, erotic subject," and represent the "unknown or forbidden," thereby making them "suitable for temporary or non-marital sexual intercourse - the ideal 'outside' woman" (p. 10). Dark-skin participants in my study expressed taking advantage of such cultural definitions of racialised bodies, sexualities, and beauty tropes as they develop their brand by drawing upon materials that are available to them to openly declare their resistance to dominant beauty norms (Scott, 1990; Stychin, 1995). Using the analogy of the film industry, participant Kamen, a Black sex worker, explains the significance of using available materials to develop a brand that will appeal to a niche clientele: 
Oh! It just means that you price differently, you offer different services. It's the same as [...] say like acting, or theatre industry [...] My Muslim friends who are actors have had to take on jobs they portray terrorists [...]. If you know Arabic, even better, they give you an AK49, they teach you how to use it, and you yell like Allah, Allah, Allah, Allah [...] within the acting, entertainment industry and regardless of their politics, they work for it because it pays. It's the same industry; it really is [...] because it's all service. We are providing entertainment or anything to that effect, and so it means as a Black person I have to charge different rates. I have to offer different services, and so it's all about [...] calculating how you are going to market yourself and if you could find a niche.

My participants' efforts to develop a brand through materials that are available to them and appeal to a niche clientele can be interpreted in at least three ways. First, the strategic performance of exoticness can be understood as a decoding of dominant cultural productions and imagery that resists hegemonic beauty norms (see Hall, 1991 [1973]). Second, the process of branding can be seen to represent their entrepreneurial tendencies - by performing exoticness, dark-skinned participants are not only positioning themselves as independent agents within the sex industry but are also creating an oppositional demand for racialised sex workers while providing an alternative option to clients. In other words, according to participants, the relatively small population (lower supply) of dark-skinned sex workers in the Canadian sex industry renders them exceptional and therefore in demand:

Well. I have an example. When I first started, and I wanted to work for an agency, and they were telling me, well since I am Black my rates would be lower and that really, really, really got to me [...] And I was thinking [...] why would my rates be low? Just because I am Black? But it's not true 'cause now that I work independently, that's not true at all. Lot of my clients, they have a preference, and everyone's different, and they are gonna chose a Black girl because they wanna Black girl [...] and my rates are just as high as my White friend. [Malinda]

I'm sort of ethnically other, and I think it's like different people have different taste and that's fine [...] Obviously White women with blond hair and blue eyes might have an easier time finding a wider slew of customers, just because 
they have more 'mainstream looks' [participant emphasis], but I think there's no lack of people for everyone else, [...] yeah I mean, I am clearly ethnically different. In some ways, I'm far from that mainstream sort of very White look. [Layla]

I did find that if I was working with all blonds that day, I made all the money. If there's too much of one, and if there's one blond, she's making all the money. But out of too much of one thing, men will pick the exact opposite. Ten Barbies? No. I want Black Barbie. [Pearlina]

The demand for the exceptional/exotic also has a spatial dimension. My participants suggest that the opportunity to appeal to a niche clientele increases in regions where the demographic population is predominantly White, both with White workers and White clients. In this context, many dark-skinned participants travel to locations that are predominantly occupied by White people to earn an income that is reflective of the cost of living by performing the exotic "Outsider" woman. Ling and Mariyam reflect:

I find especially in Vancouver it can be a big disadvantage as well. Huge, like if I were to work maybe in Calgary or Saskatchewan or something, a predominantly White community, I think that would be a definite asset. [...] I went with a friend to Kamloops, and it's predominantly White. [...] And we did one night or two nights or something. I did very well, just because there were no Asian girls there. [Ling]

Yeah, so in Alberta, I think I am very exotic. It's mostly Caucasian women, and there's not a lot of Asian women. [...] So in Vancouver, I can work a full day; I can put in twelve hours and the likelihood of me making any money that day is probably fifty percent. But in Calgary, or most cities in Alberta [...] I am at least looking at $\$ 500$ to $\$ 1,000$ a day. That's a huge difference and it kind of goes to show that my niche is more liked there than here. [Mariyam]

The third interpretation sits in contrast to the first two, perceiving the ways participants perform exoticness as reinforcing racialised stereotypes within the industry, rearticulating marked marginalisation and thus positioning racialised sex workers as relatively powerless. The practices of performing exoticness may also appear to be counter-intuitive, 
such that in the process of expectionalising or "Othering" racialised beauty, participants are further reinforcing Eurocentric standards of beauty. However, my research findings show that participants' motivations for performing exoticness are driven by market demand and by their entrepreneurial tendencies to capitalise on the opportunity for economic and social growth.

\section{Body size.}

Body size is another attribute of beauty that profoundly influences the entrepreneurial task of developing a brand. As with skin tones, issues surrounding body size are not unique to the sex industry, nor are they unique for racialised and Indigenous women. Hesse-Biber (1996) notes that thinness is equated with beauty and vitality in Eurocentric framings, while Pause (2015) explains that fatness is not desirable or valued within capitalist and neoliberal society, such that fatness is perceived to be a disorder and as contrary to the beauty ideal. Similarly, LeBesco (2004) shows that mainstream discourses usually exclude fatness and fat bodies from what is seen to be sexy and how sexiness is embodied, and Murray (2004) claims that heteronormative systems in particular exclude fat bodies from the notion of sexy. Taking a labour perspective, Larose, Kpelitse, Campbell, Zaric, and Sarma (2016) suggest that increased body size in the mainstream labour force, especially for women, is associated with reduced hourly wages and annual income.

As mentioned in Chapter 4, as part of my approach to participant recruitment, I browsed various websites and online advertisement for upscale escorts in different Canadian cities. My search involved browsing through sex workers' private websites as well as through third parties' business sites. During my search of third party websites, I noticed that the profile photos of workers who are featured in photo galleries look almost identical - they 
show predominantly White women whose weights range between $110-120$ pounds. ${ }^{26}$ This uniformity makes sense given that, to cater to the needs and desires of middle-class and upper-class patrons, many owners and managers of upscale adult entertainment establishments hire and market according to beauty norms, which include not only White bodies but also thin bodies. Sarena explains,

Working with an agency, at least in my experience, everything is very uniform, right. All of the photos, you are in a studio, you are wearing the same kind of clothes as everyone else, you have the same kind of description, so nobody looks generally better or worse than the other, everyone is just like you are, a high-end escort.

Given the demand within the sex industry for escorts with thin physiques, it appears that the majority of racialised and non-racialised sex workers conform to an ideal slim figure. Of course, maintaining a 'perfect' figure requires discipline (see Pause, 2015). According to research participants, working in the sex industry forces them to be more conscious about healthy lifestyles, including a balance of healthy eating and exercise. Maintaining a thin figure also often requires a regular workout regime and a commitment to eating out only when working. ${ }^{27}$ Many participants noted that caring for their body increases their self-esteem and also enhances their capacity to compete in the marketplace. In the following account, Tallah reflects on the importance of maintaining a thin figure to develop her brand:

I exercise five, six days a week, I watch what I eat, and, like, a month ago I went [out] on a Friday [...] I don't know what happened, I just ate the whole night. The next day I had a client, and I had one of my worst reviews. [...] He said that I was beefy. Because I have lots of muscles, and what I ate I had put on the pounds. My body looked bigger because you put fat on top of muscle I look even bigger. Especially because I'm dark-skinned I have to be very, very

\footnotetext{
${ }^{26}$ See for example http://www.cupidsescorts.ca/escorts/; http://sexyfriendstoronto.com/toronto-escorts/escorts/; http://www.myntmodels.com/platinum-escorts/

${ }^{27}$ Many sex workers pointed out that they frequently had to accompany their clients on dinner dates.
} 
careful, you know. So he wrote, 'Oh, I should have read her reviews because all I encountered a Black buff girl.' Black buff. You know, and I'm like ugh [...] that doesn't give a good image. So I learned my lesson, I'm like I have to be very careful because, yes, I mean guys want a pretty lady, they want a girl in shape. [Tallah]

Although healthy eating and regular exercise are generally seen to be good practices, selfregulating and policing in this context also reify/normalise Eurocentric ideals of feminine beauty (see Bartky, 2003; Bordo, 2003). For Bartky (2003), the disciplinary tactics of dieting and exercise are not only part of a "process by which the ideal body of femininity $[\ldots]$ is constructed" but also the process in which the feminine body has been ascribed an inferior status (p. 33). For Bordo (2003), self-regulation through contemporary regimes of beauty, dieting, and exercise is a "means to train the female body into docility and obedience to cultural demands" (p. 27). In this sense, research participants' preoccupation with thin bodies can be understood as conforming to cultural demands as part of developing their brand.

However, not all participants of this study shared a preoccupation with meeting the ideal body size. Participants who do not meet the ideal body expressed counterhegemonic decoding practices that resist the ideal figure and embrace their fat bodies. Gailey (2015) argues that "to embody fat is a tremendous accomplishment because it means generally overcoming the negative message and stereotypes propagated in the culture" (p. 53). Thus, participants who integrate their fat body into the development of their brand are not only entrepreneurially savvy, but they are also bringing to light their high self-esteem, independence, and agency. In the quotation below, Zaina explains how she disregards the ideal of thinness propagated within her ethnic culture and not only embraces her plus-size body but also realises the opportunities it brings her in the marketplace: 
Well, I am Lebanese and Moroccan and so [...] most girls in my culture are very skinny. Like there is this ideal they have to be very thin and stuff [...]. I am happy with the way my body is. Like, I am comfortable with myself. That's something that my parents think I am lying to them when I say I am happy about my body [...] and with clients and stuff, they are always going on about how exotic [...] they don't see women with my body type a lot.

Like Zaina, other plus size participants in this study emphasised their acceptance for their bodies. According to these participants, just as there is a niche market for ethnic skin tones within the Canadian sex industry, there is also a niche market - and therefore a demand - for plus size women (also see Miller-Young, 2014). Identifying this demand allows plus size participants to promote themselves as different from other, mostly thin, sex workers in the industry. In developing a brand that incorporates their fat bodies, participants also demystify Western cultural attitudes towards fatness and the embodiment of sexiness. Participants explained that women and men in society not only feel pressure to conform to the ideal of a thin body, but they also feel pressure to hide their preference and desire for more voluptuous bodies. According to my participants, the sex industry provides a mechanism for clients to experience their hidden pleasures and fantasies freely:

In Vancouver, to be honest, it's a very skinny culture. Men who like bigger girls, even they don't realise they like bigger girls [...] they all have skinny wives and girlfriends because society tells them that's what's beautiful and that's what they need to have. But then I see a complete difference when they're with me or with a girl similar to me, the way they're excited about it, and it's nothing negative, it's all positive. [Mariyam]

When I worked at the escort agency, the girl who made more money than anyone else was also the biggest girl working there. Because the number of guys who really, really want to have sex with a beautiful fat women, didn't want his friends to know about it, so we have all these stupid things we teach men, what they should find desirable instead of what they do find desirable and that blows people's mind too. [Kalinda]

It is noteworthy that attitudes about fatness within communities of colour are markedly 
different from the Eurocentric preoccupation with thinness. For instance, studies on body image and body size show that Black women express preference and tolerance for larger female silhouettes, and Black girls identify an ideal body size that is much larger than the ideal size selected by White girls (Cachelin, Rebeck, Chung, \& Pelayo, 2002; Chin Evans \& McConnell, 2003; D. Davis, Sbrocco, Odoms-Young, \& Smith, 2010; Kelch-Oliver \& Ancis, 2011; Rucker \& Cash, 1992).

While plus size participants asserted they are able to promote their brand to a niche market within the industry, these women also expressed being chastised, discriminated against, and sometimes mistreated by clients. Mariyam highlights the tension between selfacceptance and clients' culturally informed views of fatness:

I want to mention one thing. Before starting in the industry I was always pretty confident in my own skin, but I was a little unsure. I was still a little shy, but coming into the industry, I don't really give a fuck. My attitude is like I think I'm fucking gorgeous. A lot of guys are willing to pay for it, and you can shame me all you want, but you cannot define what I think my beauty means to me. So that gave me a lot of confidence, a lot of confidence [...]. But in Vancouver, there is a lot of hate towards it. A lot of guys will come and see me because of my ethnicity, not because they like my body type, and then they'll come and make weird comments like, oh, why is your tummy so big? [Mariyam]

Of course, cultural attitudes about fatness are not unique to the sex industry. Gailey (2015) points out that, given our society's attitude towards fatness, women in general who are not conventionally thin are frequently discriminated against and labelled deviant. They are also less likely to be hired and/or often subjected to low pay, and are more likely to be oppressed in public spaces through disapproving stares and verbal abuse (Gailey, 2014; also see Stevens, 2017). However, as we have seen, many research participants adopt a "body-positive" 
approach to sexual labour and transform their bodily capital into opportunity for personal, social, and economic growth (Bernstein, 2007b).

\section{"Hair matters." 28}

Just like skin tone and body size, hair - in terms of type, texture, and styling practices - is a stratifying agent that shapes research participants' entrepreneurial task of developing a brand. Furthermore, just as light skin tones and thin bodies are ranked higher on the beauty queue and in the raced hierarchy of demand within the sex industry, so is blond, straight or wavy, long, shiny hair that flows. Similarly, just as there is a preference and niche market demand for dark skin tones and fat bodies, there is also demand for dark, curly hair, cornrows, weaves, and Afros. ${ }^{29}$ In this sense, politics around hair types and textures are similar to what I have highlighted thus far. That is, light-skinned racialised and Indigenous participants who are able to transform their hair into styles and colours that are associated with White people (e.g., blond, red, ginger) are better able to perform approximations of whiteness. Merinda shares,

I actually had blond hair [laughing]. [...] When I started working independently, I dyed my hair back to brown and let it grow. It used to be short and blond [...] When I had my blond hair, it was like, people didn't know who, what kinda background I had. [...] I get all sorts of things like, 'so what's your background, Russian? Hawaiian?' [emphasis added by participant]. I am like hahaha whatever [...] and I can play this up, and whatever makes money [laughing out] [...] I will be like [laughing] Russian and Hawaiian is pretty Indigenous to me [laughing].

Similarly, for dark-skinned participants, adopting natural hair styling practices shapes the development and marketing (discussed later in this chapter) of their 'exotic' brand:

\footnotetext{
28 Subtitle borrowed from Banks (2000).

${ }^{29}$ See Banks (2000) for images of different Afro hair styles.
} 
So I was marketed to the more ethnic cultures, [...] with the tone of my skin colour, I could either be marketed to Punjabi men, Sri Lankan men, Pakistani men; there are all these ways that they made me change my hair, whether or not I was going to keep it straight, or whether I was going to leave it kinky. Like, it's curly and wavy by nature. [Kumarika]

Ultimately, different hair styling practices, whether conforming to and/or resisting hegemonic beauty standards, generate different economic outcomes in the marketplace, increasing participants' opportunities to compete. In this section, I draw attention to two other aspects of hair styling practices that Black participants are often confronted with as they perform iterations of whiteness: the monetary and time-based constraints, and the internalised tensions of performing whiteness through hairstyling practices.

First, participants who perform approximations of whiteness through their hair colour and styling practices lament the monetary and time-based constrains of doing so. Eurocentric hair colours, styles, and textures are not only equated with beauty, but they are also taken to represent femininity and professionalism within mainstream culture (see Banks, 2000; Craig, 2002). Given how mainstream cultural perceptions influence the sex industry, Black participants often chemically straighten/relax their hair or perm it to create the perfect wavy texture as part of incorporating iterations of whiteness into their brand. For these women, chemically relaxed hair looks professional (Banks, 2000), “dignified and appropriately feminine" (Craig, 2002, p. 122). However, transforming their hair to resemble that of White women's hair is costly. ${ }^{30}$ Shemika emphasises the finances involved in chemically processing Black hair:

The thing with the hair, where my hair is more processed, it's chemically processed [...] It's the silky, long flowing hair that's attractive, which costs me

\footnotetext{
${ }^{30}$ Also see Miller-Young (2014) for other expenses involved in "black performers embodiments mirroring
} norms of white femininity in pornographic media" (p. 243). 
a lot of money to make my hair that way. Where it feels like when I am working, all I'm doing is paying for ads and getting my hair done. Where it all feels like the money that people tell me that we are making, and I am in the same industry as them, and I am not making that money, I was like there's something that I doing wrong, even though I am not making that, then all my money goes to my hair and ads and everything else to keep my image attractive to make money.

In addition to the financial burden, participants who perform approximations of White beauty also discuss how time-consuming it is:

So when I first started I had like, I didn't wear wigs, but I had like hair that was like fairly long and straightened, like chemically straightened and that was like a huge issue for me, because I could never get wet if I am showering and it took so much preparation [...] and [...] I think that's one of the big issues for me is always having to have this very White-friendly appearance and it's also like very fem appearance. [...] I would be spending hours like doing my nails, doing my hair, doing my make-up putting on perfume, showering, like three times a day. Which is not my preference at all. [Sarena]

The second aspect of hair styling that Black participants draw attention to is the politics of performing approximations of whiteness. Banks (2000) notes that "hair shapes Black women's ideas about race, gender, class and sexuality, images of beauty and power" (p. 3). From this perspective, "natural hairstyles with African, African-American or Jamaican origins - such as [cornrows], dreadlocks, afros, braids - have become popular as a way of showing rejection of White-oriented images of beauty and being proud of natural Black Beauty" (Tate, 2009, p. 9). However, given that natural Black hair is not considered attractive and sexy according to dominant ideals, and given it is ranked lower on the raced hierarchy of demand and on the beauty queue, wearing natural hair reduces opportunities for Black women in the marketplace. Shemika explains,

[My hair is] more straight, which is more of work related. Compared to my hair, which was more natural and kinky and coarse, like afro thing, which is 
the big trend in the Black community to go natural hair. But natural hair for me won't make me any money. So I am in between where I would love to have dreads one day, but dreads aren't exactly considered sexually attractive.

The tension between maintaining a natural look by wearing Afro hairstyles to perform "authentic" Black beauty or Black womanhood (see Tate, 2005) and performing the "slick" "professional" femininity that Shamika refers to is prevalent among most Black participants in this study. As such, these participants reflected upon the various constrains of performing Black beauty and its implications within the sex industry. For example, in the following quotation, Sarena reflects upon a time when clients stopped seeing her because of her natural hair:

I shaved my head, and I also went natural at that time. Then I was like oh my god what have I done? [laughing out] How am I supposed to do sex work now. [...] I was working independently at that time and [...] people stopped seeing me as much when I shaved my head and I was getting reviews that were like 'oh she's very, very, pretty, and she's like wonderful, and she's like smart' [all these] positive reviews but [also] like 'she has short, afro hair.'

In the quotation below, Sarena continues to draw attention to the struggles of performing, both femininity and whiteness, by wearing a wig on top of her natural hair:

So when I went back to the agency, I was like you know what, instead of dealing with [short afro hair] [...] I will wear a wig, it will be super easy. But it actually turned into this huge issue. [...] because people do touch your head and feel your hair a lot. I have a lot of anxiety about people being like 'oh my gosh, you are wearing a wig?' and I think that plays into more race stereotypes. [...] Now I feel like I am hiding my natural hair, which cutting my hair off and going natural was a huge step for me, doing the big chop and so, and that's something I have been very proud of, so wearing a wig and me being afraid that people will see my real hair, that's not something that I have ever experienced or that I've ever felt anxiety about [...] So it's very strange and unnerving. [...] because I am too nervous to go. I'm honestly afraid that if I go to a call with straight hair, or with natural hair, I am going to get turned away at the door. 
In the quotation below, Lola highlights yet another dimension of the tension between wearing natural hair and adopting White-ish/Eurocentric hair styles:

My hair is, my natural hair doesn't look anything like this, but there's NO WAY [participant emphasis] I will wear my natural hair, not because I'm ashamed of it, but that's too much of me. That's too close to who I actually am, not my persona. So for me, putting on the straight wigs and the blond hair is separating myself from my persona, but also acknowledging that people are really racist and women who don't have this kind of hair style, like straight hair or weave looking hair or whatever, get discriminated against, by means of not getting bookings or just treated a little bit differently and stuff like that. I have some clients who you know, maybe one day I'll show them my natural hair, may be, but that's because we've built a respectful sort of thing, but meeting a new client, I need to appear as blending in as possible.

Black participants' negotiations of hair styling practices reinforce the extent to which the Canadian sex industry is shaped by the normative intersecting ideas of femininity, whiteness, and beauty. It is noteworthy that a few Black participants in this study did wear Afros, including varying lengths of extensions with individual braids. Given the various challenges of wearing natural hairstyles mentioned above, drawing from Zook (1990), I claim that the few participants who have chosen to embrace their culturally appropriate hairstyles are defying the hegemonic beauty tropes with confidence, courage, and "an extra dose of selfesteem just to get through the day" (p. 89).

\section{Advertising and Promotion}

The second entrepreneurial task that participants engage in in the marketplace is advertising and promoting their brand. The mediums and messages for advertising, promotion, and distribution used by Canadian sex workers have evolved over time. For example, in the past, street-based workers used their hypervisibility on the streets to promote their services. At present, street-based workers often render themselves invisible on the streets 
to avoid criminalisation. Furthermore, in the past, Canadian indoor sex workers often took out advertisements in the classified and personal sections of local newspapers (see Sanders, 2006). With the emergence of the internet, the advertising trend within the sex industry also shifted towards online advertising. Until recently, online marketing has been beneficial for both street-based and indoor sex workers. Craigslist, Now magazine, and Backpage.com have been some of the most popular places in which sex workers advertise their services. ${ }^{31}$ It is also common for sex workers and third parties to maintain a private business website as an advertising medium where they showcase a photo gallery of the sex worker(s) (see Sanders, 2006). Carina is a veteran of the Canadian sex industry. In the following quotation, Carina reflects on her long tenure and the different mediums and strategies of advertising that she has used over time:

Honey, our advertising was right on the street. Attire of clothing, our colourfulness, our fabulousness. We were walking billboards, that's what we were; and we spent lots of money on our hair, make-up, nails, fashion, all that. And I like to say that we were a cultural community because we only have a certain [number of workers] that was similar, we often use the same type of language, it's a bit different than regular society, yes, absolutely. [...] Certainly, any type of racial term that may have an exotic appeal, you're going to take advantage of that, right [...] You can advertise your exoticness, what I call it. So, yeah, put that into your advertising because that really helps. I would use specific sites too that maybe are geared towards that. I would put biracial [...] and, certainly, there are transsexual sites that advertise [sex workers as well]. I advertise on there [...]. I like to use Backpage because I pay for my ad with the credit card and I celebrate myself. I put my real age up there, I put my photos up there, and what I do now may be rare fantasies for men [...]. So, they know they're coming to someone older.[...] But it has appeal; it has appeal.

\footnotetext{
${ }^{31}$ At least until the advent of SESTA/FOSTA, a discussion of which falls outside the parameters of this project.
} 
The different marketing mediums and messages Carina alludes to as she reflects on her experiences highlight dynamic advertising strategies within the sex industry (see Sanders, 2006). It is evident that Carina considers various factors, such as race, age, gender, type of message, and different advertising sites in her efforts to promote her brand (see Pruitt, 2016). At the same time, Carina's advertising approaches are also based on the fundamental principles of advertising. For instance, Carina focuses on recognising and fulfilling customer needs (see Urban, 2004) and creating persuasive messages that will influence customers to take the action she wants (see Ryan \& Jones, 2009). Carina's approach also reinforces the fact that she is the best person to define her marketing strategy because she has the best knowledge about her business (see Ryan \& Jones, 2009). In this regard, Carina's approach to advertising and promotion is parallel to other research participants in this study. In addition to the above-mentioned advertising/marketing attributes, participants' advertising matrixes also include expressions of autonomy and resistance to stereotypical assumptions about racialised and Indigenous women's sexuality and the victim narrative that surrounds them.

\section{Advertising the exotic beauty.}

Participants' independent advertising strategies are quite similar to those of third parties. From an entrepreneurial perspective, self-advertising and third party advertising approaches are primarily intended to speak to the needs, desires, and fantasies of the customers and a promise to fulfil them better than the competition. Therefore, the focus is on creating a particular message about the brand that will resonate with the needs and desires of the most customers.

In order to compete in the marketplace and make a profit or a living wage, both selfadvertising and third party advertising strategies are designed to create demand for racialised 
and Indigenous women by presenting them through approximations of whiteness and/or exoticness. It is in this sense, through iterations of whiteness and exoticness, that advertising strategies are interrelated with the development of the brand. The advertising and marketing process often includes obscuring racial identities when possible, fabricating and/or altering information about physical features and characteristics, hypervisiblising racialised features, and/or playing up stereotypical tropes. The following quotations are some examples of third party and self-advertising messages:

The first one would lie all the time. 'Oh, she's like super [dark].' Okay, so I'm not super dark at all. I'm not light but I'm not dark. And they'd be like 'she's dark chocolate.' I have tattoos and stuff, and they'd be like 'she's got smooth, clean skin and big booty, big boobs.' And I'm like 'Oh, my God, I sound like a freaking balloon character. I don't sound human.' The first agency was really objectifying. [...] It was just like 'These are her features, this is what she looks like, she's 5'6", big tits, big ass' you know that T and A. So that was a really shitty experience. The second one, because their focus was on the gentleman club type thing they were very much into his experience. So they advertised me in ways that, I guess, sounded appealing to the male audience. So lots of smooth and sexy and sultry and that sort of language. Which was better, more accurate, I think. [...] But they would also include my personality type as 'funloving' or 'really fierce.' That's what I get a lot. 'She's fierce.' So they were a lot better. But it was still really like skin colour and how big my curves were, right. Black people are known for their big tits, big hair, big butts, dark skin. [Lidia]

I market myself as exotic, ebony, from the islands, you know, something that is not commonplace. It's like oh! I am Black, but I am not like all the other Black girls. [...] So you play into the fantasies of the masses, [...] you got to find that foothold and market yourself to it. If you find what brings in more money, and that's what you go with. So if I play up my exoticism, then I get a certain type of clientele, who probably have never been with a Black person, or somebody from the islands or anything like that. [...] so they want this exotic creature, goddess. [Kamen] 
I worked up in North, I worked in [city in Northern Ontario] with an agency and I said I was Native and she goes 'oh we will market you as mixed' [...] And ever since then I have been marketing myself as mixed. [Merinda]

Both third party and self-advertising strategies, in their attempts to hypervisibilise exoticness, draw on the intersections of racial tropes and geographical markers. For example, East Asian women are often depicted as "Dragon Ladies," South Asian women as "Bollywood Queens," and Black women as "Caribbean Princesses," "island beauties," hypersexual, dominant, and consumable. Participants share their experiences with these tropes below:

Oh my goodness! Voluptuous, exotic, Caribbean Princess. I never was marketed as Jamaican; it was more Caribbean, it was an island beauty, curvy. They had a picture of me and I was in a black vest, black booty shorts and black thigh-high boots, so the impression was domination, even though I wasn't trained as a dom. There was one ad that they did where it was like, 'Obey her or else,' something like that. But it was mostly Caribbean Princess, hot chocolate, that kind of thing [...] They were predictable. I didn't really feel much about it because it's all about playing your race a bit. I saw some of the ads for Latin women and the Latin love and all that stuff. So I'm not surprised that I got hot fudge, you know what I mean? [Usha]

So I was marketed as Indian beauty, like, Bollywood queen, which I felt fine with, and then that's sort of how I've been doing it since then. [...] I market myself [with] Bollywood somewhere in my title. Like, I market myself as Indian, oh, yeah! When I'm doing my ads, I have a video of me in a sari and, then, pictures of me in a lehenga and stuff like that. So I play up the Indian aspects. A lot of my clients are Indian men. [Divya]

I'll say, 'caramel-coloured Caribbean beauty.' A lot of girls say they are exotic, though. So I used to use exotic beauty, but I stopped because I noticed everybody was using it. So I'll say caramel-coloured Caribbean beauty. There's my photos there with my skin lighter and my skin darker, so blonde hair, brown hair, and guys will call and say, 'Is that the same? Are you this vixen?' I'm like, 'Yeah, we tan, too.' So I will say, 'caramel-coloured, curvy Caribbean beauty.' I put curvy in there. I say all-natural so they know that my boobs aren't enhanced. I say 39. I'm 39 forever [laughing]. [Tallah]

Ross (2009) points out that in the post-war era, White Canadians in Vancouver saw Black stripteasers as epitomising the "lascivious sensuality and wild rhythms presumed natural to 
their race" (p. 119). From this perspective, it makes sense that the process of marketing racialised women within the sex industry requires investing in the fantasy of tantalising, hypersexual, forbidden Black and Brown bodies, which also sits in opposition to the "good White girl” fantasy (see Kempadoo, 1998; Miller-Young, 2010). The tantalising and hypersexual advertising messages employed by participants are strategic tools to decode and resist White beauty norms and to market a product that will allow them to earn an income that reflects their cost of living (see Kempadoo, 1998; Miller-Young, 2010; Stychin, 1995).

In addition to mobilising tantalising and hypersexual messages, both third parties and participants, especially Black participants, use food references to advertise their brands. In the quotations above, Usha notes that she was referred to as "hot chocolate" and "hot fudge." Lidia was referred to as "dark chocolate." Tallah refers to herself as "caramel-coloured." And Serena points out that third party advertising messages refer to her as "caramel skinned," while she advertises as follows:

I do advertise myself as being, I actually do use food references in terms of skin colour a lot, [chuckles] [...] Usually it's like 'burnt almond skin' or 'caramel' or 'brown sugar' stuff like that [...] and like brown sugar skin, so sweet.

Using food references to denote Black women's skin tones is a long-standing tradition. In specifically addressing the reference to "brown sugar," Miller-Young (2014) starts from the central role sugar played in colonial plantations that consumed Black women's labour and bodies across the American South and the Caribbean. According to Miller-Young (2014), brown sugar as a metaphor exposes how Black women's sexuality and sexual labour has been historically embedded in culture and the global economy. Furthermore, "the process of refining cane sugar from its natural brown state into the more popular white, everyday 
sweetener reflects how black women, like brown sugar, represent a raw body in need of refinement" (Miller-Young, 2014, p. 5). Brown sugar "as a trope illuminates circuits of domination over black women's bodies and exposes black women's often ignored contributions to the economy, politics, and social life" (Miller-Young, 2014, p. 4). In contemporary discourse, brown sugar "thus shows how ideas about black women are naturally savage, super-sexual beings have flavoured popular tastes even as they have driven a global appetite for (their) sweetness" (Miller-Young, 2014, p. 5). On the other hand, from the standpoint that stereotypes have dual values, Miller-Young (2014) writes,

Although brown sugar has been used as a phrase to talk about black women as lecherous, prurient sex objects, unlike other tropes such as the Mammy, Jezebel, or Sapphire, it conveys sweetness, affection, and respect. In African American vernacular speech and song, brown sugar often expresses adoration, loveliness, and intimacy even as it articulates lust, sensuality, and sex [...]. [Therefore,] brown sugar is sometimes used by black people to speak to the sophisticated pleasures they derive from their own eroticism. (p. 5)

It is worth noting that some participants were particularly offended by third party advertising messages that rely on racial tropes of hypersexuality and exoticness. According to these participants, such advertising messages devalue, minimise, and objectify racialised bodies:

White women, [their ad], they all have a vast different personalities and like education backgrounds, and like 'oh this one likes to travel and she's really into surfing and yoga.' [For] everyone else it is like 'Oh, well, she's Black and she's like a Nubian Queen.' That's it [...] that's all you get. [Lidia]

When I was at the agency the pictures they took of me and the pictures they took for other girls who were not women of colour were very different. Subsequently the [pictures they took for the] other Black escort [...] were very similar to the ones I had. Very like bootylicious, kinda like borderline fetishising of Black body parts and stuff like that, so that was a problem. [Teagan] 
At the agency, it's only, luscious lips and big butt and big thighs and you know exotic, caramel-skinned this and that and the other [White] girls on the website, loveable so and so. [Leah]

Participants who object to using tropes of racialised beauty and sexuality avoid such strategies when advertising. Lidia, in the quotation below, explains her decision to only advertise the services that she provides instead of marketing the "exotic" brand:

I don't mention that I'm a person of colour at all. Like it's just my services $100 \%$, and they meet me, and they're like 'Whoa, wow', and I'm like, yeah, well. And I find like maybe just for my own self it's more, well I like it to be as anonymous for me but also being able to give the client like this is what you're getting, this is what you should expect. I'm a very tit for tat type person, so I want this experience to be about you and good and all that stuff so please let's have some sort of connection. But I also like to kind of keep the air, an element of surprise. Yeah, it's different. So I don't need to advertise that I'm a busty ebony goddess.

According to Lidia, she does not reveal her race or ethnicity in her advertisements; as such, clients are often surprised to see a person of colour when they arrive. Lidia notes that this element of surprise provides a richer experience for her and her clients. Lidia feels that she does not need to enhance her racial beauty to make a profit.

\section{Additional purposes of advertising/marketing.}

Although the primary goal of advertising is to promote a service that will meet the needs, desires, and fantasies of customers, participants also shared other reasons for crafting advertising messages differently. For instance, participants explained that advertising messages adopted by many third parties - those which obscure their race/ethnicity and mask features and characteristics by presenting all sex workers uniformly - can often benefit sex workers as it tends to increase the privacy for women, even though that is not the intent of 
third parties. Lola and Sarena emphasise the benefits of replacing real features and characteristics of sex workers with fabrications:

The owner of the place, she said [...] 'my women of colour are exotics, as you would be called.' [...] she is like, 'well in your case, you are very racially ambiguous' [...] and she's like you will fare well with Brazilian. [... ] I do think, it is something where you have to understand as well, this is also to, protect your privacy, so I could have just gone about with my own background, but I didn't feel comfortable at all because I felt on the off chance anyone who knew me was looking at the site, if they were thinking it was me, and that's my saving grace, and they will be like, but oh no it says Brazilian, so this is not her, you know. And I do think for some of the girls it's about marketing you in a way that makes you able to attract more clientele, for others it's also about protecting your privacy and anonymity. [Lola]

So I work through an agency, and I work through one of the more popular agencies in [city name]. [...] I'm placed into the exotic section [...]. Yeah, so I have probably between 8 to 10 professional photos that are all very nice, they don't show my eyes and all of my tattoos are edited out. I have a description that is completely inaccurate; it's like an exotic, caramel-skinned, they have some food reference in there, of course, long-haired, even though in my actual photos, I have short hair, Dominican beauty. I think I am described as my height, my measurement which are all completely inaccurate [laughing out] Yeah everything about it is pretty much fake, except for my height. [...] Working with an agency at least in my experience everything is very uniform, right. [Sarena]

In the quotation below, Laine articulates another dimension of advertising strategies.

From Laine's point of view, her advertising approach to play up her race is not only about appealing to a niche customer base, or about making money, but it is also about resisting normative understandings of beauty, its relationship to desirability, fantasy, and economic values; furthermore, it is about destabilising structures of power (i.e., the marketplace) and the structural position people of colour, as a group, occupy in Western societies.

In advertising [I say] Canadian-born, or raised in. [...] I am your exotic; I use these words. My exotic sparkling eyes, mixed race, all of those things. You 
know what, it's true, if I am gonna hack capitalism, then I am going to exploit all of the angles that I have, it's true. I am doing it for myself as a woman, I mean my politics are even in my body, [...]. But all of these things, using all of those markers, privileged and typically attractive markers to make money, so this is just one more thing. And my politics aren't my advertising [...]. But you can't get too political, that's [not] marketing. My twitter feed is not really me; it's just marketing. My website is not really me. [...] my exotic [country name], whatever, whatever, I do because that's a part of a piece of my entire whole or a huge piece of my identity, for sure. [Laine]

According to many participants, their advertising messages are crafted to express their autonomy and independence. As such, many of them make informed decisions, for example, on when to appropriate racial and cultural tropes and marginalised markers and when to resist them (see Scott, 1985). In the quotation below, Leah explains this sense of control and independence she experiences as an agent responsible for her own advertising:

I could advertise myself how I want to be advertised. I would use certain words that would describe myself [and] didn't even relate to things physically, because I wanted the people I catered to, I wanted men to understand that I am more than just a body, I'm intelligent, I'm very well spoken, you know I have a really great personality, so that's how I would advertise myself, and then I would state that I'm of colour.

In the quotation below, Sarena shares how she crafts her advertising message to represent her personality and politics:

I usually have like pretty cutesy things with, like, I usually make a bunch of puns in it and I advertise myself as being a student. I focus mainly on I'm funny, and I'm intelligent, and I am very nice and bubbly, and I usually try to have my personality characteristics played up. [...] I talk a lot about my weight because I'm very small right, [...] I do that because I don't see a lot of new clients [...] I have a few people who want to see me very regularly, so they know my politics and they know my analysis and they generally know that I'm pretty grumpy [laughing out] I am a grumpy escort, so they know that like I am being little tongue and cheek when I say things like that, so that works. 
It is evident that with control over her advertising message, Sarena can get paid to be whoever she wishes to be, including a critical, grumpy student. This is a compelling position for a person who is frequently subjected to multiple oppressions in her everyday life.

Last but not least, participants' advertising messages are designed thoughtfully to avoid and manage the stigma that is attached to race and sex work. Historical mythologies have depicted racialised and Indigenous women's bodies as embodying excessive or nonnormative sexualities that are publicly despised, devalued, and deemed deviant, and which are privately desired, enjoyed, and continually fetishised as alluring, pervasive, and forbidden (Barman, 2005; Henderson, 2003; Kempadoo, 1998; Miller-Young, 2014). Arguably, such perceptions continue to have a stronghold in the contemporary sex industry, resulting in various stereotypical assumptions about racialised and Indigenous sex workers. Participants Teagan and Usha recall the challenges they have faced as a result of stereotypical assumptions:

I would say advertising is challenging, because there's lots of stereotypical views about Black women who are sex worker. For instance, depending on where I'm advertising I get different kinds of responses to my ads [chuckles]. [...] I feel that as a Black woman working indoors I still won't be seeing as many clients as White women working indoors. [...] because lot of the time Black women are misrepresented as like big and extreme and out there [...] but you got this awe, these features that's so fetishised [laughing]. [Teagan]

I found that some of the calls were people wanting things like Greek services that I didn't provide and I didn't know whether that was part of the big booties sort of stereotype [...]. I had a lot of guys who liked curvy women even though I wasn't very curvy then. I had guys who wanted a little bit of domination [...] and stuff because of the angry Black woman stereotype. But still, it wasn't like my phone was ringing off the hook. It was like, here's a call for \$500, and then, the next weekend, here's another call. It wasn't like every five minutes my phone's ringing. [Usha] 
Given the deep-seated assumptions about racialised and Indigenous women's

sexuality, participants feel that their self-advertising strategies also have to focus on demystifying such stereotypes. In this regard, having control over their advertising messages has been an invaluable asset. To avoid stereotypical expectations from clients, many participants, especially Indigenous and mixed-race participants, identify themselves as White or as from a White-ish category in their advertising:

Lately, I have been advertising myself as French because I do have French in my ethnicity but I have never said I'm Métis. It doesn't look good on my ad, and I don't know, I'm proud to be Aboriginal, but it doesn't really help when advertising. [Coreen]

When I first started doing independent work, I didn't put my race at all. But I noticed that people are like 'oh what's your background?' So I normally just put Canadian, with background of European and Native. I don't know if it like makes my clientele better, but I do know that some clients only like to see like Canadian girls. I am not certain if a White girl will be a true Canadian girl [laughing out loud]. [Merinda]

I call myself the African Canadian girl in [city name]. [...] I think also being very petite Black woman changes the way I'm perceived and treated because it's not necessarily very typical [...] I am a slight little person you know, so people also project whiteness onto that as well, you know. Between the blond hair and the little itty bitty body they're like, you're like, it's almost like you're a White girl. [Teagan]

Participants with Black ancestry expressed crafting their advertising messages in ways to distance themselves from their blackness:

I just advertise myself as Brazilian because my pictures do show that I have brown skin. So I have to dissociate [...] my brown skin with being Black... So Brazilian is like the word that I use on all my profiles to dissociate myself with my African roots [...]. But in certain reviews [clients] have mentioned that I look darker. A lot of the time I take pictures in the daylight, so I do seem lighter in the pictures. [...] But there's been some incidents where [...] some guys are like 'Are you sure you're Brazilian?', you know. So it's getting harder 
and harder because, god, people have actually started visiting Brazil. So that's been kind of like 'Urgh!' [Tallah]

I don't put the Black part on my ad; I don't know why. I'm not ashamed of being half-Black. My mum's Black. I'm literally half and a half. [...] I love my Black side; I grew up with my mum, I don't put the Black part on my name because, I don't know, I just, feel like it won't really, it's just better to say mixed Asian. [...] Yeah, I lie a little bit. I kinda put half Latina, trying to hide the Black part, I don't know why I do that, I'm not racist. I just put in bold letters in my title 'mixed Asian,' and I put it right in my ad that I'm [ethnicity] and [ethnicity] [laughing]. I always think I should just be honest. [Asha]

Kimi reflects on her advertising as she highlights the intersections of stigma and criminality in sex work. Kimi articulates that by rendering her Indigeneity invisible, she is not only avoiding stigma but is also avoiding being the target of violence and arbitrary law enforcement (discussed further in Chapter 7):

I would not advertise as an Indigenous sex worker. I just advertise as a BBW companion or escort or whatever. And I think it would put me more at risk of being a target by predators posing as clients. And I would be more at risk to be visited by undercover police. And I didn't want to be under more surveillance because I identify as Indigenous. [...] When they see me, they think I'm Italian sometimes, you know, Italian it's not really like scary. [...] But with some clients, like some regular that I really know for a long time they know [...] that I'm Métis.

In the quotation below, Laine points out how advertising messages can also redirect assumptions about sex workers as victims of human trafficking. According to Laine, most of her clients are very apprehensive and are conscious that they do not seek the services from victims of human trafficking. Therefore, Laine notes that her advertising messages, especially given that her visible looks resemble that of Asians, has to signal to potential clients that she is not a victim of human trafficking. According to Laine, the way in which she crafts her advertising message is key to mitigating client apprehension: 
Like, you go right in advertising right, Canadian-born, or raised in. You will see it in advertising it's always like I was born in Hong Kong but raised. And the reason you are saying that is, those are small little flags, cues that you are trying to communicate that I am not trafficked. It's also reflected in my rates for instance or people saying I work independently.

\section{Concluding Remarks}

In this chapter, I have explored my research participants' encounters in the marketplace; namely, their approaches to developing their brand and to advertising and promoting that brand. While the primary objective of their entrepreneurial tasks is to facilitate successful competition within the marketplace and to make the best wage possible, the execution of these entrepreneurial tasks is entangled in a complex web of historical, social, and political ideologies about race, beauty, and sexuality. Thus, the strategies they enact to develop and promote their brand - most often through appropriations of whiteness and/or mobilisations of exoticness - comprise simultaneous actions that are influenced and constrained by the intersections of historical events, social relations, and interpersonal tensions. In this sense, the self-advertising strategies of participants at times depend on the intersection of raced, classed, and gendered markers and at other times reject them, generating an oppositional and alternative position to normative rhetoric. For instance, while tropes of Eurocentric feminine beauty in the marketplace function as cultural and economic currency, tropes of racialised women function to marginalise and devalue what little cultural currency they may have had to begin with.

Under these circumstances, the stories in this chapter show how racialised women resist the devaluation and marginalisation of their sexualities by adapting racialised tropes to work to their advantage. In this regard, participants' efforts to create an oppositional and 
alternative position also brings to light the complex fluidity of their identities as they perform approximations of whiteness and exoticness through materially and physically altering their corporeality. Participants' strategies for creating and promoting a competitive (and perhaps even profitable) brand highlights their role as business-savvy individuals, casting a shadow on popular public images that often depict sex workers as naïve victims who lack the responsibility, agency, and capability to assess and avoid risks.

Developing brands and promoting them are only two kinds of entrepreneurial tasks. Limiting my exploration here to just these two tasks has allowed me to map the multiplicity of the indoor sectors of the sex industry within the mainstream marketplace. Of course, future research that examines other types of entrepreneurial tasks would enhance understandings of this industry's similarities and differences to other mainstream industries in the marketplace. From an intersectional perspective, it is true that some of the market practices within the indoor sectors of the sex industry have the effect of territorialising White sex workers and White clients' experiences and stratifying racialised and Indigenous women's position within the industry. However, intentional practices in the indoor sectors also have the effect of destabilising aspects of normative raced, gendered, and classed practices, preferences, and assumptions in ways that provide racialised and Indigenous women with opportunities for enhancing their social and economic capital. 


\section{Encounters with Law Enforcement}

The relationship between law enforcement and sex work is complex and dynamic (Anderson et al., 2015; Bruckert \& Chabot, 2010; Socias et al., 2015). The two have been described as inseparable and engendered (Dewey \& Kelly, 2011) and as arbitrary and abusive (Almodovar, 2010; Bruckert \& Chabot, 2010; Saunders \& Kirby, 2010-2011). Law enforcement has been interpreted as expressing mere tolerance towards indoor sex work (Sanders \& Soothill, 2011; Scambler, 2007), as an example of public patriarchy (Sanders, 2009), and as an example of social profiling that relies heavily on stereotypes of sex workers (Bruckert \& Hannem, 2013b). In this chapter, I use these and other impressions to map my research participants' encounters with law enforcement in the communities where they live and work.

I have divided participants' stories about interactions with police officers into two major themes, both of which are related to identity management: (1) fluidity and performance of identities, and (2) the fixity of identity categories. In the first part of this chapter, I interpret the ways in which participants take advantage of the multiplicity and fluidity of categories such as race, class, and gender as they strategically interact with law enforcement through their performances of identity. Participants believe that performing the "appropriate" identity component when interacting with police officers has a profound impact on their ability to avoid not only the effects of stigma in relation to race and sex work, but also the negative effects of over-policing and under-protection. These identity components include how they position themselves as racialised, classed, and gendered subjects, as well as how they perform 
sex worker, wise mother, ignorant immigrant, and even vulnerable victim. From an intersectional perspective, racialised and Indigenous women's ability to emphasise the fluidity, exchangeability, and multiple functionality of their identities when interacting with police officers suggest that their embodied relationships to each identity component are not stable and fixed; rather, they can be displaced and/or replaced within certain social interactions.

Managing one's identity when interacting with law enforcement in order to avoid or minimise negative effects is not an easy task for my research participants. Therefore, in the second part of this chapter, I highlight the second theme by focusing on interactions in which participants' race, class, gender, and status as sex workers not only become fixed, but also shape the outcomes they face. In concert with existing literature on marginalised populations' interactions with law enforcement, I highlight participants' anxieties around interacting with police officers and bring to light the ongoing effects of colonialism, racism, classism, and sexism that characterises anti-prostitution policing practices.

It is important to note that, except for one participant in Ottawa who encountered the police after the Protection of Communities and Exploited Persons Act (PCEPA), all of the other participants' interactions with police officers are based on experiences before the law changed. As such, in this chapter, I am not comparing the effects of the old and new laws in Canada. Additionally, as discussed earlier, while all participants were engaged in indoor sectors of the sex industry at the time of interview, some women have engaged in street-based sex work in the past. One participant simultaneously worked in indoor sectors and streetbased sectors of the industry at the time of the interview. These participants' interactions with police officers are also included in this chapter. 


\section{Identity management through performance}

In this section, I describe and analyse the ways in which participants manage their identities through various face-to-face encounters with police officers. In those circumstances, participants set aside their personal feelings and impulsive inclinations and decide which front to put on to best influence the outcomes of their interactions. That is, borrowing from Goffman (1969), I suggest that these participants' actions, expressions, and performances are not only thoughtfully calculated but are also motivated by their long-term interests - they thus refrain from indulging in displays of anger, frustration, and other emotions in order to present a coherent and respectable image when interacting with police officers.

The "actor" in Goffman's dramaturgical model is also called a "player" (Goffman, 1969, p. 109). In face-to-face interactions, the self as a kind of player embodies "willingness to abide by the ground rules of social interaction" by performing face-work that "copes honorably or dishonorably, diplomatically or undiplomatically, with the judgemental contingencies of the situation" (Goffman, 1967, p. 31). According to Goffman (1967), when two or more players "find themselves in a well-structured situation of mutual impingement where each party must make a move and where every possible move carries fateful implication for all of the parties," they then engage in strategic interaction (p. 127). In strategic interactions, players' gamesmanship and their game-worthiness include

$[\ldots]$ the intellectual proclivity to assess all possible courses of action and their consequences, and to do this from the point of view of all the contesting parties; the practice of setting aside all personal feelings and all impulsive inclination in assembling the situation and in following a course of action; the ability to think and act under pressure without becoming either flustered or transparent; the capacity to refrain from indulging in current display of wit and character at the expense of longterm interests; and, of course, the ability and willingness to dissemble about anything, even one's own capacities as a gamesman. (Goffman, 1969, pp. 121-122) 
Extending the idea of strategic interaction and game-worthy attributes to research participants' face-to-face interactions with police officers, I highlight the ways in which they engage in intersectional and strategic performances to minimise negative consequences.

\section{The "wise mother."}

Tianna, a mixed-race single mother who works independently from her home, recalls an incident when she had to seek the services of law enforcement. Although this particular interaction with police officers was not related to Tianna's status as a sex worker, it is evident in her story that her decision to play up the chosen front is informed by the intersection of race and sex work. Like most participants, Tianna is conscious about the criminalisation and stigmatisation attached to sex work and about the complex tensions between marginalised populations and police officers. In this regard, her perceptions of law enforcement are shaped both by her racialised community and her sex worker community (Hubbard, 2004; J. Macdonald, Stokes, Ridgeway, \& Riley, 2007; Oliveira \& Murphy, 2014; Williamson, Baker, Jenkins, \& Cluse-Tolar, 2007).

Tianna tells me that she is a strong woman, and that she can defend herself against violent clients if necessary. Under no circumstances will she seek the services of police if she is harmed, because she believes reaching out to law enforcement as a Black sex worker would result in her arrest and the loss of her children to child protective services. Conversely, when it comes to protecting her children, Tianna's attitude towards police officers is entirely different and noteworthy. On one occasion, she panicked about the whereabouts of her youngest child and called the police:

So I ended up calling the police, told the police to come to my house, they came in the kitchen, I have a wall with the calendar, where the kids are, what 
time pickup, he's like 'if only all the parents in [city name] were like you, we'd have no problems.' So when an officer can tell you this, it gives me a little glimpse into what he has seen. They are not worried about me at all. I'm the one who is actually going to call the police, I'm going to make you work for your money, you know that's why I like to see them come around but, no, I really believe in law enforcement, despite everything that's going on, there are some really good police officers out there, really good caring officers and at the same token there are some bad ones and, hey, the police is the best organised crime out there, right, but at the same time these are the people that we call, so I follow happy medium.

Applying the premise of strategic interaction to this encounter, I suggest that by accentuating her role as a responsible mother, Tianna is communicating information to impress the police officers. From the perspective that the individual is a source of strategic information, Tianna believes that her ability to impress police offices will improve her situation, especially against the backdrop of preconceived notions about racialised single mothers and the tensions between law enforcement and the Black community (see Maynard, 2017; Weitzer \& Tuch, 2004).

Tianna's performance as a self-regulated and responsible person in that particular moment, in addition to impressing the police officers, also has long-term implications. That is, by establishing herself as a wise and responsible mother, police officers are unlikely to suspect her of being a sex worker who is running her business from her home. Furthermore, despite her personal feelings about police officers, Tianna's performance as an articulate and responsible mother perhaps also gained her some respect. Arguably, if the situation were reversed and the police officers responded to a call/complaint related to sex work in her house, then the likelihood of Tianna losing her children would be much higher, regardless of what performance she puts on. Under such circumstances, and given the historical tensions between both sex workers and racialised populations and police officers, which often evident through policing practices such as over policing, under protection of victims, abuse of power 
and other forms of differential treatments (also see Armstrong, 2016; Bruckert \& Hannem, 2013b; Maynard, 2017; Sanders \& Soothill, 2011; Weitzer \& Tuch, 2004), it is more likely that the police officers would profile Tianna as a 'bad mother' (see Smart, 1992). Tianna carrying out 'disorderly conduct' and 'antisocial behaviour' from her home could be read as endangering her children's well-being. Additionally, the classification of 'bad mother' reifies and maintains the preconceived and stigmatised attributes associated with race, sex work, and single motherhood (Bruckert \& Hannem, 2013b).

\section{The "diplomat."}

The second group of people I highlight in this chapter are those who strategically exercise diplomacy in their face-work when interacting with police officers. Drawing on diplomacy literature, Goffman (1969) suggests that diplomats and politicians have sharp gamesman qualities because they have to "represent parties of great importance in situations where minor interaction gains can have great consequences" (p. 122). In this regard, in addition to the game-worthy attributes highlighted above, Gofman notes that the diplomat possesses additional qualities such as absolute command of their temper, patience, an ability to refuse without offending, the skill to conceal their truth without lying, and the intuition to read other people's expressions but not let them discover anything more about themselves ( $\mathrm{p}$. 122-123). As I show in this section, research participants enhance their qualities of diplomacy, particularly their ability to remain calm and carry out calculated behaviours and actions when interacting with police, which results in significant benefits. Shedding light on participants' diplomacy also contradicts the hegemonic assumption that rational people will not choose sex work and that women who do so are incoherent, naïve, and uninformed. Here, I draw upon Saskia's and Lola's encounters with police officers to highlight the various ways 
in which they assemble and disassemble parts of their identities to (re)construct and (re)position their diplomatic state to circumvent negative consequences.

Saskia's ${ }^{32}$ tenure in the sex industry is diverse and includes occasional work in the street-based sector of a downtown area in a large city. According to Saskia, she used to have a drug habit and was known to police as a street-based sex worker and as a drug user, but in her encounters with law enforcement, she never feared arrest, because she has only ever been scolded for being 'out of place' as a drug user (see Cresswell, 1996) and not for her status as a sex worker. Saskia explains:

I have been stopped a lot by cops. Because of my drug problem, usually if you get caught, or if I am out somewhere, 'what you doing here?' I am like 'I'm a hooker' they're like 'oh ok, don't worry about her, 'yeah, 'she got a reason,' you know what I mean. [...] I solicited a cop accidentally one night while I was walking. And he told me that day [...] that [city name] police were not focusing on the workers, they weren't really concerned with us as breaking laws as a whole, that it was the pimps and the johns that they wanted and more specifically they wanted the gay for pays over us. I don't really get hassled. I never ever had a cop like call me up off Backpage and come to my hotel room. I have never had the hotel call the cops on me. [...] I mean I am not really worried about getting arrested, because I know if they do it's going to be more hassle, more money out for them because I will be released on bond and they probably won't even bring up a charge, it wouldn't, it wouldn't fly, you know.

This encounter draws attention to the regulation of space and to the implications of particular types of people being in places they 'do not belong.' It is evident that in Saskia's previous encounters with police officers, they were more concerned about the visual image of the city and the effect her presence, as a drug user, had on the city streets than about her visibility as a sex worker. In other words, even when Saskia was not transgressing any rules of law, her presence in the metropolis upset the supposed naturalness and image of a wealthy city

\footnotetext{
${ }^{32}$ Saskia is a mixed-race woman who successfully performs approximations of Whiteness. I discuss her performances in detail in Chapters 6 and 7.
} 
(Cresswell, 1996, p. 5). Cresswell (1996) argues that expectations about who is an appropriate person and what is an appropriate behaviour in a particular place are important components in the construction, maintenance, and evolution of the social elite's ideological values.

Shifting focus onto Saskia's interaction with law enforcement outlined in the quotation above, I draw attention to her strategic performances to shape the officer's impressions of her. First, in that moment, Saskia's decision to perform as a White, irrational, naïve, drug-using survival sex worker (a popular stereotype that is entrenched in policing practices) perhaps invoked the sympathies of this police officer (see Bruckert \& Hannem, 2013b; Williamson et al., 2007). The police officer's sympathy towards Saskia can also be framed within the invisible privileges of whiteness (Mahoney, 1997; Twine \& Gardener, 2013). Secondly, Saskia's external looks and performance as a "Whitewashed," 33 respectable woman does not disrupt the naturalness of the city's urban politics; it is only her identity as a drug user that is out of place. Therefore, in this interaction, Saskia uses Whitewashed tropes as cultural currency to avoid negative outcomes. In the quotation below, Saskia explains how her external looks do not give away her identity as a drug user:

Externally, look-wise [...] a lot of people look at me and like 'you're not an intravenous user, you have all your fucking teeth' [laughing]. Yes, I do, that's from the White side doing my dental work, you know.

In short, in this interaction, Saskia strategically performs whiteness and tropes of respectability to mitigate her position as a street-based, drug-using sex worker. Considering the possible negative implications of Saskia's intersecting identities, her strategic interaction in this particular encounter highlights her capacity to enhance her qualities of diplomacy in

\footnotetext{
${ }^{33}$ In chapter 6, Saskia explains how she performs "Whitewashed."
} 
her face-work by skillfully concealing information without lying, while also reading the officer's impressions of her without giving away further personal information.

Saskia's strategic interaction with law enforcement is also consistent with Sanders (2004) findings. That is, according to Sanders (2004), "street sex workers do not passively accept" the risks of criminalisation through over-policing (p. 1703). Rather, street-based workers actively and creatively "manage [their] occupational hazards by manipulating, separating, controlling, and [even] resisting urban spaces [...] to minimise harm and maximise profits" (Sanders, 2004, p. 1703).

Like Saskia, Lola expresses confidence in her ability to avoid negative implications when interacting with law enforcement. Lola's explanation below highlights her qualities of diplomacy through her ability to remain clam, patient, and in command of her temper even in extreme circumstances:

[...] so far I have yet to experience the problem, and I don't know if this comes back to our earlier conversation about appearing less threatening, but I have always, always had completely positive interactions with police. I have even been in some situations where I have been in a group, and I could see someone because they are like intoxicated, kind of, about to light a match to a situation. I have completely stepped in and just diffused the situation and I'm the person to do this and the police officer will be like 'I'm so sorry for wasting your time, we are just going to go.'

The following is Lola's reflections on how Black communities experience law enforcement:

My friends of colour, they all have this resentment, rightly so [...] I'm completely against police brutality, it is a problem, we are seeing it ripple throughout America right now and this has been happening forever. It's just getting to the point where we can't ignore it anymore.

Despite her community's experiences with police officers (see Maynard, 2017; Weitzer \& Tuch, 2004), Lola's ability to set aside her personal feelings about Black people's encounters 
with law enforcement, and her absolute command of her emotions, makes her appear "less threatening," disrupting the stereotypical image of the angry Black woman and resulting in different outcomes. Lola is confident that the front she chooses to display when interacting with police officers not only allows her to mitigate the situational problem but also allows her to gain some respect from police officers. Lola sees her capacity to influence police officers' impressions of her, through her performance of classy, passive, non-threatening Black woman, as a skill - she says it is a skill she acquired from the sex industry:

Maybe that comes down to the fact that you know, I'm a little manipulative, I'm kinda charming, I know how to work people, that's the other flip side of me being able to read people and see what they need. I can also know, [pause] what's the word, maneuver them as I need to and I just believe in my confidence too, if situations were to come up, to sell my innocence and to ask the right questions without appearing to be snarky while being incredibly snarky.

In this sense, Lola's approach to interacting with police officers involves intellectually assessing all possible courses of action and their consequences, then choosing an action that involves minor adjustments but yields great results (see Goffman, 1969). Furthermore, Lola's ability to think under pressure without becoming flustered or transparent and performing the contradictory characteristics of both innocence and manipulation is indicative of her gamesmanship. In addition to her demeanour, the confidence she feels in being able to diffuse any troubling situations and gain respect, despite being a Black woman, shows Lola's ability to negotiate the terms of her encounters without changing the markers of her marginalisation (i.e., race and gender). Lola's attitude and actions symbolise resistance to normative scripts of Black sex workers and their presumed power-poor structural position in Western societies.

\section{The "ignorant woman."}

Many participants in this study believe that the image of sex workers as ignorant 
women is popular within the criminal justice system. Sarena explains:

I feel super empowered to be in situation where there are police officers, because I don't feel like I am going to get harassed by them for the most part [...] I think that just given the way that I have had men in position of power relate to me through work, specifically as clients, I think that police who are going to come after you have like this, 'save her' mentality right [participant emphasis]. I think that they would be very patronising in terms of the like you think you are doing a such a good thing, but it's going to come back and bite you, and you are going to get into trouble,' and like, 'if only you knew, you are so young and naïve.' I think they would be very like 'oh sweetie' like 'you think you know [what you are doing], but you don't' [participant emphasis]. But I don't think that in general, they would have an incentive to harm me. But I'm also like articulate, able to stand up for myself, fairly assertive, attractive, and I don't come off as somebody who's marginalised. So I think they'd want to help me and be more compassionate.

Participants who strategically perform the front of the "ignorant woman" further articulate how they take advantage of stereotypical representations of sex workers when interacting with law enforcement to improve their situation. Just as in the marketplace, participants' intentional reliance on racial topes of sex workers is an act of resistance (see Scott, 1990). In this section, I provide examples of both intentional and unintentional performances of the ignorant woman.

Tallah, an independent Black escort, explains an interaction with the police and then with a judge when she reached out to law enforcement about a client who was extorting money from her:

I had a run-in with a client. [...] I started getting calls from somebody who said that he was from a gang and that I should pay protection. [...] I called the cops, they came, and I gave a statement that I was being harassed by someone. The guy [...] got arrested for extortion [...] no charge was brought against me. [...] I went to the hearing because the guy pleaded guilty and the judge spoke to me and says, 'well, you know, if you're working in this industry you're going to [...] encountering bad people. It's a high risk, you know?'

Tallah's social competencies, mannerisms, the way she dresses, where she lives, her 
educational background, and even her status as an high-end escort are markers of cultural capital (Bourdieu, 1987). In this sex worker-police interaction, these symbolic and institutionalised markers offset the stereotypical assumptions of racialised sex workers that police officers often rely upon, resulting in Tallah gaining the trust of the responding officers and taking her complaint seriously.

I interpret Tallah's encounter with the judge as follows: First, I suggest that the class markers that rendered Tallah a credible victim to law enforcement officers also shaped the judge's impression of Tallah as an "ignorant woman." Second, the judge's urge to caution or provide unsolicited advice to Tallah reflects the legal system's deep reliance on stereotypical assumptions that sex workers are ignorant and do not know better (Bruckert \& Hannem, 2013b). Third, borrowing from Sanders (2009) notion of public patriarchy, the presiding judge on this particular case not only held a narrow view of sex workers, but his advice also projects a moral judgement on Tallah's private decisions. In providing such advice, the judge is a public patriarch who is also acting in his official capacity to affirm a benchmark of appropriate sexual citizenship.

Even though Tallah did not intentionally perform the "ignorant woman," other participants in this study use their gamesmanship qualities and deliberately play into assumptions of sex workers as ignorant, uninformed women who do not know better in order to avoid or minimise negative consequences. Kalinda, a mixed-race light skin Indigenous woman who successfully performs approximations of whiteness (see Chapter 6), is one such example.

Kalinda has had several encounters with law enforcement in her capacity as a White- 
passing sex worker. Kalinda tells me that she consciously performs the role of ignorant woman when interacting with police officers to avoid negative consequences:

Like, in my experiences it's very much always been like 'oh do your parents know what you do?' 'what would your parents feel if you told them?' 'do you ever think this will make it hard for you to meet a good man later on?' [...] It's kind of the similar thing [every time]; they give us a lecture on like our futures. I just want to be like 'I'm a dyke' [laughing] 'I don't care'[...]. Ugh! It's the assumptions that bothered me, like the assumption that I'm straight, the assumption that my parents don't know and aren't proud of me, that really got me. [...] Yeah but I find with my co-workers who aren't White there tends to be much more assumption of like their status as victims or as criminals. [...] The questions seem to be about like how they got to Canada, they were trafficked or if they use drugs or whatever else or if they are pimped. [...] Where with me, I'm a bit sassy, I'm in college, so [police officers] tend to assume that I am gonna quit this and have a normal life [...] rarely any kind of an assumption of there being a pimp involved. I think it's a disappointment to them [police officers] every time they come in, and I'm still there [laughing]. [...]. Once I was asked, 'who got you into this?' and I laughed and said Google [laughing].

In other words, Kalinda believes that police officers' protectionism is the result of their impression that she is a naïve White woman who does not know what she is doing. According to Kalinda, the police officers she has encountered believe her decision to participate in the sex industry is uninformed, incoherent, and soon-to-be-regretted, and that therefore, she must be protected.

Kalinda tells me that in all her encounters with police officers, she has never felt threatened and so the outcomes of her interactions have been generally positive (i.e., she has never been arrested, harassed, or dehumanised). However, she emphasised that she is irritated and infuriated by the patronising and narrow-minded officers who often project their heteronormative assumptions onto her during their interactions. Despite such feelings, Kalinda makes an informed decision to play up the front of the ignorant White straight woman just for that moment to meet the officers' expectations. While maintaining the front of 
the ignorant White straight woman reinforces police officers' impressions of her and feeds their protectionist sentiments, it is also the reason she is the frequent target of unsolicited advice by protectionist officers.

It is clear from the quotation below that Kalinda, despite having avoided negative consequences, does not feel safe around police officers and is particularly concerned about maintaining her cover. Her perception of police is shaped by her communities' experiences both her sex worker communities and her Indigenous communities' relation to the sate (also see Carter, 2000; Hunt, 2015/2016; McCalla \& Satzewich, 2002; Razack, 2002). Kalinda explains:

Because [...] you grow up hearing from one side of the family like the police are there to help you, if you are lost go to the police and this and that. And then from my other side of the family, they have not had [chuckles] such a good history with the law. I mean my dad was taken away when he was two months old, his mother was incarcerated at the time of his birth [...] It sucks to be in a position where you suddenly realise that sometimes [...] it doesn't matter how polite you are, dealing with the police is a risk, and it sucks. I'm more afraid that it would get physical like I already have this really weird awareness. It's like, they don't know whether you are alone or whether you have other people, they come in with four guys with guns, no women with them [...] You are very aware that they can do whatever they want, they can hurt you, they can rape you, they can shoot you and probably no one would care. Probably no one will question it. It's like; it's four officers of the law against one hooker or two hookers or three hookers, you know. [...] You just get very aware of the power imbalance, and you just think how much worse it would be. I think it would be a lot more likely to get physical.

As a final example in this section, I draw upon Asha's encounter with law enforcement to highlight the intersections of performing the ignorant woman. Asha, a mixedrace single mother who visibly appears to be Asian, ${ }^{34}$ recalls her multiple encounters with police in her capacity as a sex worker. On each occasion, Asha cycles through her identities -

\footnotetext{
${ }^{34}$ I want to remind readers that, except for one, all of my participants, including Asha, are Canadian Citizens. Asha was born and raised in Canada by parents who immigrated to Canada when they were children.
} 
an indoor sex worker, a racialised sex worker, an immigrant woman, and a vulnerable single mother - to minimise negative outcomes. The first interaction that I highlight is Asha's encounter with two police officers, one male and one female, in a case where the officers were impersonating clients:

When I worked in [city name], I actually had somebody call me to a hotel, and when I got there, there was a man and a woman, and they were police officers, and they just wanted to know if I was being harmed or if I was doing it on my own free will. I was so scared, believe me, my heart was pounding [laughing] [...]. Oh, they were great, they were really nice. I explained to them that I'm independent and that I'm a dancer and I just provide companionship for money, like to help pay my bills and stuff and to take care of my son. They were really nice; they just wanted to know if I was being pimped.

In this particular interaction, just like in Tianna's story above, Asha accentuates her position as a responsible single mother who is doing her best to care for her son. In addition to performing a responsible single mother, in this encounter Asha also plays up the front of the immigrant and capitalises on law enforcements' general tolerance towards high-end, independent indoor escorts who are invisible to the public eye to improve her situation. Despite being caught off guard and feeling very nervous, Asha's capacity to think and act under pressure without becoming flustered highlights her control over the situation and her game-worthiness.

There are several key elements to Asha's performance here. First, Asha's performance of "ignorant woman" highlights her qualities as a "diplomat." That is, she takes advantage of the stereotype of the gentle Asian women by highlighting her non-confrontational demeanour, her hyper-femininity, and her visibly Asian looks to perform the naive and innocent Asian sex worker who is not aware of the risks of sex work. In addition to reinforcing police officers' impressions of her, Asha's performances also invoke their sympathies. Asha's command of 
her emotions and her patience, her ability to conceal information about her understanding of the industry and her intuition to read these officers' impressions of her, resulted in her avoiding any adverse outcome. Second, through her ability to speak fluent English, her body language, and her credentials as an independent escort, Asha further manages to control the impression that the police officers have of her by convincingly conveying the message that she is not a "victim." Third, Asha's ability to read the demeanour and body language of the police officers during this interaction allowed her to use their perceptions of her to her advantage. Asha explained how these particular officers profiled her as a naïve immigrant woman who is uninformed about the dangers of the sex industry:

'Oh my god I can't believe she's doing that' like, do you know what I mean, 'you're better than that' like 'why are you doing this' you know what I mean. That's how police officers talk to you like 'Why are you doing this; you don't need to be doing this. This is so dangerous.' That's how they talk to you.

Because she leaned into these assumptions, Asha's strategic performance of hyper-femininity and naïveté can be interpreted as not only reinforcing police officers' impression of her as an individual, but also as strengthening mainstream assumptions of sex workers more generally.

In the quotation below, Asha explains another encounter where she sought police services to resolve a dispute with clients and instilled trust in them to protect her:

I had an issue where I went to go see a couple, I explained to them on the phone, pay me for two hours and the price is for my time and that's it, and there's no extras, there's no sex, no nothing. [...] right before I was getting ready to leave, the husband wanted something, and I explained that that wasn't included and the wife went crazy and [...] she wanted the money back. I called the police [...] They [police officers] were really great [...]. They were really good, and they were like 'do you want [us] to go talk to them,' and I was like, I just wanted to leave. [The couple] wouldn't let me leave. [...] I just wanted my money and leave and that's what I got [laughing]. If I have to, I will call the police myself, I don't feel scared to call them if I need help, like I'm not scared that I'm going to get charged, if I really need help I'm going to call them. 
This particular encounter sheds light on to two aspects. First, Asha's comfort and trust in reaching out to law enforcement to protect her safety, while perhaps appearing to counter many marginalised peoples' belief that police officers will not protect their safety (see J. Macdonald et al., 2007; Weitzer \& Tuch, 2004), is consistent with Oliveira and Murphy's (2014) findings, which show that middle-class racial minorities view police officers just as favourably as non-minorities. Furthermore, Asha's past positive encounters with law enforcement also shape her ease in reaching out to them when needed (see Bruckert \& Hannem, 2013a). Second, the responding officers' impressions of Asha in this encounter are, arguably, shaped by the police officer's tolerance towards indoor and independent sex workers, and their profile of Asha, which, again, is based on symbolic, objectified, and institutionalised cues and markers of cultural capital (Bourdieu, 1987) that include Asha's style of dress, hair, make-up, body language, mannerisms, and even the house in which Asha provided services.

\section{...And now the others}

Many participants in this study have had vastly different experiences from those recounted above. They have been subjected to insults, humiliation, verbal abuse, false arrest, unlawful detention, and even physical and sexual abuse in their interactions with police officers. In this regard, my research participants' encounters with law enforcement are consistent with those reported by Goldenberg et al. (2015). According to Goldenberg et al. (2015), 17.18\% of migrant sex workers in their study reported experiences of police harassment, $10.4 \%$ reported raids at their workplace, $3.3 \%$ reported police abuse, which included physical assault and coerced sexual favours, and $2.24 \%$ reported arrest on prostitution charges. Notably, $18.40 \%$ migrant sex workers in the study reported a combined 
lifetime exposure to the above-mentioned police interactions (Goldenberg et al., 2015). Such negative encounters first and foremost, as Bruckert and Hannem (2013b) argue, does not meet the law enforcement mandate to "protect and serve the public" (p. 310). Secondly, police officers' harsh, abusive, and even violent behaviours towards sex workers, in addition to contradicting Canadian government's general position that all sex workers are vulnerable victims and they should be protected from their victimisers, also contradicts the RCMPs objective that police officers must work to gain the trust of sex workers so victims in the industry can come forward (see Chapter 2 for further discussion) (Canada. Public Safety, 2012; Ratansi, 2007; RCMP, 2013).

Furthermore, for these women, using the game-worthy attributes of diplomacy and strategic fronting is not an option. These women assert that their visible markers of skin colour, body features at the intersection of race, Indigeneity, and sex working status often results in under-protection, over-policing, and abuse of authority. This is in line with Jiwani (2002), who points out that in addition to minority communities, certain stigmatised groups and groups deemed prone to criminality are systematically both over-policed and underprotected. Bruckert and Hannem (2013a, 2013b) argue that the assumptions regarding sex work are embedded in socio-legal structures and are enforced through institutional policies and practices such as policing, such that sex workers hesitate to seek police protection when they are in trouble.

\section{Can sex workers claim to be victims?}

As discussed in Chapter 2, contemporary prohibitionist and state representations of sex work are framed by the premise that all forms of sex work are inherently violent, and that sex workers' poverty, drug use, childhood trauma, and other hardships lead to their sexual 
exploitation. Ultimately, prohibitionists and the state both take the position that sex workers are inherently victims. However, many of my participants said that they are not believed when they report any kind of victimisation to police. In the remainder of this chapter, I use examples of my participants' interactions with law enforcement to draw attention to the following: First, the law-in-books and the law-in-action often contradict each other (see Pound, 1910). Second, Jiwani (2002) notes that the "emphasis on policing certain groups of people and certain types of crimes is reflective of the social stratification system underpinning Canadian society" (p. 69). Canadian social stratification, as we have seen, infiltrates the sex industry in many ways. Consequently, prohibitionist scholars have fixed racialised and Indigenous women's position in the bottom ranks of the industry (Razack, 1998b), casting them all as less credible, hyper-disposable, and less deserving of protection (see Pratt, 2005). This has an impact on the lives of my research participants. Participants, despite their relative privilege as indoor sex workers, continue to be affected by such totalising and stigmatising rhetoric.

Meili's and Neena's accounts provide a glimpse into the negative implications of the ways racialised and Indigenous sex workers are seen to be less deserving of police protection. Meili reflects on an incident when she reached out to the police to report a case of robbery by a client. According to Meili, even though she had enough information to identify the perpetrator, the responding officers disregarded her complaint, ignored the thief, and instead started questioning her about her involvement in the industry while making her feel like the criminal:

One time, I had a problem. This person robbed me. And I called the police. Yeah, I called the police. When the person left, I called my manager's office. And I said, 'take this person's picture.' And they took the picture right away. 
From the lobby to the front door they had pictures from different angles, enough to see what he looked like. And I called 9-1-1, the police came, and I told them 'I have these pictures.' They didn't go to take. They were printed out. I asked my manager, to print it out. They didn't take [...] Even if [sex work] is my business, you can't say someone won't come and rob me. If a person comes to rob me, he's the criminal, not me.

To similar effect, Neena reflects upon an incident in which she reluctantly reports a brutal sexual assault by a stranger to police:

It was horrible. [...] I was on my way to meet a client, and I was walking, and I got attacked by a stranger. So I was viciously sexually assaulted by the stranger at gunpoint. [...] And then there was that moment of fuck should I, shouldn't I, am I calling the police [...] should I really [...] this is a stranger attack, he could be lurking anywhere, now other women are at risk. So that really put the, like oh, right. So I called the police. A guy came over, looked at how I was dressed - I was on my way to work, right-looked at how I was dressed. Questioned me like I was completely bullshitting or like 'Are you sure that happened?' 'Yes, I'm positive.' I remember even saying 'I didn't even want to call you. And this is one of the reasons I didn't want to call you.' 'WHAT ARE YOU DOING TONIGHT, WHERE ARE YOU GOING, WHY ARE YOU DRESSED LIKE THAT?' [participant emphasis] Oh, it was absolutely horrible. He must have asked me I don't know how many times 'Are you sure that's what you want to say in your statement?' It was a horrible experience. I felt like I had done something wrong, that I had to prove myself to them. And then any follow-up I had about that file it was, you know 'So you're sure you want to stick to what you said.' I couldn't wrap my head around 'cause I'm thinking, what are you trying to get at? Like if it was a client that did that to me that's still no different. So I wasn't even sure. It made no sense to me. I'm trying to think well why, okay, so he's figured it out, I work. But [...] how does that have any bearing on my statement of my horrible attack?

With this incident, Neena felt that her sex worker identity and her race not only informed the impressions of the responding officer, but that they also affected her credibility as a "true" victim of sexual assault. In the quotation below, Neena reflects upon the moment when the officer nullified her experience with sexual assault and trivialised her pain:

He [the police officer] kind of made me feel like there's something else going on. So I don't know if he thought I was a trafficked person, I can't say for sure. But the questions, the kind of things he was asking me and the way he was looking at me and kind of talking to me like I'm dumb, even though I speak 
pretty damn good English, right! I got the impression that he thought I was trying to protect somebody. Whether it be a pimp or [client].

It is not just Neena, but many sexual assault victims are not believed. Gotell (2008) and Randall (2010) discuss how concepts such as risk management or risk avoidance and responsible and/or rational femininity are deployed within the Canadian judicial process to establish and maintain the boundaries of 'good' and 'bad' victimhood in sexual assault cases. Within this legal discourse, the 'ideal victim' is the benchmark for the respectable sexual citizen (Smart, 1985). The idealised sexual citizen actively manages her behaviour to minimise and/or avoid the ever-present risk of sexual violence through her responsible, security-conscious, crime-preventing behaviours and actions (Gotell, 2008). The ideal and valorised/good victim, "characterized by her chastity and sexual morality, [...] is consistent, rational, self-disciplined and blameless" (Gotell, 2002, p. 260).

Gotell (2008) argue that the idealised femininity/womanhood paradoxically establishes "new ways of victim-blaming and also functions as a standard for assessing the credibility of actual complainants. Complainants' behaviours are explicitly measured against the normalised risk-avoiding behaviours of the supposedly 'reasonable woman"” (p.808) (also see Randall, 2010). The ideal victim undermines "the credibility of women who are seen to deviate too far from stereotypical notions of 'authentic' victims and too far from what are assumed to be predictable and 'reasonable' victim responses" (Randall, 2010, p. 398). In this regard, the typical sex worker, who is often classified as sexually immoral and/or careless and irrational for not recognising the risks "inherent" in the sex industry, is not only depicted as failing to behave responsibly and to manage risk effectively, but is also presented as lowerclass, loose, un-credible, and, ultimately, as an unworthy victim (see Jiwani, 2014; Sanders \& Soothill, 2011). 
Jaya sheds further light on how police officers routinely question the credibility of sex workers and deny their victimisation even if and when they have been visibly victimised. Jaya explains that during her interactions with police officers, the violence inflicted upon her was ignored, invalidated, and delegitimised:

I have been arrested, yeah, few times. When I was younger, I was arrested, but that's standing on a street corner being a prostitute. [...] Well, being in public was more risky. I could remember being almost kidnapped once, have a gun held to my head. A client decided to play Russian Roulette with me. And I could remember going to the police after. I was so scared, and instead of them wanting to get a report on what had just happened with a client, they were more concerned about if I had a pimp if my pimp did this to me. They weren't concerned about my safety and my well-being. So it just became frustrating like these people aren't here to understand what just had happened. Just more interested in 'DO YOU HAVE A PIMP?' 'HOW OLD ARE YOU?' [participant emphasis] you know. A crime was committed. So I didn't feel safe, I didn't feel that I belong to society, that I was important as a person, you know! So asking or seeking help is not an option for me.

Of course, the contexts in which Meili, Neena, and Jaya encountered police officers are very different - Meili working indoors in a third party managed massage parlour, Neena assaulted by a stranger, and Jaya victimised by clients while working on the streets. However, the common thread in these stories is that their victimisation was not believed, their status as sex workers became their master status (Hughes, 1945) and was used to blame them for their own victimisation; their experiences of violence, even when horrific, were trivialised or erased. Evidently, the intersectionality of these women's identities creates particular impressions for police officers and subsequent judgements about their experiences. Almodovar (2010) and Williamson et al. (2007) show that when responding to sex workers' complaints of sexual assault, police officers operate under the assumption that no one will believe a sex worker when she claims to be victimised. The normalisation of violence inflicted upon sex workers (regardless of their race) distracts police from conducting 
objective, bias-free investigations to find the perpetrators, as is the case in all of the encounters outlined above.

Furthermore, the normalisation of violence against sex workers affirms shame and stigma, while the accusation of self-inflicted violence increases female sex workers' vulnerability, impairs their human rights, and impedes third parties from responding to such incidents (Lewis et al., 2005; O'Doherty, 2011a; Scambler \& Paoli, 2008). The normalisation of violence against sex workers, which strips them of their victim status, is evident even when participants report coercion within the sex industry. Police officers denying participants their experiences of victimisation contradict law and policy discourse, popular public opinion, and prohibitionist scholarship that claims all sex workers are coerced into sex work and thus must be saved. Studies show that, in light of such discourses, many sex workers are reluctant to report crimes - both sex work-related offences and other crimes that are not related to their job - to law enforcement (Armstrong, 2016; Bruckert \& Hannem, 2013a; Saunders \& Kirby, 2010-2011). These studies identify at least two main reasons: (1) sex workers do not trust law enforcement's willingness to respond to violence perpetrated against sex workers; and (2) sex workers fear that reaching out to police will make a bad situation worse by, for example, criminalising their partners under sex work-related laws, outing sex workers' locations of work, and discrediting, insulting, and/or humiliating sex workers.

In addition to making visible the ways that violence inflicted upon sex workers is normalised, the stories from Meili, Neena, Jaya and other women also bring forth the notion that the victimisation of racialised women is similarly normalised (Jiwani, 2002; MontureAngus \& Conroy, 1995; Razack, 1998a). Razack (1998a) writes that "in a racist society any discussion of culture and violence in immigrant communities can be interpreted by White 
society as 'another sign of backwardness"' (p. 57). In this sense, violence in racialised and Indigenous communities is viewed as a cultural attribute rather than products of, for instance, racism, colonialism, patriarchy, and so on (Jiwani, 2002; Monture-Angus \& Conroy, 1995; Razack, 1998a). Denying research participants' victimisation is justified through normalising and culturalising the violence inflicted on them.

The process of culturally normalising violence among racialised and Indigenous populations then justifies under-protection of these communities by police. In the following account, Shemika, a Black woman, recounts the lengths to which she had to go to get police officers to respond to her complaint. During her tenure in the sex industry, Shemika worked as an online pornography and webcam performer for a third party site. According to Shemika, when she decided she no longer wanted to work for this particular third party, they did not let her quit; when she stopped going to work, her employer started showing up at her apartment to take her to work. Shemika made several complaints to police about her "creepy" employer, all of which were ignored. In order to get law enforcements' attention and protection, she then had to rely on popular conceptions regarding underage sex workers:

I mean, going back to when I was leaving my abusive situation of being held captive, and I was going to the police for it, they didn't want to even hear me. The only reason they did hear me is because I mention that the person may have minors in the house. I am not sure if it was true or not but it was enough to get noticed. When I think about it, if I didn't say that, I don't think they would have helped me. They were thinking that it's not even an issue that they need to check for that I am just a Black girl who's, you know, in trouble and that's it.

This particular interaction highlights several of the themes discussed thus far. Shemika was coherent rather than hysterical when she first reported her problem to police, which perhaps did not meet the predictable and expected "reasonable victim" response, and her ability to 
move in and out of the third party's establishment was perhaps mistaken for a sign of freedom. Given Shemika's race, perhaps her abusive situation was read as part of a normative cultural practice. These two factors, combined with Shamika's status as a sex worker, further diminished her credibility and justified the lack of police protection. Police turning a blind eye in abusive situations such as these leaves female sex workers particularly vulnerable in their places of work (Sherman et al., 2015).

Kumarika's circumstances, described below, further shed light on the unsympathetic and unresponsive practices of police officers in relation to violence that is inflicted upon sex workers. Kumarika, a South Asian woman, also reached out to police when she wanted to leave an abusive situation. In the following quotation, she explains her circumstances when she was forced to engage in repeated sexual activity, under the influence of alcohol, with members of an organised crime group of which she was not a member:

I was taken from my room by a client who was in a little Tamil gang. There were many of them. They had taken me to a hotel room out of the city. [...] They had four rooms, two of the rooms were dope rooms, one was a sleeping room, and the other one was the party room. I was being sexually assaulted; there was no penetration. They stole my phone. I couldn't call the police. I was so fed up. I went to the front reception and tried to get them to call. The police eventually came [...] they are the ones that told me that I was being trafficked. And it was horrendous.

The ordeal Kumarika had to endure in this incident first fits within the Canadian Criminal Code's definition of sexual assault. Second, as the responding officers pointed out, it meets the state's contemporary understandings of trafficking for the purposes of sexual exploitation (see Canada. Public Safety, 2012). However, as Kumarika points out, the responding officers in this case insulted, humiliated, disrespected, and discredited her: 
The way that the detective was interviewing me, he was telling me 'you drink alcohol?' [...] 'was there any penetration?' And I said well no, but I was sexually assaulted, and I know that there's four levels of sexual assault. So are you telling me that you're not going to charge any of the men because that sounds impossible? [...] And he didn't want to answer me. [...] He took down all my information, but then from there, it was like nothing happened with the 30 men in the room. They never done anything with that. [...] And the most humiliating and traumatising and victimising thing they could have done was when they removed me [from the hotel], they took me down the hall where the men were sitting on the floor handcuffed and through the front door. The walk down [the hall], that was so shameful, and I was frightened for my life because one, you don't call the police [on a gang] and I just did. And now I have to walk in front of them as they sit in handcuffs after a night of fuckery. Like, that was impossible.

This encounter draws attention to how police officers in this case normalise Kumarika's experiences of violence as an inherent part of her life style. Kumarika feels that the colour of her skin, the fact that she is a sex worker, her age, her gender, her looks, even her voluntary drinking and association with an organised crime group (all of these meet state's representations of the contemporary victims of sex trade), all worked against the status of the imaginary ideal victim. In addition to ignoring her experiences, she feels the police officers also failed to protect her privacy as a complainant involved in an organised crime case, which resulted in further harm and is in direct contradiction to police officers' mandate to serve and protect the public. Kumarika explains,

When I told [the police officer] that [...] I'm scared, and I don't want to go home, he [police officer] didn't give a shit. [...] They sent me back to my home. My home was broken into; my place was tossed around. I tried to get into a shelter and I couldn't, and then I called the police, and I told them that they were dirty cops and how could they let me go back. And was it because I'm a woman of colour, is it because I'm not young and White with blue eyes? Is it because you're not going to be able to do media attention because I'm not marketable? Is that why you don't want to help me 'cause you think you can't get a conviction? I told you what they were wearing; I told you their scars, their tattoos, the shoes they wore, the jewellery, the phones they had. I told you that I could get you their numbers. You could have had a lot of information from me. Instead, you just sent me home like it didn't matter or that it wasn't serious. 
In addition to feeling revictimised through this interaction, Kumarika, as a woman of colour, felt deeply discriminated. This incident further reinforces her negative perceptions about police officers and her continued mistrust of their ability to protect minority and marginalised people. Kumarika said that she will never again seek the services of police officers.

In the quotation below, Miranda shares her similar view, that she can never reach out to the police in her capacity as a sex worker. As an Indigenous woman, Miranda feels that her engagement in the sex industry will always be seen as careless and risky behaviour, thus diminishing her ability to qualify as a "good" victim even in extreme circumstances.

One, I can never call the police for help, because I will always be seen as committing a crime and they will always question, like 'wow what were you doing?' and that has always been my experience, [...] I remember, once when I went to the police for a sexual assault, they started asking me 'oh well what do you do?' and I'm like well I work at the [club name] and it's known for having association with Hell's Angels, and so they're like 'do you do drugs?' and I'm like yes and they're like 'oh well how're you paying for those drugs?' and I'm like sometimes I get them for free. They're like 'nobody gets drugs for free,' and I'm like well I do [laughing]. So they were trying to equate what happened to me, because of where I worked and because I get free drugs.

On the one hand, in this sex worker-police interaction, the impact of police officers' reliance on the assumption that sex work is inherently violent is clear. Therefore, policing practices are carried out under the premise that it is only normal for women who engage in sex work to experience violence. On the other hand, ignoring sex workers' victimisation within the industry contradicts policy initiatives that aim to save the vulnerable women from the violence that is inherent in the sex industry. Furthermore, in some instances, as in Miranda's case, victims are not only ignored but are also depicted as accomplices to criminal activities by their association with the sex industry, which then justifies police officers stripping away their victim status, even when they have been sexually assaulted. These contradicting 
narratives of "victims" and "offenders," Sanders (2009) argues, is indicative of police officers prioritising their roles as officers of social order where they enforce the 'appropriate' and 'civilised' sexual behaviour (p. 507).

\section{Differential treatment and over-policing.}

In addition to the social stratification system that underpins Canadian society, Jiwani (2002) argues that the differential treatment of racialised groups by various parts of the Criminal Justice System and the overrepresentation of racialised people in carceral institutions are evidence of over-policing. Black participants in this study suggest that they often experience differential and discriminatory policing practices. According to participants Lidia and Kaman, being a Black person is reason enough to attract negative attention from police officers:

Being a person of colour, without them knowing I'm a sex worker, is crazy awful. I've been arrested for nothing. I've received tickets for being mouthy. I was hospitalised because a White person decided that I was going to commit suicide and so the police arrested me and dragged me to the hospital. Which was great because apparently me being rational and having a good conversation and [saying] 'I'm fine' is not valid enough. [Lidia]

It doesn't make me immune because at the end of the day I'm just like everybody else, they see you as another Black person. They will haul you in like everybody else, just like they see every Black boy or every Black man, just another potential suspect for something. [Kaman]

The practice of over-policing Black people is widely supported (K. Johnson, 2004; J.

Macdonald et al., 2007; Weitzer \& Tuch, 2004), such that Black women in the sex industry take precautions to avoid interactions with police officers. The steps they take are informed by two factors: (1) their historical mistrust of police, and (2) fears that they are perceived as irrational, inferior, and lacking in credibility. 
In the following account, Lidia draws attention to the over-policing of minority communities and using their physical and racial characteristics as unalterable signifiers of inferiority (see Jiwani, 2002). According to Lidia, her autonomy as a Black woman and her ability to make rational decisions are frequently questioned. She has also been insulted, verbally abused, and, despite her effort to explain herself, arrested by police officers for being out of place. Lidia feels that the continued negative attention she receives from police officers is the result of her stigmatised position as a sex worker, even though the activities she is most often confronted on are not related to sex work. She explains,

This one was [name of police unit]. When I was arrested they called me awful names. One of them was just like 'You're a little shit.' I'm like 'Oh, my God.' And I wasn't drunk or high or anything. I was completely sober. Not that that would matter, even if I were. But I was completely sober and I was just chilling with one of my friends in [name of neighbourhood] which is a pretty nice area. And, yeah, got arrested. And it was weird.

Comparing Lidia's interaction with Saskia's encounter (discussed above), even though the circumstances are similar in terms of the regulation of space and moving along the undesired, the outcomes are very different. This indicates that visibly racialised members are often subjected to differential treatment by law enforcement officers.

The following participant's encounter with law enforcement further highlights the differential treatment that members of racialised communities are often subjected to. Participant Gladys reflects on the encounters she had with police officers at a time when she became ill while on vacation with her boyfriend. According to Gladys, the responding officers were not only unsympathetic but also insulted and humiliated her. The tone in which police officers spoke to her left her feeling inferior and disposable. Gladys feels that the responding officers in this case entered her hotel room with preconceived suspicions of criminal activity 
and/or sex work-related activities:

I have been in a situation recently where I was in a hotel room, and I became very ill. [...] Need to call the ambulance. We gave the hotel's name, and [...] cops came first. Before [my boyfriend] called, I said: 'straighten up in here.' Because something just [in my gut] told me, this might look this way to them, like a spot stray to them. And they came, and I was in extreme pain. The first thing the cops said 'OH SO WHAT'S GOING ON HERE' [pause] [participant emphasis] you know, [I'm] bent over in pain, and they were snickering to themselves. I was like 'what's the joke.' That approach, that's not the approach of, 'Are you in pain? Can you tell us what's wrong?' No. 'SO WHAT'S GOING ON IN HERE' [participant emphasis] hands in lock, you know. [...] I am reading the whole thing just as I feared. He's the John, I am the worker, and a whole lot is going on here.

Gladys' interpretation of the responding officers' unsympathetic behaviours, on the one hand, can be attributed to her internalised bias against police officers. However, on the flip side, given the mostly positive encounters experienced by White-passing participants in this study, we can reasonably assume that the race of Gladys and her boyfriend had some impact on the responding officers' behaviours. In particular, the unsympathetic reaction to Gladys' pain from the responding officers further gestures to the under-protection of minority communities and to the perception that Black communities are prone to criminality, thus justifying the practice of over-policing stigmatised and marginalised communities. Ultimately, this negative encounter with law enforcement further contributed to Gladys' mistrust in police officers and their ability to serve and protect marginalised populations.

It is important to note that female sex workers in general develop a distrust towards police at an early age, which is often further reinforced by interactions in their personal and professional lives (Sherman et al., 2015). Moreover, sex workers' distrust of police plays a significant role in their decision-making processes, in whether or not to seek the services of police in circumstances that may warrant them (Bruckert \& Hannem, 2013a). At the 
intersection of race and sex work, this distrust of police officers and their services further exasperates the tensions between police and marginalised communities.

Miranda's encounter with law enforcement, included below, points to the tension between police and stigmatised and marginalised communities. In Miranda's case, a neighbour called the police when they saw a Black man carrying a White woman out of a cab. She explains,

I don't know what happened, but the doctors were thinking that my drink must have been drugged. My friend is with me, and he brought me home [from the bar], he's Black. I can't walk, so when I got out of the cab, he's dragging me down the stairs. My neighbour calls the police on him, 'cause [my neighbour] thinks that he's trying to rape me [laughing] [...] Five cars show up to my place. I woke up in a hospital [next day] and like what the fuck happened? [...] [my friend] told me [...] when they stepped into my apartment, they were looking for drugs. They weren't caring about me. They went through my phone and stuff. I'm like 'where's my fucking phone,' like, what a huge violation of my rights. I felt more violated by what the [police] did, you know. I could never be typed as the victim in their eyes, even though the law sees me as a victim, I would always be the offender.

In this incident, without a doubt, five police cars responded to this case because of a report that a crime was in progress and the perpetrator was identified as a Black man, is an example of over policing. Secondly, as I pointed out above, Miranda is known to police as a sex worker and has been subjected to differential treatment before. Thus, the responding police officer's search of Miranda's apartment, without reason, warrant, or her permission, and while she was in need of medical attention, is another example of over-policing stigmatised communities. Overall, this case draws attention to the preconceived assumptions and harsher policing practices that marginalised and stigmatised communities are often subjected to through Canadian policing practices. 


\section{Abuses of power.}

In addition to reporting instances of under-protection and over-policing, participants in this study also said that they have encountered instances where law enforcement officers assert their authority far beyond their legal mandate. The prevalence of police officers' abuse of power through unusually harsh and punitive behaviours towards sex workers are welldocumented (Almodovar, 2010; Armstrong, 2016; Hubbard \& Sanders, 2003; Rhodes, Simic, Baros, Platt, \& Zikic, 2008; Saunders \& Kirby, 2010-2011; Williamson et al., 2007). Socias et al. (2015) argue that sex workers in public spaces are at increased risk of confrontation with law enforcement officers. Almodovar (2010) and Rhodes et al. (2008) note that police perpetrators find sex workers easy targets for the same reason serial killers do, and sex workers being raped or extorted for sexual favours by police officers happens far too often (Almodovar, 2010). According to Almodovar (2010), "criminalisation of sex work ensures that the only real 'choice' street sex workers have is the option whether or not to cooperate with the cops, give cops sex for protection, become an informant or go to jail” (p. 251-252). Weitzer and Tuch (2004) argue that "race remains a key factor in structuring attitudes towards police misconduct," (p. 305) such that Blacks and Hispanics are more likely to report police misconduct. Participants stories that I feature in this section highlight police abuse of power at the intersection of race and sex work.

The following sex worker-police interaction draws attention to the complex layers of police officers' abuse of power towards sex workers of colour. Pearlina, a Black woman who started working in the industry $17-18$ years ago, when she was in her 30 s, recounts a time when she was arrested while she was working at a massage parlour and was held for questioning for several hours: 
They came into our parlour and there was two of us there, and my best friend and me and they arrested us. There was probably fifteen cops that walked in. Half of them are from drug squad, I'm sure. That was maybe three years ago. I'm sure that someone said that the owner was funnelling drugs or something. I was like, wow, really? Like, handcuffing us, all these guns were drawn. It's like, what the hell were you expecting to find in here?

As Pearlina points out, fifteen police officers from the drug squad with heavy weapons raiding a massage parlour, based in part on faulty information and a presumption that the sex industry is inherently associated with the illicit drug trade, is a classic example of over-policing. Furthermore, according to Pearlina, arresting the women that day and holding them for over six hours before they were released was intentional - a scare tactic to induce fear among these sex workers. Such scare tactics contradict institutional policy objectives of gaining the trust of sex workers and treating them as vulnerable, traumatised victims.

In the following account, Arora reflects on a time when she experienced abuse of power when a plain-clothed officer reached out to her under the pretence of a client seeking her services. Arora's account establishes the coercive and punitive practices of this particular police-sex worker interaction:

He came in and then he said he didn't want to do the call, but [...] he was trying to get me to run for weed for him, and I'm like it's freaking two in the morning. [...] I'm not going to score for somebody. The next week he called me on Saturday [...] I knew exactly who it was when he texted and I was really sick that day and I was like dude leave me alone and he's like 'what, I never even talked to you before, ' I'm like you were here last week, and I had to ask you to leave, and he was like 'no actually I left because you're fucking fat and ugly.' He's probably try to goad me into saying 'oh if I'm so fat and ugly how come I make fucking 5,000 a week' blah blah blah, trying to get me to shoot my mouth off. I'm like ok, have a good day. I know exactly what your plan is, I don't want you playing out here, I'm not a fucking idiot.

As discussed before, a few women in this study used to work on the streets before working in the indoor sectors of the sex industry. Drawing attention to research participants' time working on the street highlights the multiplicity and fluidity of women's experiences 
within the sex industry (see also discussion in Chapter 5). Furthermore, the encounters these street-based workers have had with police officers who abuse their power illuminate how law enforcement perpetuates the idea of street-based sex workers as social and economic outcasts and as public nuisance/annoyance, thus justifying the arbitrary and discriminatory law enforcement practices they face (see Bruckert \& Chabot, 2010; Lowman, 2000; Socias et al., 2015). The few women in this study who fall into this category report that they have not had the opportunity to tell their stories of over-policing and abuses of power before.

Usha recounts an experience of interacting with police officers in her capacity as a street-based sex worker and highlights an abuse of power that is not only unlawful but clearly exceeds the serve and protect mandate:

I got arrested. It was one of my first few nights outside, on [street name]. Two individuals came for a job, and they started talking [...] They were very charismatic. They wanted to know if I had a friend that would go. So I called my friend who was on the other half of the block. I called her, said, 'I've got a date, and I'm going to come pick you up, and we'll go to the motel.' So, stupid $m e, I$ get in the car and then this really official voice says, 'YOU'RE UNDER ARREST' [participant emphasis]. [...] They started to drive and they drove, passed the person that they were supposed to get. And then I remember the faces on the girls who were standing by her because they all knew these were the cops of the stroll. I didn't know. And you're not supposed to go in a car with two guys anyway; I was like a fucking idiot. [...] They asked me where I would've taken them. I had to show them [name of motel]. [...] Basically, they were parading me in front of all of the people outside. So they drove all around stroll and then all the way up to [name of motel]. So, everybody knew I got busted that night. [...] I remember sitting in the back of that car going - my life can go either really good or really bad out of this, you just never know what's going to happen. But they didn't actually put me in jail, they just charged me and gave me this paper to show up. But it could've gone worse. They could've - I'm sure they could've picked me up and threw me in jail for whatever reason. But because I was so compliant, I guess, they didn't. And they found me entertaining.

Clearly exposing Usha's arrest and parading her all around the stroll is far beyond the legal mandate of criminal arrest procedures. Furthermore, as Usha elaborates below, her arrest did 
not meet the parameters of the anti-prostitution law that defines the criminality of solicitation.

In this regard, as Usha speculates, arresting the newbie and parading her around the stroll, in

many ways, suggests that this encounter is a self-serving operation for the police officers to

assert their authority and send a message to the rest of the sex workers on that stroll. Usha

continues,

Well, just the conversation we were having in the car, right. It was an intelligent conversation; I wasn't strung out. You know what I mean? I explained to them what I was doing and then how I didn't solicit you, and we're having this debate whether we solicited, and I'm like, 'Well, I didn't associate price and services.' And then he's like, 'Yeah, I'll see you in court.' But they thought it was funny that I was using such big words, I guess. There's stereotypical stories, right? And then, I didn't drink; I didn't do drugs, I don't think I smoked at the time. I was not what they were expecting. I'm not sure if it was - maybe race indirectly. [...] It may very well have been like saying to the others, 'Maybe we can get you.' Or something. I don't know. But I thought it was about humiliating me, but then later I thought no, it was more about sending that message that, 'We got one.'

Kimi, a Métis woman who currently works as an independent in-call and out-call

service provider, used to work on the streets and consume drugs. Kimi recounts her experience interacting with police officers while she was on the street. This encounter evidences the disrespect and abuse Indigenous sex workers often experience:

I only had experience with the police when I was living and working on the street. Oh, they didn't treat me well the last time they arrest me. When I arrive in the provincial woman jail close to [name of city]. They asked me if I want to put a charge against my boyfriend and I was like actually, I don't have any boyfriend, but I just got arrested by your friend there, and they just did that to me. [...]. They were very aggressive and violent [manhandled me], they broke my glasses, and I had like some blood and some sand in my mouth because they push me on the ground and they had their feet on me. Actually, it's really, it was an aggression and assault. It was pretty brutal [...] No, they didn't treat me well when I was on the street. As soon as they knew me and I was always visible in the street they were harassing me [...] They broke all my material for smoking crack. It was a just disaster and un-fun time of my life dealing with them.

Kimi believes that her interactions with these particular police were so aggressive and abusive 
because she was a drug-using street-based sex worker (see Armstrong, 2016). Kimi

elaborates:

I think it was because I was a sex worker and a drug user [...] I can easily pass as a White woman and I pass as a White person all the time, so I think it was because I was a sex worker and living on the street and using drugs and visible in public space. They hate me for that.

Here again I draw parallels between Saskia's and Kimi's experiences to highlight the arbitrary enforcement of laws and regulation, including sex work-related laws. That is, both women have had experience working on the streets, both were drug users, and both pass as White, yet the outcomes they experienced when interacting with police are very different. The difference in these encounters can be attributed to the different policing practices in different cities, which further indicates the incoherence of federal laws that take a pan-sex industry approach to regulating sex work-related matters.

The final example in this section further articulates the physical, emotional, and psychological harm street-based sex workers face when interacting with police officers. Carina is a mixed-race, White-passing trans woman who has been working in the sex industry for a long time. While she currently provides services to regulars (i.e., a set of clientele she has known for a long time and who seek her services frequently) in indoor settings, she used to stroll the streets of a metropolitan area before the internet era. Carina reflects on her encounters of arbitrary and discriminatory abuses of power with police officers during her time working the streets:

And also with the police, from running [name of establishment], we became targets for the police who charged me with operating a common bawdy house, and I said, 'Look, there's nothing common about us.' Yes, certainly when I was younger. At one point, during the 70s, they were entrapping us. [...] They would entrap us and then charge us. So, there was an incident once when I was very young; I think I was 16 or 17. I was walking home one night - I had just 
been out with some friends, and a police car came along and started bothering me, asking me for ID, told me to get in the car - there was a police dog in the back. And the next thing I know, I'm down in [name of location] with this police officer, who I know carries a gun, and a barking police dog, and I'm forced to perform oral sex [pause] yeah, at three in the morning, in [name of location], which is a very deserted place at that time.

Sanders (2009) notion of public patriarchy can be applied here to Carina's sexual assault by a police officer. That is, the gendered and sexual dimension of control enforced by punitive policing practices are aimed at enforcing "appropriate" conduct among those considered to be sexually "disordered" and "uncivil" (Sanders, 2009, p. 507). Carina's position as a trans sex worker subjects her to multiple oppressions and increased risk of police targeting. In this instance, structural stigma (Bruckert \& Hannem, 2013b) and institutional and social transphobia (Socias et al., 2015) shape punitive practices by police, which include disproportional targeting, arbitrary arrest, and being subjected to physical and sexual violence.

\section{Concluding Remarks}

In this chapter, I have highlighted research participants' encounters with police officers as they manage their identities by performing respectability, vulnerability, empowerment, and even exploitation. The lived realities of my participants draw attention to the experiential element of identities - in particular the relationality of fixed and fluid racial classifications (Hekman, 1999). In this regard, research participants' performances when interacting with police officers both conform to and resist normative discourses that fix participants' role in the sex industry. Such performances are carefully thought out and designed to fit certain circumstances, to influence the impressions of police officers, and, ultimately, to avoid negative consequences. In this way, my participants' behaviours and actions when encountering law enforcement can be framed as an opposition and resistance to universal claims of truth. 
Additionally, we also see how some women are not able to subvert power relations during their encounters with police officers. Here we see how socially constructed race-, class-, gender-based normative assumptions and discourses have a strong hold and shape policing practices on the ground. Law enforcement's reliance on normative narratives at the intersection of sex work prevents some participants from escaping systemic criminalisation and stigmatisation. As a result, even when participants' victimhood is consistent with hegemonic policy discourse and public opinion, their intersections of race, gender, and sex work denies them the legal classification of victim and the emotional responses they deserve. To this end, it is clear that the law and policy approach to sex work and race issues on the ground are contradictory at best. 


\section{Barriers and Alternate Priorities to Engaging in Activism}

In this final chapter, I focus on participants' motives for and constraints to engaging with sex workers' rights organisations (SWROs) and, by extension, the Sex Workers' Rights Movement (SWRM) more generally. My participants' decisions to engage with or avoid sex work activism partly depends on how they perceive and relate to the SWRM and partly on their decisions around stigma management and other structural obstacles. These factors not only inform participants' decisions to engage with or avoid activism, but they also shape their general perceptions of the SWRM and sex worker activism. These perceptions are dynamic and can be located on a spectrum from standing in complete solidarity with the SWRM and active engagement with related activism to having no engagement with the movement and/or the outright rejection of the central tenets of the movement.

The stories I highlight in this chapter bring to the fore participants' interpretations of the SWRM's values, interests, and political purpose and how they negotiate structural, political, and representational intersectionality (see Crenshaw, 1991). Exploring this process provides a broader understanding of issues that participants have to grapple with in order to choose their level of engagement with activism. To contextualise the experiences of participants in this chapter, I start with a brief overview of the Canadian SWRM and the various strategies SWRM activists have used over the years to advocate for the collective rights of sex workers. This overview is followed by a discussion of four categories of participant alignment with advocacy I found in my research: active solidarity, silent participation, focusing on alternate priorities, and resistance to the SWRM. It is noteworthy 
that research participants' perceptions, constraints, and priorities are rather fluid and may fit in more than one cluster simultaneously or may alternate between clusters at different times and in different circumstances.

\section{The Canadian SWRM ${ }^{35}$}

The Canadian SWRM, like most twenty-first-century social movements, consists of multiple social and political agendas (see Johnston, 2014). One of the agendas of the SWRM is to decriminalise sex work by influencing law and policy reform at various levels of government - municipal, provincial, and federal. The SWRM's strategies to organise and mobilise on behalf of the community of sex workers ${ }^{36}$ are not static; rather, they are complex and fluid processes that evolve over time and which vary according to historical, cultural, social, and political contexts (see Polletta, 1999; Polletta \& Jasper, 2001; Tarrow, 2011; Taylor, 2013; Taylor \& Whittier, 1992; Tilly, 2004, 2008).

Despite various challenges to collective mobilisation (Chateauvert, 2013) and despite being known as a failed movement (Weitzer, 1991) sex workers have been fighting against social injustices for a very long time. Carol Leigh, a renowned activist and member of COYOTE, ${ }^{37}$ in the early 70 's coined the term "sex work," with the intention of establishing a collective that is inclusive of all genders and occupations within the industry (Beer, 2010; Bernstein, 2007b; Chateauvert, 2013). Since then, the SWRM in North America and many

\footnotetext{
${ }^{35}$ This is not a comprehensive overview of the SWRM. Rather, the information featured in this section is that which is deemed to be most relevant to the findings presented in this chapter.

${ }^{36}$ I am using the term community of sex workers to refer to the discursive community. Taylor (2013) defines "discursive community" as a community "held not only by common action and bonds of solidarity but also by identities, symbols, shared identity discourse, and practices of everyday life that attribute participants' experiences to particular forms of social injustice" (p. 43).

${ }^{37}$ Founded in 1973 in San Francisco, COYOTE is arguably the best-known, most visible, and most historically significant sex workers' rights organisation in North America. http://www.coyotela.org/what_is.html
} 
other parts of the world has embraced the term and fought for recognition of sex work as work. As sex work scholars point out, part of the SWRM's collective actions since the late 1970s have been grounded in legal campaigns to legitimise the position of sex workers and to decriminalise sexual activity between consenting adults (Beer, 2010; Brock, 1998; Jenness, 1993; Weitzer, 1991).

Over the past two decades, Canadian SWROs have organised and mobilised around key issues to raise public awareness about the injustices faced by Canadian sex workers. Many of these coordinated actions, in addition to being political and revolutionary, have also been strategically crafted to suit the current political climate. For example, in the early 1980s, the Alliance for the Safety of Prostitution (ASP), an organisation run by sex workers and allies to mobilise against violence, identified sex workers as victims of solicitation laws, violence, and bad clients (see Arthur, Davis, \& Shannon, 2013; NSWP, 2014). In the 1980s and 1990s, various drop-in centres across the country drew on the images of vulnerable streetbased sex workers and their housing insecurities to procure resources such as places to shower, eat, rest, and spend time (see Arthur et al., 2013; Cargo \& Clamen, 2013; G. MacDonald, Jeffrey, Martin, \& Ross, 2013). The organisation Stella (Montreal) strategically crafted political actions to raise awareness about injustices faced by sex workers in the '90s, which included distributing pamphlets during the city's largest outdoor Jazz Festival; undertaking masked protests in front of City Hall, occupying the front steps and placing red garlands and lanterns over its entryway; and presenting a human-sized cake with a stripper inside to the Quebec labour minister (Clamen, Gillies, \& Salah, 2013).

More recently, efforts to raise awareness about issues surrounding the safety and security of sex workers and to support the constitutional challenge brought forth in the case of 
Canada (Attorney General) v. Bedford (2013), sex workers and their allies held rallies outside of the steps of the Supreme Court of Canada, holding up red umbrellas, banners, and signs (POWER, 2013). Similarly, during the time when Bill C-36 (now the PCEPA) was before parliament, rallies were held outside of the Canadian Parliament building to show dissent and raise awareness about the harms of the proposed laws (POWER, 2014).

These kinds of publicly coordinated performances of political action, organised by various SWROs on behalf of the SWRM and the community of sex workers, signals the coming-together of different groups of people to express their shared grievances and collective purpose: the decriminalisation of sex work and the protection of sex workers' rights. The coordinated collective political actions that I feature in this chapter highlight the symbolic coherence of these actions, achieved by repeating a few familiar performances (see Tilly, 2008). The symbolic coherence of collective political action in the public helps to bring together different events for the same cause (see Tilly, 2008).

\section{Criticisms of the Canadian SWRM.}

The SWRM has faced many criticisms, particularly from prohibitionist groups. These groups, who believe that sex work is not a real choice but instead view women's participation in the sex industry as a result of personal, economic, and political conditions, often criticise the SWRM for promoting the idea of the "happy hooker" (Farley et al., 2004; O'ConnellDavidson, 1998). One prominent criticism is that sex worker activists are predominantly White, advocating from their privileged positions, and are therefore atypical of the majority of women that perform sexual labour (Farley et al., 2004; O'Connell-Davidson, 1998). Such critiques, advanced by prohibitionists, appear to have some merit. The members of COYOTE, for instance, are predominantly White, economically privileged, indoor sex workers who are 
well-educated and earn enough money to not only cover business expenses such as renting/owning workspaces and placing online ads but also to help finance alternative artistic and intellectual careers (Bernstein, 2007b). Furthermore, Panichelli, Wahab, Saunders, and Capous-Desyllas (2015) point out that "much of what has been recognised as sex worker rights organising in the USA has been geared towards the needs, priorities and perspectives of mostly White women" (p. 235).

Similar criticisms can be extended to the SWRM in Canada, even though there is a handful of SWROs for and by racialised and/or Indigenous sex workers (e.g., Butterfly, SWAN, SWAVE). A brief overview of the history of sex worker activism in Toronto indicates that predominantly White people have been the founders of and key players in most by-and-for sex worker organisations (see "A Brief History Of Sex Worker Activism in Toronto," 1997). SWROs in Vancouver, Montreal, and Halifax also appear to have been largely founded by, and are predominantly operated by, White activists (see Arthur et al., 2013; Cargo \& Clamen, 2013; G. MacDonald et al., 2013). Ferris (2015) notes that even though the Canadian SWRM fights against the higher prevalence of Indigenous women's marginalisation, criminalisation, and victimisation within the street-based sex industry, "sex work activism in Canada remains primarily a White enterprise" (p. 136). Participants of this study certainly feel that White women are overrepresented in major leadership roles within most Canadian SWROs that are run by sex workers (I return to this issue later in the chapter). The perception of White overrepresentation within the SWRM, coupled with repertoires of sex work activism, shape participants' perceptions of the SWRM and their personal engagements with sex work activism. 


\section{Participants' Perceptions of the Canadian SWRM}

For the purpose of this study, I organise my participants' perceptions into four interrelated clusters. The first cluster, at one end of the spectrum, has strong ties to the SWRM and expresses a sense of belonging to the community and movement in dynamic ways. The second cluster consists of participants who share the collective awareness that sex workers as a group are not only perceived as illegitimate but also hold a stigmatised and marginalised position in society. Despite acknowledging the political relevancy of the SWRM to advocate on behalf of all sex workers, participants in cluster two make conscious decisions to not publicly express their solidarity or engage in sex work-related public activities. Instead, these participants tend to engage in micro-mobilisations or in everyday resistance through interpersonal and social interactions to raise awareness and produce knowledge about sex workers within their communities of colour.

Participants in the third cluster experience a multitude of structural constrains. These race-, class-, and space-based constraints interfere with participants' abilities to develop social cohesion with the sex worker community, which informs and shapes their perceptions in turn. The fourth and final cluster, at the other end of the spectrum, is made up of participants who outright reject the political relevancy of the SWRM. Given the criminalised and stigmatised nature of sex work, participants in this cluster are convinced that publicly engaging in sex work activism not only exposes their identities but also puts them at risk, and therefore they believe it is best to avoid such activities at any cost. In the remainder of this chapter, I unpack my participants' stories within these clusters to help elucidate understandings of participants' perceptions of the SWRM and sex work activism more broadly. 


\section{Cluster one: Active solidarity with the SWRM.}

Participants in this cluster generally have a strong sense of belonging with the sex worker community, and they believe in the political relevancy of the SWRM - not only to raise awareness of the unjust and marginalised position of sex workers in society, but also to resist on behalf of all sex workers (see Morris, 1992; Sutton, 2010; Taylor \& Whittier, 1992). Furthermore, women in this cluster strongly believe that maintaining a collective consciousness and building solidarity with the SWRM plays a significant role in establishing the credibility and integrity of the movement. These participants believe that establishing strong ties with the broader community, category, and practices of sex work is important to convince policy makers that the oppression and discrimination sex workers face is systemic, structural, and institutional (see Young, 1990). Participants' expressions of their collective consciousness and solidarity with the SWRM varies and is dependent on a multitude of factors.

\section{Collective identity of "sex worker."}

Some participants in this cluster take the approach of adopting the collective identity of "sex worker" to express their solidarity with the SWRM and to enhance their sense of belonging to the community of sex workers. For the purpose of this study, I read this process as developing a political consciousness that shapes their perception, locating them within the group/community of sex workers that unjustly holds an illegitimised and marginalised position in society (see Morris, 1992; Taylor \& Whittier, 1992). Adopting a collective identity and developing a collective consciousness is an integral part of any social movement (see Polletta \& Jasper, 2001). Collective consciousness is an important element of political action as it brings sometimes-vastly different people together for a common political purpose (see 
Tarrow, 2011). Furthermore, most participants in this cluster have built their personal identities through inter-subjective relations and their involvement in political action, such that their political activism becomes a venue from which to express their personal identities, including their identities as "sex workers" (see Farro \& Lustiger-Thaler, 2014). The following quotations exemplify participants' dynamic ways of expressing their sex worker identities:

I identify myself as a queer woman of colour, South-Asian, as a sex worker, as an activist. [Kameli]

In my everyday life for many years, [and] I still identify as a former sex worker, former South-Asian sex worker, activist, advocate. [Priya]

Oh, I identify as a sex worker, my god of course [laughing] that's a big one [laughing]. [Rose]

The way I represent myself on my website and to [my] clients tends to be in line with my politics. And my politics consist of recognising, you know, all my identities as fluid. [...] I think without acknowledging my multiple identities, I feel like I would just be lost. [Angela]

\section{Active engagement with the SWRM.}

Some participants in this cluster express their solidarity with the SWRM by actively engaging in various political actions and events on behalf of all sex workers, especially racialised and Indigenous sex workers. ${ }^{38}$ These participants may or may not be directly involved with any SWRO. However, they use their bodies in coordinated public actions, such as street marches and protests. Such solidarity from these participants affect the course of sex workers' communities, shape the social, cultural, and political landscape, and embody the political consciousness of the movement (see Sutton, 2010). Given that not many racialised and Indigenous sex workers actively engage with SWROs or the SWRM, some participants in

\footnotetext{
${ }^{38}$ It is important to note that very few racialised and Indigenous sex workers engage in political activism and therefore, in order to protect the privacy of my research participants, I will withhold revealing aspects of their political life. I have also changed the pseudonyms for participants in this chapter in an attempt to further protect their confidentiality.
} 
this cluster feel a strong sense of obligation and responsibility to be part of the political action to raise awareness about the experiences of racialised and Indigenous sex workers. These participants strongly believe that failure to do so will result in far greater consequences that will continue to affect the dignity and respect of all racialised and Indigenous sex workers. Reka and Vicky share their views:

I have been put in this place so many times, becoming the one voice that represent every single migrant woman, [...], because I am the only non-White person [...] It becomes very hard, but I always have to remember that it is also a privilege for me to be there, because those women are not able to be there. So I then take on responsibility [...] to explain what this means to us. [Reka]

I'm very outspoken in sex work activism, [...] [many] sex workers don't have my privilege [...]. So it's almost like a heavy burden, it's a lot. [Vicky]

Although participants in this group initially decided to actively engage with SWROs on the basis of representational need, they express a heightened sense of obligation and responsibility that gives way to ambivalent feelings about their roles as sex work activists.

Reka reflects on the overwhelming time commitment involved in her volunteer position:

Incredible hours. This December I was working 70 hours a week on activism work. Which is why I burnt out and I had to go away at Christmas. [...] The day I was on a flight away, I was doing a press conference at [name of location], so that was my morning [laughing] and then I had two interviews and then I took a flight out [...] Yes. It overwhelms me because it's hard work and [...] because there is no one else currently who is doing the work and doing it to the extent that I'm doing. [...] I want to do this work because it's needed. [...] But it's hard work; it is work that sometimes you have to go home and cry about.

Below, Reka notes that at times she feels her volunteer work with the local SWRO is akin to exploitation and even coercion:

First of all, I wanna talk about coercion and exploitation and victimisation, putting people in a situation where they have to do work they don't necessarily want to do. I want to do this work because it's needed, but it's very coercive. I will leave that there. 
Reka's ambiguous feelings are noteworthy, as it may shed light into how sex workers of color may experience activism as an overwhelming burden and an inescapable responsibility.

Vicky, an Indigenous sex worker activist, also speaks about the emotional toll of being one of very few Indigenous women who publicly advocates for sex workers' rights, and she struggles to balance the limits of her ability to speak on behalf of all Indigenous sex workers. Vicky's words highlight another dimension of the tension in this representational logic:

It does create a lot of stress [...] lot of people are [interested] because I am not that stereotype sex worker [...] I try not to speak for other women or speak about other experiences, because like I don't have experience working on the street and I have very different experiences.

As Vicky notes, the relative privilege that she enjoys as an indoor sex worker (e.g., lucrative income, safety, flexibility, independence) means that her experience as an indoor sex worker cannot be generalised to represent the experiences of all Indigenous sex workers.

Like Reka and Vicky, other participants in this group also grapple with these tensions in their roles as sex worker activists. Given that the essentialist and normalising representations of racialised and Indigenous sex workers in popular culture causes further hesitation in racialised and Indigenous sex worker activists, raising awareness about this multiply marginalised population can become yet another source of intersectional disempowerment (see Crenshaw, 1991). In the remainder of this section, I discuss how intersectionality informs my participants' engagement or lack of engagement in sex work activism.

While some participants in this cluster may experience internalised stigma, participants also discuss the effects of stigma from external projections of stereotypical assumptions. Although non-racialised sex workers and sex worker allies pay a huge price for 
advocating publicly on behalf of sex workers, participants in this cluster shed light on the intersections of race-based politics and sex work-based politics that they confront in their roles as activists. According to participants, the stigma attached to them at the intersection of racialisation and sex work is often used to undermine their credibility when making claims on behalf of all sex workers. For example, in the following quotation, Vicky suggests that prohibitionists use her sex worker status to discredit her:

the attacks against us are heightened. Yes, White sex workers get attacked, you know verbally too, but for us, it's like that much more [...] we do get heightened attacks against us.

On the other hand, to avoid the stigma attached to racialisation and sex work, participants who hide their sex worker status are also silenced on the premise that they do not have the experiential knowledge to advocate for sex workers' rights. Petra, for example, held a leadership position in one of the SWROs in a large metropolitan area. In the following quotation, she recalls her various interactions with members of society:

All kinds of things would happen. I was silenced one too many times in a meeting because I didn't have 'credentials.' [...] I didn't play the victim card, I never have. I don't personally disclose, so I [...] never gain credibility [...] I think that it was easier to try and make me feel other because I was Black. [...] And then there were ways in which policymakers and law enforcement, social workers, would treat me [...] I would say something, and somebody else would say the exact same thing, and they would endorse the other [White] person who said it [...] But yeah, these things would happen, like work men would come in [...] and hand the invoice to my employee instead of to me [...]. They would assume that the White woman at the table [held a higher rank] not me.

In addition to being ignored because of her assumed lack of experiential knowledge and for being a Black woman, Petra also points out that she has too often had to confront the popular unyielding cultural representations of women of colour:

I remember when I earned that position [name of organisation]; there were people who still thought I got the job because I was Black. [...] I also take on 
this sort of angry, unapproachable Black woman stereotype [...]. But really, I was passionate about the issues, and I would hold people accountable for their use of resources and lack of response in investment and sex work issues.

Suppressing or misconstruing Petra's emotions echoes the historical tendency of Western thought to subordinate emotions, a process that was/is "instrumental in justifying the subordination of women, non-European peoples and other voices, whose political voice were strategically defined as dominated by emotion and hence invalid" (Barvosa, 2008, p. 63). Furthermore, participants in this group's encounters with popular cultural representations that classify racialised and Indigenous people as inferior and unintelligible speak to the continued patterns of White supremacy (see Mahoney, 1997). This profoundly hinders the ability of participants to effectively engage in sex work activism.

Although it rarely occurs, the popular cultural assumptions about racialised women's involvement in the sex industry have the potential to influence assumptions and behaviours within sex worker communities as well. In the following quotation, Petra recalls an incident when sex workers who were seeking the services and resources from the organisation she worked at would not trust her because she is Black. According to Petra, because of her race, she is often reduced to stereotypical tropes of Black people rather than being seen as a qualified person who earned a specific job:

Some people never get past the race. So, even when I was an outreach worker or a support worker people from the sex industry, organised crime folks would scratch 'b-i-t-c-h' [spells out bitch] on my car. And then some sex workers [...] were so suspicious of me. I've had conversations with sex workers [...] on the phone when I'm doing direct support at [name of organisation]. And then I say, 'Oh, come on in.' [...] So then, they would come in to [name of organisation], and you should see the look on their face when they saw that I was Black. [...]. They were shocked. [...] They thought that I was a spy and that I couldn't be trusted. Because, it's the Black guy [...] that's taking all White [girls] and putting them into the sex work, right! [...] So it took years and years and years to build a reputation. But still, it just never stops because 
there's so much whiteness in this issue, people don't assume that you would ever go into and see an [organizer] who would be Black.

Evidently, sex work activism has posed tremendous challenges for some of my participants. Perhaps it is such challenges that deter racialised and Indigenous women from engaging in sex work activism, resulting in what appears to be a series of predominantly White-run SWROs and SWRM actions. In this regard, the stories of my participants'- even though small in numbers - require considerable attention in order to improve the position of racialised and Indigenous sex worker activists. Vicky explains,

I really want to emphasise the point about like speaking out, as an Indigenous sex worker, I wish I knew [what I know] now, like [when] I started. When I started sex work activism, I was like, wow I feel like I really belong here, talking about my experiences and now it's like 'I wish I used a pseudonym for that..., I wish I did this..., I wish I had talked to somebody about that first.' [...] We need to have like strategy put in place for sex work activists.

In the face of these challenges, participants who continue to engage in sex work activism to express their solidarity with the SWRM and to raise awareness about racialised and Indigenous women's involvement in the sex industry deserve high praise. Understanding these participants' challenges illuminates the cost of political activism at the intersection of race, stigma, and sex work.

\section{Cluster two: Silent participation.}

The second cluster on the spectrum features participants who express their solidarity with the SWRM less vocally and/or less visibly than those in cluster one. As such, they neither publicly adopt a "sex worker" identity nor publicly engage with SWRM activities. These participants cite various reasons for keeping their distance from sex work activism, including the stigma associated with racialisation and sex work and the various costs associated with sex work visibility: 
For women of colour, I think coming out, speaking out, is harder because we carry race stereotypes in everything that we do. [Vicky]

I think women of colour have always been constructed and continue to be constructed as Andrea Smith calls inherently rapeable, inherently dirty, inherently diseased and when you combine that with the sex trade then you know it's like the huge stigma that makes you not want to, you know be exposed to the world. Even though you know you are not inherently dirty, you are not inherently diseased, and you are doing the same thing a White women's doing, just across the street [laughing]. [Angela]

Participants in this cluster also worry that their engagement in sex work activism would out their involvement in the sex industry to their family members. Given the stereotypes and ensuing stigma that exists at the intersections of race and sex work, these participants believe that their families would be disappointed and/or disown them for tainting the reputation of their family and/or their communities of colour:

My parents even don't know I am a sex worker [...]. For me to be able to speak at [a public event] on my experiences with the possible threat of being outed, to like everybody that I want to be close with that's a serious problem. [Angela]

And I think for Aboriginal people in the sex trade, there's often this invisible aspect to them because the family thing is so strong, and if word gets out back in the reserves that they're whoring in [name of city], there's so much stigma and shame attached to that. [Shashi]

I know, my family knows that I am queer and that's enough, that's more than enough struggle and frictions. So I am not going to add on top of that. [...] This is a great industry, I am not ashamed to be a sex worker, but I also really appreciate my material safety and comforts of having a family and having those resources, and if I were to cut myself off of that, I don't know if I will be ok. [...] If that's internalised shame, I will take it, I will try and deal with it. But I also really appreciate being able to have material comforts. [...] Why put myself in situations where I'm taking away that from myself, because of work. [Aarabi]

I think from my experience [...] our family's on this high pedestal, everyone's looking at, you know, the kids and the family. What we're doing, who we're doing it with. [Priya]

I think it mostly has to do with not wanting to out myself, and really it's the stigma that comes along with it, and like, I already kind of have this fraught 
relationship with [laughing out] like Middle Eastern community [laughing] and [...] it would probably like, totally cement my exclusion from the Middle Eastern community [laughing] like forever and always, absolutely. [Ramani]

Under these circumstances, participants' expressions of solidarity with the SWRM are premised on their realisation and acknowledgement of the political relevancy of the SWRM to address the injustices and marginalisation of all sex workers. Accordingly, participants in this cluster express their gratitude to those who are visible in the public realm advocating on behalf of all sex workers, though they do not actively engage themselves. In particular, participants in this cluster express a high degree of appreciation for the three applicants in Canada v. Bedford (2013). For example, Nisha noted, "Yeah, good job ladies, like good job! Like fucking paving the way for lot of people," and Violet spoke of those who advocated for the rights of sex workers during the Senate hearings for PCEPA:

I am actually grateful for the women who are able to stand up with their real names and their real faces on television, radio, go before the [Senate], because I can't, and I know lot of women who can't, and that's part of why people aren't hearing our voices.

Furthermore, the belief of these participants in the political relevancy of the SWRM also leads them to believe in maintaining strong ties with SWROs. Thus, given their anxieties around public political actions and to avoid stigma, many participants connect virtually with the SWRM. In the following quotation, Lilly explains that her virtual engagement with the SWRM allows her to avoid the risks of outing herself and maintain a great degree of privacy:

I follow a group on Facebook, and I will read news articles [on their Facebook page], but I really don't go to any events they have or anything like that. [...] I don't want to end up on the news, and my parents see it [laughing] and things like that. So I just like to check out the Facebook group, and I haven't really gone for any events, although it would be nice, but I just don't wanna risk it. 
Ferris (2015) points out that, despite various limitations, the "prolific, rich, and interactive" online sex work activism, in addition to facilitating solidarity, is an important communication medium for sex workers who might otherwise have no access to it (p. 84). Opting to engage with local SWROs virtually allows Lilly to strengthen her collective sense of sex worker social cohesion with the SWRM. Participants' virtual engagement with the SWRM is noteworthy. Most research participants I interviewed for this study are connected to the sex worker community through various social media sites linked to SWROs and/or the SWRM. As mentioned in Chapter 4, this virtual connection made it feasible for me to access my research participants from various cities as well. The online community allows women in the sex industry to protect their privacy to the extent that they wish to do so.

Participants in this cluster - although they may hide their "sex worker" identity and avoid public engagement with the SWRM - express their solidarity with the SWRM by engaging in various micro-mobilisation activities in their everyday social and interpersonal interactions. These micro-mobilisations include subtle efforts to raise awareness and deconstruct normative assumptions about sex workers within communities of colour as well as contributing money, signing petitions, and other small but significant acts of support (see Tilly, 2008). The micro-mobilisations that participants in this cluster engage in may not result in the same outcomes as those of collaborated/coordinated collective public actions. Nonetheless, they are political (Scott, 1985; Tilly, 2008). In particular, these participants believe that remaining closeted about their work increases their ability to raise awareness and make social change in the various networks which they inhabit (Sandoval, 2000). The oppositional or differential awareness that women in this cluster raise requires them to read the power dynamics within communities of colour and respond to them in ways that will help 
them both maintain social ties with their communities of colour and deconstruct normative narratives through creative paths to activism (Doetsch-Kidder, 2012; Sandoval, 2000). Ramani explains in the quotation below:

So I actually don't really know if I would be making headway in increasing understanding in [the Middle Eastern] community by like outing myself. because I would just not be a part of it for the rest of my life. So it almost feels like I can actually do more good by staying in the community and then when people say terrible, bigoted things like from totally not knowledgeable perspective I can then be like, 'ha, have you considered it this other way instead' and then maybe I can be like taken a tiny little bit seriously you know. Because I still have some sense of veneer respectability [laughing out] yeah. So I mean even just as a strategy of like how to get these words across, I mean being totally excluded isn't doing anyone any good.

Participants' social cohesion within racialised and Indigenous communities, their urge to protect their families from the negative effects of stigma, and their desire to avoid disappointing them with news of their involvement in the sex industry is instructive. During my fieldwork, I came to appreciate the value research participants place on maintaining a sense of social cohesion with their families and communities of colour. My participants' strong ties to family can be located within hooks (1994b) criticism of traditional, unidimensional depictions of the private sphere/homeplace as belonging to women, as the essential place for warmth and comfort, shelter, food, and nurturing of souls. According to hooks (1994b), historically, Black people have learned about dignity and integrity through interpersonal interactions in the homeplace. For some Black people, their homeplace is not only where they learned to have faith, but was also one site where they could freely confront issues of humanisation. For hooks, the homeplace also represents a radical political dimension and a space where one can resist, and thus she writes, 
Black women resisted by making homes where all Black people could strive to be subjects, not objects, where they could be affirmed in their minds and hearts, where they can restore to themselves the dignity denied to them on the outside in the public world. (hooks, 1994b, p. 94)

According to my participants, it is through their relationships with their families and communities of colour that they feel they can restore the dignity that has been denied to them in mainstream society. Research participants in this cluster also pointed out that their families and communities of colour taught them to fight for their equality and resist marginalisation. These women feel strongly that it is within their family and communities that they hold the credibility and power necessary to create new awareness and positive knowledge about sex work and sex workers. It is in this sense that women in this cluster use their differential and oppositional consciousness-raising for social change. In this regard, participants' efforts to negotiate the political dilemmas engendered by various facets of their lives shed light on their political intersectionality (Crenshaw, 1991; Kempadoo, 2003).

\section{Cluster three: Focusing on alternate priorities.}

The third cluster on the spectrum is made up of participants who do not have ties to the SWRM and also do not engage in sex work activism. These participants point to race-, class-, and space-based obstacles for their disassociation from the SWRM. For instance, participants in this cluster express being burdened by lower income and family care responsibilities that hinder their ability to engage in both macro and micro political actions. When faced with the choice between political engagement and generating income or honouring their care responsibilities, many participants choose the latter. These obstacles shape participants' perceptions of the SWRM and of activism in general. 


\section{Space-based obstacles.}

Most SWROs are geographically located in metropolitan areas. Similarly, most, if not all, coordinated political actions take place in metropolitan areas. As a result, some participants who live and work in the suburbia of large cities or in rural areas find it difficult to engage in social and political activities organised by the SWRM or by SWROs. In the quotation below, Vivian points to her lack of involvement with the local SWROs because of their geographical location. Vivian also alludes to the financial cost of traveling to most SWROs: $:^{39}$

I know of [organisation name]. I don't live there, so it's very hard for me to get out there, and I notice a lot of those kind of advocacy groups are based in [city name], and I'm not in [city name] a lot. And it's very hard for me to get down there and it's very expensive. I don't really have any type of involvement.

In Chapter 6, I discuss how many participants in this study strategically travel to different geographical locations in order to maximise their marketability and their income. However, few participants are willing to absorb the time commitment and financial burden of traveling, even relatively short distances, to engage in sex work activism.

\section{Class-based obstacles.}

Given the geographical locations of SWROs and their events, participants in this cluster point out that they often have to choose between working to make money and spending money on bus/taxi rides to attend political events. As such, participants in this

\footnotetext{
${ }^{39}$ To contextualise the expensive aspect of traveling to a metropolitan area like Toronto from the suburbs, I spent $\$ 21.25$ on one-way taxi and bus fares when I went from downtown Toronto to a suburban public library to interview participants for this study. During my fieldwork for this study, I spent between $\$ 6.00$ and $\$ 8.00$ for a single (one-way) bus ride to downtown Toronto from the suburban areas. It also cost me between $\$ 10.00$ and $\$ 15.00$ for taxi fares from the interview location (usually a public library) in the suburban location to a central bus station, where buses to Toronto are located.
} 
cluster see activism in general as a privileged pursuit that is not a priority for working-class

women. Vivian explains this intersection of class and activism:

I find that a lot of advocacy is done by White people because White people have a lot more time and resources because they make more money. Advocacy, if you really think about it, advocacy is a middle-class thing. Upper-middleclass thing. If you're poor, you're not going to advocate for yourself. You know why? Because you're fighting to put food on the table. To pay your bills. It's a middle-upper-middle-class thing.

In addition, Viola emphasises other class markers that discourage participants'

engagement with sex work activism. Referring to her desire to get involved in activism, Viola speaks to the class-based limitations:

I do, but I have to do it in a pair of trousers, a blouse and 3-inch heels, fit in with the White women, you understand. That's how I will have to do it. I couldn't go in as myself, as a Black woman. [...] Na, I am in the now, I'm aware. I'm very much aware, in what type of world I am living in [...]. I couldn't go there like this, because I'm the crackhead sex worker, that's what they believe, right! It's not just in the clothes that you wear, or the shoes that you wear. [...] You can't have [...] coarse hair. Most of the times Black women put extensions and hair weaves, and it's always exuberant and lavish. But you are not going to take out a $\$ 250$ hairstyle to sit on the steps or protest with people.

Viola's narrative renders visible the invisible "knapsack" of resources enjoyed by White sex worker activists (McIntosh, 1997). As Viola points out, investing money in transforming one's visual looks through beautification and approximations of whiteness might be worth the effort to realise financial benefits (see Chapter 6) but not to engage in political activism.

\section{Race-based obstacles.}

Participants in this cluster feel that most SWROs do not offer programs, services, and resources that are inclusive of diversity; thus, participants in this cluster do not seek out services or resources and/or engage in events organised by SWROs. Given that only a handful of SWROs in the country offer race- and culture-specific programs, services, and resources, 
and given that these SWROs are located in major metropolitan areas, sex workers who live

outside of these cities are disconnected from these particular organisations. As such,

participants in this cluster feel they do not have the space or opportunity to express their

frustrations of everyday racism and sexism that they experience in the industry and in society.

Aarabi explains:

Sometimes I get really upset and angry. Frankly, because there's a lot of BS that happens because I'm not White. Or because this is a White-dominated industry and it's very frustrating and angering. And I find that there's not enough space for me to be an angry Black female sex worker or be an angry Black woman, gosh darn it! So there's not a lot of space for that, and that's also very frustrating. So when I am like super tired, or just the way people relate to me, the way men relate to me just because of my Blackness or just because in general, because I am women even, it is very frustrating. So if I try to articulate that in more White-dominated spaces, like at [name of organisation], [...] it's quite clear to me that it's a White woman's world, because most of the people that go to [name of organisation], on the Tuesdays group for the current workers group, it's only like once a month, most of them are White, most of them work indoors, and it's a different kind of conversation [...] I want to be like, 'you White girls have it so easy,' but I cannot say that. There should be space for me to be able to like 'you White girls have it too easy' and like not to say that I wish hardship on anyone, but like give me a little sunshine you know.

Participants in this cluster feel that the lack of space within most SWROs is partly the result

of activists who run these organisations, who do not have the lived experiences, or the multidimensional needs and priorities that result from disenfranchisement and oppressed social status. In the following quotation, Tammy speaks to both:

The majority of them don't even represent the people they're trying to represent. Fact. Like, at [name of organisation], [...] the staff are [...] they have good intentions, but they lack the experience. [...] [They are] White women, people who've graduated from women's studies [programs] and lots of lesbians. [...] A lot of them feel kind of justified because they're like 'Oh, well, I'm a social justice warrior and I believe in consent and the ability to do what you want with your body. And if you're put in a situation where you need to do this sort of work then that's okay and there's support and laws and rights and blah, blah, blah and whatever, whatever.' But they come from [...] the 
upper-middle-class neighbourhoods, been to private schools. [...] But you don't know what the day-to-day struggles are like. You don't know what it's to have to literally wash your clothes in a bathtub because you can't afford to go to the freaking laundromat. [...] I remember going once without food so my child could eat, you know. [...] But, the little organisations filled with these White women who don't know shit.

These race-, class-, and space-based obstacles to engaging with the SWRM and SWROs are important barriers to consider. Based on the stories of participants in this cluster, it is evident that they have developed the perception that the SWRM is made up of privileged White people who seek to address White people's needs and experiences. As previously mentioned, this is a prominent criticism of the SWRM that is advanced by prohibitionist groups as well. Participants' perceptions, when combined with prohibitionist criticism, implies that the SWRM is engaging in the passive reproduction of whiteness. Deliovsky (2010) claims, "passive participation involves acquiescing to relations of ruling by not taking an active role in resisting unequal relations" (p. 87). In this regard, participants' stories presented here can be used as additional information to address criticisms and, if necessary, alter situations in the growth and evolution of the Canadian SWRM.

\section{Cluster four: Resistance to the SWRM.}

The final cluster on the spectrum is made up of a small number of participants who neither relate to the broader community of sex workers nor associate with the SWRM. Participants in this cluster reject the political relevancy of the SWRM, along with its reform initiatives and intervention strategies to protect sex workers' rights. These participants believe that engaging in sex work activism is not only a waste of time but is also a risky endeavour that could lead to further stigmatisation and criminalisation. Based on participants' stories, their resistance to associating with the SWRM is based on two premises. 
The first premise is that they have only temporary or interim involvement within the sex industry. As mentioned in Chapter 5, many participants in this study choose the sex industry as a primary or secondary means of income generation because they are still in school or because they lack access to professional and/or well-paying jobs. Thus, many participants are involved in the sex industry on a temporary or interim basis until they find an alternative job or career. As such, these participants do not want to establish social ties with the sex worker community or movement, maintain a group/collective identity, or develop a political consciousness towards sex work. Ramani and Violet explain:

But I mean I don't publicly identify as a sex worker. I'm not even sure if I really like privately identify as a sex worker. But rather like someone who does sex work or has done sex work [...] I guess partially because, for me it's not at the forefront of [my] career that I'm committed to. [...] I mean I see it as kind of a semi-temporary means to an end until other things I have been working towards happen. So because of that I guess I'm kind of uncomfortable, [...] like appropriating the term 'sex worker.' [Ramani]

I have another job actually, part-time with the government, that I'm hoping is going to turn into something full-time. Actually, I got into sex work more actively because this job remained part-time, it's a great job in my field, and I love it, but the hours aren't enough, there's a lot of unpaid downtimes, and I needed something to fill in the gap, and this [sex work] works perfectly. [Violet]

Furthermore, participants used phrases such as "not a passion" and "a means to an end" to describe their involvement in the industry:

I rarely identify as a sex worker, and I think about that a lot, and I am not sure why I don't tag that on, because I do tag on a lot of things on to, my identity and social location [...]. I wish I had more connection with them [SWROs]. But sex work politics aren't my passion. [Niro]

I don't identify myself as a sex worker. For me it's not a passion, it's just a job; it's a means to get by. [...] I will if I had made a career out of it but this is hopefully temporary, and I don't aspire to do this for the rest of my life.

[Feroza] 
Participants in this cluster also clearly emphasised that their job did not define them. For example, Shashi notes that “it's my job, it's not who I am," and Nisha reiterates that "just to re-establish [...] my work does not define who I am."

The second premise of participants' resistance, which is interrelated with the first, is their dissociation from their involvement in the sex industry under the category of "work." Gowri elaborates:

The other piece I really should say is, not everyone identifies as a sex worker. [...] some people don't identify this as work. They just participate, they have experience in the sex trade, you know. That is a big thing because it's a very, kind of, almost becoming like a Westernised term, you know to frame the argument in terms of like just labour and like being a work issue when it's lot broader than that. [...] Because some people will say like I do this for various reasons, I did this because [...] I needed drugs or I needed money to pay rent that day or needed whatever, whatever, whatever [...] It's circumstantial for sure.

Gowri's reflections can be located within Cabezas' $(2005,2009)$ claim for expanding the concept of sexual rights within human rights instruments and feminist circles to encompass a broader set of actions besides and beyond "work." Cabezas (2009) is critical of sex workers' ability to connect to ideas that serve to strengthen their determination to organise, fight back against abuse, and redirect their lives. She supports her claim by pointing to the example of women's participation in the sex industry in Cuba, where many women "attach themselves to foreigners" and who are not ready to identify their actions as "sex work" or embrace the discourse of "sex workers' rights" or "sexual rights" (p. 160).

In other words, participants in this cluster do not associate their involvement in the sex industry under the category of "work." Given participants' temporary involvement in the sex industry, until they find a suitable job/career, they are not ready to identify their actions as "sex work." Instead, they see their involvement in the sex industry as a "means to an end." In 
this regard, they are also not ready to embrace the discourse of "sex workers" rights" or "sexual rights" and thus do not see the political relevancy of sex work activism.

\section{Concluding Remarks}

In this chapter, I bring my research participants' perspectives of activism in general and sex work activism in particular to the fore. The findings presented in this chapter can be read as a source of information for broader conversations about challenges to grassroots organising. It is evident that participants' intersectional positions condition their motives to engage in or refrain from sex work activism and also shape their perceptions about activism in general and about sex work activism in particular.

Among the various reasons provided by participants, stigma management is one of the primary reasons for participants in this study disassociating from the sex worker community and declining to engage in activism. One of the key goals of the SWRM is to raise awareness about the effects of stigma resulting from the criminalisation of sex work and sex workers, and advocate for decriminalisation. In this regard, the findings presented in this chapter highlight the various political tensions that participants grapple with as they negotiate their desire to express solidarity with the SWRM's values and to serve their self-interest through preserving their sense of dignity and respectability. It is important to consider the various barriers and alternate priorities that participants in this study face, especially with regards to the invisibility of racialised and Indigenous sex workers at coordinated rallies, protests, and street marches. 


\section{Conclusion}

Masks of Woman

I.

This is my daily mask

daughter, sister

wife, mother

poet, teacher

grandmother.

My mask is control

concealment

endurance

my mask is escape

from my

self.

\section{II. (Noh mask of benign woman)}

Over my mask

is your mask

of me

an Asian woman grateful

gentle

in the pupils of your eyes

as I gesture with each

new play of

light

and shadow

this mask be

comes you.

But here

I shall remove

your mask

of me and

my daily mask

of me

like the used skin

of a growing reptile

it peels away

and releases.

Mitsuye Yamada (1990, pp. 114-115).

I started this project with two objectives in mind. First, to deconstruct and even decolonise prejudicial popular representations of racialised and Indigenous sex workers by asking them how they understand their own involvement in the sex industry. Second, to contribute to a growing body of literature on the experiences of racialised and Indigenous indoor sex workers. The deconstruction and decolonisation processes, on the one hand, involve tracing research participants' entrepreneurial attitudes, tendencies, and preferences to better understand their decisions to undertake and continue in sex work. In this regard, my 
participants' choices and decisions regarding employment conditions and monetary rewards are grounded at the intersections of the opportunities sex work has to offer, especially over and against the opportunities that are available to them in the mainstream, often minimum wage, labour force.

On the other hand, the deconstruction and decolonisation processes involve analysis of my participants' intersectional experiences of how they enact control, perform endurance, and strategically conceal parts of their identities in order to navigate the effects of stigma, criminalisation, and marginalisation in their day-to-day lives. This analysis allows me to trouble the rhetoric of forced sex work that focuses on coercion in the various relationships between workers and third parties, between trafficking and the migration of women, and the emphasis on border-related issues of organised crime, all of which depict sex workers as vulnerable and agentless women who are caught up in these processes.

Grounded in Crenshaw's conception of intersectionality, I rely on the postintersectional approach of collaborative intersectionality to expose the incoherence in the dominant narratives that are placed onto racialised and Indigenous women's participation in the sex industry. My commitment to Crenshaw's intersectionality is two-fold: First, the broader concept of intersectionality allows me to bring to the forefront stories of my research participants. In doing so, I am taking a step towards acknowledging that they are the experts of their own lives, and I am also attempting to counteract the neglect that racialised and Indigenous indoor sex workers have faced for so long. Even though participants of my study are not the most marginalised members of the sex working community, intersectionality allows me to highlight that generalising the experiences of racialised and Indigenous women in the street-based sex industry, who represent a very small subset of sex workers, to address 
issues of all racialised and Indigenous sex workers' discrimination and marginalisation, is nonsensical. The intersectional analysis I employ in this dissertation draws attention to my participants' multiple burdens, intersecting structural inequalities, and overlapping discriminations, along with their continuous shifting between multiply marginalised and partially privileged subject positions.

As outlined in Chapter 3, intersectionality has been often criticised for its ambiguity, open-endedness, lack of clear cut definition, and lack of specific parameters of inquiry. By relying on collaborative intersectionality, I undoubtedly capitalise on the uncertainties, vagueness, open-endedness, and methodological malleability of intersectionality to reconceptualise research participants' multiple and shifting identities, experiences, and corporeal practices. In this regard, my second reason for my commitment to Crenshaw's intersectionality highlights her assertion that intersectionality is a provisional concept that can be linked to contemporary politics through postmodern theory. Collaborative intersectionality, grounded in traditional intersectionality and articulated in this way, highlights intersectionality's constant movement in analytical thinking - an analysis-in-progress making it clear that intersectionality theory is never complete nor exhausted by its prior articulations or movements.

Thus, at the broader level, based on the stories of my participants, I might alternately understand these women as wearing a set of daily masks - the masks they have created for themselves as well as the masks we, as a society, have put on them - as a stage prop or costume that enhances their performance. My participants' daily performances and social interactions at the intersection of race, class, gender, age, sexuality, and space, as we have seen, sometimes conform to society's perceptions of them, and at other times, work to 
deconstruct the imposed mask of the "vulnerable victim" of the sex industry. In this regard, the main aim of this project is to show that the lived experiences of the forty racialised and Indigenous women in this study are more or less like anyone else's. Their object is to earn an income that reflects the cost of living, to do their best to succeed in their jobs and strategically interact with political issues or matters that can harm them. This is one of the messages that I want to convey through this project.

From a specific level, my efforts to deconstruct prejudicial representations of racialised and Indigenous sex workers and add to the growing literature on the subject starts with tracing, although briefly, the historical and contemporary representations of sex workers and of racialised and Indigenous sex workers more specifically. As I highlight in Chapter 2, sex workers have historically been misunderstood and misrepresented in public policy initiatives of law and order to control/regulate space, health, the moral fabric of society, gender-based violence, and even international relations. For instance, as I have demonstrated, in order to regulate contagious diseases, public policy globally and locally classified sex workers as vectors and subjected them to harsher criminal and moral controls. Efforts to control and regulate noise levels, littering, and loitering in public spaces were at one point depicted as a 'prostitution problem' and therefore targeted sex workers who were in the public. More recently, policy efforts to tackle missing and murdered Indigenous women and girls and the exploitation of migrant workers, couched under the guise of "human/sextrafficking" initiatives, are focused on rescuing individuals who work in the sex industry. Despite the shifting nature of these narratives, they have consistently misrepresented sex workers' lived experiences, which has resulted in increased stigmatisation and criminalisation. 
In Chapter 5, I demonstrated how participants of this study embody control of their lived realities as mothers, daughters, sisters, partners, teachers, civil servants, and students as they make informed decisions to work in the sex industry, on a part-time or full-time basis, against the backdrop of women's general poverty, the undervaluation and ghettoisation of women's work, and the increasing lack of professional jobs or jobs that pay a living wage. This chapter illustrates how my participants embody control and informed decision-making practices from behind their daily masks - masks that change depending on the immediate circumstances they are dealing with. The qualities of agency, control, and rationality they express are all contrary to what is expected from the "victim" label society fixes onto sex workers.

In Chapter 6, I explored how participants enact their various roles - how they wear their daily masks and the masks that society puts onto them - to not only survive but also succeed in the marketplace, against the backdrop of racially stratified hiring practices. Here too, their control, endurance, strategic concealment, and escape from themselves become evident as they simultaneously conform to and deconstruct cultural perceptions that exist at the intersections of race and sex work. While feminists, anti-racism scholars/activists, and other critical thinkers may disagree with the strategic use of essential identity categories and the strategic embodiment of racial tropes, participants in this study clearly describe their performances in the marketplace as necessary entrepreneurial tasks for their income generation. Similarly, in Chapter 7, I showed how various performances - which include putting on the masks of the wise mother, the diplomat, and the ignorant woman - influence their interactions with law enforcement, allowing them to not only manage the stigma associated with race and sex work but also to avoid negative outcomes such as arrest. In this 
chapter, I underscored that for some participants, their location at the intersection of race and sex work renders them vulnerable to regulatory practices of over-policing and underprotection.

In the final chapter, Chapter 8 , I draw attention to the various tensions that participants grapple with as they encounter sex work activism and the sex workers' rights movement. The stories in this chapter highlight research participants' endurance as they wear the masks of mothers, daughters, sisters, and partners and navigate their position(s) against the backdrop of stigma that is attached to race and sex work in public spaces. Here, I further articulate the fluidity of identities through participants' lived realities. For instance, the stories presented in this chapter highlight the tensions most participants grapple with as they negotiate solidarity with the SWRM against their race-, class-, space- and stigma-based barriers and the necessary priorities of their lived realities. Focusing on these tensions provides a glimpse into the absence of racialised and Indigenous women in public political actions.

Borrowing from themes in Yamada (1990) "Masks of Woman," I see that my participants have chosen to wear various masks and perform the part that fits each situation in their daily lives, while they simultaneously have masks imposed on them through the perceptions of onlookers. In this regard, the lived experiences of my racialised and Indigenous research participants are complexly fluid and multidimensional as they negotiate their identities and decide whether or not to conform to behaviours that align with their various positions. As such, any unidimensional or essentialising classification of sex workers, of racialised and/or Indigenous women, or of people working in the indoor sectors of the Canadian sex industry is illogical and unproductive. The growing body of research in this 
particular area of sex work studies, I believe, will raise more appropriate social, political, and legal awareness.

\section{Moving Forward}

I conclude by pointing to some gaps in contemporary research on racialised and Indigenous indoor sex workers that I encountered while carrying out my research. As discussed in Chapter 2, mapping the historical contexts of racialised women's participation in the Canadian sex industry is an important priority for critical sex work studies and critical race studies. Developing a historical perspective allows us to understand how specific events, emotions, and attitudes have led to the establishment and maintenance of, for example, the rhetoric of South Asians and East Asians as the "trafficker" and the "trafficked victim," respectively. As mentioned above, there is some evidence that points to racialised women's involvement in prostitution in the early twentieth century. Though research has been done on the settlement of Chinese, Japanese, Sikh, and Black communities in Canada in or before the nineteenth century, there has been little research on the historical involvement of these ethnic communities with the sex industry.

In Chapter 6, I explored only two types of entrepreneurial tasks. Examining other types of entrepreneurial task would further enhance our understating of the multiplicity of the indoor sex industry and how racialised and Indigenous women engage in it. Furthermore, given the recent anti-advertising laws in Canada and SESTA/FOSTA in the United States, it is important that critical sex work scholars examine indoor workers' entrepreneurial activities to understand how the new law and policy will continue to affect sex workers. 
Another area of research that requires attention is the effect of Canada's new prostitution laws. Given the long-standing practices of over-policing and under-protecting marginalised communities that are discussed in Chapter 7, it is important to understand how the new laws - purportedly aimed at "protecting" sex workers - affect racialised and Indigenous women. Since the enforcement of the new laws, anecdotal evidence suggests an increase in over-policing of massage parlours, for instance, with many racialised indoor sex workers being subjected to criminalisation and deportation. A systematic analysis of this particular impact of the new law would be an important endeavour for critical sex work researchers. Furthermore, it would be valuable to explore the strategies racialised and Indigenous women in the indoor sectors of sex industry develop to manage the effects of these new laws and succeed in the shifting landscape of the marketplace. 


\section{References}

Adachi, K. (1991). The enemy that never was: a history of the Japanese Canadians. In. Toronto: McClelland \& Stewart.

Allen, K., \& Walker, A. (1992). A feminist analysis of interviews with elderly mothers and their daughters. In J. Gilgun, K. Daly, \& G. Handel (Eds.), Qualitative Methods in Family Research (pp. 198-214). California: Sage Publications.

Almodovar, N. J. (2010). The Consequences Of Arbitrary And Selective Enforcement Of Prostitution Laws. Wagadu, 8.

Amnesty, I. (2016). Sex workers at risk: A research summary on human rights abuses against sex workers. London: Amnesty International Ltd.

Anderson, S., Jia, J. X., Liu, V., Chattier, J., Krüsi, A., Allan, S., . . Shannon, K. (2015). Violence prevention and municipal licensing of indoor sex work venues in the Greater Vancouver Area: narratives of migrant sex workers, managers and business owners. Cult Health Sex, 17(7), 825-841. Retrieved from https://www.ncbi.nlm.nih.gov/pubmed/25686777. doi:10.1080/13691058.2015.1008046

Anderson, S., Shannon, K., Li, J., Lee, Y., Chettiar, J., Goldenberg, S., \& Krusi, A. (2016). Condoms and sexual health education as evidence: impact of criminalization of in-call venues and managers on migrant sex workers access to HIV/STI prevention in a Canadian setting. BMC Int Health Hum Rights, 16(1), 30. Retrieved from https://www.ncbi.nlm.nih.gov/pubmed/27855677. doi:10.1186/s12914-016-0104-0

Anzaldúa, G., \& Moraga, C. (1983). This bridge called my back: writings by radical women of color ( $2 \mathrm{~d}$ ed.). New York: Kitchen Table, Women of Color Press.

Armstrong, L. (2016). From Law Enforcement to Protection? Interactions between Sex Workers and Police in a Decriminalized Street-Based Sex Industry: Table 1. British Journal of Criminology, azw019. doi:10.1093/bjc/azw019

Arthur, J., Davis, S., \& Shannon, E. (2013). Overcomming Challenges: Vancouver's Sex Worker Movement. In E. v. d. Meulen, E. M. Durisin, \& V. Love (Eds.), Selling Sex: Experience, Advocacy, and Research of Sex Work in Canada. Vancouver, Toronto: UBC Press.

Banks, I. (2000). Hair matters: beauty, power, and Black women's consciousness. New York: New York University Press.

Barman, J. (2004). Tamimg Aboriginal Sexuality: Gender, Power, and Race in British Columbia, 1850-1900. In M. A. Irwin \& J. Brooks (Eds.), Women and gender in the American West (1st ed.). Albuquerque: University of New Mexico Press.

Barman, J. (2005). Aboriginal Women on the Streets of Victoria: Rethinking Transgressive Sexuality During the Colonial Encounter. In K. Pickles \& M. Rutherdale (Eds.), Contact zones: Aboriginal and settler women in Canada's colonial past (pp. 205-227). Vancouver: UBC Press.

Bartky, S. (2003). Foucault, Femininity, and the Modernization of Patriarchal Power. In R. Weitz (Ed.), The politics of Women's Bodies (Second ed.). New York: Oxford University Press.

Barvosa, E. (2008). Wealth of Selves: Multiple Identities, Mestiza Consciousness and the Subject of Politics. College Station: Texas A\&M University Press. 
Batnitzky, A., \& McDowell, L. (2011). Migration, nursing, institutional discrimination and emotional/affective labour: ethnicity and labour stratification in the UK National Health Service. Social \& Cultural Geography, 12(2), 181-201. doi:10.1080/14649365.2011.545142

Beale, F. (1970). Double jeopardy: to be Black and female In T. Cade (Ed.), The Black Woman (pp. 90-110). New York: Signet.

Beer, S. (2010). The Sex Worker Rights Movement In Canada: Challenging The 'Prostitution Laws'. (PhD), University of Windsor, Windsor.

Bell, L. (2013). Ethics and Feminist Research. In S. N. Hesse-Biber (Ed.), Feminsit Research Practice: A primer. London: Sage.

Benoit, C., Jansson, M., Millar, A., \& Phillips, R. (2005). Community-academic research on hard-to-reach populations: benefits and challenges. Qual Health Res, 15(2), 263-282. Retrieved from http://www.ncbi.nlm.nih.gov/pubmed/15611208. doi: $10.1177 / 1049732304267752$

Benoit, C., \& Millar, A. (2001). Dispelling Myths and Understanding Realities: Working Conditions, Health Status, and Exiting Experiences of Sex Workers. Retrieved from Victoria, B.C.:

Bernstein, E. (2007a). Sex Work for the Middle Classes. Sexualities, 10(4), 473-488. doi:10.1177/1363460707080984

Bernstein, E. (2007b). Temporarily Yours: Intimacy, Authenticity and the Commerce of Sex. Chicago and London: The University of Chicago press.

Bhopal, K. (2010). Gender, identity and experience: Researching marginalised groups. Women's Studies International Forum, 33(3), 188-195. doi:10.1016/j.wsif.2009.12.005

Bilge, S. (2013). INTERSECTIONALITY UNDONE: Saving Intersectionality from Feminist Intersectionality Studies. Du Bois Review, 10(2).

Blair, C. M. (2010). I've Got to Make My Livin': Black Women's Sex Work in Turn-of-the Centurey Chicago. Chicago and London: The University of Chicago Press.

Block, S. (2017). Racialized Canadians continue to face barriers to decent work. Retrieved from http://behindthenumbers.ca/2017/11/29/racialized-canadians-barriers-to-work/

Bordo, S. (2003). Unbearable Weight: Feminism, Western Culture (Tenth ed.). Berkeley: University of California Press.

Bouclin, S. (2004). Exploited employees or exploited entrepreneurial agents? A look at erotic dancers. Canadian Woman Studies, 23(3-4).

Bourdieu, P. (1984). Distinction: A Social Critiques of the Judgement of Taste (R. Nice, Trans.). Cambridge, MA: Harwards University Press.

Bourdieu, P. (1987). What Makes a Social Class? On The Theoretical and Practical Existence Of Groups. Berkeley Journal of Sociology, 32, 1-17.

Bourdieu, P. (1991). Language of Symbolic Power. Cambridge: Polity Press.

Bourdieu, P. (1992). An Invitation to Reflexive Sociology. Chicago: The University of Chicago Press.

Bourgeois, R. (2015). Colonial Exploitation: The Canadian State and the Trafficking of Indigenous Women and Girls in Canada. UCLA L. Rev., 62.

Bowleg, L. (2012). The Problem With the Phrase Women and Minorities: Intersectionalityan Important Theoretical Framework for Public Health. American Journal of Public Health, 107(7), 1267-1273. 
Brah, A., \& Phoenix, A. (2004). Ain't I A Woman? Revisiting Intersectionality. Journal of International Women's Studies, 5(3), 75-86.

Brand, D. (1999). Black Women and Work: The Impact of Racially Construced Gender Roles on the Sexual Division of Labour. In E. Dua \& A. Robertson (Eds.), Scratching the Surface: Canadian anti-racist feminist thought. Toronto: Women's Press.

Brents, B. G., \& Hausbeck, K. (2010). Sex Work Now: What the Bluring of Boundaries around the sex Industry Means for Sex Work, Research, and Activism. In M. H. Ditmore, A. Levy, \& A. Willman (Eds.), Sex Work Matters: Exploring Money, Power, and Intimacy in the Sex Industry. London \& New York: Zed Books Ltd.

Brewis, J., \& Linstead, S. (1998). Time After Time: The Temporal Organization of RedCollar Work. Time \& Society, 7(2-3), 223-248. doi:10.1177/0961463x98007002004

Brewis, J., \& Linstead, S. (2000). Sex, Work, and Sex Work: Eroticizing Organization (Vol. 15). London: Routledge.

A Brief History Of Sex Worker Activism in Toronto. (1997, 2001). Retrieved from http://www.walnet.org/csis/groups/swat/torontohistory.html

Bright, D. (1995). Loafers Are Not Going to Subsist Upon Public Credulence: Vagrancy and the Law in Calgary, 1900-1914. Journal of Canadain Labour Studies, 36, 37-58.

Brinkmann, S., \& Kavle, S. (2012). Ethics in Qualitative Psychological Research. In W. Stainton Rogers, C. Willig, \& ProQuest (Eds.), The SAGE Handbook of Qualitative Research in Psychology. London;Los Angeles, Calif;: SAGE Publications.

Brock, D. (1998). Making work, making trouble: prostitution as a social problem. Buffalo;Toronto;: University of Toronto Press.

Brock, D. (2000). Victim, Nuisance, Fallen Women, Outlaw, Worker? In D. E. Chunn \& D. Lacombe (Eds.), Law as a gendering practice (pp. 79-99). Don Mills, Ont: Oxford University Press.

Brooks, S. (2010a). Hypersexualization and the dark body: Race and inequality among black and latina women in the exotic dance industry. Sexuality Research and Social Policy, 7(2), 7080. doi:10.1007/s13178-010-0010-5

Brooks, S. (2010b). Unequal Desires: Race and Erotic Capital in the Stripping Industry. Albany: State University of New York Press.

Browne, K. (2005). Snowball sampling: using social networks to research non - heterosexual women. International Journal of Social Research Methodology, 8(1), 47-60. doi:10.1080/1364557032000081663

Bruckert, C. (2002). Taking it off, putting it on: women in the strip trade. Toronto: Women's Press.

Bruckert, C. (2012). Workin' It: Sex Workers Negotiate Stigma. In S. Hannem \& C. Bruckert (Eds.), Stigma Revisted: Implications of the mark.

Bruckert, C. (2015). Protection of Communities and Exploited Persons Act: Misogynistic Law Making in Action. Canadian Journal of Law and Society / Revue Canadienne Droit et Société, 30(01), 1-3. doi:10.1017/cls.2015.2

Bruckert, C., \& Chabot, F. (2010). Challenges: Ottawa Area Sex workers Speak out. Retrieved from Ottawa:

Bruckert, C., \& Hannem, S. (2013a). Rethinking the Prostitution Debates: Transcending Structural Stigma in Systemic Responses to Sex Work. Canadian Journal of Law and Society / Revue Canadienne Droit et Société, 28(01), 43-63. doi:10.1017/cls.2012.2 
Bruckert, C., \& Hannem, S. (2013b). To Serve and Protect? Structural Stigma, Social Profiling, and the Abuse of Police Power in Ottawa. In E. v. d. Meulen, E. M. Durisin, \& V. Love (Eds.), Selling Sex: Experience, Advocacy And Reaearch on Sex Work in Canada (pp. 297-313). Vancouver: UBC.

Bruckert, C., \& Law, T. (2013). Beyond Pimps, Procurers and Parasites: Mapping Third Parties in the Incall/Outcall Sex Industry. Retrieved from Ottawa:

Bruckert, C., \& Parent, C. (2006). The In-Call Sex Industry: Classed and Gendered Labour on the Margins. In G. Balfourd \& E. Comack (Eds.), In Criminalizing Women: Gender and (In)Justice in Neo-liberal Times (pp. 95-112). Black Point, N.S.: Fernwood.

Brunschot, E. G. V., Sydie, R. A., \& Krull, C. (2000). Images of Prostitution. Women \& Criminal Justice, 10(4), 47-72. doi:10.1300/J012v10n04_03

Bungay, V., Halpin, M., Atchison, C., \& Johnston, C. (2011). Structure and agency: reflections from an exploratory study of Vancouver indoor sex workers. Cult Health Sex, 13(1), 15-29. Retrieved from http://www.ncbi.nlm.nih.gov/pubmed/20967651. doi:10.1080/13691058.2010.517324

Burman, E. (1997). Minding the Gap: Positivism, Psychology, and the Politics of Qualitative Methods. Journal of Social Issues, 53(4).

Butterfly. (2016). Journey of Butterflies. Retrieved from Toronto: https://docs.wixstatic.com/ugd/5bd7546d9ddaec30e947efbef4e94b7e7ee828.pdf

Cabezas, A. L. (2005). Accidental Crossings: Tourism Sex Work and Women's Rights in the Dominican Republic. In M. Waller \& S. Marcos (Eds.), Dialogue and Difference: Feminisms Chalenge Globalization (pp. 201-229). New York: Palgrave MacMillan.

Cabezas, A. L. (2009). Economies of desire: sex and tourism in Cuba and the Dominican Republic. Philadelphia: Temple University Press.

Cachelin, F. M., Rebeck, R. M., Chung, G. H., \& Pelayo, E. (2002). Does Ethnicity Influence Body-Size Preference? A Comparison of Body Image and Body Size. OBESITY RESEARCH, 10(3).

Calás, M. B., Ou, H., \& Smircich, L. (2013). "Woman" on the move: mobile subjectivities after intersectionality. Equality, Diversity and Inclusion: An International Journal, 32(8), 708-731. doi:10.1108/edi-05-2012-0037

Canada (Attorney General) v. Bedford, No. 34788, 72 (Supreme Court of Canada 2013).

Canada. Public Safety, C. (2012). National action plan to combat human trafficking (1100206817;9781100206813;). Retrieved from Ottawa, Ont:

Carastathis, A. (2008). The invisibility of privilege: a critique of intersectional models of identity. Les Ateliers de l'Éthique, 3(2), 23-38. Retrieved from http://carletonu.summon.serialssolutions.com/2.0.0/link/0/eLvHCXMw3V3PS8MwF A7qSRCZv An5ORIVLZm RHBwxyKHhRh27mkTeoKsxtd59 ve0m6tcOTevLYBh qSfnzJe neF0KYe9NxNjghTQI hZ2Cr1TAUgExGSyLIvUEd2UX4jk84B24b2N32E eFUJVkWr 7Lz8-y7FmXOte9Qn6vMg-M0wQmNrmBJ2M0LfV-

kUUCy3Iwo2pvhnH-

NCaEt5mxbRatPulmuL92W2p2tNKK8HxwD3k5SQzIm6bWsgFKkoEVi1NsmaGIdz IMKwUIuboHr gjJ682gHbdgTFjqHc3svi_rmnaVcVkOWW6dPVluIjetL0yK7Zoq6YZGNYsJoVrxHd uKjxI9jYCzFE-n1GIt5N FUANFo7DE 7HnX6K3-IbOkvFO5Mx5uQAeBlVQbtZyn0MIr0tq7SAaNzvoLcioRfZt7ED7pusDsqXyQ9KyCkZosDx9RF4BA7 SOATpL6QoDt1TQCgHY0EQANQjQDRYBX- 
T58WE0eHL06OfGnyT60XSwE7InsKgiL3XxpTwlFNiadbjkccpEr9OTYSyQ4IUH2Tpi-CM3P--4 O -MgF2V0j95LslMVSXaFbSgHsN8uXX3Jvea8.

Carastathis, A. (2013). Identity Categories as Potential Coalitions. Signs, 38(4).

Carbado, D. W. (2013). Colorblind Intersectionality. Signs: Journal of Women in Culture and Society, 38(4), 811-845.

Carbado, D. W., Crenshaw, K. W., Mays, V. M., \& Tomlinson, B. (2013). Intersectionality: Mapping the Movements of a Theory. Du Bois Review, 10(2).

Cargo, A.-L., \& Clamen, J. (2013). Né dans le Redlight: The Sex Workers' Movement in Montreal. In E. v. d. Meulen, E. M. Durisin, \& V. Love (Eds.), Selling Sex: Experience, Advocacy, and Research of Sex Work in Canada. Vancouver, Toronto: UBC Press.

Carrington, K., Donnermeyer, J. F., \& DeKeseredy, W. S. (2014). Intersectionality, Rural Criminology, and Re-imaging the Boundaries of Critical Criminology. Critical Criminology, 22(4), 463-477. doi:10.1007/s10612-014-9257-0

Carter, S. (2000). Catergories and Terrains of Exclusion: Constructing the "Indian Women" in the Early Settlement Era in Western Canada. In C. A. Cavanaugh \& R. R. Warne (Eds.), Telling Tales: Essays in Western Women's History (pp. 60-81). Vancouver:: UBC Press.

Catro, R., \& Corral, L. (1993). Women of Color and Employment Discrimination: Race and Gender Combined in Title VII Claims. Berkeley La Raza Law Journal, 6(2). doi:10.15779/Z38666V

Chan, W., \& Chunn, D. E. (2014). Racialization, crime and criminal justice in Canada. Toronto [Ontario]: University of Toronto Press.

Chang, R. S., \& Culp-Jr, J. M. (2002). After Intersectionality. UMKC LA W REVIEW, 71(2).

Chant, S. H. (2007). Gender, generation and poverty: Exploring the feminisation of poverty in africa, asia and latin america. Northampton, MA, USA; Cheltenham, UK: Edward Elgar.

Chant, S. H. (2010). The international handbook of gender and poverty: concepts, research, policy. Northampton, MA;Cheltenham, UK: Edward Elgar.

Chapkis, W. (1997). Live Sex Acts: women performing erotic labor. New York: Routledges.

Chateauvert, M. (2013). Sex Workers Unite: A History of the Movement from Stonewall to SlutWalk. Boston: Beacon Press.

Childs, M., Ciarrocchi, S., Gleeson, C., Lowman, J., Pacey, K., Paradis, F., . . Weich, L. (2006). Beyond decriminalization: Sex Work, Human Rights and a New Framework for Law Reform. Retrieved from Vancouver:

Chin Evans, P., \& McConnell, A. R. (2003). Do Racial Minorities Respond in the Same Way to Mainstream Beauty Standards? Social Comparison Processes in Asian, Black, and White Women. Self and Identity, 2(2), 153-167. doi:10.1080/15298860309030

Cho, S. (2013). Post-Intersectionality. Du Bois Review: Social Science Research on Race, $10(2)$.

Cho, S., Crenshaw, K. W., \& McCall, L. (2013). Toward a Field of Intersectionality Studies: Theory, Applications, and Praxis. Signs, 38(4).

Choo, H. Y., \& Ferree, M. M. (2010). Practicing Intersectionality in Sociological Research: A Critical Analysis of Inclusions, Interactions, and Institutions in the Study of Inequalities*. Sociological Theory, 28(2), 129-149,245. Retrieved from 
http://proxy.library.carleton.ca/login?url=http://search.proquest.com/docview/5212081 $\underline{41 \text { ? accountid }=9894}$

http://WC2PU2SA3D.search.serialssolutions.com/?ctx_ver=Z39.88-

2004\&ctx_enc=info:ofi/enc:UTF-

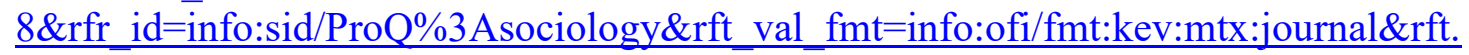
genre $=$ article\&rft.jtitle $=$ Sociological + Theory $\&$ rft.atitle $=$ Practicing + Intersectionality $+\mathrm{i}$ $\mathrm{n}+$ Sociological + Research $\% 3 \mathrm{~A}+\mathrm{A}+\mathrm{Critical}+$ Analysis + of + Inclusions $\% 2 \mathrm{C}+$ Interactions $\% 2 \mathrm{C}+$ and + Institutions + in + the + Study + of + Inequalities $*$ \&rft.au $=\mathrm{Choo} \% 2 \mathrm{C}+\mathrm{Hae}+\mathrm{Yeon}$ $\% 3 \mathrm{BFerree} \% 2 \mathrm{C}+\mathrm{Myra}+$ Marx \&rft.aulast $=$ Choo\&rft.aufirst $=$ Hae\&rft.date $=2010-06-$ $01 \&$ rft.volume $=28 \&$ rft.issue $=2 \&$ rft.spage $=129 \&$ rft.isbn $=\&$ rft.btitle $=\&$ rft.title $=$ Sociol ogical+Theory\&rft.issn $=07352751 \&$ rft $i d=$ info:doi $/$.

Clamen, J., Gillies, K., \& Salah, T. (2013). Working for Change: Sex Workers in the Union Struggle. In E. v. d. Meulen, E. M. Durisin, \& V. Love (Eds.), Selling Sex:

Experience, Advocacy, and Research of Sex Work in Canada. Vancouver, Toronto: UBC Press.

Cler-Cunningham, L., \& Christensen, C. (2001). Violence aganist women in Vancouver's street level sex trade and the police response. Retrieved from Vancouver:

Cole, E. R. (2008). Coalitions as a Model for Intersectionality: From Practice to Theory. Sex Roles, 59(5-6), 443-453. doi:10.1007/s11199-008-9419-1

Collins, P. H. (1986). Learning from the Outsider Within: The Sociological Significance of Black Feminist Thought. Social Problems, 33(6), 14-32.

Collins, P. H. (1998). It's All in the Family: Intersections of Gender, Race, and Nation. Hypatia, 13(3), 62-82. Retrieved from http://www.jstor.org.proxy.library.carleton.ca/stable/3810699.

Collins, P. H. (2000). Black feminist thought: knowledge, consciousness, and the politics of empowerment (2nd, rev. 10th anniversary;Rev. 10th anniversary; ed.). New York;London;: Routledge.

Cook, J., \& Fonow, M. (1990). Knowledge and women's interests: Issues of epistemology and methodology in feminist sociological research. In J. Nielsen (Ed.), Feminist Research Methods. Boulder: West View.

Corbin, J. (2017). Grounded theory. The Journal of Positive Psychology, 12(3), 301-302. doi:10.1080/17439760.2016.1262614

Cost of Living in Canada. (2016). Retrieved from www.numbeo.com/cost-ofliving/country result.jsp? country=Canada

Coulmont, B., \& Hubbard, P. (2009). Consuming sex: socio-legal shifts in the space and place of sex-shops. Paper presented at the Socio-Legal Studies Association Conference 2009, Leicester De Montfort Law School.

Crack, L. (2014). Brief Submitted to: The House of Commons Senate Committee on Legal and Constitutional Affairs Regarding Bill C-36: Protection of Communities and Exploited Persons Act. Brief Index Bill C36. Retrieved from https://sencanada.ca/content/sen/committee/412/lcjc/briefs/c-36/c-

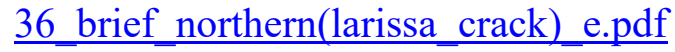

Craig, M. L. (2002). Ain't I a beauty queen?: black women, beauty, and the politics of race. Oxford;New York;: Oxford University Press.

Craig, M. L. (2006). Race, beauty, and the tangled knot of a guilty pleasure. Feminist Theory, 7(2), 159-177. doi:10.1177/1464700106064414 
Crenshaw, K. (1989). Demarginalizing the Intersection of Race and Sex: A Black Feminist Critique of Antidiscrimination Doctrine, Feminist Theory and Antiracist Politics. The University of Chicago Legal Forum.

Crenshaw, K. (1991). Mapping the Margins: Intersectionality, Identity Politics, and Violence against Women of Color. Stanford Law Review, 43(6).

Cresswell, T. (1996). In place/out of place: geography, ideology, and transgression. In. Minneapolis: University of Minnesota Press.

Davis, C. (2008). Intersectionality as buzzword: A sociology of science perspective on what makes a feminist theory successful. Feminist Theory, 9(1), 67-85.

Davis, D., Sbrocco, T., Odoms-Young, A., \& Smith, D. M. (2010). Attractiveness in African American and Caucasian women: is beauty in the eyes of the observer? Eat Behav, 11(1), 25-32. Retrieved from http://www.ncbi.nlm.nih.gov/pubmed/19962117. doi:10.1016/j.eatbeh.2009.08.004

Day, S. (1996). The Law and the Market: Rhetorics of exclusion and inclusion among London prostitutes. In O. Harris (Ed.), Inside and Outside the Law: Antrhropological Studies of Authority and Ambiguity. London and New York: Routledge.

Day, S. (2007). On the Game: Women and Sex Work. London: Pluto Press.

Deliovsky, K. (2010). White Femininity: Race, Gender \& Power. Halifax \& Winnipeg: Fernwood Publishing.

Denton, N. A., \& Deane, G. D. (2010). Researching Race and Ethnicity: Methodological Issues. In P. H. Collins \& J. Solomos (Eds.), The Sage Handbook of Race and Ethnic Studies. Los Angeles: Sage.

Dewey, S. (2011). Neon wasteland: on love, motherhood, and sex work in a rust belt town. Berkeley: University of California Press.

Dewey, S., \& Kelly, P. (2011). Policing pleasure: sex work, policy, and the state in global perspective. New York: New York University Press.

Doetsch-Kidder, S. (2012). Social Change and Intersectional Activism: The Spririt of Social Movement. New York: Palgrave Macmillan.

Duong, K. (2012). What Does Queer Theory Teach Us about Intersectionality? Politics \& Gender, 8(03), 370-386. doi:10.1017/s1743923x12000360

Durisin, E. M., Meulen, E. v. d., \& Bruckert, C. (Eds.). (2018). Red Light Labour: Sex work regulation. Agency, and Resistance. Vancouver: UBC Press.

Dyer, R. (1997). White. London: Routledge.

Dyer, S., McDowell, L., \& Batnitzky, A. (2008). Emotional labour/body work: The caring labours of migrants in the UK's National Health Service. Geoforum, 39(6), 20302038. doi:10.1016/j.geoforum.2008.08.005

Ehrenreich, B., \& Hochschild, A. R. (Eds.). (2002). Global Woman: Nannies, Maids, and Sex Workers in the New Economy. New york: Metropolitan Books.

Farley, M. (2004). "Bad for the Body, Bad for the Heart": Prostitution Harms Women Even if Legalized or Decriminalized. Violence Against Women, 10(10), 1087-1125. doi: $10.1177 / 1077801204268607$

Farley, M., Cotton, A., Lynne, J., Zumbeck, S., Spiwak, F., Reyes, M. E., . . Sezgin, U. (2004). Prostitution and Trafficking in Nine Countries. Journal of Trauma Practice, 2(3-4), 33-74. doi:10.1300/J189v02n03_03

Farley, M., Lynne, J., \& Cotton, A. J. (2005). Prostitution in Vancouver: violence and the colonization of First Nations women. Transcult Psychiatry, 42(2), 242-271. Retrieved 
from https://www.ncbi.nlm.nih.gov/pubmed/16114585.

doi: $10.1177 / 1363461505052667$

Farro, A. L., \& Lustiger-Thaler, H. (2014). Introduction: Subjectivity and Collective Action.

In A. L. Farro \& H. Lustiger-Thaler (Eds.), Reimagining Social Movements from Collectives to Individuals. Surrey: Ashgate.

Ferris, S. (2007). The lone streetwalker": Missing women and sex work-related news in mainstream canadian media. West Coast Line, 4l(1).

Ferris, S. (2015). Street sex work and Canadian cities : resisting a dangerous order. Edmonton, Alberta, Canada: The University of Alberta Press.

Finch, J. (1984). 'It's great to have someone to talk to': The ethics and politics of interviewing women. In C. Bell \& H. Roberts (Eds.), Social Researching: Politics, Problems, Practice (pp. 70-97). London: Routledge Kegan Paul.

Forbat, L., \& Henderson, J. (2005). Theoretical and practical reflections on sharing transcripts with participants. Qual Health Res, 15(8), 1114-1128. Retrieved from https://www.ncbi.nlm.nih.gov/pubmed/16221883. doi:10.1177/1049732305279065

Forna, A. (1991). Pornography and Racism: Sexualizing Oppression and Inciting Hatred. In C. Itzin (Ed.), Pornography: women, violence and civil liberties (pp. 102-112). Oxford, England: Clarendon.

Foucault, M. (2008). The Birth of Biopolitics: Lectures at the Collège de France, 1978-1979 (G. Burchell, Trans.). New York: Palgrave Macmillan.

Fraser, P. (1985). Report of the Special Committee on Pornography and Prostituion. Retrieved from Ottawa:

Gabriel, C. (1999). Restructring at the Margins: Women of Colour and the Changing Economy. In E. Dua \& A. Robertson (Eds.), Scratching the Surface: Canadian antiracist feminist thought. Toronto: Women's Press.

Gailey, J. A. (2014). The hyper(in)visible fat woman: Weight and gender discourse in contemporary society. New York: Palgrave Macmillan.

Gailey, J. A. (2015). Transforming the Looking-Glass: Fat Women's Sexual Empowerment through Body Acceptance. In H. Hester \& C. Walters (Eds.), Fat Sex: New Directions in Theory and Activism. Surrey: Ashgate.

Gall, G. (2006). The Political Economy of the Sex Industry. In Sex Worker Union Organising: An International Study (pp. 36-45). New York: Palgrave MacMillan.

Gardener, T. A. (1980). Racism in Pornography and the Women's Movement. In L. Lederer (Ed.), Take back the night: women on pornography (1st ed., pp. 94-101). New York: Morrow.

Gergen, M. (2008). Qualitative Methods in Feminist Psychology. In W. Stainton Rogers, C. Willig, \& ProQuest (Eds.), The SAGE handbook of qualitative research in psychology. London;Los Angeles, Calif;: Sage publications.

Goffman, E. (1959). The Presentation of Self in Everyday Life. New York: Anchor Books.

Goffman, E. (1963). Stigma: Notes on the Management of Spoiled Identity. New York: Simon \& Schuster Inc.

Goffman, E. (1967). Interaction ritual: essays on face-to-face behavior. Chicago: Aldine Pub. Co.

Goffman, E. (1969). Strategic Interaction. Philadelphia: University of Pennsylvania Press.

Goldenberg, S. M., Krusi, A., Zhang, E., Chettiar, J., \& Shannon, K. (2017). Structural Determinants of Health among Im/Migrants in the Indoor Sex Industry: Experiences 
of Workers and Managers/Owners in Metropolitan Vancouver. PLoS One, 12(1), e0170642. Retrieved from https://www.ncbi.nlm.nih.gov/pubmed/28141835. doi:10.1371/journal.pone.0170642

Goldenberg, S. M., Liu, V., Nguyen, P., Chettiar, J., \& Shannon, K. (2015). International migration from non-endemic settings as a protective factor for HIV/STI risk among female sex workers in Vancouver, Canada. J Immigr Minor Health, 17(1), 21-28. Retrieved from https://www.ncbi.nlm.nih.gov/pubmed/24700025. doi:10.1007/s10903-014-0011-1

Gotell, L. (2002). The Ideal Victim, The Hysterical Complainant, And The Disclosure Of Confidential Records: The Implications Of The Charter For Sexual Assault Law. Osgood Hall Law Journal, 40.

Gotell, L. (2008). Rethinking Affirmative Consent In Canadian Sexual Assault Law: Neoliberal Sexual Subjects And Risky Women. Akron Law Review, 41.

Green, M. A., Evans, C. R., \& Subramanian, S. V. (2017). Can intersectionality theory enrich population health research? Soc Sci Med, 178, 214-216. Retrieved from https://www.ncbi.nlm.nih.gov/pubmed/28238539. doi:10.1016/j.socscimed.2017.02.029

Grillo, T. (1995). Anti-Essentialism and Intersectionality: Tools to Dismantle the Master's House. BERKELEY WOMEN'S LAW JOURNAL, 10.

Hagens, V., Dobrow, M. J., \& Chafe, R. (2009). Interviewee Transcript Review: assessing the impact on qualitative research. BMC Med Res Methodol, 9, 47. Retrieved from https://www.ncbi.nlm.nih.gov/pubmed/19580666. doi:10.1186/1471-2288-9-47

Hail-Jares, K., Shdaimah, C., \& Leon, C. (Eds.). (2017). Challenging Perspectives on StreetBased Sex Work. Chicago: Temple University Press.

Hall, S. (1991 [1973]). Encoding, decoding. In S. During (Ed.), Encoding, decoding. (pp. 90103). London: Routledge.

Hallgrimsdottir, H. K., Phillips, R., \& Benoit, C. (2006). Fallen Women and Rescued Girls:Social Stigma and Media Narrative of the Sex Industry in Victoria, B. C., from 1980 to 2005. Canadian Review of Sociology/Revue canadienne de sociologie, 43(3), 265-280.

Ham, J. (2017). Sex work, immigration and social difference (1 ed. Vol. 7;7.;). London;New York;: Routledge, Taylor and Francis Group.

Ham, J. (2018). Using difference in intersectional research with im/migrant and racialized sex workers. Theoretical Criminology. doi:10.1177/1362480618819807

Ham, J., \& Gilmour, F. (2016). 'We all have one': exit plans as a professional strategy in sex work. Work, Employment and Society, 31(5), 748-763.

doi:10.1177/0950017016666198

Hamermesh, D. S. (2011). Beauty Pays: Why Attractive People are More Successful. Princeton and Oxford: Princeton University Press.

Hancock, A.-M. (2007). Intersectionality as a Normative and Empirical Paradigm. Politics \& Gender, 3(02). doi:10.1017/s1743923x07000062

Hanger, A., Maloney, J., Canada. Parliament.House of Commons.Standing Committee on, J. H., Rights, \& Canada.Parliament. House of Commons.Subcommittee on Solicitation, L. (2006). The challenge of change: A study of canada's criminal prostitution laws. Retrieved from Ottawa: 
Hannem, S. (2018). Everybody Knows Everybody: Sex Work in Rural and Small Communities. In E. M. Durisin, E. v. d. Meulen, \& C. Bruckert (Eds.), Red Light Labour: Sex Work Regulation, Agency, and Resistance. Vancouver: UBC Pres.

Harding, S. (1987). Feminism and methodology: social science issues. Bloomington: Indiana University Press.

Harding, S. (1991). Whose science? Whose knowledge? . Milton Keynes: Open University Press.

Harding, S. (1993). Rethinking standpoint epistemology: What is "strong objectivity"? In L. A. E. Potter (Ed.), Feminist epistemologies (pp. 49-82). New York: Routledge.

Hekman, S. (1999). Identity Crises: Identity, Identity Politics and Beyond. In S. Hekman (Ed.), Feminism, Identity and Difference. London: Frank Cass.

Henderson, J. (2003). Settler feminism and race making in Canada. Toronto: University of Toronto Press.

Henne, K., \& Troshynski, E. (2013). Mapping the margins of intersectionality: Criminological possibilities in a transnational world. Theoretical Criminology, 17(4), 455-473. doi: $10.1177 / 1362480613494990$

Hesse-Biber, S. N. (1996). Am I thin enough yet?: the cult of thinness and the commercialization of identity. New York: Oxford University Press.

Hesse-Biber, S. N. (2012). Feminist Research: Exploring, Interrogating, and Transforming the Interconnections of Epistemology, Methodology, and Method. In S. N. Hesse-Biber (Ed.), Handbook of feminist research: Theory and praxis. Thousand Oaks: SAGE.

Hesse-Biber, S. N. (2013a). Conclusion: Putting together your research project. In S. HesseBiber (Ed.), Feminist Research Practice: A Primer. London: Sage.

Hesse-Biber, S. N. (2013b). Feminist Approaches to In-Depth Interviewing. In S. Hesse-Biber (Ed.), Feminist Research Practice: A Primer. London: Sage.

Hobson, J. (2005). Venus in the dark: blackness and beauty in popular culture. New York: Routledge.

hooks, b. (1994a). Essentialism and Experience. In Teaching to Transgress: Education as the Practice of Freedom. New York: Routledge.

hooks, b. (1994b). Homeplace: A Site of Resistance" Yearning: race, gender, and cultural politics.

hooks, b. (2000). Feminist theory: from margin to center. In (2nd ed., Vol. 5). Cambridge, MA: South End Press.

Hubbard, P. (2004). Cleansing the metropolis: sex work and the politics of zero tolerance. Urban Studies, 41(9), 1687-1702. doi:10.1080/0042098042000243101

Hubbard, P., \& Sanders, T. (2003). Making Space for Sex Work: Female Street Prostitution and the Production of Urban Space. International Journal of Urban and Regional Research, 27(1), 75-89.

Hughes, E. C. (1945). Dilemmas and Contradictions of Status. American Journal of Sociology, 40(5), 353-359.

Hunt, S. (2010). Colonial Roots, Contemporary Risk Factors: a cautionary exploration of the domestic trafficking of Aboriginal women and girls in British Columbia, Canada. Alliance News.

Hunt, S. (2013). Decolonizing Sex Work: Developing an Intersectional Indigenous Approach. In E. v. d. Meulen, E. M. Durisin, \& V. Love (Eds.), Selling Sex: Experience, Advocacy, and Research on Sex Work in Canada. Vancouver: UBC Press. 
Hunt, S. (2015/2016). Representing Colonial Violence: Trafficking, Sex Work, and the Violence of Law. Atlantis, 37.2(1).

Hunter, M. L. (2002). “IF YOU'RE LIGHT YOU'RE ALRIGHT”: Light Skin Color as Social Capital forWomen of Color. Gender \& Society, 6(2), 175-193.

Hunter, M. L. (2005). Race, gender, and the politics of skin tone. New York: Routledge. Hutchinson, D. L. (2001). Identity Crisis: "Intersectionality," "Multidimensionality," and the Development of an Adequate Theory of Subordination. Michigan Journal of Race \& Law, 6(2), 285-318.

Jay, S. (2014). Advancing Women's Equality, Countering the Entrenchment of Sexualized Racism by Abolishing Prostitution. Brief Index Bill C36. Retrieved from https://sencanada.ca/content/sen/committee/412/lcjc/briefs/c-36/c36 brief asianwomencoalitionendingprostitution(suzannejay) e.pdf

Jeffrey, L. (2004). Prostitution as Public Nuisance: Prostitution Policy in Canada. In J.

Outshoorn (Ed.), The Politics of Prostitution: Women's Movements, Democratic States and the Globalisation of Sex Commerce. Cambridge: Cambridge University Press.

Jeffrey, L. (2005). Canada and migrant sex-work: Challenging the 'foreign' in foreign policy. Canadian Foreign Policy, 12(1).

Jeffrey, L., \& Macdonald, G. (2006). "It's the Money, Honey": The Economy of Sex Work in the Maritimes. Canadian Review of Sociology/Revue canadienne de sociologie, 43, 313-327. doi:10.1111/j.1755-618X.2006.tb02227.x

Jeffreys, S. (2008). The Industrial Vagina: The Political Economy of the Global Sex Trade. New York: Routledge.

Jenness, V. (1993). Making it work: the Prostitutes' Rights Movement in perspective. In. New York: de Gruyter.

Jiwani, Y. (2002). The Criminalization of "Race" and the Racialization of Crime. In W. Chan \& K. Mirchandani (Eds.), Crimes of Colour: Racialization and the Criminal Justice System in Canada (pp. 67-86). Peterborough: Broadview Press.

Jiwani, Y. (2014). Posthumous Rescue: The Shafia Young Women as Worthy Victims. Girlhood Studies, 7(1). doi:10.3167/ghs.2014.070104

Johnson, K. (2004). Police-Black Community Relations in Postwar Philadelphia: Race and Criminalization in Urban Social Spaces, 1945-1960. The Journal of African American History, 89(2), 118-134.

Johnson, R. (2005). Gender, Race, Class and Sexual Orientation: Theorizing the Intercestions. In G. MacDonald, L. O. Rachel, \& C. C. Smith (Eds.), Feminism, Law, Inclusion: Intersectionality in Action. Toronto: Sumach Press.

Johnston, H. (2014). What is a Social Movement. Cambridge: Polity press.

Kay Hoang, K. (2011). "She's Not a Low-Class Dirty Girl!": Sex Work in Ho Chi Minh City, Vietnam. Journal of Contemporary Ethnography, 40(4), 367-396. doi:10.1177/0891241611403481

Kaye, J. (2017a). Responding to Human Trafficking: Dispossession, Colonial Violence, and Resistance among Indigenous and Racialized Women. Toronto: University of Toronto Press.

Kaye, J. (2017b). Settler Colonialism, Sex Work, Criminalization, and Human Trafficking. In Responding to Human Trafficking: Dispossession, Colonial Violence, and Resistance among Indigenous and Racialized Women. Toronto: University of Toronto Press. 
Kelch-Oliver, K., \& Ancis, J. R. (2011). Black Women's Body Image: An Analysis of Culture-Specific Influences. Women \& Therapy, 34(4), 345-358.

doi:10.1080/02703149.2011.592065

Kempadoo, K. (1998). Introduction :Global sex workers rights. In K. Kempadoo \& J.

Doezema (Eds.), Global Sex Workers: Rights, Resistance, and Redefinition. New

York: Routledge.

Kempadoo, K. (2001). Women of Color and the Global Sex Trade: Transnational Feminist Perspectives. Meridians, 1(2).

Kempadoo, K. (2003). Globalizing sex workers' rights. Canadian Woman Studies, 22(3-4).

Kempadoo, K. (2012). Introduction: Abolitionism, Criminal Justice, and Transnational

Feminism. In K. Kempadoo, J. Sanghera, \& B. Pattanaik (Eds.), Trafficking and

Prostitution Reconsidered: New Perspective on Migration, Sex Work, and Human

Rights (2nd ed.). London: Paradigm Publishers.

Kempadoo, K., \& Doezema, J. (Eds.). (1998). Global Sex Workers: Rights, Resistance, and Redefinition. London: Routledge.

King-O'Riain, R. C. (2006). Pure Beauty: Judging Race in Japanese American Beauty Pageants. Minneapolis: University of Minnesota Press.

King, D. K. (1988). Multiple Jeopardy, Multiple Consciousness: The Context of a Black Feminist Ideology. Signs, 14(1).

Knudsen, S. V. (2006). Intersectionality - A Theoretical Inspiration in the Analysis of Minority Cultures and Identities in Textbooks. In E. r. Bruillard, B. Aamotsbakken, \& M. Horsley (Eds.), Eighth International Conference on, Learning Educational, Media (pp. 61-76). Utrecht, The Netherlands: IARTEM.

Lam, E. (2016). Inspection, policing, and racism: How municipal by-laws endanger the lives of Chinese sex workers in Toronto. Canadian Review of Social Policy, 75, 87-112.

Landry, D., \& Maclean, G. (1996). The Spivak Reader. New York: Routledge.

Larose, S. L., Kpelitse, K. A., Campbell, M. K., Zaric, G. S., \& Sarma, S. (2016). Does obesity influence labour market outcomes among working-age adults? Evidence from Canadian longitudinal data. Econ Hum Biol, 20, 26-41. Retrieved from https://www.ncbi.nlm.nih.gov/pubmed/26650919. doi:10.1016/j.ehb.2015.09.007

Law, T. (2012). Cashing in on Cachet? Ethnicity and Gender in the Strip Club. Canadian Journal of Women and the Law, 24(1), 135-153. doi:10.3138/cjwl.24.1.135

LeBesco, K. (2004). Revolving bodies? The struggle to redefine fat identity. Amherst: University of Massachusetts Press.

Leidholdt, D. A. (2004). Prostitution and Trafficking in Women. Journal of Trauma Practice, 2(3-4), 167-183. doi:10.1300/J189v02n03_09

Letherby, G. (2003). Feminist Research in Theory and Practice. Buckingham: Open University Press.

Lever, J., Kanouse, D. E., \& Berry, S. H. (2005). Racial and Ethnic Segmentation of Female Prostitution in Los Angeles County. Journal of Psychology \& Human Sexuality, 17(12), 107-129. doi:10.1300/J056v17n01_07

Levine-Rasky, C. (2011). Intersectionality theory applied to whiteness and middle-classness. Social Identities, 17(2), 239-253. doi:10.1080/13504630.2011.558377

Levine, P. (2000). Orientalist Sociology and the Creation of Colonial Sexualities. Feminist review, 65(Reconstructing Femininities: Colonial Intersections of Gender, Race, Religion and Class), 5-21. 
Levine, P. (2003). Prostitution, race, and politics: policing venereal disease in the British Empire. New York: Routledge.

Lewis, J., \& Maticka-Tyndale, E. (2000). Licensing Sex Work: Public Policy and Women's Lives. Canadian Public Policy - Analyse De Politiques, 26(4).

Lewis, J., Maticka-Tyndale, E., Shaver, F., \& Schramm, H. (2005). Managing Risk and Safety on the Job. Journal of Psychology \& Human Sexuality, 17(1-2), 147-167. doi:10.1300/J056v17n01_09

Lim, L. L. (Ed.) (1998). The Sex Sector: The economic and social bases of prostitution in Southeast Asia. Geneva: International Labour Office.

Lowman, J. (2000). Violence and the Outlaw Status of (Street) Prostitution in Canada. Violence Against Women, 6(9), 987-1011.

Lucas, A. M. (1995). Race, Class, Gender, and Deviancy: The Criminalization of Prostitution. BERKELEY WOMEN'S LAW JOURNAL, 10.

Lucas, A. M. (2005). The Work of Sex Work: Elite Prostitutes' Vocational Orientations and Experiences. Deviant Behavior, 26(6), 513-546. doi:10.1080/01639620500218252

MacDonald, G., Jeffrey, L. A., Martin, K., \& Ross, R. (2013). Stepping All Over the Stones: Negotiating Feminism and Harm Reduction in Halifax. In E. v. d. Meulen, E. M. Durisin, \& V. Love (Eds.), Selling Sex: Experience, Advocacy, and Research of Sex Work in Canada. Vancouver, Toronto: UBC Press.

Macdonald, J., Stokes, R., Ridgeway, G., \& Riley, J. (2007). Race, Neighbourhood Context and Perceptions of Injustice by the Police in Cincinnati. Urban Studies, 44(13), 25672585. doi:10.1080/00420980701558400

Mackey, F. (2010). Done with slavery: the Black fact in Montreal, 1760-1840 (Vol. 21;21.;). Montreal;Ithaca;: McGill-Queen's University Press.

Mahdavi, P. (2010). Race, space, place: notes on the racialisation and spatialisation of commercial sex work in Dubai, UAE. Cult Health Sex, 12(8), 943-954. Retrieved from http://www.ncbi.nlm.nih.gov/pubmed/20936551. doi:10.1080/13691058.2010.512393

Mahdavi, P. (2013a). The geography of sex work in the United Arab Emirates. In F. W. Twine \& B. Gardener (Eds.), Geographies of Priviledge. New York and London: Routledge.

Mahdavi, P. (2013b). Privileged Bodies in Pleasure and Leisure Spaces: Sex, Music, and Dance Clubs. In F. W. Twine \& B. Gardener (Eds.), Geographies of Privilege. London and New York: Routledge.

Maher, J., Pickering, S., \& Gerard, A. (2013). Sex Work: Labour, mobility and sexual services. London and New York: Routledge.

Mahoney, M. R. (1997). Racial Construction and Women as Differentiated Actors. In R. Delgado \& J. Stefancic (Eds.), Critical White Studies: Looking Behind the Mirror (pp. 305-309). Philadelphia: Temple University Press.

Man, G. (2004). Gender, work and migration: Deskilling chinese immigrant women in Canada. Women's Studies International Forum, 27(2), 135-148. doi:10.1016/j.wsif.2004.06.004

Mar, L. R. (2010). Brokering belonging: Chinese in Canada's exclusion era, 1885-1945. Toronto: University of Toronto Press.

Mauthner, M. (1998). Speaking and Listening: Reflecting Multilayered Voices. In J. Ribbens \& R. Edwards (Eds.), Feminist Dilemmas in Qualitaive Research: Public Knowledge and Private Lives (pp. 39-57). London: Sage. 
Maynard, R. (2015/2016). Fighting wrongs with wrongs? How Canadian anti-trafficking crusades have failed sex workers, migrants, and Indigenous communities. Atlantis, 37.2(1).

Maynard, R. (2017). Policing Black lives: state violence in Canada from slavery to the present. Winnipeg: Fernwood.

McCall, L. (2001). Sources of Racial Wage Inequality in Metropolitan Labor Markets: Racial, Ethnic, and Gender Differences. American Sociological Review, 66(4).

McCall, L. (2005). The Complexity of Intersectionality. Signs, 30(3), 1771-1800.

McCall, L. (2007). Increasing class disparities among women and the politics of gender equity. In D. S. Cobble (Ed.), The Sex of Class: Women Transforming American Labour. Ithaca: Cronell University Press.

McCalla, A., \& Satzewich, V. (2002). Settler Capitalism and the Construction of Immigrant and "Indians" as Racialized Other. In W. Chan \& K. Mirchandani (Eds.), Crimes of colour: racialization and the criminal justice system in Canada. Peterborough, Ont: Broadview Press.

McIntosh, P. (1997). White Privilege and Male Privilege: A Personal Account of Coming to See Correspondences through Work in Women's Studies. In R. Delgado \& J. Stefancic (Eds.), Critical White Studies: Looking begaind the mirror (pp. 291-299). Philadelphia: Temple University.

Millar, H., O’Doherty, T., \& SWAN. (2015). The Palermo Protocol \& Canada: The Evolution And Human Rights Impacts Of Antitrafficking Laws In Canada (20022015). Retrieved from Vancouver:

Miller-Young, M. (2010). Putting Hypersexuality to Work: Black Women and Illicit Eroticism in Pornography. Sexualities, 13(2), 219-235. doi:10.1177/1363460709359229

Miller-Young, M. (2014). A Taste for Brown Sugar: Black Women in Pornography. Durham and London: Duke University Press.

Monture-Angus, P., \& Conroy, B. (1995). Thunder in my soul: a Mohawk woman speaks. Halifax, N.S: Fernwood Pub.

Morris, A. D. (1992). Political Conciousness and Collective Action. In A. D. Morris \& C. M. Muller (Eds.), Frontiers in Social Movement Theory. New Haven and LondonYale University Press.

Morton, J. W. (1973). In the sea of sterile mountains: the Chinese in British Columbia. Vancouver: Douglas.

Moss, P. (2007). Emergent Methods in Feminist Research. In S. N. Hesse-Biber (Ed.), Handbook of feminist research: theory and Praxis. London: Sage Publications.

Moss, W., \& Gardner-O’Toole, E. (1991). Aboriginal People: History of Discriminatory Laws. Government of Canada Retrieved from http://dsp-psd.pwgsc.gc.ca

Murray, S. (2004). Locating Aesthetics: Sexing the Fat Woman. Social Semiotics, 14(3), 237247. doi:10.1080/10350330408629678

Mutua, A. (2006). The Rise, Development and Future Directions of Critical Race Theory and Related Scholarship. Denver University Law Review, 84(2), 329-394.

Mutua, A. (2013). Multidimensionality Is To Masculinities What Intersectionality Is To Feminism. Nevada Law Journal, 13(12), 341-367.

Nagel, J. (2010). Ethnicites and Sexualities. In P. H. Collins \& J. Solomos (Eds.), The Sage Handbook of Race and Ethnic Studies. Los Angeles: Sage. 
Naples, N. A. (2003). Feminism and method: ethnography, discourse analysis, and activist research. In. New York: Routledge.

Nash, J. C. (2008). re-thinking intersectionality. Feminist review, 89, 1-15.

Nash, J. C. (2011). Practicing Love: Black Feminism, Love-Politics, and PostIntersectionality. Meridians: feminism, race, transnationalism, 11(2).

Nash, J. C. (2014). The Black body in ecstasy: reading race, reading pornography. London;Durham;: Duke University Press.

Nielsen, J. (1990). Feminist research methods. Boulder: West View.

"No more" Ending sex-trafficking in Canada: Report of the National Task Force on Sex Trafficking of Women and Girls in Canada. (2014). Retrieved from Toronto:

Novek, S. (2013). Filipino Health Care Aides and the Nursing Home Labour Market in Winnipeg. Can J Aging, 32(4), 405-416. Retrieved from https://www.ncbi.nlm.nih.gov/pubmed/24063532. doi:10.1017/S071498081300038X

NSWP. (2014). Alliance for the Safety of Prostitutes Formed in Vancouver. History of Sex Worker Rights Movement: North Americna and the Caribbean. Retrieved from http://www.nswp.org/timeline/event/alliance-the-safety-prostitutes-formed-vancouver

NWAC. (2014). Sexual exploitation and trafficking of aboriginal women and girls: Literature Review and Key Informant Interviews. Retrieved from

O'Connell-Davidson, J. (1995). The Anatomy of 'Free Choice' Prostitution. Gender, work, and organization, 2(1), 1-10.

O'Connell-Davidson, J. (1998). Prostitution, power, and freedom. In. Ann Arbor: University of Michigan Press.

O'Doherty, T. (2011a). Criminalization and Off-Street Sex Work in Canada. Canadian Journal of Criminology and Criminal Justice, 53(2), 217-245. doi:10.3138/cjecj.53.2.217

O'Doherty, T. (2011b). Victimization in off-street sex industry work. Violence Against Women, 17(7), 944-963. Retrieved from https://www.ncbi.nlm.nih.gov/pubmed/21665856. doi:10.1177/1077801211412917

O’Doherty, T., Millar, H., Clancey, A., \& Mackenzie, K. (2018). Misrepresentations, Inadequate Evidence, and Impediments to Justice: Human Rights Impacts of Canada's Anti-Trafficking Efforts. In E. M. Durisin, E. v. d. Meulen, \& C. Bruckert (Eds.), Red Light Labour: Sex Work Regulation, Agency, and Resistance. Vancouver: UBC Press.

Oakley, A. (1981). Interviewing women: A contradiction in terms. In H. Roberts (Ed.), Doing Feminist Research (pp. 30-61). London: Routledge.

Oliveira, A., \& Murphy, K. (2014). Race, Social Identity, and Perceptions of Police Bias. Race and Justice, 5(3), 259-277. doi:10.1177/2153368714562801

Panichelli, M., Wahab, S., Saunders, P., \& Capous-Desyllas, M. (2015). Queering whiteness: Unpacking privilege within the US sex worker rights movement. In M. Laing, K. Pilcher, \& N. Smith (Eds.), Queer Sex Work. London and New York: Routledge.

Pause, C. (2015). Human Nature: on Fat Sexual Identity and Agency. In H. Hester \& C. Walters (Eds.), Fat Sex: New Directions in Theory and Activism. Surrey: Ashgate.

Perry, A. (2005). Metropolitan Knowledge, Colonial Practice, and Indeginous Womanhood: Missions in the Nineteenth-Century British Columbia. In K. Pickles \& M. Rutherdale (Eds.), Contact zones: Aboriginal and settler women in Canada's colonial past. Vancouver: UBC Press. 
Phoenix, J. (1999). Making sense of prostitution. New York;Houndmills, Basingstoke, Hampshire;: Macmillan Press.

Pitcher, J. (2015). Sex work and modes of self-employment in the informal economy: diverse business practices and constraints to effective working. Soc Policy Soc, 14(1), 113123. Retrieved from http://www.ncbi.nlm.nih.gov/pubmed/25506264. doi:10.1017/S1474746414000426

Policy and guidelines on racism and racial discrimination. (2005). Retrieved from Tronto:

Polletta, F. (1999). "Free Spaces" in collective action. Theory and Society, 28, 1-38.

Polletta, F., \& Jasper, J. M. (2001). Collective identity and social movements. Annual Review of Sociology, 27, 283-305.

Pound, R. (1910). Law in Books and Law in Action. American Law Review, 44(12).

Poutanen, M. A. (2002). Regulating Public Spaces in Early Nineteenth-Century Montreal: Vagrancy Laws and Gender in a Colonial Context. Social History, 35(69).

POWER. (2013). Rally at the supreme court - sex workers, we support you! [Press release]

POWER. (2014). Sex workers and allies rally on parliament hill as the senate committee hearings on bill c36 begin [Press release]

Prasad, M. (1999). The Morality of Market Exchange: Love, Money, and Contractual Justice. Sociological Perspectives, 42(2).

Pratt, G. (2005). Abandoned Women and Spaces of the Exception. Antipode, 37(5).

Pruitt, M. V. (2016). "Just a Gigolo": Differences in Advertisements of Male-for-Female and Male-for-Male Online Escorts. Deviant Behavior. doi:10.1080/01639625.2016.1260384

Puar, J. K. (2005). Queer times, queer assemblages. Social Text, 23(3-4), 121-139.

Puar, J. K. (2007). Terrorist Assemblages: Homonationalim in queer times. Durham and London: Duke University Press.

Puar, J. K. (2012). "I would rather be a cyborg than a goddess": Becoming-Intersectional in Assemblage Theory. philoSOPHIA, 2(1), 42 - 58.

Purdie-Vaughns, V., \& Eibach, R. P. (2008). Intersectional Invisibility: The Distinctive Advantages and Disadvantages of Multiple Subordinate-Group Identities. Sex Roles, 59(5-6), 377-391. doi:10.1007/s11199-008-9424-4

Purkayastha, B. (2012). Intersectionality in a Transnational World. Gender \& Society, 26(1), 55-66. doi:10.1177/0891243211426725

Raguparan, M. (2014). (Il)legal subjects? Contested identities of Canadian indoor sex workers. Multidisciplinary Journal of Gender Studies, 3(1), 328-350. doi:10.4471/generos.2014.32

Randall, M. (2010). Sexual Assault Law, Credibility, and "Ideal Victims": Consent, Resistance, and Victim Blaming. Canadian Journal of Women and the Law, 22(2), 397-433. doi:10.3138/cjwl.22.2.397

Ratansi, Y. (2007). Turning Outrage Into Action To Address Trafficking For The Purpose Of Sexual Exploitation In Canada. Retrieved from Ottawa:

Ravon, L., \& Stefov, D. (2016). Shortchanged: Make Work Paid, Equal, Valued for Women. Retrieved from Ottawa:

Razack, S. (1998a). Looking white peopple in the eye: Gender, race, and culture in courtrooms and classrooms. Toronto: University of Toronto Press.

Razack, S. (1998b). Race, Space, and Prostitution: The Making of the Bourgeois Subject. Canadian Journal of Women and the Law, 10. 
Razack, S. (2002). Gendered Racial Violence and Spatialized Justice: the Murder of Pamela George. In S. Razack (Ed.), Race, Space and the Law: Unmapping a White Settler Society. Toronto: Between the Lines.

RCMP. (2013). Domestic Human Trafficiking for Sexual Exploitation in Canada. Retrieved from Ottawa:

REAL Women of Canada: Brief on Bill C-36 Protection of Communities and Exploited Persons Act. (2014). Brief Index Bill C36. Retrieved from https://sencanada.ca/content/sen/committee/412/1cjc/briefs/c-36/sm_c36 brief_realwomenofcanada e.pdf

Reinharz, S. (1992). Feminist methods in social research. New York: Oxford University Press.

Rhodes, T., Simic, M., Baros, S., Platt, L., \& Zikic, B. (2008). Police violence and sexual risk among female and transvestite sex workers in Serbia: qualitative study. BMJ, 337, a811. Retrieved from http://www.ncbi.nlm.nih.gov/pubmed/18667468. doi:10.1136/bmj.a811

Rivers-Moore, M. (2013). Affective sex: Beauty, race and nation in the sex industry. Feminist Theory, 14(2), 153-169. doi:10.1177/1464700113483242

Robinson-Moore, C. L. (2008). Beauty standards reflect eurocentric paradigms-so what? skin color, identity, and black female beauty. The Journal of Race \& Policy, 4(1).

Rose, G. (1993). Feminism and Geography. Minneapolis: The University of Minnesota Press.

Rose, T. (2004). Longing to Tell: Black Women Talk about Sexuality and Intimacy. New York: Macmillan.

Rosen, E., \& Venkatesh, S. A. (2008). A "Perversion" of Choice: Sex Work Offers Just Enough in Chicago's Urban Ghetto. Journal of Contemporary Ethnography, 37(4), 417-441.

Ross, B. (2009). Burlesque West: Showgirls, sex, and sin in postwar Vancouver. Toronto: University of Toronto Press.

Rucker, C. E., \& Cash, T. F. (1992). Body images, Body size preceptions, and eating behaviours among African-American and White College Women. International Journal of Eating Disorder, 12(3).

Ryan, D., \& Jones, C. (2009). Understanding Digitial Marketing: Marketing Strategies for Engaging the Digital Generation. London and Philadelphia: Kogan Page.

Ryley, B. (1997). Gold Diggers of the Klondike: Prostitution in Dawson City, Yukon, 18981908. Canada: Watson \& Dwyer Publishing Ltd.

Samuels, R.-S. (2008). Identity, Oppression, and Power: Feminisms and Intersectionality Theory. Affilia: Journal of Women and Social Work, 23(1).

Sanders, T. (2004). The risks of street prostitution: punters, police and protesters. Urban Studies, 41(9), 1703-1717. doi:10.1080/0042098042000243110

Sanders, T. (2005a). 'It's Just Acting': Sex Workers' Strategies for Capitalizing on Sexuality. GENDER, WORK AND ORGANIZATION, 2(4), 319 - 342. doi:10.1111/j.14680432.2005.00276.x

Sanders, T. (2005b). Sex Work: A risky business. Devon: Willan Publishing.

Sanders, T. (2006). Behind the personal ads: the indoor sex markets in Britain. In R. Campbell \& M. O'Neil (Eds.), Sex Work Now: . Devon: Willan Publishing. 
Sanders, T. (2009). Controlling the 'anti sexual' city: Sexual citizenship and the disciplining of female street sex workers. Criminology and Criminal Justice, 9(4), 507-525. doi:10.1177/1748895809343403

Sanders, T., \& Ponsaers, P. (2008). Selling sex in the shadow economy. International Journal of Social Economics, 35(10), 704-716. doi:10.1108/03068290810898927

Sanders, T., \& Soothill, K. (2011). The policing of pleasure: 'What kind of police service do we want?'. The Police Journal, 84. doi:10.1358/pojo.2011.84.2.557

Sandoval, C. (2000). Methodology of the oppressed (Vol. 18). Minneapolis, MN: University of Minnesota Press.

Sanghera, J. (2005). Unpacking Trafficking Discourse. In K. Kempadoo, J. Sanghera, \& B. Pattanaik (Eds.), Trafficking and Prostituion Reconsidered: New Perspective on Migration, Sex Work, and Human Rights. Boulder, CO: Paradigm Publishers.

Sangster, J. (2001). Regulating girls and women: sexuality, family, and the law in Ontario, 1920-1960. Oxford: Oxford University Press.

Saunders, P., \& Kirby, J. (2010-2011). Move Along: Community-based Research into the Poiicing of Sex Work in Washington, D.C. Social Justice, 37(1).

Scambler, G. (2007). Sex Work Stigma: Opportunist Migrants in London. Sociology, 41(6), 1079-1096. doi:10.1177/0038038507082316

Scambler, G., \& Paoli, F. (2008). Health work, female sex workers and HIV/AIDS: global and local dimensions of stigma and deviance as barriers to effective interventions. Soc Sci Med, 66(8), 1848-1862. Retrieved from http://www.ncbi.nlm.nih.gov/pubmed/18295948. doi:10.1016/j.socscimed.2008.01.002

Scott, J. C. (1985). Weapons of the weak: everyday forms of peasant resistance. New Haven: Yale University Press.

Scott, J. C. (1990). Domination and the arts of resistance: hidden transcripts. New Haven: Yale University Press.

Shah, S. P. (2003). Sex work in the global economy. New Labor Forum, 12(1), 74-81.

Shannon, K., Kerr, T., Allinott, S., Chettiar, J., Shoveller, J., \& Tyndall, M. W. (2008). Social and structural violence and power relations in mitigating HIV risk of drug-using women in survival sex work. Soc Sci Med, 66(4), 911-921. Retrieved from http://www.ncbi.nlm.nih.gov/pubmed/18155336. doi:10.1016/j.socscimed.2007.11.008

Shannon, K., Strathdee, S. A., Goldenberg, S. M., Duff, P., Mwangi, P., Rusakova, M., . . . Boily, M.-C. (2015). Global epidemiology of HIV among female sex workers: influence of structural determinants. The Lancet, 385(9962), 55-71. doi:10.1016/s0140-6736(14)60931-4

Sharpley-Whiting, T. D. (2007). Pimps up, ho's down: hip hop's hold on young Black women. New York: New York University Press.

Shaver, F. M. (2005). Sex work research: methodological and ethical challenges. J Interpers Violence, 20(3), 296-319. Retrieved from http://www.ncbi.nlm.nih.gov/pubmed/15684139. doi:10.1177/0886260504274340

Sherman, S. G., Footer, K., Illangasekare, S., Clark, E., Pearson, E., \& Decker, M. R. (2015). "What makes you think you have special privileges because you are a police officer?" A qualitative exploration of police's role in the risk environment of female sex 
workers. AIDS Care, 27(4), 473-480. Retrieved from http://www.ncbi.nlm.nih.gov/pubmed/25360822. doi:10.1080/09540121.2014.970504

Sloan, M. M., Evenson Newhouse, R. J., \& Thompson, A. B. (2013). Counting on Coworkers: Race, Social Support, and Emotional Experiences on the Job. Social Psychology Quarterly, 76(4), 343-372. doi:10.1177/0190272513504937

Smart, C. (1985). Leagal Subjects and Sexual Objects: Ideology, Law and Female Sexuality. In J. Brophy \& C. Smart (Eds.), Women-in-Law: Explorations in Law, Family and Sexualities (pp. 50-70.). U.S.A: Routledge \& Kegan Paul Pc:.

Smart, C. (1992). The woman of legal discourse. Social and Legal Studies, 1, 24-44.

Smith, L. T. (1999). Decolonizing Methodologies: Reaearch and Indigenous peoples. London: University of Otago press.

Socias, M. E., Deering, K., Horton, M., Nguyen, P., Montaner, J. S., \& Shannon, K. (2015). Social and Structural Factors Shaping High Rates of Incarceration among Sex Workers in a Canadian Setting. J Urban Health, 92(5), 966-979. Retrieved from http://www.ncbi.nlm.nih.gov/pubmed/26260991. doi:10.1007/s11524-015-9977-9

(2016). Professor Kimberlé Crenshaw's keynote speeh at the 2017 Women of the World Festival (WOW) [Retrieved from https://www.youtube.com/watch?v=-DW4HLgYPlA

SPOC. (2018). Resources. Retrieved from http://www.spoc.ca/resources.html

Standing, K. (1998). Writing the Voices of the Less Powerful: Research on Lone Mothers. In J. Ribbens \& R. Edwards (Eds.), Feminist Dilemmas in Qualitative Reserch: Public Knowledge and Private Lives. London: Sage.

Stanley, L., \& Wise, S. (1993). Method, methodology and epistemology in feminist research process. In L. Stanley (Ed.), Feminist praxis: Theory and epistemology in feminist sociology. New York: Routledge.

Staunæs, D. (2010). Where have all the subjects gone? Bringing together the concepts of intersectionality and subjectification. NORA - Nordic Journal of Feminist and Gender Research, 11(2), 101-110. doi:10.1080/08038740310002950

Stevens, C. (2017). Fat on Campus: Fat College Students and Hyper(in)visible Stigma. Sociological Focus, 51(2), 130-149. doi:10.1080/00380237.2017.1368839

Stychin, C. F. (1995). Law's Desire: Sexuality and the Limits of Justice. London: Routledge.

Sutton, B. (2010). Bodies in Crisis: Culture, Violence, and Women's Resistance in Neoliberal Argentina. New Brunswick, New Jersey, and London: Rutgers University Press.

Tarrow, S. (2011). Power in Movement: Social Movements and Contentious Politics (3rd ed.). Cambridge: Cambridge University Press.

Tate, S. (2005). Black Skins, Black Masks: Hybridity, Dialogism, Performativity. Hants: Ashgate.

Tate, S. (2007). Black beauty: Shade, hair and anti-racist aesthetics. Ethnic and Racial Studies, 30(2), 300-319. doi:10.1080/01419870601143992

Tate, S. (2009). Black Beauty: Aesthetics, Stylization, Politics. Furnham and Burlington: Ashgate.

Taylor, V. (2013). Social Movement Participation in the Global Society: Identity, Networks, and Emotions. In J. v. Stekelenburg, C. Roggeband, \& B. Klandermans (Eds.), Dynamics, Mechanisms, and Processes: THe Future of Social Movement Research. Minneapolis: University of Minnesota Press. 
Taylor, V., \& Whittier, N. (1992). Collective Identity in Social Movement Communities: Lesbian Feminist Mobilization. In A. D. Morris \& C. Muller (Eds.), Frontiers of Social Movement Theory. New Haven, Connecticut: Yale University Press.

Tilly, C. (2004). Social Movements, 1768-2004. Boulder and London: Paradigm Publisher.

Tilly, C. (2008). Contentious Performances Cambridge: Cambridge University Press.

Tomlinson, B. (2013). Colonizing intersectionality: replicating racial hierarchy in feminist academic arguments. Social Identities, 19(2), 254-272. doi:10.1080/13504630.2013.789613

Trinh, T. M. (1990). Not You/Like You: Post-Colonial Women and the Interlocking Questions of Identity and Difference. In G. Anzaldua (Ed.), In Making Face, Making Soul: Creative and Crtical Perspectives by Women of Colour. San Fransciso: Aunt Lute Foundation Books.

Twine, F. W., \& Gardener, B. (2013). Introduction. In F. W. Twine \& B. Gardener (Eds.), Geographies of Privilege. New York and London: Routledge.

Urban, G. L. (2004). Digital Marketing Strategy: Text and Cases. New Jersey: Pearson Education, Inc.

Valentine, G. (2007). Theorizing and Researching Intersectionality: A Challenge for Feminist Geography*. The Professional Geographer, 59(1), 10-21. doi:10.1111/j.14679272.2007.00587.x

Valentine, P. (1996). Nursing: a ghettoized profession relegated to women's sphere. International Journal of Nursing Studies, 33(1).

Valverde, M. (2008). The age of light, soap, and water: moral reform in English Canada, 1885-1925 : with a new introduction. Toronto: University of Toronto Press.

van der Meulen, E. (2012). When sex is work: organizing for labour rights and protections. Labour/Le Travail, 147+. Retrieved from https://proxy.library.carleton.ca/http://go.galegroup.com/ps/i.do?id=GALE\%7CA2982 $92667 \&$ sid $=$ summon\&v $=2.1 \& u=0$ cul carleton\& $i=r \& p=A O N E \& s w=w \& a s i d=e 70 a 6 b$ f4de9202195387abf7063eefa0.

van der Meulen, E., Durisin, E. M., \& Love, V. (Eds.). (2013). Selling Sex: Experience, Advocacy, and Research on Sex Work in Canada. Vancouver: UBC Press.

van der Meulen, E., \& Valverde, M. (2013). Beyond the Criminal Code: Municipal Licensing and Zoning Bylaws. In E. v. d. Meulen, E. M. Durisin, \& V. Love (Eds.), Sessling Sex: Experience, Advocacy, and Research on Sex Work in Canada. Vancouver: UBC Press.

Vault, M. L. D., \& Gross, G. (2007). Feminist Interviewing. In S. N. Hesse-Biber (Ed.), Handbook of Feminist Research: Theory and Praxis. London: Sage.

Wade, L. (2014). When Whiteness is the Standard of Beauty. The Society Pages. Retrieved from https://thesocietypages.org/socimages/2014/05/16/white-as-beautiful-black-aswhite/

Walby, K. (2010). Touching encounters: The sex and work of male-for-male internet escorts. $(\mathrm{PhD})$, Carleton University, Ottawa.

Walby, S., Armstrong, J., \& Strid, S. (2012). Intersectionality: Multiple Inequalities in Social Theory. Sociology, 46(2), 224-240. doi:10.1177/0038038511416164

Walker, S. (2007). Style and Status: Selling Beauty to African American Women, 1920-1975. Lexington: The University Press of Kentucky. 
Weheliye, A. G. (2014). Hebeas Viscus: Racializing Assemblages, Biopolitics, and Black Feminist Theories of the Human. London and Durham: Duke University Press.

Weissbrodt, D., \& Meili, S. (2012). Recent Developments in the Human Rights of Trafficked Persons. In C. v. d. Anker \& I. v. Liempt (Eds.), Human Rights and Migration: Trafficking for Forced Labour. Hampshire: Palgrave Macmillan.

Weitzer, R. (1991). Prostitutes' Rights in the United States: The Failure of a Movement. The Sociological Quarterly,, 32(1), 23-41.

Weitzer, R., \& Tuch, S. A. (2004). Race and Perceptions of Police Misconduct. Social Problems, 51(3), 305-325.

Weldon, J. (2010). Show me the money: A sex worker refelects on research into the sex industry. In M. Ditmore, A. Levy, \& A. William (Eds.), Sex work matters: Exploring money, power and intimacy in the sex industry. New York: Zed Books.

Wesley, J. K. (2003). Exotic dancing and the negotiation of identity: The Multiple Uses of Body Technologies. Journal of Contemporary Ethnography, 32(6), 643-669.

Williamson, C., Baker, L., Jenkins, M., \& Cluse-Tolar, T. (2007). Police-Prostitute Interactions. Journal of Progressive Human Services, 18(2), 15-37. doi:10.1300/J059v18n02 03

Yamada, M. (1990). Masks of Woman. In G. Anzaldua (Ed.), Making Face, Making Soul Haciendo Caras: Creative and Critical Perspective of Women of Colour. San Franciso: Aunt lute foundation books.

Young, I. M. (1990). Justice and the politics of difference. Princeton, N.J: Princeton University Press.

Yuval-Davis, N. (2006). Intersectionality and Feminist Politics. European Journal of Women's Studies, 13(3), 193-209. doi:10.1177/1350506806065752

Yuval - Davis, N. (2007). Intersectionality, Citizenship and Contemporary Politics of Belonging. Critical Review of International Social and Political Philosophy, 10(4), 561-574. doi:10.1080/13698230701660220

Zavella, P. (1993). Feminist Insider Dilemmas: Constructing Ethnic Identity with Chicana Informants. A Journal of Women Studies, 13(3).

Zingsheim, J. (2010). Developing Mutational Identity Theory: Evolution, Multiplicity, Embodiment, and Agency. Cultural Studies <=> Critical Methodologies, 11(1), 2437. doi: $10.1177 / 1532708610386546$

Zook, K. B. (1990). Light Skinned-ded Naps. In G. Anzaldua (Ed.), Making face, Making soul Haciendo Caras: Creative and Critical Perspectives by Women of Colour. San Francisco: Aunt Lute Foundation Books. 


\section{Appendix I}

Carleton University Research Office Research Ethics Board

1325 Dunton Tower 1125 Colonel By Drive Ottawa, ON K1S 5B6 Canada Tel: 613-520-2517 ethics@carleton.ca

\section{Ethics Clearance Form - New Clearance}

This is to certify that the Carleton University Research Ethics Board has examined the application for ethical clearance. The REB found the research project to meet appropriate ethical standards as outlined in the Tri-Council Policy Statement: Ethical Conduct for Research Involving Human, 2nd edition, and the Carleton University Policies and Procedures for the Ethical Conduct of Research.

Date of Clearance: January 24, 2014

Researcher: Menaka Raguparan (Student - Phd)

Department: Faculty of Public Affairs\Law (Department of)

University: Carleton University

Research Supervisor (if applicable): Prof. Diana Young and Prof. Lara Karaian

Project Number: 100834

Alternate File Number (if applicable):

Project Title: Social, legal and political identities of racialized women in the Canadian sex industry

Clearance Expires: May 31, 2014

\section{All researchers are governed by the following conditions:}

Annual Status Report: You are required to submit an Annual Status Report to either renew clearance or close the file. Failure to submit the Annual Status Report will result in the immediate 
suspension of the project. Funded projects will have accounts suspended until the report is submitted and approved.

Changes to the project: Any changes to the project must be submitted to the Carleton University Research Ethics Board for approval. All changes must be approved prior to the continuance of the research.

Adverse events: Should a participant suffer adversely from their participation in the project you are required to report the matter to the Carleton University Research Ethics Board. You must submit a written record of the event and indicate what steps you have taken to resolve the situation.

Suspension or termination of clearance: Failure to conduct the research in accordance with the principles of the Tri-Council Policy Statement: Ethical Conduct for Research Involving Humans, 2nd edition and the Carleton University Policies and Procedures for the Ethical Conduct of Research may result in the suspension or termination of the research project.

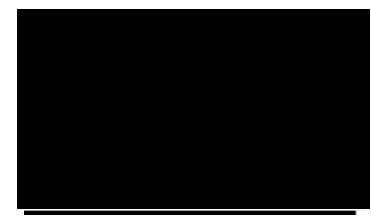

Andy Adler

Chair, Carleton University Research Ethics Board

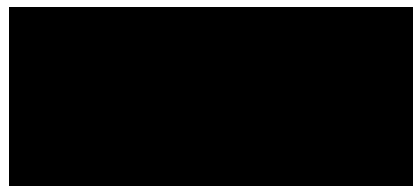

Louise Heslop

Vice-Chair, Carleton University Research Ethics Board 
Carleton University Research Office Research Ethics Board

1325 Dunton Tower 1125 Colonel By Drive Ottawa, ON K1S 5B6 Canada Tel: 613-520-2517 ethics@carleton.ca

\section{Ethics Clearance Form - Clearance Renewal}

This is to certify that the Carleton University Research Ethics Board has examined the application for ethical clearance. The REB found the research project to meet appropriate ethical standards as outlined in the Tri-Council Policy Statement: Ethical Conduct for Research Involving Human, 2nd edition, and the Carleton University Policies and Procedures for the Ethical Conduct of Research.

Original Date of Clearance: January 24, 2014

Renewal Date of Clearance: May 02, 2014

Researcher: Menaka Raguparan (Student Research: Ph.D. Student)

Department: Faculty of Public Affairs\Law (Department of)University: Carleton University

Research Supervisors (if applicable): Diana Young and Lara Karaian

Project Number: 100834

Alternate File Number (if applicable):

Project Title: Social, legal and political identities of racialized women in the Canadian sex industry

Clearance Expires: May 31, 2015

All researchers are governed by the following conditions:

Annual Status Report: You are required to submit an Annual Status Report to either renew clearance or close the file. Failure to submit the Annual Status Report will result in the immediate suspension of the project. Funded projects will have accounts suspended until the report is submitted and approved. 
Changes to the project: Any changes to the project must be submitted to the Carleton University Research Ethics Board for approval. All changes must be approved prior to the continuance of the research.

Adverse events: Should a participant suffer adversely from their participation in the project you are required to report the matter to the Carleton University Research Ethics Board. You must submit a written record of the event and indicate what steps you have taken to resolve the situation.

Suspension or termination of clearance: Failure to conduct the research in accordance with the principles of the Tri-Council Policy Statement: Ethical Conduct for Research Involving Humans, 2nd edition and the Carleton University Policies and Procedures for the Ethical Conduct of Research may result in the suspension or termination of the research project.

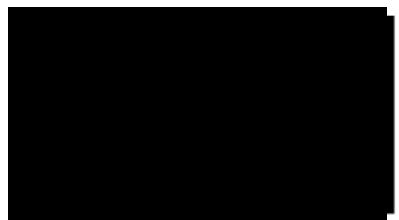

Andy Adler

Chair, Carleton University Research Ethics Board

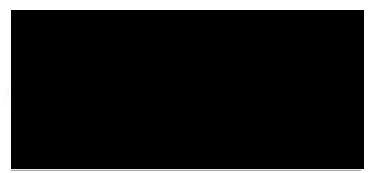

\section{Louise Heslop}

Vice-Chair, Carleton University Research Ethics Board 


\section{Appendix II}
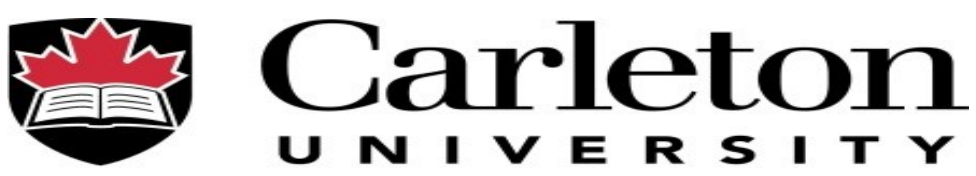

Canada's Capital University

\section{Research Participants Needed!}

- Are you a woman or identify as one for work?

- Do you identify as Indigenous or as visible minority?

- Do you work independent in-call or out-call or for an escort agency in Canada?

- Do you want to share your experience, stories and perspectives as a woman of colour working in the indoor sex industry?

I would like to invite women of colour across Canada who are involved in the indoor sex industry to participate in my PhD research ${ }^{40}, \mathrm{co}-$ supervised by Professors Diana Young and Lara Karaian.

The purpose of this research is to give racialized sex workers a voice on the legal and regulatory issues surrounding the sex industry and debunk myths about racialized women's involvement in the sex industry.

Interviews will be conducted in Vancouver from March 3 - 10. All interviews are confidential. You will receive an honorarium of $\$ 75.00$ for your time and knowledge.

To participate in this study please contact Menaka Raguparan:

Call or text: 613-304-3697 /Email: menaka.raguparan@carleton.ca

\footnotetext{
${ }^{40}$ This project has been reviewed and received ethics clearance from the Carleton University Research Ethics Committee. For questions or concerns please contact the ethics committee chair, Prof. Andy Adler at ethics@carleton.ca
} 


\section{Appendix III}

\section{Facebook Ad}

\section{Research Participants Needed}

-Are you a woman or identify as one for work?

-Do you identify as Indigenous or as visible minority?

-Do you work independent in-call or out-call or for an escort agency in Canada?

-Do you want to share your experience, stories and perspectives as a woman of colour working in the indoor sex industry?

I would like to invite women of colour across Canada who are involved in the indoor sex industry to participate in my PhD research, co-supervised by Professors Diana Young and Lara Karaian. The purpose of this research is to give racialized sex workers a voice on the legal and regulatory issues surrounding the sex industry and debunk myths about racialized women's involvement in the sex industry.

Interviews will be conducted in person or via Skype. All interviews are confidential. You will receive an honorarium of $\$ 75.00$ for your time and knowledge.

To participate in this study please contact Menaka Raguparan:

- Call or text: $\quad 613-304-3697$

- Email: menaka.raguparan@carleton.ca

This project has been reviewed and received ethics clearance from the Carleton University Research Ethics Committee. For questions or concerns please contact the ethics committee chair, Prof. Andy Adler at ethics@carleton.ca. 


\section{Appendix IV}

\section{Direct Contact with Sex workers}

Hello,

My name is Menaka and I am a researcher at Carleton University in Ottawa. I am doing a research on visible minority women who are involved in the indoor sex industry.

I would like to invite you to participate in research - participation involves sitting with me for a interview. I will be in [city name and dates] to conduct interviews and I hope you will participate in my study. I can also conduct interviews via Skype - if you prefer.

The purpose of the study is to dispel the negative stereotypes of women of colour who participate in the sex industry and focus on the human dignity. I will keep your identity confidential and I will pay $\$ 75$ honorarium for your time and knowledge.

I really hope you will participate in this study - your contribution is important.

If you have any further questions, or need more information please email me back at menaka.raguparan@carleton.ca.

looking forward to hearing from you

menaka 


\section{Appendix V}

Carleton

U N I V E R S I T Y

\section{Canada's Capital University}

\section{Letter of Information}

Dear Madame,

\section{Project Title: Social, Legal and Political Identities of Racialized Women in the Canadian Sex Industry}

I am inviting you to participate in a study that is part of my PhD thesis in the Department of Law and Legal studies at Carleton University under the co-supervision of Professors Diana Young and Lara Karaian.

To date, no Canadian research considers the lived experience of racialized female sex workers working in the indoor sex industry. The primary objective of this research project is to explore how racialized women in the Canadian indoor sex industry characterize their own behaviour, choices and identities. In this study, I focus on racialized sex workers' everyday experiences, their political and social position, and the strategies by which they conform to and/or resist stereotypical images of indoor sex workers. In doing so, I am hoping to address the gap in the research on sex work.

Your participation in this study involves an in-depth interview with me. The interview may take about 1.5 hours to 2 hours. During the interview you don't have to answer any questions that you don't feel like answering. You can take a break at anytime during the interview. You also have the right to stop the interview at any time. If you decide to withdraw from the research project, I will destroy the data from this interview immediately. You will receive a cash honorarium of $\$ 75$ at the end of the interview for your time and knowledge.

With your permission, the interview will be recorded. The recording will be transcribed by typing it into a document. The typed document will not have any names or other identifying information. If you wish, I can give you a copy of this document, so that you can review our conversation and make any corrections, changes, or edits that you like. Once the interview is typed the recording will be deleted. Only I will have access to the typed interview.

I will keep the consent form and the typed interview in separate places. The consent form will be kept in a safe and secure location at my house. The typed interview will be stored in removable storage devices such as a USB and stored in a locked filing cabinet. The contents of the interview, without your identifying details will be published in the forms of a thesis, academic articles, books, or conference presentations.

I will do my best to protect your privacy and confidentiality. I will use pseudonyms. However, given the nature of the industry and the size of the population of sex workers, there is a risk that you might be identified as a participant in the study. For example, if you learned about this study from a 
friend or acquaintance, she will probably know that you participated in this study. Also if you tell me something that you already had told someone else, they may be able to connect you to the pseudonym that I will use in the final document. Therefore, I strongly recommend that you don't tell me anything that you really need to be kept secret. In addition, because this research deals with some personal experiences it may cause some emotional discomfort. I will do my best to minimize these occurrences; however, I want you to know that you can stop the interview at any time or decline to answer any question that makes you feel uneasy.

Your participation in this research project is very important. This is an opportunity for you to share your experiences, stories and perspectives on racialized sex workers identity. Your contribution adds an important dimension to the current conversation about racialized indoor sex workers. Your stories and life experience could potentially alter the public perceptions and facilitate the formulation of alternative ways to understand the different identities of those who are involved in selling sexual services.

This project has been reviewed and received ethics clearance from the Carleton University Research Ethics Committee. If you have any questions or require more information about this study please contact me. If you have any questions or concerns with regards to the ethical conduct of this study or your involvement in it you may contact the ethics committee chair, Prof. Andy Adler at ethics@carleton.ca

Thank you for your time and consideration.

Sincerely

Menaka Raguparan (Student Researcher)

PhD Candidate, Department of Law and Legal Studies Carleton University 1125 Colonel By Drive, Ottawa ON K1S5B6 Tel: 613-697-6052

e-mail: menaka.raguparan@carleton.ca
Dr. Diana Young (Research Supervisor) Associate Professor Department of Law and Legal Studies Carleton University 1125 Colonel By Drive, Ottawa ON K1S5B6 Tel: 613-520-2600 ext 1981 e-mail: diana.young@carleton.ca

Dr. Lara Karaian (Research Supervisor)

Assistant Professor

Institute of Criminology \& Criminal Justice /

Department of Law \& Legal Studies

Carleton University1125 Colonel By Drive

Ottawa, ON K1S 5B6

Tel: 613-520-2600 ext 1458

e-mail : 1ara.karaian@,carleton.ca 


\section{Carleton \\ Canada's Capital University}

\section{CONSENT FORM}

The information presented in the above letter has been reviewed orally and I have had the opportunity to ask any questions related to this study, to receive satisfactory answers to my questions, and any additional details I wanted. I understand that this is a study being conducted by Menaka Raguparan of the Department of Law and Legal Studies at Carleton University.

I am aware that I have the option of allowing my interview to be audio recorded to ensure an accurate recording of my responses.

I am also aware of the possible risks that may come from my participation in this research, with the understanding that Menaka Raguparan will take all the reasonable measure to minimize and manage such occurrences.

I am informed that I may withdraw my consent at any time.

I understand that this project has been reviewed and received ethics clearance from the Carleton University Research Ethics Committee. If I have any comments or concerns resulting from my participation in this study, I may contact the Chair, Carleton University Research Ethics Committee at 613-123-4567.

With full knowledge of all preceding, I agree, of my own free will, to participate in this study.

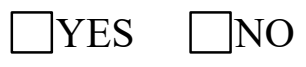

I agree to have my interview audio recorded. $\square$ YES $\square$ NO

I agree to the use of anonymous quotations in any thesis or publication that comes of this research.

\section{$\square$ YES $\square$ NO}

Participant Name: (Please print)

Participant Signature:

Researcher Name: (Please print)

Research Signature: Date: 


\section{Appendix VI}

\section{Carleton \\ U N I V E R I T Y \\ Canada's Capital University}

\section{ORAL SCRIPT}

Hello, my name is Menaka Raguparan and I am a PhD student in the Department of Law and Legal Studies at Carleton University. I am conducting a research study under the co-supervision of Dr. Diana Young (Law and Legal Studies) and Dr. Lara Karaian (Criminology).

To date, no Canadian research considers the lived experience of racialized female sex workers working in the indoor sex industry. The purpose of this study is to explore how racialized women in the Canadian indoor sex industry characterize their own behaviour, choices and identities. In this study, I focus on racialized sex workers' everyday experiences, their political and social position, and the strategies by which they conform to and/or resist stereotypical images of indoor sex workers. In doing so, I am hoping to address the gap in the research on sex work and to consider the role of stereotypes about racialized sex workers on their selfimage.

Do you understand the purpose of this study? Do you have any questions regarding this study?

This interview may take about 1.5 hours to 2 hours. During the interview I will ask you some questions about your views on the common perceptions of sex workers. For example, how you feel about the stereotypical image of sex workers? Whether you think it is an appropriate representation of racialized women involved in the sex industry? Basically, I am interested in hearing your story about your identity as a racialized woman who is involved in the sex industry and how you think others perceive your identity. I don't want to know about what type of work you do, who you work for, who you work with and where you work or how much money you make.

Your participation in this study is completely voluntary. I will make every possible effort to keep your identity confidential. . I will use code names to protect your true identity.

You don't have to answer any questions that you don't feel like answering: you can just say that you don't want to talk about it, and we won't talk about it.

You can take a break at anytime during the interview.

You also have the right to stop the interview at any time. If you decide to withdraw from the research project I will destroy the data from this interview immediately. 
You will receive a cash honorarium of $\$ 75.00$ at the end of the interview for your time and knowledge

If it is alright with you, I would like to tape record this interview; I like to tape record interviews for two reasons - with a tape recorder I can listen to what you're saying, rather than writing notes all the time, and with a tape recorder I can accurately document what you say.

The recording will be transcribed by typing it into a document. When I am typing it I will delete any names or other identifying information. I will also give you a copy of this document, so that you can review our conversation and make any corrections, changes, or edits that you like. I will try my very best to reconnect with you to get you comments and feedback, but for whatever reasons I am unable to reconnect with you I will proceed to use the material that I have. Once the interview is typed the audio recording will be destroyed. Only I will have access to the typed interview.

I will keep the consent form and the typed interview in separate places. The consent form will be kept in a safe and secure location at my house. The typed interview will be stored in removable storage device, such USB and stored in a locked filing cabinet.

Do you have any questions about the interview session or concerns about recording the interview or the way the data is being stored?

I want you to know that I will do my best to protect your privacy and confidentiality. I will protect your confidentiality by changing any personal and potentially identifiable information during transcription. I will alter any atypical speech patterns and/or distinctive use of words/phrases.

However, I want to let you know that, despite my efforts to protect your true identity, given the nature of the industry and the size of the population, there are some possible risks to maintaining your privacy and confidentiality. For example, if you learned about this study from a friend or acquaintance, she probably knows that you participated in this study. Also if you tell me something that you already had told someone else, there is a possibility that person will be able to connect you to the pseudonym I will use in the final document. I strongly recommend that you don't tell me things you really want to remain secret. In addition, because this research deals with some personal experiences, please let me know at any time if you are feeling any discomfort and we can stop the interview.

Do you have any questions? Would you like me to explain anything further?

Your participation in this research project is very important. By participating in this study, you have the opportunity to share your experiences, stories and perspectives on racialized sex workers identity. By sharing your stories, experiences and perspectives you are contributing to the discussions about ways in which you are being identified and represented in law and society. Your contribution adds an important dimension to the current conversation about racialized indoor sex workers. Your stories and life experience could potentially alter the public 
perceptions and facilitate the formulation of alternative ways to understand the different identities of those who are involved in selling sexual services.

Finally, I would like to inform you that this project has been reviewed and received clearance from the Carleton University Research Ethics Committee. If you have any questions or concerns with regards to the ethical conduct of this study or your involvement in it you may contact the ethics committee chair, Prof. Andy Adler at ethics@carleton.ca

If you don't have any other questions you can read and sign the consent form so that we can begin the interview. 


\section{Appendix VII}

\section{Sample Questions for open ended interviews}

Probe:

The sex industry is a social, political, legal, economical and cultural fact. Yet women's involvement in this industry has always been controversial. Women in the sex industry are generally represented or perceived as either women who are forced into the industry, exploited and manipulated or as women who make a choice to participate in this industry.

\section{Question 1):}

As a racialized woman engaged in contemporary sex industry, how do you feel about these perceptions?

What factors influenced you to become a sex worker?

\section{Question 2)}

Can you talk to me about the way you identify yourself?

How do you want to be represented and how do you want to be perceived by the general public?

Can you tell me more about whether and how your race has shaped your experiences?

Probe:

Even though the sex industry is not illegal in Canada, most, if not all activities related to the industry are illegal, making it especially difficult for women to participate in the industry.

\section{Question 3)}

As a racialized woman working in the indoor sex industry, are you affected by the law enforcement practice?

Can you talk to me about your experiences in this context?

Can you tell me more about whether and how the space that you occupy/work in has shaped your experiences?

\section{Probe:}

With the growing influence of Sex workers rights advocacy groups, you see an increased trend in other advocacy groups becoming allies of sex workers, like women's rights groups, 
health and safety groups All these groups play a significant role in pressuring the government to change existing laws pertaining to the sex industry.

\section{Question 4)}

How do you think women's groups and/or sex worker's rights advocacy groups perceive racialized women in the sex industry?

Do you think these groups understand your experience as a racialized woman in the industry?

What do you think the effects of being perceived in this/these ways for you?

\section{Question 5)}

Do you think the law, women's groups, and/or sex worker's rights advocacy groups adequately represent racialized women involved in the sex industry?

Can you give me some examples of how they are adequately/inadequately represented?

Probe:

So the popular perception within academia, for example, is that racialized women work the street based sex industry and white women work the indoor based industry.

\section{Question 6)}

As a racialized woman working in the indoor sex industry how would you respond to such popular perceptions?

What are your thoughts about indigenous and racialized women working on the street? 